\title{
LAND TO OCEAN TRANSFER OF EROSION-RELATED ORGANIC CARBON, WAIPAOA SEDIMENTARY SYSTEM, EAST COAST, NEW ZEALAND
}

by

\author{
Hannah Lema Brackley
}

\author{
A thesis \\ Submitted to the Victoria University of Wellington \\ in fulfilment of the requirements for the degree of \\ Doctor of Philosophy \\ in Science
}

Victoria University of Wellington

2006 


\section{ABSTRACT}

Mountainous islands of the Pacific Rim (such as New Zealand) purportedly deliver up to $40 \%$ of the suspended sediment load and up to $35 \%$ of the riverine particulate organic carbon (POC) load to the world's oceans. On the east coast of New Zealand's North Island, the Waipaoa River drains a steep, $2205 \mathrm{~km}^{2}$ catchment located on the active collisional East Coast Continental Margin. It has an annual suspended sediment load of $15 \mathrm{Tg}\left(15 \times 10^{12} \mathrm{~g}\right)$, making up $\sim 7 \%$ of New Zealand's total yield to the Pacific Ocean, and a mean annual POC discharge to the Pacific Ocean of $86.7 \mathrm{Gg}\left(86.7 \times 10^{9} \mathrm{~g}\right)$. The annual loss of OC to the floodplain is $\sim 9 \%$ of this annual POC discharge $(\sim 7.8 \mathrm{Gg})$.

A range of analyses (including organic carbon content $(\% \mathrm{OC})$, stable carbon isotopes $\left(\boldsymbol{\delta}^{13} \mathrm{C}\right)$, radiocarbon $\left({ }^{14} \mathrm{C}\right)$, carbon to nitrogen ratios $(\mathrm{C} / \mathrm{N})$ a and carbon loadings (OC:SA)) were performed on correlative sediments from a transect of 7 cores from depositional sites located on the Waipaoa River floodplain and adjacent continental shelf and slope. Results were used to determine biogeochemical characteristics of organic carbon $(\mathrm{OC})$ at a range of depositional sites during its transfer from terrestrial source to marine sink, and how large floods impact OC transfer to the marine environment.

The high temporal variability in OC content (0.2 to 3.5\%) and different source signatures $\left(\boldsymbol{\delta}^{13} \mathrm{C}\right.$ of -26.7 to $-20.6 \%$ ) of Waipaoa River floodplain deposits prevented the establishment of a clear benchmark signature for flood deposits that may be recognisable in the marine sedimentary record. The high spatial and temporal variability of floodplain sediment OC, combined with the areal extent of floodplains within the catchment, indicates the appreciable modulating effect the floodplain has on OC transfers to the ocean. Since extensive stopbanks were constructed on the main floodplain since the 1940's, sequestration of OC in floodplain sediments has reduced by about half, increasing the overall efficiency of the Waipaoa River in transferring terrestrial OC directly to the marine environment. 
Flood layers are preserved in the marine sedimentary record. Continental shelf sediments indicate that during Cyclone Bola (March 1988, a rainfall event with a $>100$ year return period), the extreme river discharge produced a hyperpycnal (negatively buoyant) plume, preserved as a $\sim 10 \mathrm{~cm}$ thick layer on the inner shelf and a $\sim 1 \mathrm{~cm}$ thick layer on the mid-shelf. The flood layer contains a significant amount of terrestrially-sourced OC (up to $86 \%$ of total OC in $>25 \mu \mathrm{m}$ fraction) which subsequently was rapidly buried by normal marine deposits (in which $\sim 60 \%$ of OC in $>25 \mu \mathrm{m}$ fraction is terrestrial), thereby preserving its strong terrestrial source signature.

As sediments are physically and biologically processed at various depositional sites across the continental shelf and slope, they lose some of their modern terrestrial OC, and the concurrent addition of marine sourced OC results in the sediments gaining a stronger marine biogeochemical signature $\left(\boldsymbol{\delta}^{13} \mathrm{C}\right.$ values increasing from $26.2 \%$ for floodplain sediments to $-21.6 \%$ or for upper continental slope sediments).

Carbon loading (OC:SA) and ${ }^{14} \mathrm{C}$ data revealed the contributions of kerogen, modern terrestrial OC and modern marine OC to the total OC of continental shelf and slope surface sediments. Sediments retain about $40 \%$ of their terrestrial OC following transport to the continental slope, of which a significant amount consists of kerogen. Because of high erosion rates within the catchment, kerogen associated with the particles escapes oxidation, and therefore makes up a large part of the POC flux. Kerogen is preserved across the margin to the mid-slope, where only $8 \%$ of the bulk sediment OC consists of modern terrestrial OC, $58 \%$ is modern marine OC and $34 \%$ is kerogen. Biomarker analyses of surface samples also support findings that terrestrial OC is being transferred across the continental margin, with plant sterols, long chain alcohols and long chain fatty acids (biomarkers indicative of vascular plants) persisting as far offshore as the mid-continental slope.

Results presented verify and add to the understanding of OC transfers and transformations at a range of depositional sites from terrestrial source to marine sink. This study provides the first quantitative assessment of land to ocean OC transfers from New Zealand. These findings, together with information on sediment 
budgets and depositional rates of $\mathrm{OC}$ in terrestrial and marine depositional environments, could provide a vital step toward establishing global OC budgets for small mountainous island environments. 


\section{ACKNOWLEDGEMENTS}

Firstly, I owe many thanks to my supervisors Jim Johnston, Noel Trustrum, Lionel Carter and Kevin Tate. Each providing expertise, they gave me their time so freely and provided the necessary guidance and enthusiasm throughout this study. I am extremely appreciative of all their support.

I am also indebted to my family and friends, who provided much encouragement and support. They always had faith in my ability to complete the thesis, particularly when the going got tough, and they helped me overcome the inevitable hurdles along the way.

My sincere appreciation goes to staff and students from North Carolina State University (NCSU) - in particular Lonnie Leithold and Neal Blair, for all of their mentoring and guidance. As well as being fantastic teachers, they are also wonderful friends to me. My sincere thanks also go to Dave Perkey and John Sneed, for their assistance with laboratory work during my stays at NCSU.

I also owe thanks to the staff and students from the Virginia Institute of Marine Sciences (VIMS) - in particular Steve Kuehl, Tara Kniskern, Elizabeth Canuel and Beth Waterson. They freely assisted with laboratory analyses and their interpretations, which helped to improve my understanding and strengthen this study a great deal.

I could not have completed this research without the backing of my employers, initially Landcare Research NZ Ltd. and recently GNS Science, and also the tremendous support provided by the National Institute of Water and Atmospheric Research (NIWA).

Finally, this thesis is dedicated to my father, Paul Brackley, who sadly did not get to see its completion, but I know would be so proud. 


\section{TABLE OF CONTENTS}

\section{Chapter 1: Introduction}

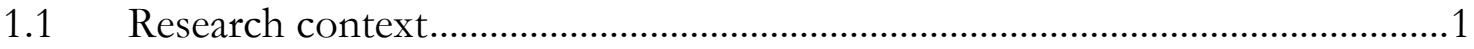

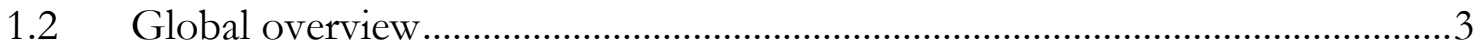

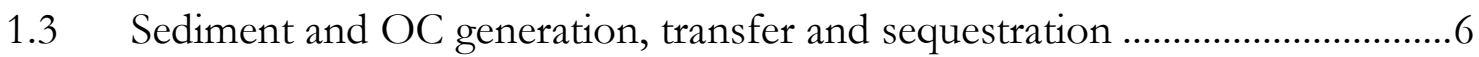

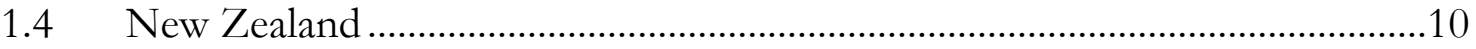

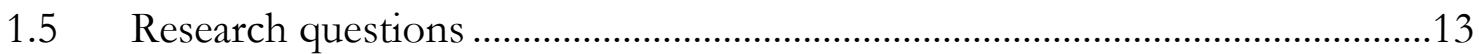

\section{Chapter 2: Waipaoa Sedimentary System}

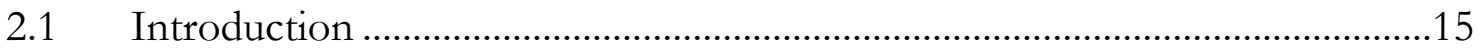

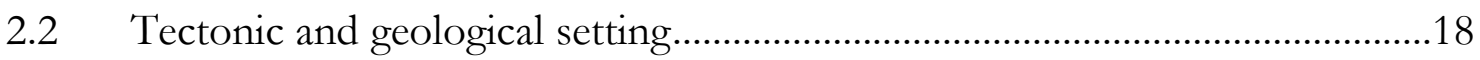

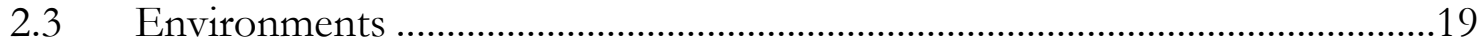

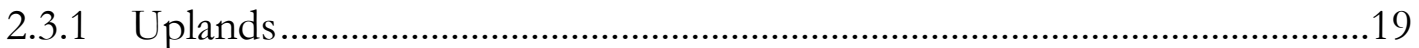

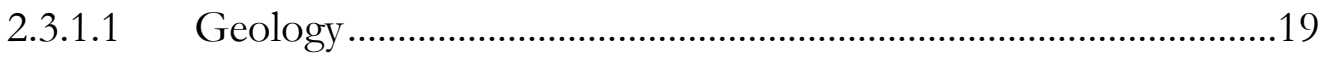

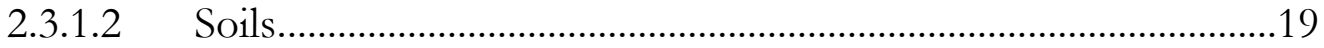

2.3.1.3 Erosion processes ........................................................................19

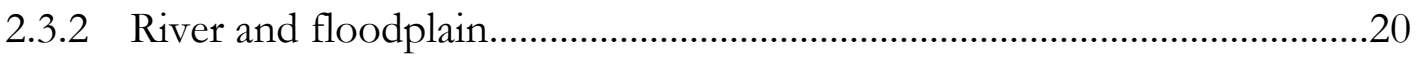

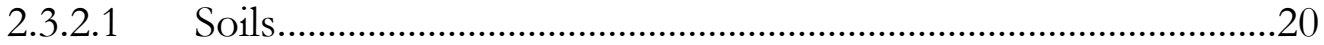

2.3.2.2 Sedimentation and storage …......................................................21

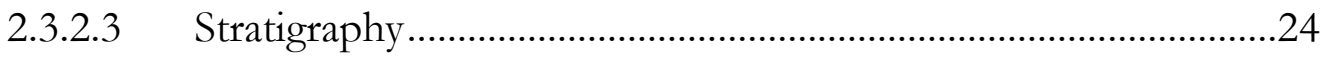

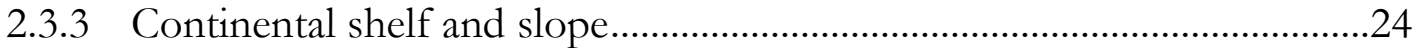

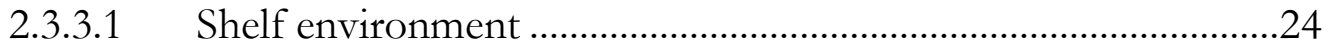

2.3.3.2 Shelf circulation .......................................................................27

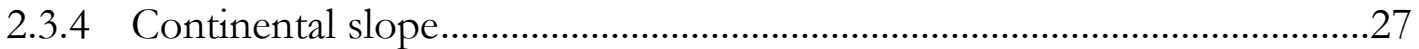

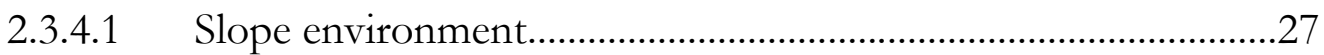

2.3.4.2 Slope circulation...................................................................27

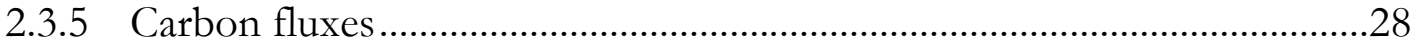

\section{Chapter 3: Methods}

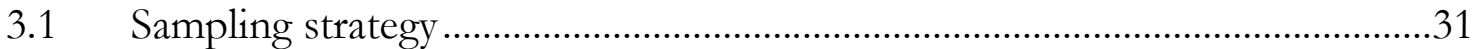

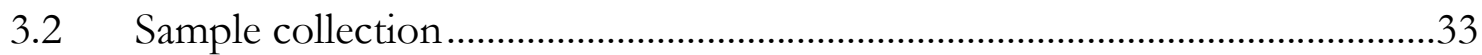

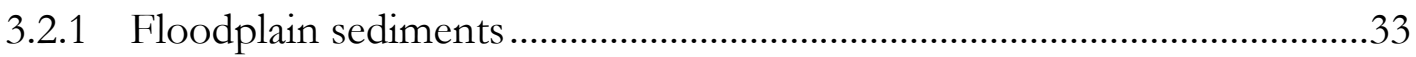




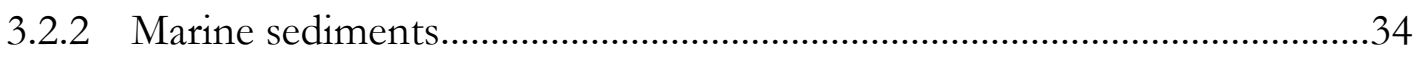

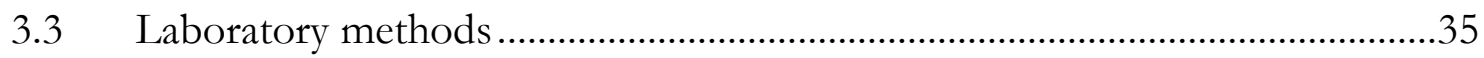

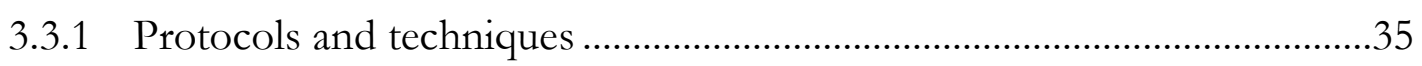

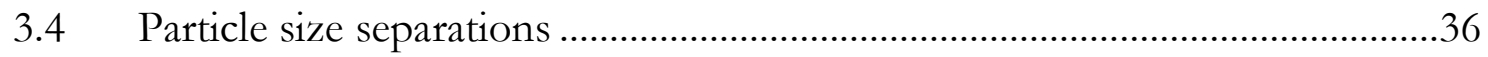

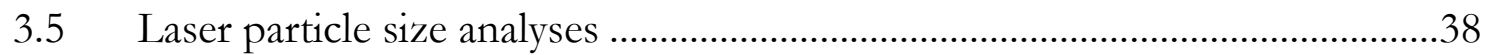

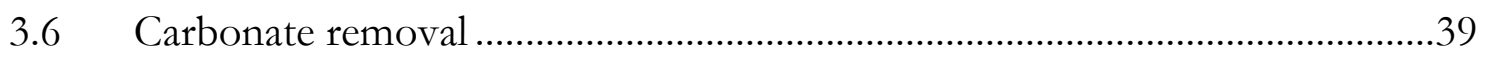

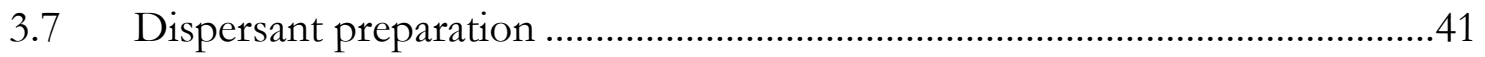

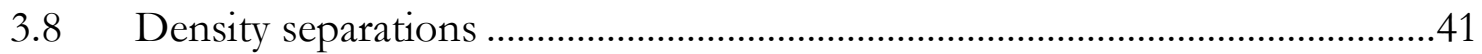

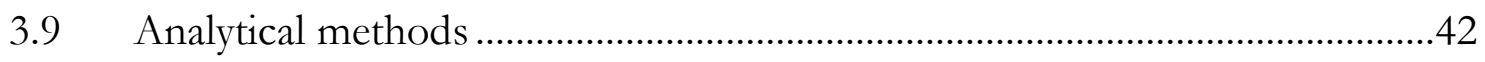

3.9.1 Carbon and nitrogen contents and stable isotopes..................................42

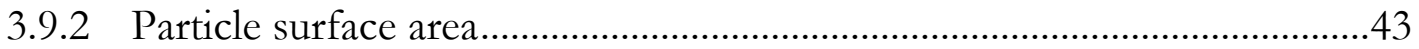

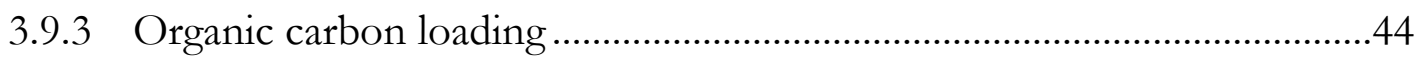

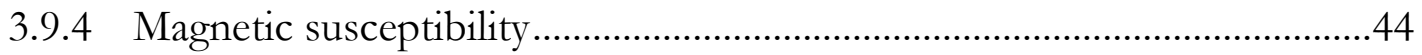

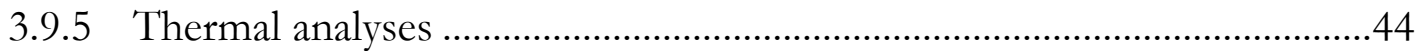

3.9.6 Lead-210 and caesium-137 analyses.........................................................45

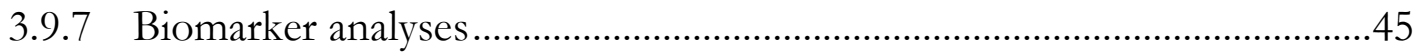

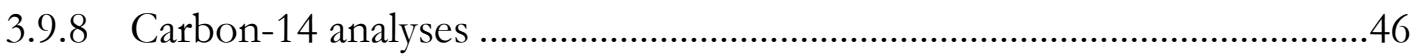

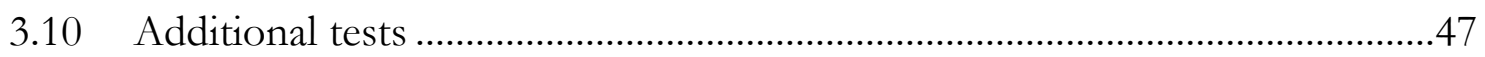

3.10.1 NCSU elemental analyser comparisons...................................................4

3.10.2 Inter-laboratory comparisons ....................................................................48

3.10.3 Effects of sample storage on organic carbon ............................................51

\section{Chapter 4: Waipaoa River floodplain}

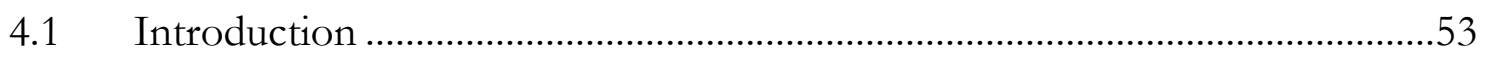

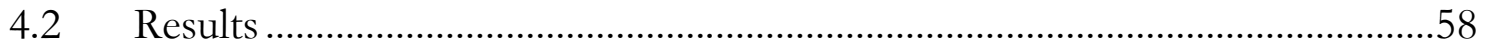

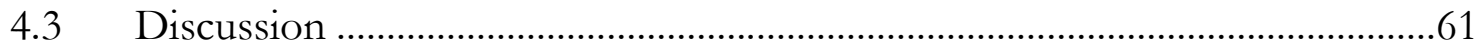

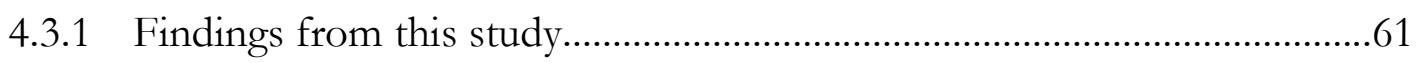

4.3.2 Comparison with previous McPhail's bend studies ...................................64

4.3.3 Role of the floodplain in modulating OC transfers....................................65

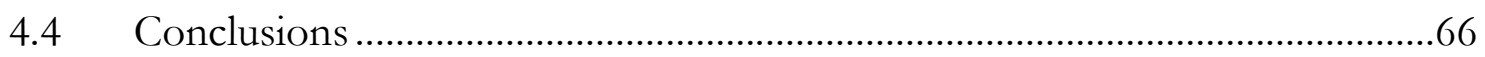


Chapter 5: Using terrestrial organic carbon to assist in flood identification on the continental shelf and slope

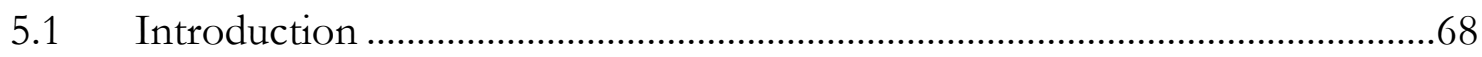

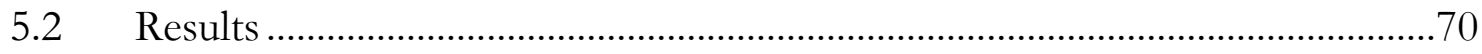

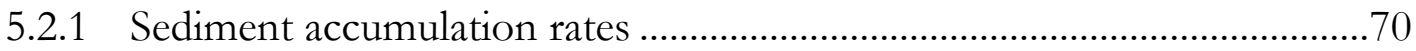

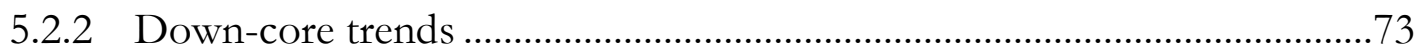

5.2.3 Clay fraction surface areas and carbon loading ........................................81

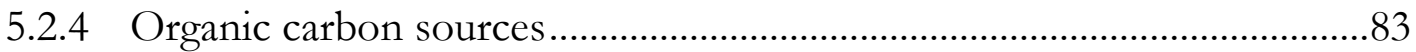

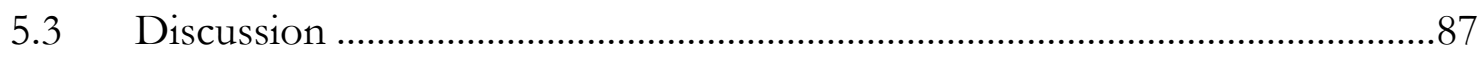

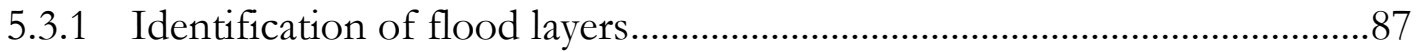

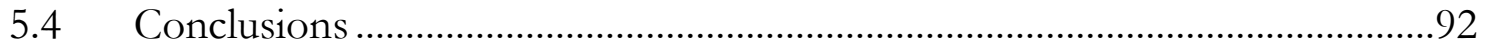

Chapter 6: Transformation of organic carbon signature across the continental shelf and slope

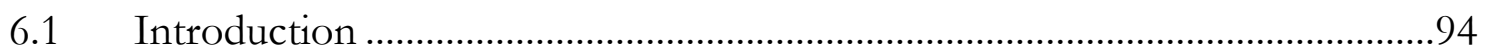

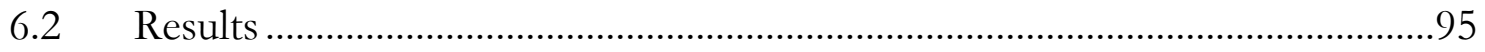

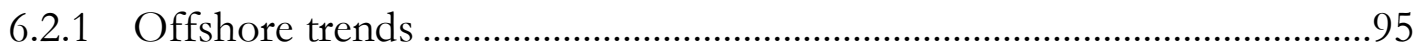

6.2.2 Organic carbon source determination ........................................................99

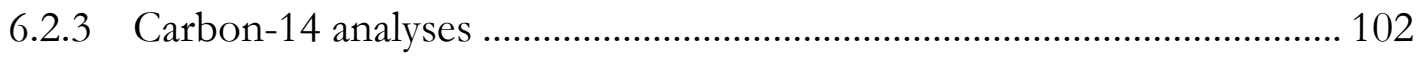

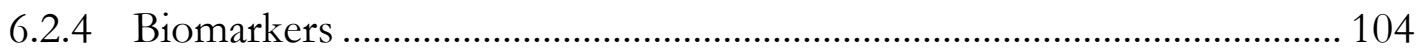

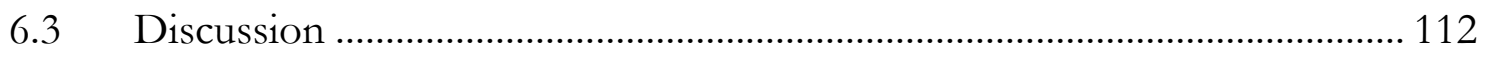

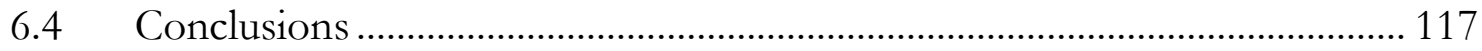

Chapter 7: Organic carbon transformations and conceptual modelling

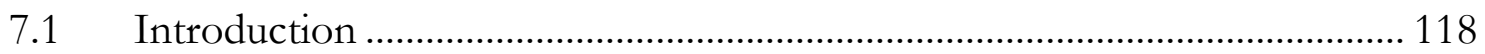

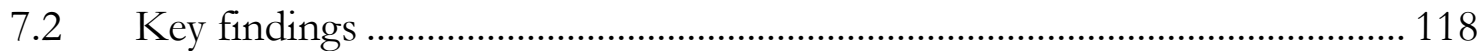

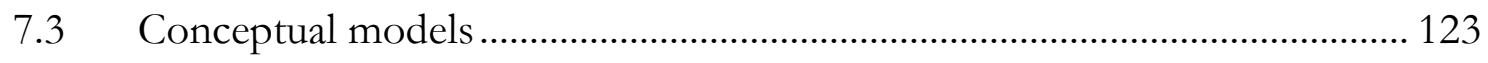

7.4 Global significance and future directions.................................................... 126 


\section{LIST OF FIGURES}

\section{Chapter 1}

Figure 1.1: Conceptual model of sediment and organic carbon transfers within the Waipaoa Sedimentary System .......................................................2

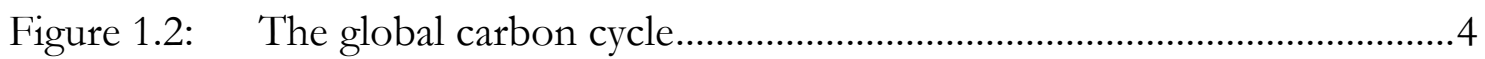

Figure 1.3: Sediment plume during storm event, Waipaoa River..............................6

\section{Chapter 2}

Figure 2.1: Location map of the onshore catchment and offshore setting of the Waipaoa Sedimentary System .............................................................16

Figure 2.2: Annual suspended sediment yields from New Zealand rivers............22

Figure 2.3: McPhail's bend, indicating changes in planform geometry since 1868

Figure 2.4: Bathymetry, morphology and sediment thickness of the Waipaoa Sedimentary System continental shelf and slope

\section{Chapter 3}

Figure 3.1: Location map indicating positions of the McPhail's bend floodplain core and shelf/slope multi-cores 32

Figure 3.2: View of the Waipaoa River floodplain and overbank deposition after Cyclone Bola, March 1988

Figure 3.3: Multi-core sampler onboard RV Tangaroa 34

Figure 3.4: Vacuum drying set-up for drying samples following the removal of carbonate.

Figure 3.5: Sediment settling method used to collect clay fractions 37

Figure 3.6: Comparison of sieving and laser particle size determination methods for samples from core U2303.

Figure 3.7: Sample \%OC with increasing time in $4 \mathrm{M} \mathrm{HCl}$. 40

Figure 3.8: Carlo Erba FlashEA 1112 CHNS analyser, NCSU .43

Figure 3.9: Beckman Coulter SA 3600 analyser, NCSU .43 
Figure 3.10: Inter-laboratory comparisons of $\% \mathrm{OC}, \delta^{13} \mathrm{C}$ and $(\mathrm{C} / \mathrm{N}) \mathrm{a}$ for the floodplain core.

Figure 3.11: Inter-laboratory comparisons of $\% \mathrm{OC}, \delta^{13} \mathrm{C}$ and $(\mathrm{C} / \mathrm{N})$ a for core $\mathrm{U} 2303$

Figure 3.12: Inter-laboratory comparisons of $\% \mathrm{OC}, \delta^{13} \mathrm{C}$ and $(\mathrm{C} / \mathrm{N})$ a for core $\mathrm{U} 2305$

Figure 3.13: Inter-laboratory comparisons of $\% \mathrm{OC}, \delta^{13} \mathrm{C}$ and $(\mathrm{C} / \mathrm{N})$ a for core W697. .50

\section{Chapter 4}

Figure 4.1: $\quad$ 1948-1988 flood layers at McPhail's bend 55

Figure 4.2: Aerial photograph of McPhail's bend, superimposed with isopachs of flood sediment thickness deposited by the August 2002 storm event 56

Figure 4.3: (A) Clay content, (B) $\% \mathrm{OC},(\mathrm{C}) \delta^{13} \mathrm{C}$ and (D) $(\mathrm{C} / \mathrm{N}) \mathrm{a}$ trends of bulk sediments from the McPhail's bend floodplain core 58

Figure 4.4: Relationship between clay content and \%OC for the bulk floodplain sediments from McPhail's bend. .59

Figure 4.5: Comparison of \%OC contents for the two McPhail's bend cores analysed by (A) Gomez et al. (2004b) and (B) this study .64

\section{Chapter 5}

Figure 5.1: Excess ${ }^{210} \mathrm{~Pb}$ activity for the inner shelf core (U2303)..... . .70

Figure 5.2: Core U2303 excess ${ }^{210} \mathrm{~Pb}$ activity corrected for clay content, indicating varying down-core sediment accumulation rates .71

Figure 5.3: $\quad$ Particle size, $\% \mathrm{OC}, \boldsymbol{\delta}^{13} \mathrm{C}$ and $(\mathrm{C} / \mathrm{N})$ a trends suggest the presence of a flood layer (13-23 cm depth) within the inner shelf core (U2303)....74

Figure 5.4: Particle size, $\% \mathrm{OC}, \delta^{13} \mathrm{C}$ and $(\mathrm{C} / \mathrm{N})$ a trends for the mid-shelf core (U2305), in which small flood layers may be preserved .76

Figure 5.5: Particle size trend for the top $9 \mathrm{~cm}$ of the mid-shelf core (U2305) ...78 
Figure 5.6: $\quad$ Particle size, $\% \mathrm{OC}, \delta^{13} \mathrm{C}$ and $(\mathrm{C} / \mathrm{N})$ a trends for the upper slope core (W697), in which there are no apparent flood layers

Figure 5.7: Down-core trends in (A) surface area and (B) carbon loading for the inner shelf (U2303), mid-shelf (U2305) and upper slope (W697) clay fractions

Figure 5.8: Determination of marine OC isotopic signature from bulk samples and clay fractions of shelf and slope sediments.

Figure 5.9: Determination of terrestrial OC isotopic signature, from suspended sediment samples collected at the Kanakanaia, Te Arai and Omapere sites.

Figure 5.10: Down-core terrestrial OC contributions for the shelf and slope cores as determined by $\delta^{13} \mathrm{C}$ mass balance calculations .85

Figure 5.11: SPOT image of Poverty Bay, taken 18 days after Cyclone Bola .90

\section{Chapter 6}

Figure 6.1: (A) Trends in carbon content (\%OC) and (B) Trends in $\delta^{13} \mathrm{C}$ for the WSS transect of surface samples. .96

Figure 6.2: (A) Trends in $(\mathrm{C} / \mathrm{N}) \mathrm{a}$ and $(\mathrm{B})$ Trends in carbon loading (OC:SA) for the WSS transect of surface samples .98

Figure 6.3: Contributions from terrestrial and marine $\mathrm{OC}$ sources to \%OC, for bulk samples and clay fractions from the WSS transect. 100

Figure 6.4: Contributions from terrestrial and marine OC sources to carbon loadings (OC:SA), for bulk samples and clay fractions from the WSS transect . 101

Figure 6.5: Kerogen, modern terrestrial and modern marine OC components of (A) $\% \mathrm{OC}$ and (B) OC:SA for bulk surface samples from the continental shelf and slope 103

Figure 6.6: Concentrations of plant sterols normalised to sediment OC 105

Figure 6.7: Concentrations of long-chain $\left(\mathrm{C}_{22}-\mathrm{C}_{28}\right)$ alcohols normalised to sediment OC. 106

Figure 6.8: Concentrations of dinoflagellate sterols normalised to sediment OC 
Figure 6.9: Concentrations of diatom sterols normalised to sediment OC ....... 107

Figure 6.10: Ratio of plant-to-diatom sterols ........................................................ 108

Figure 6.11: Concentrations of long-chain $\left(\mathrm{C}_{22}-\mathrm{C}_{32}\right)$ fatty acids normalised to

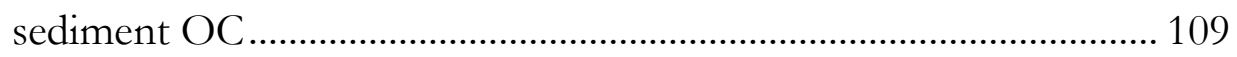

Figure 6.12: Concentrations of short-chain $\left(\mathrm{C}_{12}-\mathrm{C}_{16}\right)$ saturated fatty acids normalised to sediment OC ................................................................. 110

Figure 6.13: Ratio of terrestrial-to-aquatic fatty acids normalised to sediment OC

\section{Chapter 7}

Figure 7.1: Land to ocean depositional environments of the WSS

Figure 7.2: Diagrammatic model of OC transfers and transformations across the depositional environments of the WSS

Figure 7.3: Diagrammatic model of OC processing in the surface mixed layer of the seabed, as particles are transported across the shelf and slope......... 


\section{LIST OF TABLES}

\section{Chapter 1}

Table 1.1: Estimated annual global discharges of POC 5

\section{Chapter 2}

Table 2.1: Summary of erosion processes operating in the Waipaoa catchment, and their contributions to suspended sediment yield and carbon loss 28

\section{Chapter 3}

Table 3.1: Comparison of sieve/pipette and laser particle size determination methods for samples from core U2303 …………................................ 38

Table 3.2: Comparison of analyses using Carlo Erba 1108 CHNS analyser and Carlo Erba FlashEA 1112 CHNS analyser........................................... 47

Table 3.3: Comparison of floodplain sample analyses following storage in refrigerator and freezer.................................................................. 52

\section{Chapter 5}

Table 5.1: Modern accumulation rates for continental shelf and slope sediments

Table 5.2: Approximate ages of flood layers within continental shelf sediments

Table 5.3: Comparison of $\% \mathrm{OC}, \delta^{13} \mathrm{C}$ and $(\mathrm{C} / \mathrm{N})$ a for bulk samples and clay fractions of flood and non-flood sediments within the floodplain and shelf cores 


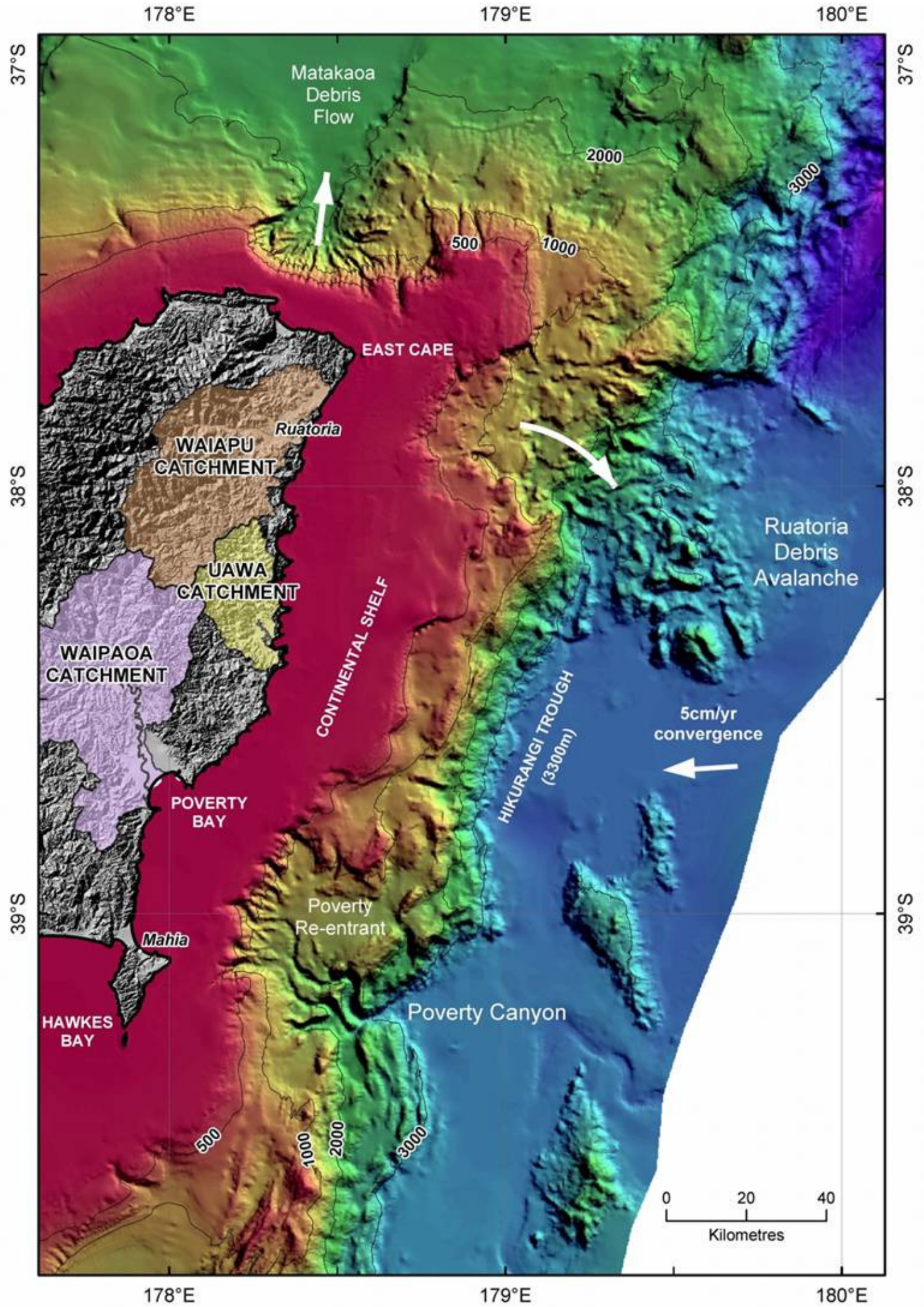

Frontispiece: Digital terrain model and swath bathymetry of the Waipaoa

Sedimentary System and surrounds, on the east coast of New Zealand's North Island. Illustrated is the Waipaoa River basin, continental shelf (red) and dissected continental slope (yellow/green), leading to the Hikurangi Trough (blue).

(Image courtesy of National Institute of Water and Atmospheric Research (NIWA). 


\section{CHAPTER 1: INTRODUCTION}

\subsection{RESEARCH CONTEXT}

This study investigates the land to ocean transfer of erosion-related organic carbon (OC) within the Waipaoa Sedimentary System (WSS) on the East Coast of New Zealand's North Island (Frontispiece). It examines the biogeochemical characteristics of $\mathrm{OC}$ at a range of depositional sites during its transport from terrestrial source to marine sink, and how large floods impact OC transfer to the marine environment.

The WSS is ideal for investigating the transfer and transformations of OC along the transport pathway from the terrestrial to the marine environment, as it is a generally well-characterised watershed, with erosion and sedimentary sequences and processes having been established both on land and offshore (e.g. Foster \& Carter 1997; Trustrum et al. 1999; Gomez et al. 2001). It is a mountainous catchment draining an active collisional margin, consequently having high sediment and nutrient fluxes to the ocean. In addition, the Waipaoa River periodically generates hyperpycnal plumes, possibly transporting large amounts of sediment across the continental shelf (Hicks et al. 2004a) and potentially playing an important role in the offshore transport of terrigenous OC.

A conceptual model has been developed (Figure 1.1) to highlight the environments and processes under investigation in this study, and how they fit within the overall OC cycle. 

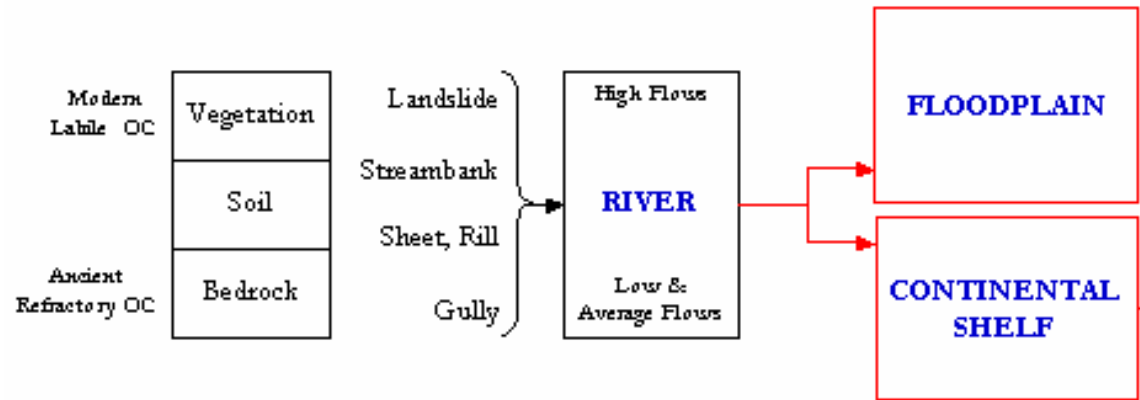
CONTINENTAL SLOPE

Figure 1.1: Conceptual model of sediment and organic carbon transfers within the Waipaoa Sedimentary System.

The conceptual model illustrates an earth surface profile, in which vegetation and topsoil are dominated by modern labile OC (i.e. soil turnover times up to several decades (Tate et al. 1995)), and are underlain by subsoil and bedrock with progressively more ancient and refractory OC. In the New Zealand landscape, sheet and rill erosion processes are often minor contributors to sediment yield. However because they strip the uppermost soil and vegetation layers, with high OC contents, they can be significant contributors to OC exports. Shallow landsliding processes are greater contributors to sediment yields, but the lower OC content of eroded subsoils dilutes their contribution to OC exports. While the dominance of gully erosion in some New Zealand landscapes contributes greatly to sediment yields, particularly at low and moderate river flows, the generally low and dominantly refractory $\mathrm{OC}$ of these bedrock sources results in relatively small contributions to OC exports.

In the WSS, the short steep river drains a mountainous watershed. The development of stopbanks in the lower Waipaoa River has reduced the frequency of bankfull discharge from the natural situation, so bankfull discharge is generally only exceeded during very large events, and floodplain sediment and OC sequestration only tends to occur at such times, when landsliding is often a greater contributor to sediment generation. Contrastingly, the majority of river flows are below bankfull discharge, and the gully-dominated sediments containing ancient refractory OC are transported directly offshore to the continental shelf and slope. This conceptual model of 
sediment and OC generation, transfer and sequestration is used to frame the research issues addressed by this study.

This study aims to alleviate current deficiencies in a key area of global research, namely: how riverine sediment inputs to the ocean (including floods and resulting hyperpycnal flows) influence the transfer and sequestration of terrigenous $\mathrm{OC}$ in the ocean; the fate of terrestrial OC following its discharge to the ocean (by resolving the portion of terrestrial OC being preserved in marine sediments); and identification of the biogeochemical processes acting on OC at various depositional sites along the transport pathway. The following three sections discuss the global and national context of these research deficiencies as they relate to the conceptual model outlined above.

\subsection{GLOBAL OVERVIEW}

The marine carbon $(\mathrm{C})$ pool is by far the largest within the global C cycle (Figure 1.2) containing an estimated $38000 \operatorname{Pg} C\left(1 \mathrm{Pg}=10^{15} \mathrm{~g}\right)$, with the geologic pool (comprising coal, oil and gas) being the second largest at $5000 \mathrm{Pg}$ C. The terrestrial $\mathrm{C}$ pool, including both soil and vegetation components, is the third largest estimated to be $\sim 2860 \mathrm{Pg}$ in total, made up of $1550 \mathrm{Pg}$ of soil organic carbon (SOC), $750 \mathrm{Pg}$ of soil inorganic carbon (SIC) and $560 \mathrm{Pg}$ of vegetation C (IPCC 1995). Recent research has suggested the SOC pool could in fact be as high as 2344 $\mathrm{Pg}$, if previously unaccounted for OC stored at depths down to $3 \mathrm{~m}$ is taken into account (Jobbagy \& Jackson 2000). The atmospheric C pool (760 Pg) is comparable to SIC and is increasing at a rate of $\sim 3.2 \mathrm{Pg} \mathrm{C} \mathrm{y}^{-1}$ (Lal 2003) due to increased $\mathrm{CO}_{2}$ emissions since the mid-twentieth century. 


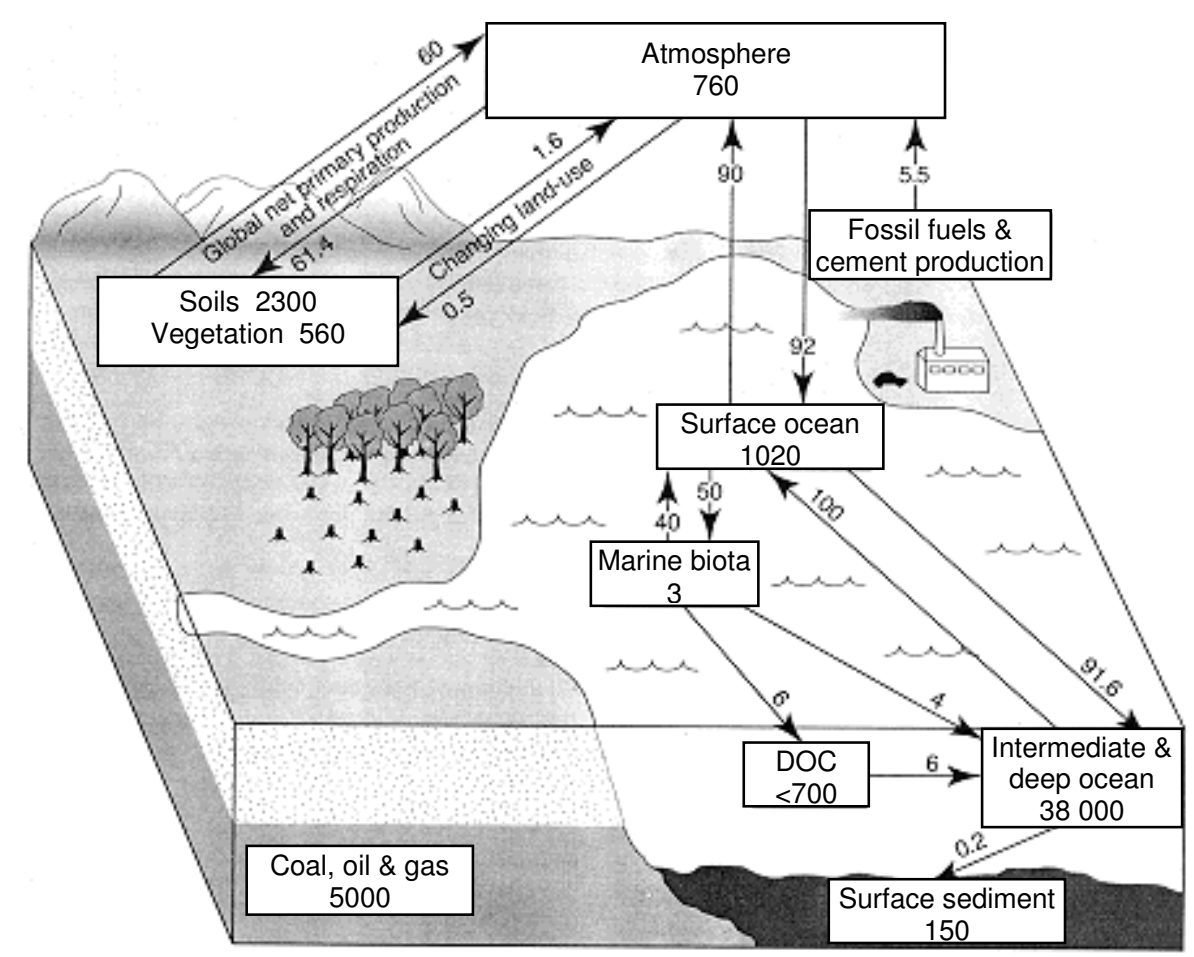

Figure 1.2: The global carbon cycle, showing reservoirs (in $\mathrm{Pg} \mathrm{C}$ ) and fluxes (in $\mathrm{Pg}$ $\mathrm{C}^{-1}$ ) as annual averages. Diagram from IPCC (1995) with additions from Lal (2003). Note absence of riverine and shallow marine OC fluxes, hence their emphasis in this study.

Biological processes both on land and in the ocean strongly affect the highly dynamic global $\mathrm{C}$ cycle on all time scales. In both settings, oxygenic photosynthesis is responsible for most of the production of organic matter (OM) and at the biochemical level, the processes that result in Net Primary Production (NPP) (i.e. the amount of photosynthetically fixed $\mathrm{C}$ available to the first heterotrophic level in an ecosystem) are very similar. Linking biogeochemical and ecological processes, NPP is a major determinant of $\mathrm{C}$ sinks both on land and in the ocean. In terrestrial systems, even fairly small increases in NPP can result in substantial C storage in plants and soils, however even large increases in ocean NPP will not result in substantial C storage due to the rapid turnover of oceanic plant biomass (Field et al. 1998).

Rivers are the major link between the terrestrial and marine pools, with the annual movement of $\mathrm{C}$, rather than the amount stored in various reservoirs, being of key importance to the global C cycle (Schlesinger 1997). The mainly fluvial transport of C from land to ocean occurs in three forms: particulate organic carbon (POC) consisting of woody debris, leaf litter and soil organic matter; dissolved organic 
carbon (DOC), formed by the decomposition of $\mathrm{C}$ in soil and leaf litter and from autochthonous release of organic compounds within the river network; and dissolved inorganic carbon (DIC) which is largely in the form of $\mathrm{HCO}_{3}{ }^{-}, \mathrm{CO}_{3}{ }^{-}$ and dissolved $\mathrm{CO}_{2}$. Collectively POC and DOC are called total organic carbon (TOC), with recent estimates suggesting DOC and POC comprise $\sim 60 \%$ and $\sim 40 \%$ of riverine TOC discharges respectively (Hedges et al. 1997). However, these estimates are based on studies from continental landmasses, whereas more recent studies suggest that POC provides the greatest proportion of TOC from mountainous rivers draining collisional margins (Scott et al. In Press).

While the transport and fate of terrestrial OC can potentially impact strongly on the global $\mathrm{C}$ cycle, they remain largely unknown and poorly quantified. As illustrated by Figure 1.2, the riverine flux of $\mathrm{C}$ from land to ocean was not factored into the global C cycle at the time of the IPCC 1995 Climate Change Report. The importance of this flux has since been recognised, and a number of studies over about the last decade have estimated annual global discharges of POC from rivers to the oceans, as summarised in Table 1.1.

Table 1.1: Estimated annual global discharges of POC.

\begin{tabular}{|c|c|}
\hline Authors & $\begin{array}{c}\text { Annual POC flux } \\
\left(\operatorname{Pg~C~y~}^{-1}\right)\end{array}$ \\
\hline McKee et al. (2004) & 0.250 \\
\hline Probst (2002) & 0.200 \\
\hline Chen et al. (2001) & 0.240 \\
\hline Meybeck \& Vörösmarty (1999) & 0.195 \\
\hline Ittekot (1998) & 0.231 \\
\hline Hedges et al. (1997) & 0.150 \\
\hline Ludwig et al. (1996) & 0.170 \\
\hline Lal (1995) & 0.085 \\
\hline Meybeck (1993) & 0.170 \\
\hline Sarmiento \& Sundquist (1992) & 0.250 \\
\hline
\end{tabular}

These global POC estimates vary by a factor of three, with values ranging from 0.085-0.250 $\operatorname{Pg} \mathrm{C}^{-1}$. This variability may at least partially be accounted for by the different methods used to calculate POC, e.g. by extrapolating data from selected rivers or using empirical relationships between observed OC fluxes and river basin characteristics, then scaled up to the global level. Clearly there is a need for more 
detailed POC measurements to more accurately determine terrestrial OC fluxes at the catchment scale, which will in turn allow more accurate global POC flux estimates to be made. This is particularly relevant to small mountainous catchments with a high sediment yield (Figure 1.3). For example, New Zealand's three East Coast rivers that drain the Raukumara peninsula contribute $\sim 0.3 \%$ of the global sediment supply to the ocean (Hicks et al. 2004a).

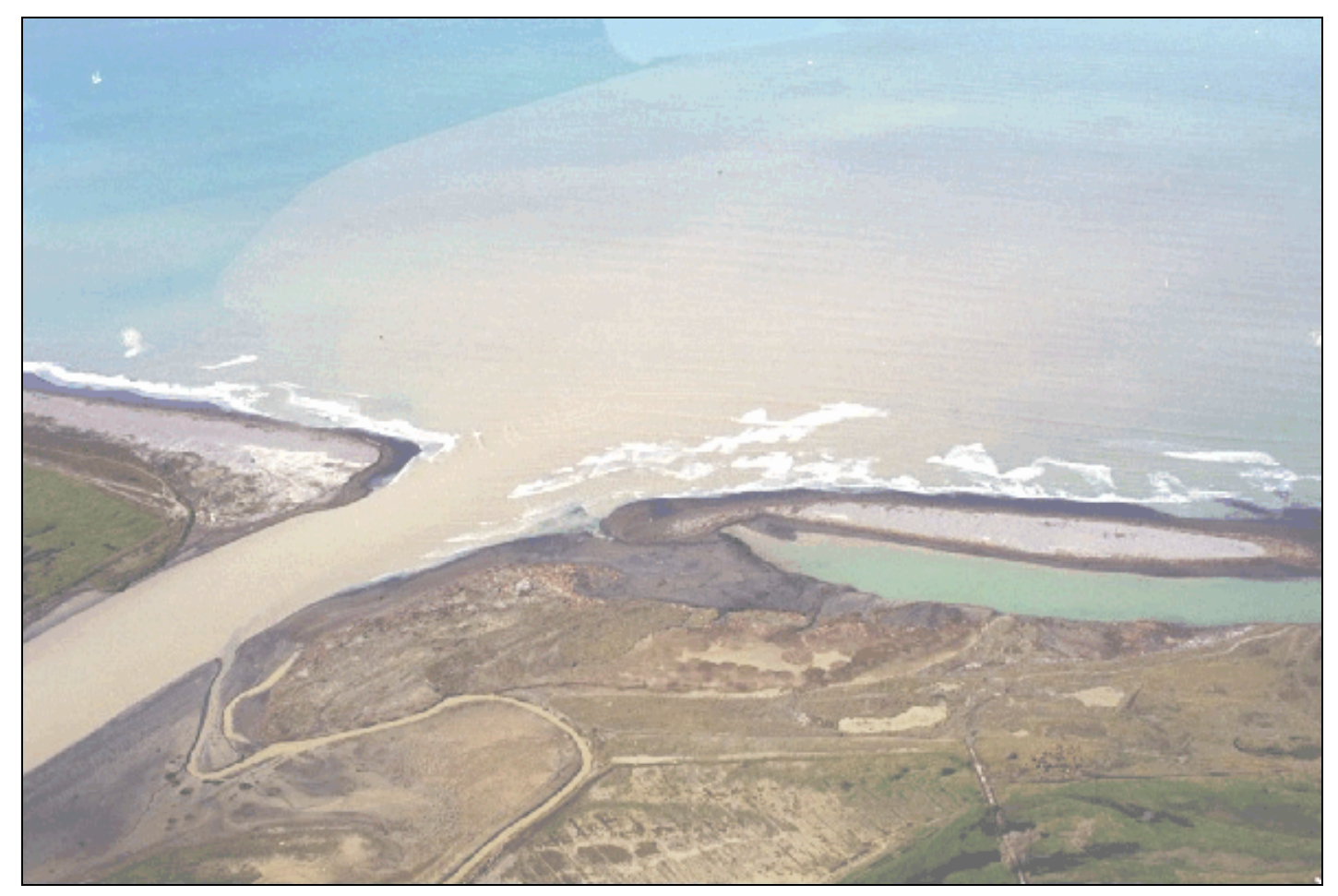

Figure 1.3: Sediment plume during storm event, Waipaoa River, 7 August 2002. (Photo: D. Peacock, 2002).

\subsection{SEDIMENT \& OC GENERATION, TRANSFER AND SEQUESTRATION}

The global export of OC is tightly linked to the total flux of continental sediment to the oceans. Accordingly, a number of recent studies (Milliman \& Syvitski 1992; Milliman 1995; Milliman et al. 1999; Lyons et al. 2002; Farnsworth \& Milliman 2003) have emphasised the contribution of mountainous oceanic islands to global land to ocean sediment and OC fluxes. It has been suggested that although these islands make up only $\sim 3 \%$ of the continental landmass, the short steep rivers, highly variable rainfalls and potentially high erosion rates combine to enable the rapid transport of water and sediment from the islands, resulting in them contributing up to $33 \%$ of the total annual sediment yield to the world's oceans (Milliman \& Syvitski 
1992). It has more recently been estimated that mountainous islands of the Pacific Rim may contribute up to $40 \%$ of the global land to ocean sediment flux (Farnsworth \& Milliman 2003) and 35\% of the POC flux (Lyons et al. 2002). These global figures are estimates, made from limited OC measurements and using average sediment yields to determine POC yields. New Zealand is one of the Pacific Rim's mountainous islands exporting a disproportionate amount of sediment to the ocean - it constitutes $\sim 0.2 \%$ of the global land area, yet contributes $\sim 1 \%$ of the global suspended sediment flux to the ocean. This study will improve on previous estimates, by making sequential land to ocean OC measurements that will allow more robust scaling-up to the national level by applying these findings to other catchments with similar characteristics.

Depending on the type of erosion processes, soil can make a large contribution to the eroded material lost from a landscape, and by association, can lead to substantial OC losses. It was suggested by Lal (1995) that globally, 5.7 Pg of C is displaced annually by soil erosion, and of that, $70 \%(3.99 \mathrm{Pg})$ is redeposited within terrestrial ecosystems and $20 \%(1.14 \mathrm{Pg})$ is lost as $\mathrm{CO}_{2}$ from decomposition. This breakdown suggests that globally, only $10 \%(0.57 \mathrm{Pg})$ of the erosion-derived OC is ultimately transported to the oceans. However, in the case of mountainous islands, where rivers generally have steep gradients, short courses and small floodplains, there is likely to be less opportunity for redeposition, as the rivers more efficiently transport sediment to the ocean, particularly during floods (Gomez et al. 2003). Thus the percentage of terrigenous $\mathrm{OC}$ lost during transport to the ocean from mountainous islands requires further investigation.

When severe erosion removes the underlying parent material as well as soil, sedimentary rocks can contribute a large quantity of ancient refractory OC. These sedimentary rocks are estimated to contain $10^{7}$ Pg of OC (Hedges \& Keil 1995) with $>95 \%$ of the total organic matter in most rocks consisting of kerogen (i.e. insoluble OC in sedimentary rocks). The fate of this ancient OC in river systems is of great importance to the global $\mathrm{C}$ cycle, as it plays a role in moderating global atmospheric $\mathrm{CO}_{2}$ and $\mathrm{O}_{2}$ levels over geologic timeframes (Hedges 1992; Petsch et al. 2000). Being very insoluble and unreactive, kerogen is slowly oxidised through the 
weathering of bedrock following exposure at the earth's surface, and may subsequently be replaced with more modern $\mathrm{OC}$ as it is transported to the ocean (Blair et al. 2003).

Because the transfer and fate of terrestrial OC are largely controlled by the transport of sedimentary particles, erosion and deposition processes occurring within a sedimentary system will strongly influence its OC transfers and transformations. It is understood that in basins with stable land use patterns, streamflow events of moderate magnitude and frequency are more important than large magnitude, low frequency flood events (Hicks et al. 2000). This was confirmed for New Zealand's Waipaoa River basin by Trustrum et al. (1999) using magnitude-frequency analyses, where it was found that frequent low magnitude events play a greater role in sediment generation and transfer than the large, less common storms, and it was calculated that $86 \%$ of the sediment load is transported by events with return periods less than 10 years. This was attributed to the relatively low contributions to catchment sediment yield by landsliding, compared to the frequent generation of sediment from gully erosion during lower magnitude events (Trustrum et al. 1999). In contrast, where erosion thresholds are higher and mass movement dominates, it is expected that low frequency, high magnitude events play the major role in sediment generation and transfer. One such example is New Zealand's Tutira catchment, where landsliding accounts for the majority of the sediment mobilised during large magnitude events (Page et al. 1994b). Another example is north California's Eel River, where $\sim 50 \%$ of the annual sediment load is discharged during a 1-2 week winter period, and on longer time scales sediment transport is dominated by large floods with recurrence intervals in the order of decades (Leithold \& Blair 2001).

Much research into the role of terrestrial POC fluxes in the global $\mathrm{C}$ cycle has been carried out on large, low gradient rivers, such as the Amazon (Hedges et al. 1986, 1994; Richey et al. 1990), Yangtze (Milliman et al. 1984) and Paraná (Depetris \& Kempe 1993), where floodplain sedimentation results in the storage of a large portion of terrestrial sediment and POC, and hence have a strong influence on riverine inputs to the ocean. Because the flux of riverine POC is moderated by 
transfers in and out of storage, it can be greatly influenced by large floodplains and deltas, where there is potential for greater processing of the $\mathrm{OC}$ as it is transported through the system, and before deposition in the marine environment. Probst (2002) suggested that of the OC transported by such rivers, about two thirds may be oxidised and released to the atmosphere (as $\mathrm{CO}_{2}$ ) during its transport, as well as in the coastal and estuarine zones, and following its discharge to the ocean. Again, this part of the global C cycle has not yet been well quantified.

Recent studies by Leithold and Blair (2001) and Blair et al. (2003) into the fate of terrestrial OC have used a "source-to-sink" approach, following the evolution of terrestrial OC from the erosion of bedrock (source) through to deposition on the continental slope (sink) within the Eel Sedimentary System in northern California. Due to earlier indications that most of the OC in continental margin sediments is sorbed to clay-sized mineral grain surfaces, they focussed their research on those fine sediments. The clay fraction $(<4 \mu \mathrm{m})$ was isolated and used to track changes in the OC loading (ratio of OC to surface area (OC:SA)) of those particles to determine how watershed processes contributed to the amount and composition of OC being transported through the system and buried in ocean sediments (Blair et al. 2003).

Sediments on the Eel shelf were found to have retained their terrestrial OC signature, with a significant fraction consisting of bedrock-derived kerogen that had escaped oxidation. It was suggested that this preservation of ancient OC results from high uplift rates, mass wasting of the bedrock and rapid transfer and burial in the marine environment. Collectively, these factors emphasise that watershed processes have a vital role in determining the amount and character of OC being sequestered on continental margins (Leithold \& Blair 2001). To further follow the evolution of OC from bedrock to seabed through the Eel Sedimentary System, Blair et al. (2003) used a multi-tracer approach $\left({ }^{14} \mathrm{C} /{ }^{12} \mathrm{C}\right.$ and $\left.\delta^{13} \mathrm{C}\right)$ to sequentially track changes in OC loadings from various sources as clay-sized particles were transferred through the system. Their findings indicate that OC in the Eel Sedimentary System gets progressively younger in terms of ${ }^{14} \mathrm{C}$ age as first terrestrial and then marine $\mathrm{OC}$ are added to the bedrock OC during transport through the system. The isotopic 
composition and OC:SA of the clay-sized particles allowed contributions from kerogen, terrestrial and marine OC sources to be determined. While modern OC was added to the particles during contact with surficial terrestrial and marine productivity, at least $50 \%$ of the kerogen OC was found to survive transport through the Eel Sedimentary System and reach the continental slope (Blair et al. 2003). This is in contrast to deltaic systems such as the Amazon, where up to $70 \%$ of the terrestrial $\mathrm{OC}$ is lost from particles on discharge to the marine environment (Aller et al. 1996; Keil et al. 1997).

\subsection{NEW ZEALAND}

Recently, the impact of erosion on the transfer of terrestrial OC has become of increasing interest and importance, particularly in response to New Zealand ratifying the Kyoto Protocol and the associated future prospect of possible full national $\mathrm{C}$ accounting. Tate et al. (2000) and Trotter et al. (2004) tested the hypothesis that the loss of $\mathrm{C}$ from indigenous forest and soils is balanced by the uptake of $\mathrm{C}$ by planted forests and scrub, effectively meaning New Zealand has carbon-neutral terrestrial ecosystems. Landsliding was assumed to be the major erosion process resulting in loss of SOC to the coast, and OC losses were based on regional sediment yield data at the national scale, using an average SOC content of $1.89 \%$. Different erosion processes were then considered, to help in quantifying scaling errors resulting from national scale calculations. For this purpose, previously calculated sediment budgets for the North Island's Waipaoa and Tutira catchments (Page et al. 1994a, 1994b; Trustrum et al. 1998, 1999) were used to quantify sediment contributions from

different erosion processes, such as gully, shallow landslide and sheet erosion. Average OC contents for a variety of disturbed and undisturbed (but deforested) soil profiles were used to estimate the amount of SOC removed by each erosion process (Tate et al. 2000).

The impact of erosion on New Zealand's C budget is significant, as reported by Page et al. (2004). Soil is a major C store, containing $4640 \pm 120 \mathrm{Tg} C$ to a depth of $1 \mathrm{~m}$ (Tate et al. 2005) and highly erodible sedimentary rocks at deeper depths potentially contain additional large stores of ancient OC. It is estimated that $\sim 209$ 
Tg of suspended sediment is lost from New Zealand's landscape and delivered to the ocean each year (Hicks et al. 2002) and by association, a potentially significant amount of OC is also lost from the landscape. Having ratified the Kyoto Protocol, and anticipating a possible future need for quantification of anthropogenic erosionrelated OC losses, New Zealand has been developing a national terrestrial C budget, in which the annual sequestration of eroded SOC is estimated for land and marine environments and lost to the atmosphere as $\mathrm{CO}_{2}$. The proportion of these fluxes that is anthropogenic is also being investigated (Trustrum et al. 2002).

New Zealand's first assessment of the national terrestrial $\mathrm{C}$ balance, at various spatial scales, was reported by Tate et al. (2000). Results suggested that although some of the country's ecosystems are C sinks, overall New Zealand is a net source of $\mathrm{C}$, with an estimated 3-11 $\mathrm{Tg}$ of soil C (generated by erosion of the landscape) being lost to the coast each year. If landsliding was considered to be the main sediment source, annual $\mathrm{C}$ losses from erosion would be $\sim 3 \mathrm{Tg} \mathrm{C}$, while if all erosion processes are factored in, annual $\mathrm{C}$ losses of up to $\sim 11 \mathrm{Tg} \mathrm{C}$ are possible (Tate et al. 2000). To reduce the large uncertainty in this initial estimate, further work has since been carried out to assess the extent of New Zealand's erosionrelated $\mathrm{C}$ losses at the national scale, and the annual loss of soil $\mathrm{C}$ to the ocean is now thought to be $\sim 4 \mathrm{Tg} C$ (Hicks et al. 2004b) to 3 \pm 1 Tg C (Scott et al. In Press). Given that land use change can increase erosion rates by more than an order of magnitude (Page \& Trustrum 1997), the provocative hypothesis is that anthropogenic influences have changed New Zealand's OC export dramatically. However, the proportion of this OC loss that is anthropogenically induced, and the extent of $\mathrm{OC}$ processing and $\mathrm{CO}_{2}$ emissions during transfer from terrestrial source to marine sink, is still not well defined. More needs to be known about the transfer of OC from New Zealand's landscape to the ocean, and the geochemical processes involved along the transport pathway and following deposition on the continental shelf and slope.

The effect of historical land use change is another significant uncertainty in New Zealand's national terrestrial OC budget. By refining previous work, Tate et al. (2003) tested the hypothesis that recent land use changes in New Zealand have 
resulted in an overall loss of SOC. Afforestation and reforestation of grazing land over the past 15 years have been the major land use changes resulting in large vegetation $\mathrm{C}$ sinks (6-9 $\left.\mathrm{Tg} \mathrm{C}^{-1}\right)$, however it has been suggested that these changes in land use may in fact lead to mineral soil losses of $0.7 \pm 0.3 \mathrm{Tg} \mathrm{C}^{-1}$ for the 1990 2000 period (Tate et al. 2003). The contribution of soil erosion was not factored in to these effects of land use changes on the terrestrial OC budget, and it remains a potentially large uncertainty.

In New Zealand, a major source of erosion-related SOC losses is landslide-prone soft rock hill country. A recent study by Page et al. (2004) provides vital insight into erosion-related losses from a steepland catchment. SOC fluxes from landslide and sheetwash erosion were calculated for the Tutira catchment in New Zealand's North Island for the 114-year period of European pastoral farming, where a lake acts as an efficient trap for sediments and nutrients within the catchment. These sediments contain a high resolution record of storm-induced erosion of the soft-rock hill country. By linking estimated erosion rates with soil and sediment OC contents, a mass balance approach was used to calculate erosion-related OC losses and gains.

When scaled up to the national level, the gross loss of $\sim 0.94 \mathrm{Mg} \mathrm{C} \mathrm{ha}^{-1} \mathrm{y}^{-1}$ from erosion-prone terrain at Tutira equates to a national gross loss of $2.5 \mathrm{Tg} \mathrm{C} \mathrm{y}^{-1}$ from similar terrain, of which $2.1 \mathrm{Tg} \mathrm{C} \mathrm{y}^{-1}$ is associated with pastoral farming (Page et al. 2004). It was concluded that improved management and changing land use to reduce erosion rates of New Zealand's landslide-prone soft rock hill country would significantly lower OC losses and associated $\mathrm{CO}_{2}$ emissions.

Recent work by Hicks et al. (2004a) has illustrated that the high suspended sediment loads of rivers draining New Zealand's East Coast Continental Margin (ECCM) can result in the generation of negatively buoyant (hyperpycnal) plumes, which are likely to make an important contribution to marine sediment transport across the continental shelf. It was calculated that the Waipaoa River suspended sediment concentration exceeds the $40000 \mathrm{mg} \mathrm{L}^{-1}$ threshold for hyperpycnal flows approximately once every 40 years, in contrast to the return period of $\geq 10$ years 
suggested by Foster and Carter (1997). The impact of hyperpycnal plumes on WSS terrestrial OC fluxes to the ocean has not previously been investigated.

\subsection{RESEARCH QUESTIONS}

It is apparent that there are significant gaps in the research of land to ocean OC transfers at both catchment and global scales, with the erosion-related transfer of OC from its terrestrial source to marine sink being a poorly quantified link in global $\mathrm{C}$ budgets. In particular, the biogeochemical processes acting at various depositional sites as OC is transported to the open ocean, and the proportion of terrigenous OC that is preserved in ocean sediments are not well understood or quantified.

This study will assist in refining New Zealand's national erosion-related C budget, by identifying and quantifying transformations in sediment-associated OC along the transport pathway from terrestrial source to marine sink. This study makes the first field measurements of OC characteristics of continental shelf and slope sediments of the ECCM, enabling a critical assessment of previously predicted OC budgets.

Sediments from the floodplain, continental shelf and slope depositional environments of the North Island's Waipaoa Sedimentary System (see Chapter 2) will be used to determine whether OC is lost or preserved as erosion-related sediment is transferred to the marine environment. In addition, the proportion of terrigenous $\mathrm{OC}$ in marine sediments will be determined using carbon isotopes and selected biomarkers, to establish whether terrigenous OC is replaced by marine OC along the transport pathway. The impacts that land-based floods have on the marine sediment and OC record will also be investigated.

For the purposes of this study, these issues can be defined by the following research questions:

- How do flood events impact the transfer \& fate of terrestrial OC in the marine environment?

- Is OC lost or preserved as it moves along the transport pathway from source to sink? 
- What changes in biogeochemical signature occur at various OC depositional sites along the system?

This work is also fundamental to the construction of accurate $\mathrm{C}$ budgets, which will contribute to global budgets that are currently deficient in direct measurements. The work will assist in identifying land to ocean riverine OC fluxes that control global C fluxes.

This thesis is organised methodically, following the sediment transport route through the Waipaoa Sedimentary System (WSS) from source to sink. In Chapter 2 the components of the WSS are characterised, starting with the uplands and progressing through the catchment to the floodplain, continental shelf and slope, while in Chapter 3 the methodological and analytical techniques used in this study are described. Chapter 4 sets out to characterise Waipaoa River floodplain sediments and establish a benchmark signature for erosion-related sediment and flood sequences, to assist with their recognition offshore. It also illustrates the influence of floodplain morphology and river dynamics on modulating OC transfers to the ocean. The biogeochemical characteristics of continental shelf and slope sediments are investigated in Chapter 5, to identify the relative role of individual flood layers and high frequency, low magnitude river discharges (ambient conditions). Then, the questions of (a) how flood events in the river catchment impact the transfer and fate of terrestrial OC to the marine environment and (b) how the marine environment influences the OC signature, are addressed. In Chapter 6, the transfer of sediment and OC across the Poverty Bay continental shelf and slope is tracked, to determine whether OC is lost or preserved as sediment moves along the transport pathway from terrestrial source to marine sink. Changes in the biogeochemical signature occurring at various OC depositional sites along the source to sink system are also investigated. In the concluding Chapter 7, results from this study are used to develop a conceptual model of OC transfers and transformations for the WSS and offer implications for the global $\mathrm{C}$ budget. 


\section{CHAPTER 2: WAIPAOA SEDIMENTARY SYSTEM}

\section{$2.1 \quad$ INTRODUCTION}

Located on the East Coast of New Zealand's North Island (Frontispiece \& Figure 2.1), the Waipaoa Sedimentary System (WSS) has been much studied since the mid1990s. Largely prompted by the impact of Cyclone Bola in March 1988, research has mainly focussed on terrestrial hillslope erosion processes, as they are the largest source of sediment within the catchment (e.g. DeRose et al. 1998; Page et al. 1999, 2000; Trustrum et al. 1999; Reid \& Page 2002; Betts et al. 2003; Gomez et al. 2003). Downstream impacts of such active erosion on the Waipaoa River floodplain have also been studied (Peacock 1998) and using historical flood records, the floodplain stratigraphy has been well established (Gomez et al. 1998, 1999). The regional tectonic framework on land was investigated by Berryman et al. (2000), who identified a succession of river terrace remnants in order to establish the importance of tectonic and climatic controls on landscape change. As downcutting occurs at up to four times the rate of tectonic uplift in some reaches, fluvial terrace formation is believed to be primarily controlled by climate fluctuations. Eden et al. (2001) identified a number of regionally characterised tephra layers within the Waipaoa catchment, and using these in conjunction with pollen and charcoal analyses from both terrestrial and marine cores, Wilmshurst et al. (1999) developed a record of Holocene vegetation change in the Gisborne region. Suspended sediment yields of the Waipaoa River have been studied by Hicks et al. $(2000,2002)$ which have assisted in linking watershed processes to offshore sedimentation (e.g. Gomez et al. (2004a). 


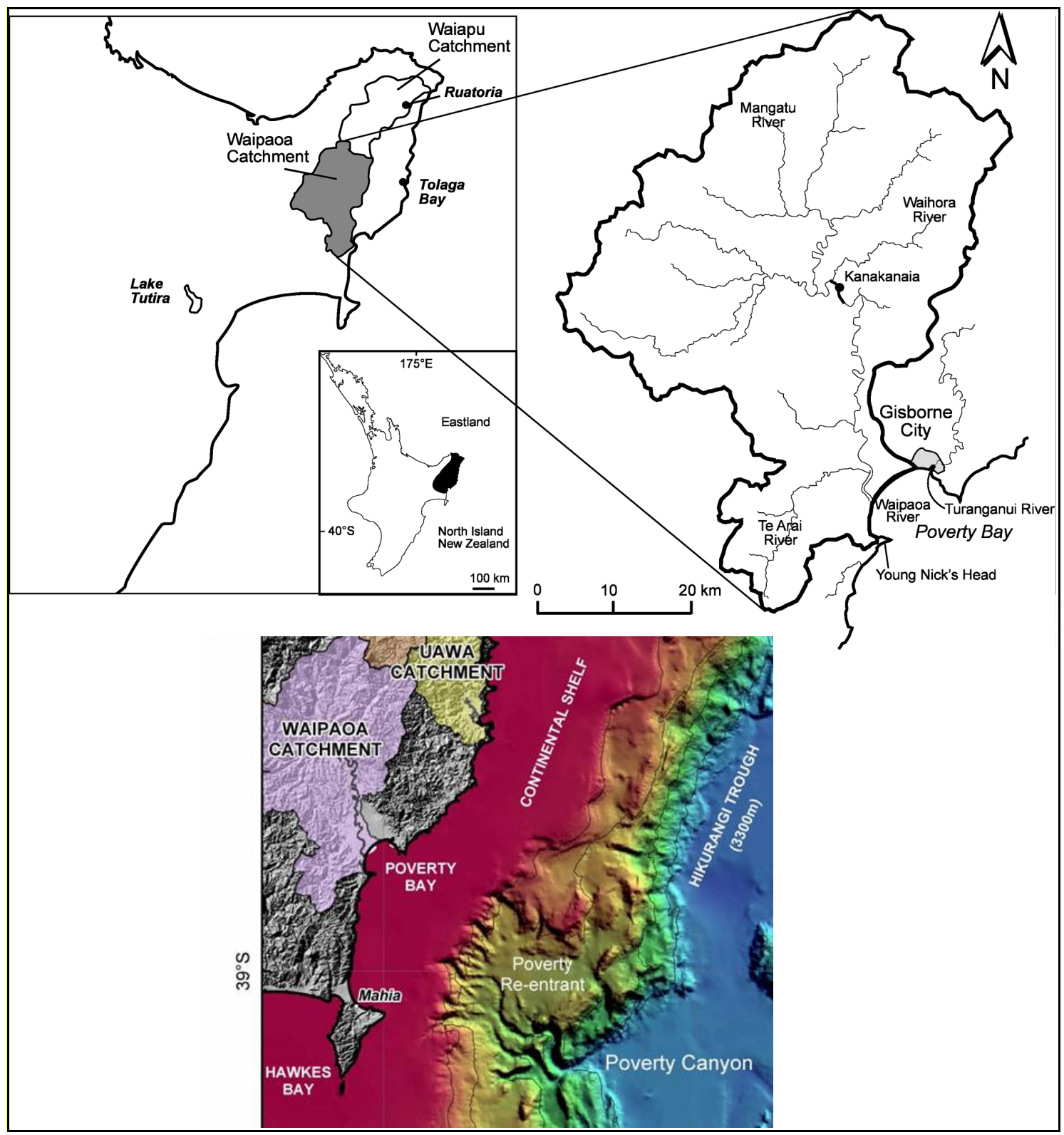

Figure 2.1: Location map of the onshore catchment and offshore setting of the Waipaoa Sedimentary System. (Figures courtesy of Landcare Research and NIWA).

The offshore environment of the WSS has also received growing interest, following a "source-to-sink" approach to sediment transfer. Foster and Carter (1997) investigated the dispersal and deposition of riverine sediments on the continental shelf, and inferred an increase in modern shelf sedimentation rates in response to increased erosion in the catchment. Carter et al. (2002) used a giant piston core from a deep slope basin off Hawkes Bay, to determine how terrigenous fluxes from the eastern North Island had changed over the last 15000 years, and confirmed the role of the continental shelf and slope in effectively trapping terrigenous sediment. Orpin (2004) documented Holocene hemipelagic sedimentation on the Poverty slope, the seaward extension of the Waipaoa dispersal system, and suggested it is an 
important sink for riverine sediment that should be included in a margin-wide sediment budget. Research culminated in setting up the "source-to-sink" NZ-US MARGINS Programme, jointly funded by the US National Science Foundation (NSF) and New Zealand's Foundation for Research, Science and Technology (FRST).

Organic carbon (OC) fluxes within the WSS have also recently been investigated. Gomez et al. (2003) determined the particulate organic carbon (POC) yield of the Waipaoa River, and used $\delta^{13} \mathrm{C}$ and $\mathrm{C} / \mathrm{N}$ values to identify the $\mathrm{OC}$ sources and influence of different erosion processes. Gomez et al. (2004b) used a single core to study the OC in a suite of Waipaoa River floodplain sediments deposited since 1853, and determine whether geochemical variations could be attributed to historical variations in sediment sources. The signatures of large-scale environmental processes are also well preserved within both the terrestrial and marine sedimentary records of the WSS. Gomez et al. (2004a) used textural variations within the highresolution floodplain and continental shelf records from the WSS, along with a continental slope sedimentary record from Hawkes Bay, to illustrate long-term changes in terrestrial erosion processes and sediment supply, resulting from changes in regional climate patterns, particularly the El Niño-Southern Oscillation.

The WSS has been chosen as one of two key global sites for the US NSF initiated MARGINS Source-to-Sink (S2S) program (Kuehl et. al 2003). The program will use a systems approach to examine coupled land and ocean environments, to understand the fundamental processes shaping the earth's surface through the transfer of sediment from terrestrial sources to marine sinks, and thereby improve the ability to predict associated environmental impacts. The S2S program aims to address three fundamental questions:

- What processes control the rate of sediment and solute production in a dispersal system?

- How does transport through the system alter the magnitude, grain size, and delivery rate to sediment sinks?

- How is variability of sediment production, transport, and accumulation in a dispersal system preserved by the stratigraphic record? 
The WSS is globally significant in that it represents a relatively simple setting to model the modulation of forcing signals (climatic, eustatic, tectonic and human) across a near-complete spectrum of sedimentary environments, and offers an opportunity to attempt closure of a sediment budget through time and space (Kuehl et. al 2003). The combination of these factors and the findings of this study will also assist in closing a carbon (C) budget for the WSS, and determine the fate of terrestrial OC as it is transferred to the marine environment.

\subsection{TECTONIC AND GEOLOGICAL SETTING}

The Gisborne-East Coast region is positioned within a zone of active deformation associated with the Hikurangi subduction margin, where oblique collision is subducting the Pacific Plate beneath the Australian Plate. Offshore evidence of the plate boundary is indicated by the 3300 m-deep Hikurangi Trough, approximately $90 \mathrm{~km}$ southeast of the Raukumara Peninsula (e.g. Lewis et al. (1998)) (Figure 2.1). Such active tectonism has resulted in uplift of up to $4 \mathrm{~mm} \mathrm{y}^{-1}$ in the region (Ota et al. 1992), with the middle reaches of the Waipaoa catchment being uplifted at a rate of $0.5-1.1 \mathrm{~mm} \mathrm{y}^{-1}$ (Berryman et al. 2000).

The Gisborne-East Coast geology is defined by 3 structural divisions: the East Coast Allochthon (Cretaceous-Paleocene); a Neogene (Miocene-Pliocene) sequence; and the Motu Block of Jurassic to early Cretaceous greywacke (Moore \& Mazengarb 1992). The Waipaoa River catchment is underlain by the first two divisions, while the early Cretaceous greywacke of the Raukumara Range and its younger Cretaceous cover sequence lie just beyond the northwest boundary of the catchment.

Dominated by a maritime climate, the Waipaoa River catchment has a mean precipitation ranging from $\sim 1000 \mathrm{~mm} \mathrm{y}^{-1}$ at the coast to $>2500 \mathrm{~mm}^{-1}$ in the headwaters, and the area also periodically experiences cyclonic and localised storms, particularly in the March-May period. During Cyclone Bola (6-9 March 1988), the East Coast's largest historical storm, the four-day rainfall was $300 \mathrm{~mm}$ at the coast and $900 \mathrm{~mm}$ inland (Page et al. 2001). 


\subsection{ENVIRONMENTS}

The following suite of environments is the pathway followed by erosion-related sediment and $\mathrm{OC}$ - from areas of generation, during transfer and in storage.

\subsubsection{Uplands}

\subsubsection{Geology}

Dominating the upland geology, the internally complex East Coast Allochthon contains a series of sheets separated by thrust faults or bentonitic melange zones. Having been extensively displaced from their original depositional site, the rocks consist of crushed and sheared argillites, mudstones and sandstones (Mazengarb \& Speden 2000). In the lower Waipaoa River catchment, the East Coast Allochthon is overlain by a thick sequence of moderately indurated Miocene-Pliocene sandstone, mudstone, alternating sandstone and mudstone, and minor limestone (Mazengarb \& Speden 2000).

\subsubsection{Soils}

Soils of the Waipaoa River catchment uplands have formed through the weathering of fine-grained sedimentary rocks, mantled in places by rhyolitic tephras. Soil sequences are related to the topography, underlying rock, presence/thickness of tephra, and rainfall, which are poorly defined and described for much of the steeplands and higher terraces (Eden \& Trustrum 1994). Because of deforestation and subsequent erosion, soils on steeplands of the catchment are shallow (10's of $\mathrm{cm}$ deep) with low organic matter (OM) contents and water-holding capacities (Page et al. 2000). Landsliding on steep hillslopes removes the topsoil and some weathered bedrock, resulting in shallow and young ( $<100$ years) soils in these areas as they slowly redevelop over time. In some less steep forested areas, however, soil profiles 1-2 m deep have developed (Reid \& Page 2002).

\subsubsection{Erosion Processes}

Erosion rates within the Waipaoa River catchment are naturally high, due to the weak and highly deformed rocks, active tectonism, steep slopes, and periodic intense rainstorms. However, the severity of erosion has increased dramatically since the arrival of European settlers in the late 1820s, and subsequent deforestation from 
1880-1920. Reforestation with Pinus radiata began in the Waipaoa River catchment headwaters in the 1960's, targeting areas of severe and extremely eroding land, in an attempt to stabilise soils on the hillslopes. The aim was to reduce the suspended sediment discharge, and to a much lesser extent, the bedload discharge (which is 1\% of the suspended sediment discharge) (Peacock 1988). Only $\sim 6 \%$ of the basin now remains under indigenous forest and scrub, with $\sim 20 \%$ planted in exotic forest and $\sim 70 \%$ in pasture (Page et al. 2001).

The range of erosion processes active within the Waipaoa catchment include gully (activated by the smaller, frequent rain events), landslide (only activated during the infrequent, higher magnitude rainstorms), earthflow, sheet, streambank, and tunnel gully (Page et al. 2000). Gullies contribute more than 50\% of the river suspended sediment load; landslides contribute 10-19\% (increasing with storm size); sheet erosion contributes $\sim 10 \%$; and the balance is from earthflow, streambank, tunnel gully, and riverbeds, roads etc. (Page et al. 2000). As landslides are only triggered by large storms, they make a significant contribution to overbank sedimentation during flood events. Discharges below bankfull are responsible for transporting $76 \%$ of the suspended sediment, so most of the gully-derived sediment is transported to the coast (Page et al. 2000).

\subsubsection{River and Floodplain}

\subsubsection{Soils}

Soils of the floodplains, tidal flats and beachlands were divided into four classes by Pullar (1962), according to their parent material, age and texture of sediment and flooding/drainage:

- Recent soils from alluvium (87.7\%), on floodplains where periodic flooding occurs.

- Yellow-brown pumice soils (5.5\%), derived from rhyolitic tephra deposited on beach lands.

- Yellow-brown sands (4.5\%), formed near the coast through accumulation of sandy materials and shell fragments.

- Saline gley soils $(2.3 \%)$, found on tidal flats that are often flooded with seawater. 
The recent soils can be split into three groups of increasing age - the Waipaoa, Matawhero and Waihirere series. Being close to the river, Waipaoa soils have developed since 1932, as a result of rapidly accumulating deposits on the Gisborne plains. They have poorly developed structures and very low $\mathrm{C}$ and nitrogen levels, due to the sediment source (rock) and short flood return intervals limiting the build up of OM. Matawhero soils (20-300 yr BP) are found on higher parts of the modern floodplain that are only periodically flooded. They are deep, friable and well-drained soils with higher OM contents than the Waipaoa soils. The widely distributed Waihirere soils (300-1820 yr BP) are in areas that have been free of flooding for a long time. They are friable, well developed and highly fertile for most crops, making them the best all-purpose soils on the Gisborne Plains (Pullar 1962).

The soil at McPhail's bend (32 km from the river mouth) (see Figure 3.1) is the Waipaoa silt loam, a soil widely used for beef and fat-lamb production, and extensive cropping. The soil is slightly alkaline, contains high amounts of calcium but low amounts of magnesium, and is dominated by smectite clays, causing shrinking and swelling with changing soil moisture contents (Molloy 1993). The weakly developed structure means the Waipaoa silt loam does not drain well, there are few crevices for grass roots to penetrate, and the sandier types are prone to drying out in summer. The Waipaoa silt loam also tends to be infested by Bermuda Grass (Cynodon dactylon), an exotic weed species that has established as a result of rhizomes being transported in flood sediments (Pullar 1962).

\subsubsection{Sedimentation and Storage}

The $2205-\mathrm{km}^{2}$ WSS has a specific sediment yield of $6800 \mathrm{t} \mathrm{km}^{-2} \mathrm{y}^{-1}$ and is drained by the Waipaoa River into Poverty Bay. The Waipaoa River is New Zealand's second largest river in terms of sediment supply, annually delivering $\sim 15 \mathrm{Tg}$ of sediment to the marine environment (Figure 2.2), with the bedload yield being $\sim 1 \%$ of the suspended load. Surpassed only by the extremely muddy Waiapu River ( $\left.35 \mathrm{Tg} \mathrm{y}^{-1}\right)$, the Waipaoa contributes $7 \%$ of New Zealand's total suspended sediment yield to the Pacific Ocean, and makes up $\sim 0.1 \%$ of the global suspended sediment discharge (Hicks \& Shankar 2003). 


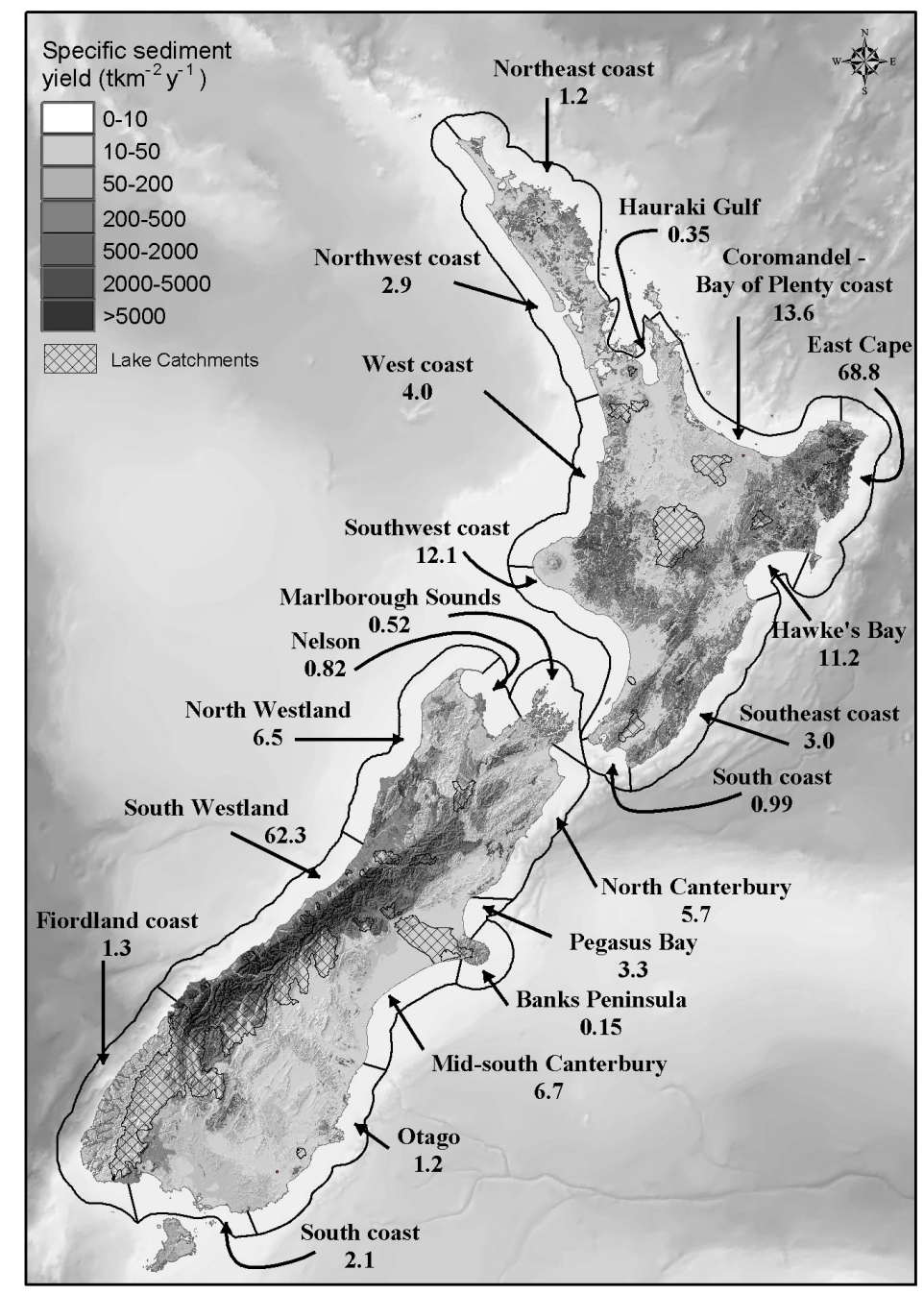

Figure 2.2: Annual suspended sediment yields (in $\mathrm{t} \mathrm{km}^{-2} \mathrm{y}^{-1}$ ) from New Zealand rivers. (From Hicks \& Shankar (2003)).

The Waipaoa is dominantly a gravel bed river, with a gravel-sand transition occurring approximately $8 \mathrm{~km}$ from the mouth, and a change in morphology from a braided system in the upper $12 \mathrm{~km}$ to a single thread channel bordered by a welldefined floodplain in the middle and lower reaches (Rosser 1997). Approximately 32 $\mathrm{km}$ from the mouth, McPhail's bend (Figure 2.3) is a $2.5 \mathrm{~km}$ long meander bend $\left(0.5-\mathrm{km}^{2}\right.$ area) of the Waipaoa River floodplain that has remained under pasture since colonisation, unlike other areas further downstream which have been cultivated. 


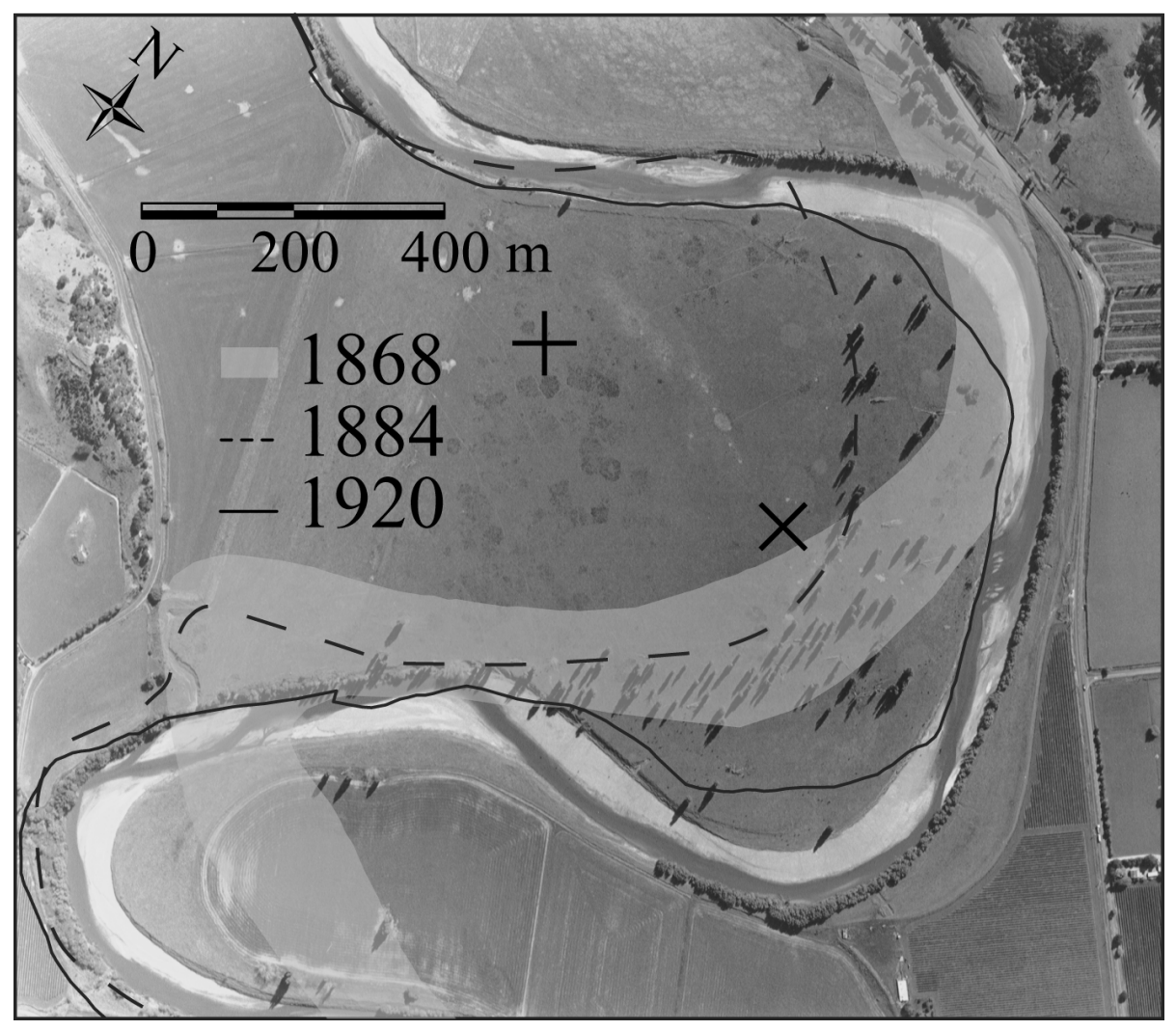

Figure 2.3: McPhail's bend, indicating changes in planform geometry since 1868 . The core site of Gomez et al. $(1998 ; 1999 ; 2003 ; 2004 b)$ is marked by the + and the core site for this study by the $\mathrm{X}$.

The geometry of McPhail's bend has undergone dramatic changes in response to deforestation in the upper catchment in the late $19^{\text {th }}$ and early $20^{\text {th }}$ centuries (Figure 2.3). Since 1920 it has become more stable, as a result of the river reaching a new equilibrium following deforestation. Tree plantings and other bank protection works have also been carried out since 1920 (Peacock 1998). Up until 1948, $1 \mathrm{~m}$ high stopbanks existed around McPhail's bend, but they fell into disrepair following the 1953 emplacement of a floodway across the neck of the bend. Now bordered by 2 $\mathrm{m}$ high stopbanks, the floodway has decreased the volume of flow across the bend and reduced the width of the active floodplain (Gomez et al. 1998).

While the mean annual flood at Kanakanaia (drainage area of $1582 \mathrm{~km}^{2}$ ) (Figure 2.1) is $1070 \mathrm{~m}^{3} \mathrm{~s}^{-1}$, a river discharge in excess of $1700 \mathrm{~m}^{3} \mathrm{~s}^{-1}$ is necessary before McPhail's bend is inundated by floodwaters (a return period of $\sim 4$ years). When discharge at McPhail's bend exceeds $1800 \mathrm{~m}^{3} \mathrm{~s}^{-1}$, active overbank flow occurs across the bend, and suspended sediment is advectively transported from the channel to the floodplain (Gomez et al. 1998). 


\subsubsection{Stratigraphy}

Previous studies (Gomez et al. 1998, 1999) have established a detailed floodplain stratigraphy for McPhail's bend. Flood deposits have been correlated to historic hydrologic records and survey data for the 1948-1995 period to calculate the rates of vertical accretion for individual flood events in the Waipaoa River (recurrence intervals typically 5-60 years). Gomez et al. (1998) identified seven recent (19481996) flood events within the floodplain stratigraphy, preserved as $0.1-0.3 \mathrm{~m}$ thick fining-up sequences of horizontally bedded overbank sediments, and estimated vertical accretion rates for six of them. Though most floods were fairly short-lived, lasting 6-20 hours, the vertical accretion rates at McPhail's bend were generally high (14-18 $\mathrm{mm} \mathrm{h}^{-1}$ ), except for the Cyclone Bola flood of March 1988, with a rate of only $6 \mathrm{~mm} \mathrm{~h}^{-1}$. Gomez et al. (1998) suggested that this much lower accretion rate was not the result of limited sediment input, but rather the prolonged high flow velocities that prevented deposition of suspended sediments on the floodplain.

In concert with the vertical floodplain accretion was in-channel deposition, causing extreme changes in the channel cross section. Both factors acted to stabilise the planform geometry, while the gradual increase in channel depth and reduction in bankfull channel width resulted in a constant channel capacity (Gomez et al. 1998).

McPhail's bend is well suited as a site at which to study the terrestrial OC characteristics of the WSS. With the floodplain stratigraphy already well established, the OC associated with the overbank sediments will be characterised, allowing comparisons to be made with the sediments that have escaped floodplain deposition and been transported to the marine environment.

\subsubsection{Continental Shelf and Slope}

\subsubsection{Shelf Environment}

The Poverty Bay continental shelf and slope are located on the tectonically active northern Hikurangi margin of New Zealand (e.g. Lewis et al. (1998)). The shelf terminates $\sim 22-26 \mathrm{~km}$ from shore, in $\sim 140-170 \mathrm{~m}$ water depth, and is enclosed at its seaward limit by the Lachlan and Ariel structural ridges (Figure 2.4), rising from 50-70 $\mathrm{m}$ depth to break the sea surface at Penguin and Ariel rocks (Foster \& Carter 
1997; Lewis et al. 1999; Barnes et al. 2002). Synclinal deformation and subsidence of $1.5-2 \mathrm{~mm} \mathrm{y}^{-1}$ on the middle shelf basin has trapped $>35 \mathrm{~m}$ of sediment since the last glacial maximum (Foster \& Carter 1997).

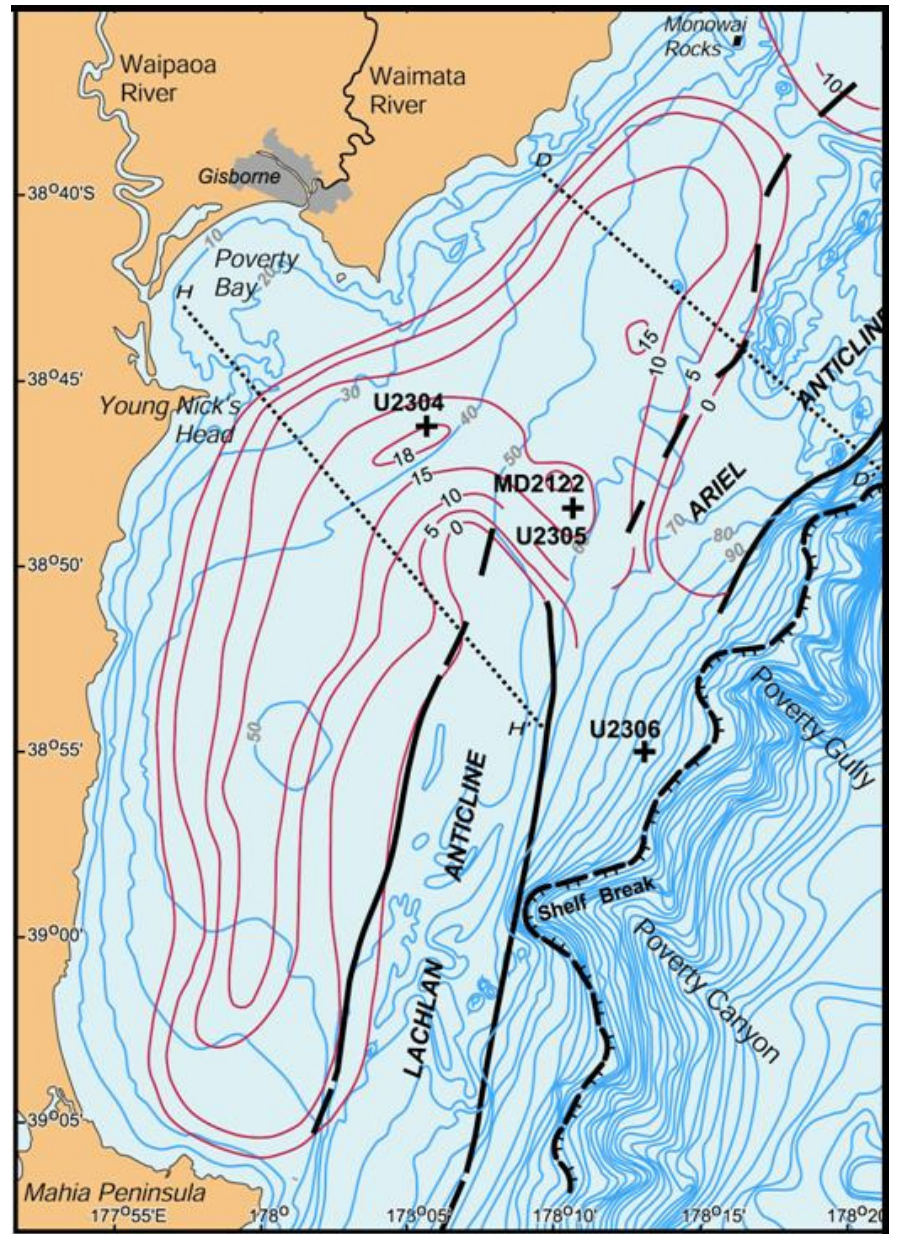

Figure 2.4: Bathymetry, morphology and sediment thickness (red isopachs) of the Waipaoa Sedimentary System continental shelf and slope.

(Based on figure from Foster and Carter (1997))

Poverty Bay is $10 \mathrm{~km}$-wide and south-eastward facing, opening onto the continental shelf, which is bordered by Mahia Peninsula to the southwest and Monowai Rocks to the northeast. Beyond Poverty Bay, sediment particle size declines with distance offshore. Inner shelf sediments are sand-dominated and a "mud blanket" extends to the edge of the shelf, except near the anticlines on the outer shelf, where outcropping Neogene rocks are surrounded by gravely and sandy sediments, and between the Lachlan Ridge and Ariel Bank, where fine sediments cover the sea floor (Foster \& Carter 1997). Orpin (2004) indicated that $\sim 140 \mathrm{~km}^{2}$ of terrigenous mud is present seaward of the Lachlan and Ariel Anticlines, thus extending the terrigenous sediment basin suggested by Foster and Carter (1997). 
With the Waipaoa River's high suspended sediment load, the Poverty Bay marine environment is dominated by large inputs of mud-dominated terrigenous sediment (silt and clay). Most of the time, the Waipaoa River mud component is contained in a buoyant or hypopycnal plume, which moves around the south coast of the bay in an anticlockwise fashion, and out to the open shelf. Anecdotal evidence of a fluid mud deposit on the inner shelf after Cyclone Bola in March 1988 is consistent with deposition from a hyperpycnal plume (Foster \& Carter 1997), though such a deposit has not yet been identified in the shelf sedimentary record offshore from the Waipaoa River. It is thought that when the Waipaoa River suspended sediment concentration exceeds $\sim 40000 \mathrm{mg} \mathrm{l}^{-1}$, outflows from the river mouth are likely to change from being hypopycnal to hyperpycnal (Hicks et al. 2004a). This issue is addressed further in chapter 5 , due to the identification of a flood layer preserved in inner shelf sediments.

Recent modelling by Hicks et al. (2004a) indicates that the high suspended sediment loads of rivers draining New Zealand's East Coast Continental Margin (ECCM) could result in the generation of negatively buoyant (hyperpycnal) plumes, which may make an important contribution to marine sediment transport trajectories across the continental shelf. It was calculated that the Waipaoa River suspended sediment concentration exceeds the $40000 \mathrm{mg} \mathrm{L}^{-1}$ threshold for hyperpycnal flows approximately once every 40 years, in contrast to the return period of $\geq 10$ years suggested by Foster and Carter (1997).

Research by Orpin et al. (2003) suggests a change has occurred in sedimentation patterns on the Poverty Bay shelf since the sediment load of the modern Waipaoa River has dramatically increased with the onset of accelerated erosion rates within the catchment. During the Holocene, when the Waipaoa River was presumably less muddy, the highest accumulation rates were at the subsiding mid-shelf basin, whereas the modern sediment accumulation rate at the mid-shelf is only half that on the outer shelf. In addition, an increasing frequency of cross-shelf flows may be increasing the sediment flux to the slope (Orpin et al. 2003). 
For this study, four cores (U2303, U2304, U2305 and U2306) were collected from a transect (27-113 m water depth) across the continental shelf (see Chapter 3).

\subsubsection{Shelf Circulation}

Ocean circulation in Poverty Bay is not greatly influenced by tides and shelf currents, but is responsive to wind forcing, particularly when wind speeds exceed 4 $\mathrm{m} \mathrm{s}^{-1}$ (Stephens et al. 2001). Circulation on the Poverty Bay shelf is dominated by the north-east flowing Wairarapa Coastal Current (WCC) (Carter \& Gomez In Review).

\subsubsection{Continental Slope}

\subsubsection{Slope Environment}

The Poverty slope is dominated by the structurally complex Poverty re-entrant, a large indentation that probably originated as a giant landslide scar (Lewis et al. 1998, 2004), and has been modified by ongoing structural deformation, canyon incision, and eustatic sea level changes. Terrigenous sediment has been dispersed beyond the continental shelf since the mid-Holocene, with the majority of terrigenous sediment being trapped in shelf and upper slope basins. Sedimentation on the mid-slope has occurred at a rate of $\sim 0.6 \mathrm{~mm} \mathrm{y}^{-1}$, with sediment accumulating in two mid-slope basins - the Paritu trough $\left(\sim 900 \mathrm{~km}^{2}\right)$ and a lower slope basin $\left(\sim 12 \mathrm{~km}^{2}\right)$ (Orpin 2004).

Cores W697 (1198 m water depth) and W698 (1428 m) were collected for this study from an upper slope feeder canyon and a mid-slope platform, respectively, on the Poverty slope (A Orpin 2005, pers. comm.).

\subsubsection{Slope Circulation}

Ocean circulation on the continental slope is dominated by the East Cape Current (ECC), opposing the WCC on the shelf. It is nominally positioned seaward of the $1000 \mathrm{~m}$ isobath, although there is evidence that it extends almost to the shelf break at $\sim 150 \mathrm{~m}$ (Stanton et al. 1997; Chiswell \& Roemmich 1998) off Tolaga Bay. The regional bathymetry and Poverty Bay re-entrant may influence the ECC's passage across the Waipaoa margin; as the subtropical inflow rounds the East Cape, the flow 
is split - part produces the East Cape Eddy, and the remainder moves southwest as the ECC, which interacts with the Wairarapa Eddy (Carter \& Gomez In Review).

\subsubsection{Carbon Fluxes}

Globally, rivers transport $\sim 0.15 \mathrm{Pg}\left(\sim 0.15 \times 10^{15} \mathrm{~g}\right)$ of POC from the continents to the oceans each year, but it still remains a mystery that only a small fraction of the OC preserved in marine sediments appears to be terrestrially derived (Hedges et al. 1997). Recent studies suggest destruction of the terrestrial OC following discharge to the ocean (Hedges et al. 1997). This study seeks to address this issue.

With $>40 \%$ of New Zealand's landscape comprised of soft-rock hill country (Tate et al. 2000) similar to that of the Waipaoa catchment, research within the WSS is critical for contributing to national-scale $\mathrm{C}$ budget research. The dominance of gully erosion in the Waipaoa catchment indicates it contributes $\sim 50 \%$ of the suspended sediment yield to the coast, whereas the low OC content of the bedrock source suggests it only accounts for up to $5 \%$ of the total OC loss from this catchment. In contrast, sheet erosion generates only $\sim 10 \%$ of the suspended sediment yield, but is mainly composed of carbon-rich topsoil, so it could account for up to $\sim 50 \%$ of the OC losses. Shallow landslides (15\% of suspended sediment yield) accounted for $\sim 25 \%$ of OC loss, again contributing largely carbon-rich sediments, while earthflows, tunnel gullies, bank erosion and vegetation inputs generated the remaining $20 \%$ of OC losses from the catchment (Tate et al. 2000).

Table 2.1: Summary of erosion processes operating in the Waipaoa catchment, and their contributions to suspended sediment yield and carbon loss. Contributions are based on initial estimates by Tate et al. (2000), in which only the upper $1 \mathrm{~m}$ of gully areas were considered.

\begin{tabular}{lcc}
\hline Erosion Process & $\begin{array}{c}\text { Contribution to } \\
\text { suspended } \\
\text { sediment yield (\%) }\end{array}$ & $\begin{array}{c}\text { Contribution to } \\
\text { catchment carbon } \\
\text { loss (\%) }\end{array}$ \\
\hline Gully erosion & $>50$ & $2-5$ \\
Sheet erosion & $\sim 10$ & 50 \\
Shallow landslides & 15 & 25 \\
Earthflows, tunnel gullies, bank & $\sim 15-25$ & 20 \\
erosion etc. & & \\
\hline
\end{tabular}


Whether the transfer of OC from terrestrial ecosystems to the ocean represents a major OC loss depends on the fate of the associated sediment once it has reached the marine environment (Tate et al. 2000). To determine the production, storage and output of POC from the Waipaoa River basin, Gomez et al. (2003) estimated POC yield as a percentage of the suspended sediment discharge by combining some measured OC contents of suspended sediment samples with sediment rating curves for two sites within the catchment. They also used a sequence of dated overbank sediments from McPhail's bend to represent suspended sediment transported at high flows and assess floodplain OC sequestration. Carbon isotope compositions $\left(\boldsymbol{\delta}^{13} \mathrm{C}\right)$ and carbon to nitrogen ratios $(\mathrm{C} / \mathrm{N})$ were used to help determine the influence of different erosion processes and OC sources.

In the Waipaoa River catchment, the dominance of gully erosion under all flow conditions is reflected in both suspended sediment and POC yields across the complete range of flows (when the whole profile is considered, not just the top 1 $\mathrm{m})$. POC content rapidly declines with increasing discharge and suspended sediment concentrations, then stabilises at a value similar to the bedrock OC content, suggesting the POC source is mainly from gully erosion of sedimentary rocks, with a smaller contribution from landsliding during extreme events (Gomez et al. 2003). The mean annual POC yield at Kanakanaia was calculated to be $86.7 \mathrm{Gg}\left(86.7\right.$ x $10^{9}$ g), with the annual loss to storage (i.e. floodplain deposition) being $\sim 4 \%$ (3.6 Gg). An estimated discharge from the Waipaoa River basin $\left(2205 \mathrm{~km}^{2}\right)$ to the Pacific Ocean of $\sim 130 \mathrm{Gg} \mathrm{C}^{-1}$ indicates that the Waipaoa River is very efficient at transporting OC from the landscape to the ocean (Gomez et al. 2003).

Based on the work of Gomez et al. (2003), floodplain sediments from a single site were used by Gomez et al. (2004b) to analyse the OC content and isotopic signature of sediments deposited on McPhail's bend between 1850 and 2002. They were then able to trace the sediment sources and determine the cause of variations over the historical record. The impact of deforestation in the Waipaoa catchment was evident in the floodplain sediments as a $\sim 50 \%$ increase in OC content in post- 1927 sediments. This estimate was based on preservation of the landsliding signature, and 
more positive $\delta^{13} \mathrm{C}$ signatures than for suspended sediments from low to intermediate magnitude flood events.

In support of findings by Gomez et al. (2003) that Waipaoa River POC is dominantly sourced from gully erosion of sedimentary rocks, an old ${ }^{14} \mathrm{C}$ date $(4031$ \pm 40 BP) determined for floodplain sediments by Gomez et al. (2004b) suggests that organic material associated with Waipaoa River suspended sediments is dominantly composed of refractory OC (derived from weathered sedimentary rocks) and mixed with some younger material within the catchment.

The new work of this study will extend and enhance previous investigations of the WSS, by determining the fate of terrestrial OC as it is transferred from the uplands and floodplains of the watershed to the Poverty Bay continental shelf and slope. 
"It is common sense to take a method and try it. If it fails, admit it frankly and try another. But above all, try something." (Franklin D. Roosevelt)

\section{CHAPTER 3: $\quad$ METHODS}

This chapter provides a description of sample collection, the procedures used to partition them into physically separated size fractions and the methods used to characterise the fractions chemically and radiochemically. In addition, some quality assurance testing was carried out, and this is also described.

\subsection{SAMPLING STRATEGY}

The methods used in this study were selected as being the most appropriate for determining the quantities and biogeochemical characteristics of organic carbon (OC) associated with the floodplain and marine sediments collected from the Waipaoa Sedimentary System (WSS). By determining the characteristics of OC at different depositional sites within the WSS, inferences can then be made as to the sources of OC and the transformations it may experience as it is being transported from terrestrial source to marine sink.

While a number of sediment cores from the WSS have previously been studied for other purposes, the following seven discussed within this chapter were collected specifically for this study, and had not been analysed previously.

A sediment core was collected from the Waipaoa River floodplain at McPhail's bend, a meander bend $32 \mathrm{~km}$ from the river mouth (Figure 3.1). A detailed stratigraphy had previously been established for this part of the floodplain at a nearby site by Gomez et al. $(1998,1999)$ allowing some correlations to be made.

A transect of 6 multi-cores was collected from across the Poverty Bay continental shelf and slope, ranging from $27 \mathrm{~m}$ to $1428 \mathrm{~m}$ water depth (Figure 3.1). The midshelf core (U2305) was collected from the locus of shelf sediment deposition, with an estimated 45 m thickness of postglacial mud (e.g. Foster \& Carter 1997; Gomez 
et al. 2004a). The location is similar to that of the 16-m Calypso piston core, MD972122 for which a sedimentary record (including particle size, tephra, geochemistry etc.) had previously been developed (Gomez et al. 2004a).

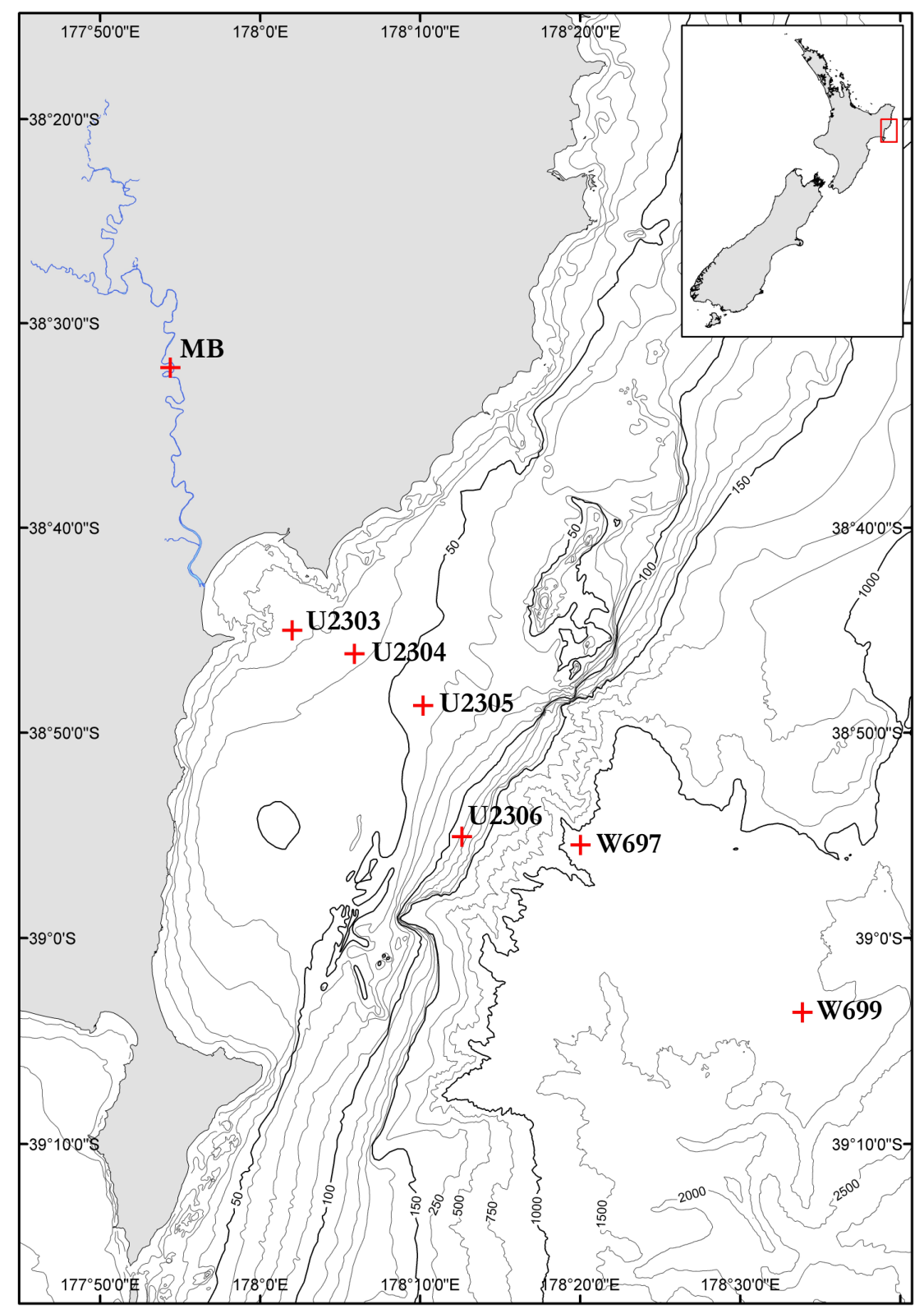

Figure 3.1: Location map indicating positions of the McPhail's bend floodplain core (MB) and shelf/slope multi-cores (U2303-W699).

The shelf break is at $\sim 150 \mathrm{~m}$ water depth. 


\subsubsection{Floodplain Sediments}

A $6.87 \mathrm{~m}$ core $(75 \mathrm{~mm}$ diameter) was collected from McPhail's bend in February 2002, using a truck-mounted drilling rig equipped with a model B-40 Mobile Drill with a hollow stem auger. Preliminary stratigraphic descriptions were carried out in the field, and the cores were chilled to $\sim 4^{\circ} \mathrm{C}$ within a few hours of collection. Unit thicknesses were corrected for core compaction (average $\sim 20 \%$ ) and on returning to the laboratory, cores were split in half lengthwise, allowing more thorough descriptions (Appendix A) and magnetic susceptibility measurements (Appendix B). Half of each core was frozen until prepared for chemical and physical analyses, while the remaining half was frozen and retained as an archive (see 3.10.3) The sampling interval of the core was irregular, and was determined largely by flood layer thickness. Flood deposits were differentiated on the basis of colour and texture, and a range of identifiable flood events was sampled, with sediment taken from near the centre of each layer to minimise the effects of any post-depositional oxidation or soil formation.

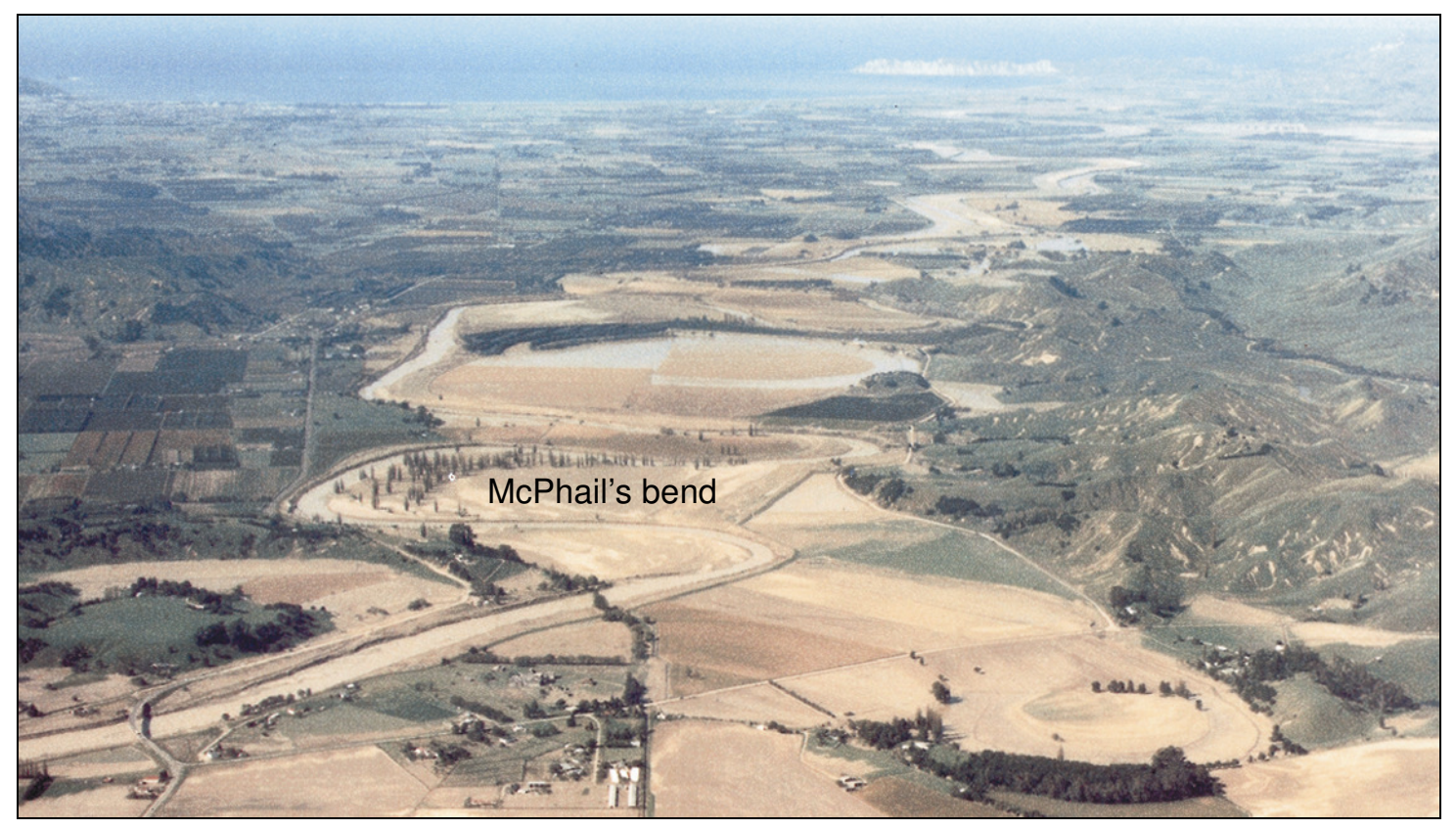

Figure 3.2: View of the Waipaoa River floodplain and overbank deposition after Cyclone Bola, March 1988, looking downstream $\sim 35 \mathrm{~km}$ from the river mouth. McPhail's bend is marked. (Photo: N. Trustrum, 1988). 


\subsubsection{Marine Sediments}

Multi-cores from the Poverty Bay continental shelf and slope were collected from RV Tangaroa on NIWA voyages TAN0103 (March 2001) and TAN0106 (May 2001) following standard methodologies (Black et al. 2002). Multi-cores were used because they preserve the sediment-water interface well, which was vital for the investigation of contemporary processes occurring in the marine environment. After their collection, the cores $(\sim 35-50 \mathrm{~cm}$ in length) were promptly sectioned into $1-\mathrm{cm}$ horizontal intervals and frozen. Three of the multi-cores (U2303, U2305 and W697) were initially sampled at $\sim 6$-cm intervals to obtain broad down-core trends, then later sampled at $\sim 3$-cm or smaller intervals, for greater detail. The surface sediment (0-1 cm interval) of all the cores was analysed to determine biogeochemical trends across the continental shelf and slope transect.

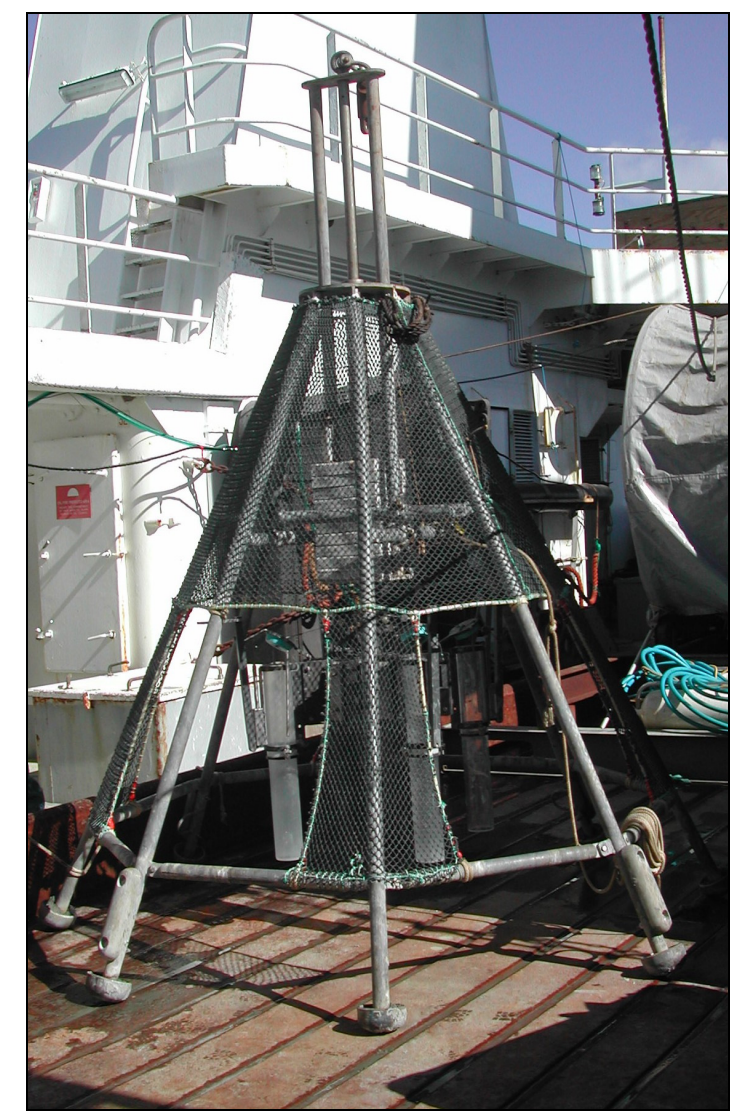

Figure 3.3: Multi-core sampler onboard RV Tangaroa. 


\subsection{LABORATORY METHODS}

\subsubsection{Protocols and techniques}

The methods used for this research were based on and closely follow those developed by Leithold and Hope (1999), Leithold and Blair (2001), Blair et al. (2003) and Leithold et al. (2005). Their laboratory protocols and techniques have previously been scrutinised and tested, and are consequently robust and internationally respected. By following these stringent procedures, the results from this research can be critically compared with data from the international literature. Use of comparable procedures also allows international correlations to be made with other sedimentary systems such as the Eel River System.

Initially, a limited number of samples were sent to two laboratories for analysis: to Otago University for $\% \mathrm{OC}, \% \mathrm{H}$ and $\% \mathrm{~N}$ elemental analyses, and to the Institute of Geological and Nuclear Sciences (GNS) in Wellington for $\% \mathrm{OC}$ and $\% \mathrm{~N}$ along with $\delta^{13} \mathrm{C}$ and $\delta^{15} \mathrm{~N}$ isotopic analyses. At a later stage, a limited number of samples were also taken to North Carolina State University (NCSU) and analysed for \%OC, $\% \mathrm{~N}$ and $\delta^{13} \mathrm{C}$. After returning from NCSU, it was decided to complete the analyses at the National Institute of Water and Atmospheric Research (NIWA) laboratory in Wellington, as the equipment there was very similar to that used at NCSU, which had so far provided the most reliable data. However, the opportunity eventually arose to take the remaining samples to NCSU and carry out all remaining analyses there. Hence all the data reported here were generated at NCSU. A comparison of the data analysed at the various laboratories is presented in Section 3.10.2.

\section{Equipment Cleanliness}

Before use, all laboratory glassware was washed with detergent and rinsed thoroughly with deionised (DI) water. All openings were then covered with foil, and the glassware was annealed at $510^{\circ} \mathrm{C}$ for 6 hours. Metal ware was also washed, rinsed and annealed in this way. Equipment that could not go into the muffle furnace (e.g., sieves, vial caps, plastic ware, etc.) was washed with detergent and rinsed with DI water, then rinsed in sequence with methanol, acetone, methanol and DI water again, covered in foil and dried at a lower temperature (E Leithold 2003, pers. comm.). 


\section{Sample Drying}

To reduce the risk of OC loss during preparation, samples were freeze-dried rather than oven-dried. However, when $\mathrm{HCl}$ solution was added to samples to remove carbonate, the freeze dryer could not be used and these samples were dried under vacuum. To do so, the samples (in their small pre-weighed glass beakers) were covered with a watch glass and placed in a glass desiccator. Vacuum grease was used to seal the desiccator; a trap (a flask sitting in a dewar containing a propanol/dry ice mixture) was placed between the desiccator and pump, and a strong vacuum established. The system was run until samples were completely dry (approximately 48 hours) (E Leithold 2003, pers. comm.).

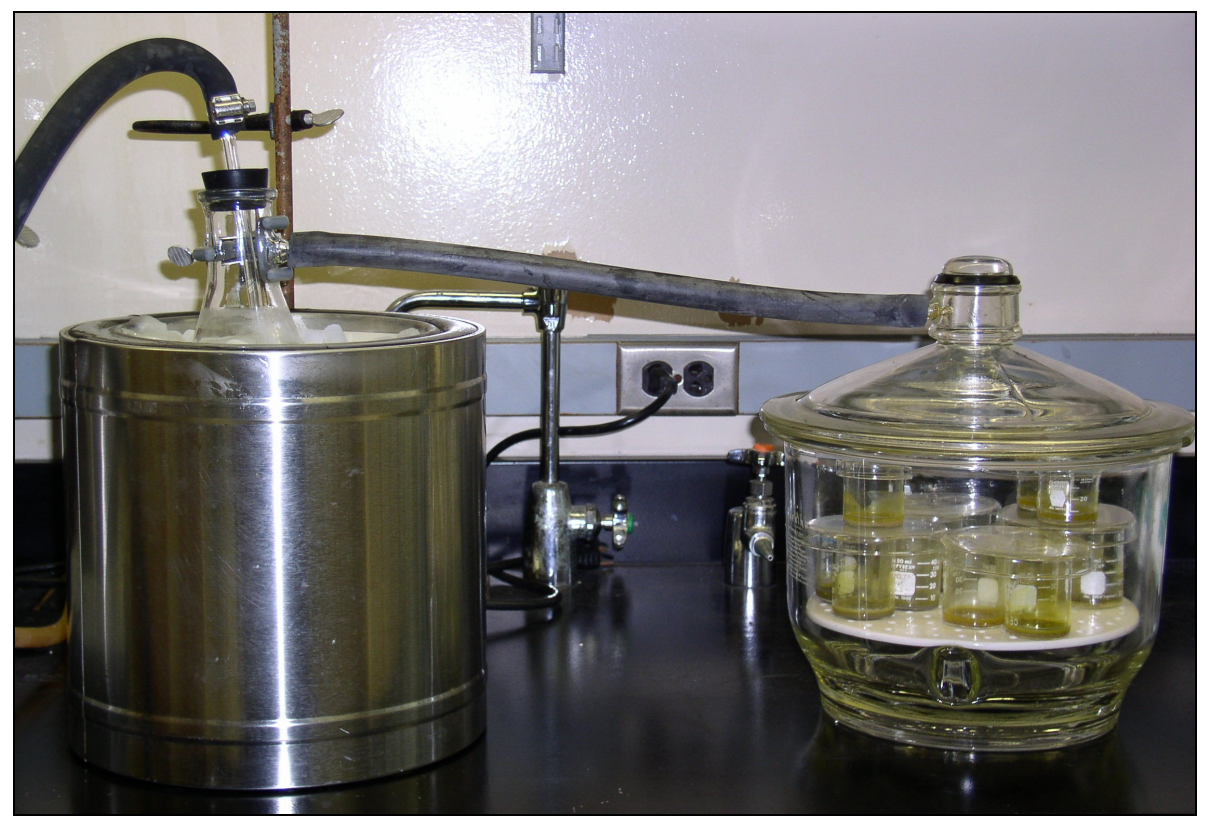

Figure 3.4: Vacuum drying set-up for drying samples following the removal of carbonate.

\subsection{Particle Size Separations}

Sieving $>25 \mu m$ Fractions

Approximately $5 \mathrm{~g}$ of bulk sediment was suspended in a small volume of distilled water $(\sim 100 \mathrm{ml})$, sonicated for 5 minutes (with passive cooling) and then washed through a $25 \mu \mathrm{m}$ stainless steel sieve. Grains larger than $25 \mu \mathrm{m}$ were retained on the sieve, while the fine silt $(4-25 \mu \mathrm{m})$ and clay $(<4 \mu \mathrm{m})$ fractions were washed into a $1000 \mathrm{ml}$ cylinder (Leithold et al. 2005). 


\section{Settling Fine Silt and Clay Fractions}

When all the fine silt and clay had been washed through the $25 \mu \mathrm{m}$ sieve, $5 \mathrm{ml}$ of $0.002 \mathrm{M}$ sodium hexametaphosphate solution (Calgon) was added to prevent flocculation of the particles, and the total volume of fluid recorded. The cylinder contents were well stirred, then two $20 \mathrm{ml}$ aliquots of suspended sediment transferred to a centrifuge tube, as a subsample of all particles finer than $25 \mu \mathrm{m}$. The cylinder was covered with foil and left to rest. Two hours later, a subsample of particles finer than $4 \mu \mathrm{m}$ was collected from $10 \mathrm{~cm}$ depth and transferred to centrifuge bottles. Samples were centrifuged at $2500 \mathrm{rpm}$ until the supernatant was clear (30-45 minutes). Five $\mathrm{ml}$ of the supernatant was then pipetted into a preweighed beaker and dried, allowing correction of the sample weight for remaining dispersant. Residual supernatant was decanted from the centrifuge bottles, and the bottles and wet sediment weighed, covered and then placed in the freezer. They were later freeze dried, and re-weighed (Leithold et al. 2005).

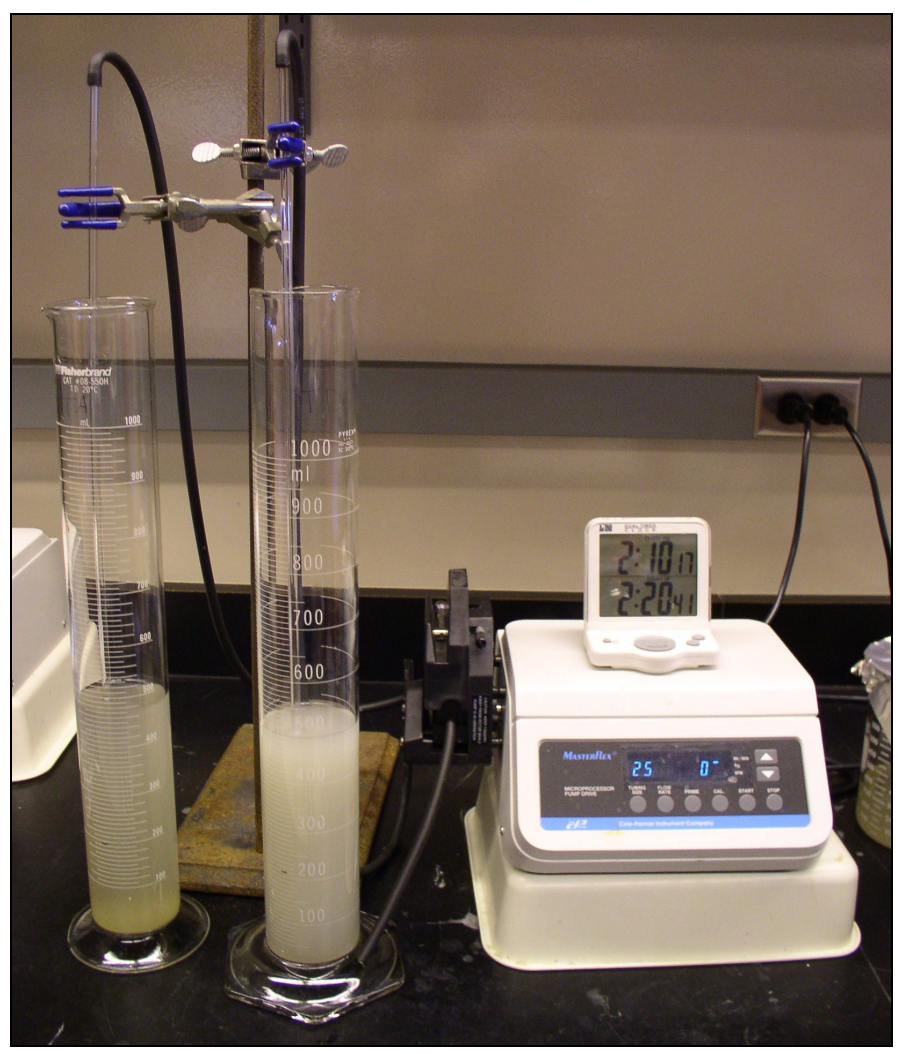

Figure 3.5: Sediment settling method used to collect clay $(<4 \mu \mathrm{m})$ fractions. 


\subsection{LaSER Particle Size ANALySES}

Ideally, all samples would have been separated into size fractions using the sieving and settling methods outlined above, to provide particle size data as well as individual size fractions for elemental and isotopic analyses. However, time limitations did not permit all of the floodplain core samples to be separated into size fractions, thus the suite of 28 bulk samples from the floodplain core was analysed for particle size at the School of Chemical and Physical Sciences, Victoria University of Wellington (VUW). The 11 marine samples from core U2303 that had been separated into the 3 size fractions $(<4 \mu \mathrm{m}, 4-25 \mu \mathrm{m},>25 \mu \mathrm{m})$ were also analysed, to allow some comparison of data between the two methods. Analyses were performed on a Malvern Mastersizer 2000, using the principle of laser light scattering to determine the particle size of the sample suspended in water, with samples being sonicated for 2 minutes before measurement.

Table 3.1: Comparison of sieve/pipette and laser particle size determination methods for samples from core U2303.

\begin{tabular}{lcccccc}
\hline & \multicolumn{3}{c}{ Laser Method } & \multicolumn{3}{c}{ Sieving Method } \\
\hline Depth & $\% \mathbf{~} \mathbf{2 5} \boldsymbol{\mu m}$ & $\mathbf{\%}<\mathbf{\mu m}$ & $\mathbf{\%}<\mathbf{2 5} \boldsymbol{\mu m}$ & $\mathbf{\%}>\mathbf{2 5} \boldsymbol{\mu m}$ & $\mathbf{\%}<4 \boldsymbol{\mu m}$ & $\mathbf{\%}<\mathbf{2 5} \boldsymbol{\mu m}$ \\
\hline $0-1 \mathrm{~cm}$ & 85.48 & 5.49 & 14.52 & 91.38 & 2.42 & 8.62 \\
$6-7 \mathrm{~cm}$ & 87.83 & 4.85 & 12.17 & 92.32 & 2.58 & 7.68 \\
$12-13 \mathrm{~cm}$ & 70.22 & 10.90 & 29.78 & 58.66 & 13.50 & 41.34 \\
$14-15 \mathrm{~cm}$ & 14.07 & 26.84 & 85.93 & 28.81 & 19.43 & 71.19 \\
$16-17 \mathrm{~cm}$ & 21.37 & 22.20 & 78.63 & 17.01 & 20.60 & 82.99 \\
$18-19 \mathrm{~cm}$ & 9.88 & 35.28 & 90.12 & 4.90 & 51.15 & 95.10 \\
$20-21 \mathrm{~cm}$ & 31.20 & 25.99 & 68.80 & 30.89 & 31.99 & 69.11 \\
$22-23 \mathrm{~cm}$ & 13.45 & 32.84 & 86.55 & 63.55 & 11.95 & 36.45 \\
$24-25 \mathrm{~cm}$ & 86.15 & 4.87 & 13.85 & 91.70 & 1.91 & 8.30 \\
$30-31 \mathrm{~cm}$ & 84.76 & 5.29 & 15.24 & 84.94 & 4.15 & 15.06 \\
$\mathbf{3 3 - 3 4} \mathrm{cm}$ & 84.06 & 6.25 & 15.94 & 83.22 & 4.25 & 16.78 \\
\hline
\end{tabular}



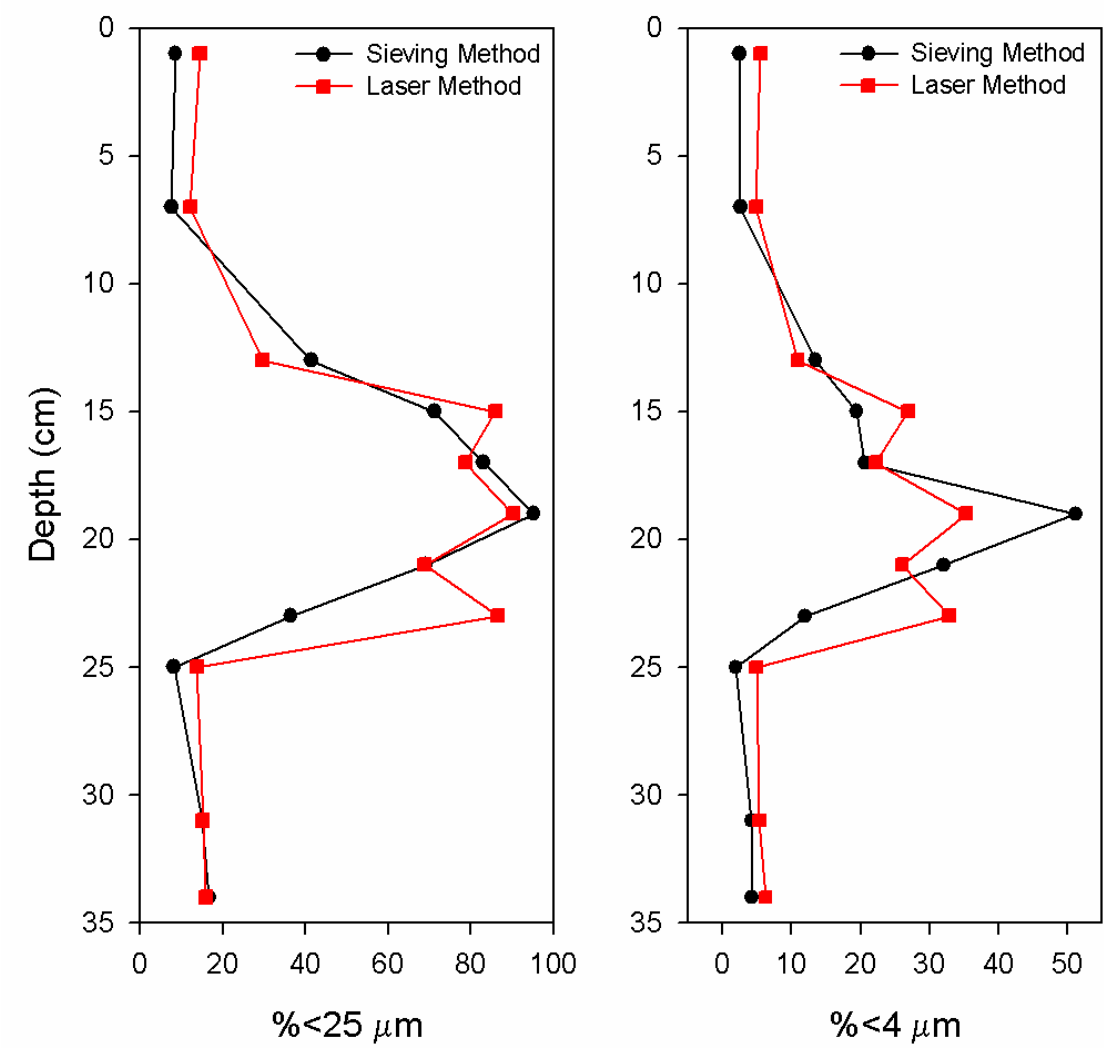

Figure 3.6: Comparison of sieving and laser particle size determination methods for samples from core U2303.

Overall, results from the two methods of particle-size determination were generally comparable (Table 3.1 and Figure 3.6) for the samples from core U2303, producing very similar down-core trends. Hence it was decided the Malvern Mastersizer 2000 would provide acceptable particle-size data (\% clay) for the floodplain samples that were not separated using sieve and settling techniques.

Additional particle size data were obtained for the top $9 \mathrm{~cm}$ of core U2305 at a later stage, to allow a more detailed examination of changes in particle size following the interpretation of initial data. These additional particle size analyses were carried out at the NIWA laboratory in Wellington, using a Sedigraph 5100 particle size analyser with a precision of $\sim \pm 0.1 \phi$ (Carter et al. 2002).

\subsection{CARBONATE REMOVAL}

Standard methodologies (Leithold \& Hope 1999; Leithold \& Blair 2001; Blair et al. 2003 ) use the vapour of $12 \mathrm{M} \mathrm{HCl}$ to remove inorganic $\mathrm{C}$ from samples. However, it 
became evident that this was not removing all of the carbonate from the samples used in this study, so $4 \mathrm{M} \mathrm{HCl}$ in solution was added; a series of acidification tests were run to determine the optimum length of time for liquid acid treatment required to remove all the carbonate from the samples.

The OC content of two samples was determined before any acidification, as well as following acidification with $4 \mathrm{M} \mathrm{HCl}$ for 2, 4 and 6 days. The results are summarised in the following graph:

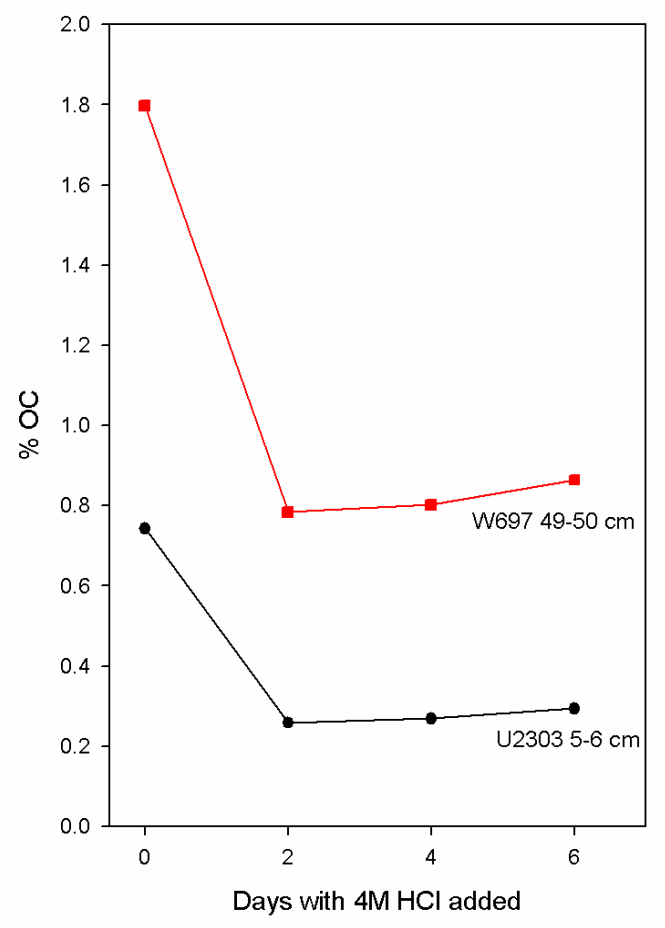

Figure 3.7: Sample \%OC with increasing time in $4 \mathrm{M} \mathrm{HCl}$.

From these results it is evident that adding liquid $4 \mathrm{M} \mathrm{HCl}$ to the samples for more than 2 days is sufficient to dissolve the carbonate component. Thus 4 days was adopted as the standard length of time to ensure the complete removal of carbonate from all samples.

Accordingly, for this study inorganic $\mathrm{C}$ was removed by placing dry samples in small glass beakers, weighing them, and adding $\sim 5 \mathrm{ml}$ of $4 \mathrm{M} \mathrm{HCl}$ to each. They were then placed in a glass desiccator, the air was removed with a vacuum pump, and the samples treated for about 96 hours. Samples were then vacuum dried, with a glass trap submerged in a propanol/dry ice mixture to freeze and collect the $\mathrm{HCl}$. The dry 
samples were weighed once again to correct for weight gain due to the formation of chloride salts. They were transferred to glass vials and stored in a freezer, in large jars with desiccant at the bottom, until required for analyses (E Leithold 2003, pers. comm.).

\subsection{Dispersant Preparation}

Because electrostatic forces tend to cause clays to flocculate, it was necessary to add a dispersant before extracting a representative clay fraction. To make up the dispersant, $20 \mathrm{~g}$ of sodium hexametaphosphate powder was completely dissolved in $100 \mathrm{ml}$ of warm, deionised water. When cool, the solution was filtered through a combusted glass fibre filter into a glass bottle with a glass stopper. Hexane $(50 \mathrm{ml})$ was added, and the bottle shaken for at least 2 hours. The solution was then poured into a glass separatory funnel to separate the sodium hexametaphosphate solution from the hexane - the dispersant was stored in a glass bottle, and the hexane discarded (following methods outlined by Leithold et al. 2005).

\subsection{DENSITY SEPARATIONS}

A number of bulk sediment samples had visible quantities of particulate organic matter (e.g., roots and plant matter) incorporated with the sediment, so a solution of sodium polytungstate (SPT) with a density of $1.9 \mathrm{~g} \mathrm{ml}^{-1}$ was used to separate the 'light' fraction from the sediment, based on their density differences. To make up the density medium, $140 \mathrm{~g}$ of SPT powder was dissolved in $100 \mathrm{ml}$ of DI water, and $1 \mathrm{ml}$ of the solution weighed to check that the density was correct (weight $\sim 1.9 \mathrm{~g}$ ). More SPT powder or water was added to increase or decrease the density as necessary. To remove any undissolved impurities, the solution was filtered through a combusted glass fibre filter under vacuum, $50 \mathrm{ml}$ of hexane added, and the mixture put on a shaker for about 2 hours. It was then poured into a separatory funnel, the SPT solution decanted, and the hexane discarded.

To separate the 'light' fraction (e.g. roots and plant matter) from the sediment of selected bulk samples, a few grams of the sample was placed in a 10-ml conical glass 
centrifuge tube, $\sim 8 \mathrm{ml}$ of SPT $\left(1.9 \mathrm{~g} \mathrm{ml}^{-1}\right)$ solution added, and the tube shaken vigorously to mix. It was then centrifuged at $3000 \mathrm{rpm}$ for 30 minutes, so the light fraction floated to the top of the SPT solution, and the sediment remained at the bottom of the tube. The light fraction was poured onto a combusted glass fibre filter, and rinsed thoroughly with DI water while under vacuum, to remove the SPT. It was then washed off the filter into a glass beaker, and freeze-dried before being analysed for $\% \mathrm{OC}$ and $\delta^{13} \mathrm{C}$ independently of the sediment (Leithold et al. 2005).

\subsection{ANALYTICAL METHODS}

\subsubsection{Carbon and Nitrogen Contents and Stable Isotopes}

At NCSU, samples were analysed for their OC and nitrogen contents using a Carlo Erba 1108 CHNS analyser in May 2002, and a Carlo Erba FlashEA 1112 CHNS analyser (Figure 3.8) in September 2003. The relative precision was $2 \%$. The $\mathrm{CO}_{2}$ produced from oxidation of the OC was trapped cryogenically (Blair \& Carter 1992) and ${ }^{13} \mathrm{C}$ values determined on a Finnigan MAT Delta $\mathrm{E}$ isotope ratio mass spectrometer, from which $\delta^{13} \mathrm{C}$ values were calculated; the absolute precision was $0.2 \%$.

Following convention (e.g. Craig 1953) the ratios of ${ }^{12} \mathrm{C}$ to ${ }^{13} \mathrm{C}$ are reported as the per-mil difference between the ratio of the sample and the ratio of the international PDB standard, where:

$$
\delta^{13} \mathrm{C}(\% 0)=\frac{\left({ }^{13} \mathrm{C} /{ }^{12} \mathrm{C}\right) \text { sample }}{\left({ }^{13} \mathrm{C} /{ }^{12} \mathrm{C}\right) \mathrm{PDB}}-1 \times 1000
$$

Terrestrial C3 plants (e.g. trees, shrubs and temperate zone grasses) are depleted in ${ }^{13} \mathrm{C}$, with characteristic $\delta^{13} \mathrm{C}$ values being between about $-24 \%$ and $-28 \%$, while marine phytoplankton typically have $\delta^{13} \mathrm{C}$ values of about $-18 \%$ to $-24 \%$. Terrestrial C4 plants (e.g. tropical grasses and maize) are enriched in ${ }^{13} \mathrm{C}$ relative to both marine plankton and C3 terrestrial plants, with $\delta^{13} \mathrm{C}$ values characteristically being around $-10 \%$ o to $-15 \%$. These differences in $\delta^{13} \mathrm{C}$ signatures make it possible to determine the source of OC associated with the sediments (Leithold \& Hope 1999). 


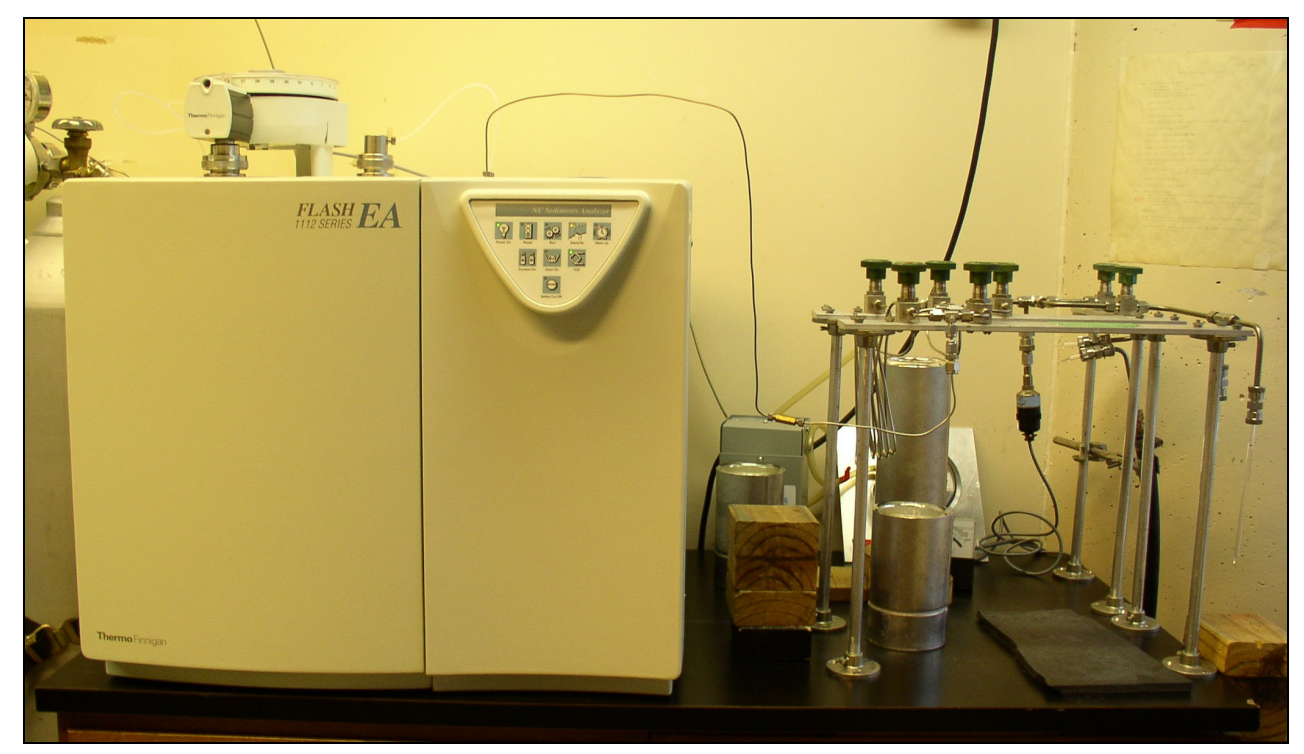

Figure 3.8: Carlo Erba FlashEA 1112 CHNS analyser, NCSU.

\subsubsection{Particle Surface Area}

In preparation for surface area (SA) analysis, subsamples were rinsed several times with distilled water to remove any dispersant, before being freeze-dried and then heated in air for 12 hours at $350^{\circ} \mathrm{C}$ to remove the organic fraction. Samples were analysed for SA using a Beckman Coulter SA 3600 analyser at NCSU (Figure 3.9). They were degassed at $150^{\circ} \mathrm{C}$ for 45 minutes and the SA measured using the multipoint BET method (Branauer et al. 1938).

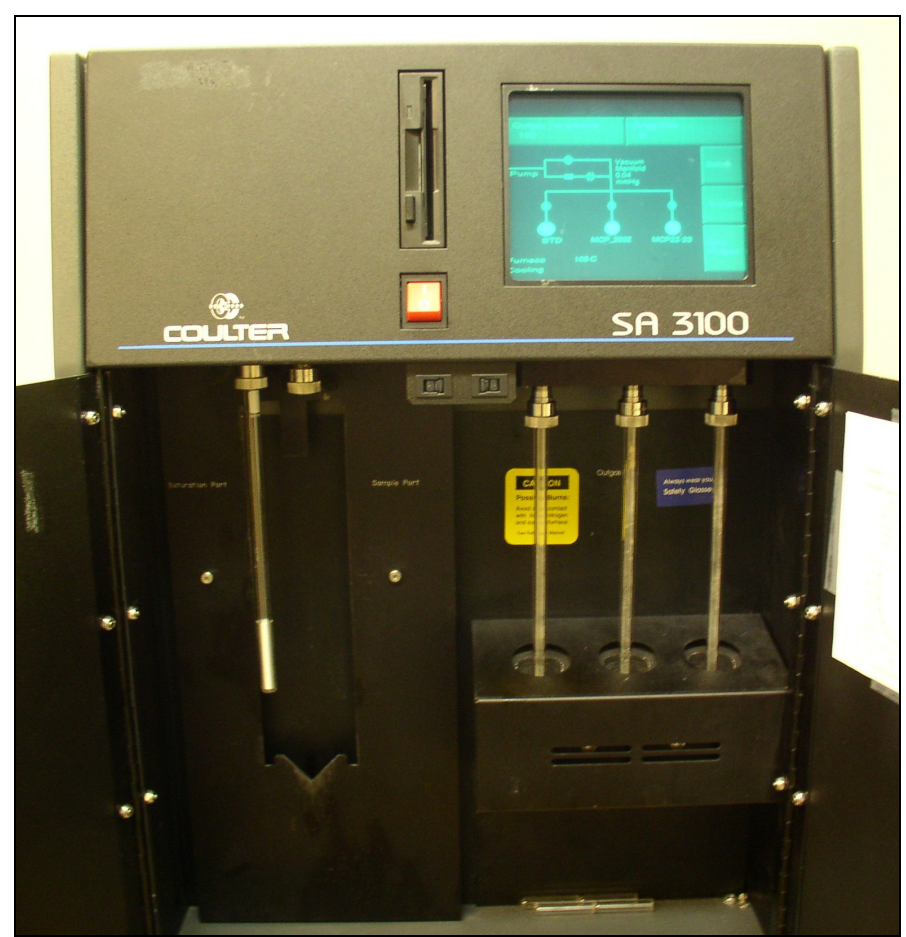

Figure 3.9: Beckman Coulter SA 3600 analyser, NCSU. 


\subsubsection{Organic Carbon Loading}

OC concentrations were normalised to the SA of the sample to reduce the influence of particle size. The OC loadings (OC:SA) were calculated in $\mathrm{mg} \mathrm{C}^{-2}$.

\subsubsection{Magnetic Susceptibility}

Magnetic susceptibility measures the 'magnetisability' of a $2-3 \mathrm{~cm}^{3}$ volume of sample, indicating the presence of iron-containing minerals. It is the ratio of a sample's degree of magnetisation to the strength of the magnetic field with which it is brought into contact. The down-core magnetic susceptibility profile of the floodplain sediments (Appendix B) was measured to allow correlation with that of a previously collected floodplain core (Gomez et al. 1999) with flood layers expected to show as peaks in the profile. Magnetic susceptibility was measured in the laboratory using a Bartington MS2 Magnetic Susceptibility System fitted with an MS2E/1 surface-scanning sensor. In preparation for measurement, the core was split in half length-wise, and each half tightly covered with plastic film. The core and sensor were left to reach room temperature before starting measurements, which were carried out at $20-\mathrm{mm}$ intervals, using the 0.1 scale and CGS units. The purpose-designed "Multisus" software allowed measurements to be recorded and stored on file, and compensations to be made for factors such as instrumental drift.

\subsubsection{Thermal Analyses}

Thermal analyses were conducted on two marine sediment samples, as a trial to determine whether it would be a suitable procedure for determining differences in the character of OC. The two samples were both clay fractions, from the 1-2 cm section of core U2305 and 0-1 cm section of core W697. Before analysis, carbonate was removed with $\mathrm{HCl}$, in the same way as those samples prepared for elemental and isotopic analyses.

A SDT Q600 was used, concurrently performing differential scanning calorimetry (DSC), thermogravimetric analysis (TGA) and differential thermal analysis (DTA). It measures the heat flow and weight changes over a temperature range, which can be associated with transitions and reactions in materials. The starting temperature was 
$30^{\circ} \mathrm{C}$ and samples were heated (in alumina pans) at a rate of $20^{\circ} \mathrm{C} /$ minute, to a final temperature of $600^{\circ} \mathrm{C}$. (TA Instruments 2002)

\subsubsection{Lead-210 and Caesium-137 Analyses}

${ }^{210} \mathrm{~Pb}$ geochronology is commonly used to calculate marine sediment accumulation rates, as ${ }^{210} \mathrm{~Pb}$ is a naturally occurring radioisotope that permanently adsorbs onto fine-grained particles in the water column. This is referred to as "unsupported" ${ }^{210} \mathrm{~Pb}$ and can be detected on marine sediments if they have been deposited less than 4 to 5 half-lives previously $\left(t^{1 / 2}=22.3\right.$ y) (Crockett $\&$ Nittrouer 2004). ${ }^{137}$ Cs is an anthropogenic radioisotope that was introduced into the global environment during atmospheric testing of atomic weapons, which began in $~ 1954$ and reached a peak between 1962 and 1964. Thus the presence of ${ }^{137} \mathrm{Cs}$ also can be used to indicate sediment deposition after 1954 (Crockett \& Nittrouer 2004). Together, the radioisotope data allow calculation of modern (last 100 years) sedimentation rates on the continental shelf and slope (after Appleby \& Oldfield 1992).

${ }^{210} \mathrm{~Pb}$ and ${ }^{137} \mathrm{Cs}$ data for the Poverty Bay shelf cores U2303, U2304, U2305, U2306 were measured by S. Kuehl and T. Kniskern, Virginia Institute of Marine Sciences, Virginia, USA, while for cores W697 and W699 the ${ }^{210} \mathrm{~Pb}$ data were provided by C. Alexander, Skidaway Institute of Oceanography, Georgia, USA.

\subsubsection{Biomarker Analyses}

Biomarkers are organic compounds formed by specific living organisms that can be preserved and later recognised in sediments (Canuel \& Zimmerman 1999) thus allowing the sources and transport of OM to be determined. Biomarkers have been used in a number of studies to differentiate between terrestrial and marine OC sources and to trace the transport and fate of terrestrial $\mathrm{OM}$ in the marine environment (Schubert \& Stein 1996; Bianchi et al. 1997, 2002; Fahl \& Stein 1997; Goni et al. 1998; Amo \& Minagawa 2003). The distinctive biomarkers of terrestrial and marine $\mathrm{OM}$ provide useful tools for determining relative contributions of organic matter sources in marine sediments. 
Subsamples of the most recent (2002) floodplain sediment and the bulk surface samples from the 6 shelf/slope cores were analysed for biomarkers in the laboratory of Dr E. Canuel at the Virginia Institute of Marine Sciences, Virginia, USA. Details of the preparatory and analytical procedures can be found in Canuel and Zimmerman (1999) and Canuel (2001). The samples were analysed for a number of biomarkers including plant sterols, long-chain alcohols, long-chain fatty acids, shortchain saturated fatty acids, diatom sterols and dinoflagellate sterols.

\subsubsection{Carbon-14 Analyses}

Surface samples from the Poverty Bay shelf/slope cores U2303, U2305, U2306 and W697 were selected for ${ }^{14} \mathrm{C}$ analyses. This involved the acidified bulk samples being run on the Carlo Erba FlashEA 1112 CHNS elemental analyser (at NCSU) and the $\mathrm{CO}_{2}$ being collected and analysed for ${ }^{14} \mathrm{C}$ analysis by accelerator mass spectrometry at the National Ocean Sciences AMS facility (NOSAMS), Massachusetts, USA.

At the ${ }^{14} \mathrm{C}$ laboratory, the $\mathrm{CO}_{2}$ is reduced to graphite using a catalyst $(\mathrm{Fe})$ in the presence of excess hydrogen. The graphite was pressed into a target, which is analysed on the accelerator along with standards and process blanks. Instantaneous ratios of ${ }^{14} \mathrm{C}$ to ${ }^{13} \mathrm{C}$ and ${ }^{12} \mathrm{C}$ are recorded and converted to a radiocarbon age, using a radiocarbon half-life of 5568 years (NOSAMS 1999). Ages are expressed in radiocarbon years.

${ }^{14} \mathrm{C}$ contents are reported as fraction modern, relative to the National Bureau of Standards and Technology (NBS) Oxalic Acid I standard (Olsson 1970). Modern is defined as $95 \%$ of the radiocarbon concentration (in A.D. 1950) of the NBS standard normalized to a $\delta^{13} \mathrm{C}$ of $-19 \%$ (Olsson 1970). Corrections for natural fractionations are made by normalising the $\delta^{13} \mathrm{C}$ values of the samples to $-25 \%$, and further corrections are made for procedural blank contributions. The relative precisions for the fraction modern and ${ }^{14} \mathrm{C}$ ages were $12 \%$ and $2 \%$ respectively for the NBS-22 hydrocarbon standard (Blair et al. 2003). 


\subsection{ADDITIONAL TESTS}

\subsubsection{NCSU Elemental Analyser Comparisons}

Between the two visits to the NCSU laboratory (May 2002 and September 2003) a new Elemental Analyser was installed - a Carlo Erba FlashEA 1112 CHNS analyser replaced the Carlo Erba 1108 CHNS analyser. It was therefore necessary to run a series of tests to ensure results from the two instruments would be comparable. Samples that had been run on the original 1108 CHNS analyser were re-run on the FlashEA 1112 CHNS analyser, which also had the capacity to run larger samples (an advantage when samples have very low OC contents).

Table 3.2: Comparison of analyses using Carlo Erba 1108 CHNS analyser and Carlo Erba FlashEA 1112 CHNS analyser $(\mu$ moles $C=\% \mathrm{OC} *$ mg sample $* 0.833)$.

\begin{tabular}{|c|c|c|c|c|c|c|}
\hline Sample & Analyser & Boat size & Hmoles C & $\% \mathrm{OC}$ & $\% \mathbf{N}$ & $\delta^{13} \mathrm{C}$ \\
\hline \multirow[t]{3}{*}{$\mathrm{W} 6976-7 \mathrm{~cm}<25 \mu \mathrm{m}$} & 1108 & Small & $?$ & 0.70 & 0.08 & -22.67 \\
\hline & 1112 & Small & 23 & 0.66 & 0.09 & -22.87 \\
\hline & 1112 & Large & 75 & 0.69 & 0.09 & -22.84 \\
\hline \multirow[t]{3}{*}{$\mathrm{W} 6976-7 \mathrm{~cm}<4 \mu \mathrm{m}$} & 1108 & Small & $?$ & 1.03 & 0.12 & -22.22 \\
\hline & 1112 & Small & 32 & 1.01 & 0.14 & -22.65 \\
\hline & 1112 & Large & 107 & 1.03 & 0.14 & -22.42 \\
\hline \multirow[t]{3}{*}{ W697 $27-28 \mathrm{~cm}>25 \mu \mathrm{m}$} & 1108 & Small & $?$ & 0.43 & 0.04 & -23.76 \\
\hline & 1112 & Small & 15 & 0.41 & 0.05 & -24.21 \\
\hline & 1112 & Large & 132 & 0.43 & 0.04 & -23.64 \\
\hline
\end{tabular}

Results (Table 3.2) indicate there is relatively little variation in $\% \mathrm{OC}, \% \mathrm{~N}$ and $\delta^{13} \mathrm{C}$ values between the two analysers. Both small $(\sim 50 \mathrm{mg})$ and large $(\sim 300 \mathrm{mg})$ samples were run on the FlashEA 1112 CHNS to determine whether the sample size influenced results. The $\% \mathrm{OC}$ and $\% \mathrm{~N}$ values were within $0.03 \%$ and $0.01 \%$ respectively, and the $\delta^{13} \mathrm{C}$ values were well within acceptable limits for the finer samples $(<25 \mu \mathrm{m}$ and $<4 \mu \mathrm{m}$ ), while the greatest difference was $0.6 \%$ for the $>25$ $\mu \mathrm{m}$ sample. This is not unexpected, as coarser samples often tend to be more heterogeneous in nature, and therefore more variation is likely between repeated analyses. Differences between the two analysers did not appear to be significant either, and it was decided valid comparisons could be made of results from the two instruments. 


\subsubsection{Inter-laboratory Comparisons}

Though all data interpreted in this study was generated at NCSU, a range of analyses were carried out at Otago University, GNS, NCSU and NIWA, as outlined in section 3.3.1. The following graphs present all data collected during the course of this study, allowing the comparison of data analysed at the various laboratories for the floodplain core and marine cores U2303, U2305 and W697. All data used in these graphs is 'raw' (i.e. marine data is uncorrected for salt content), only represents the bulk samples, and has been averaged where there were multiple analyses on a single sample.
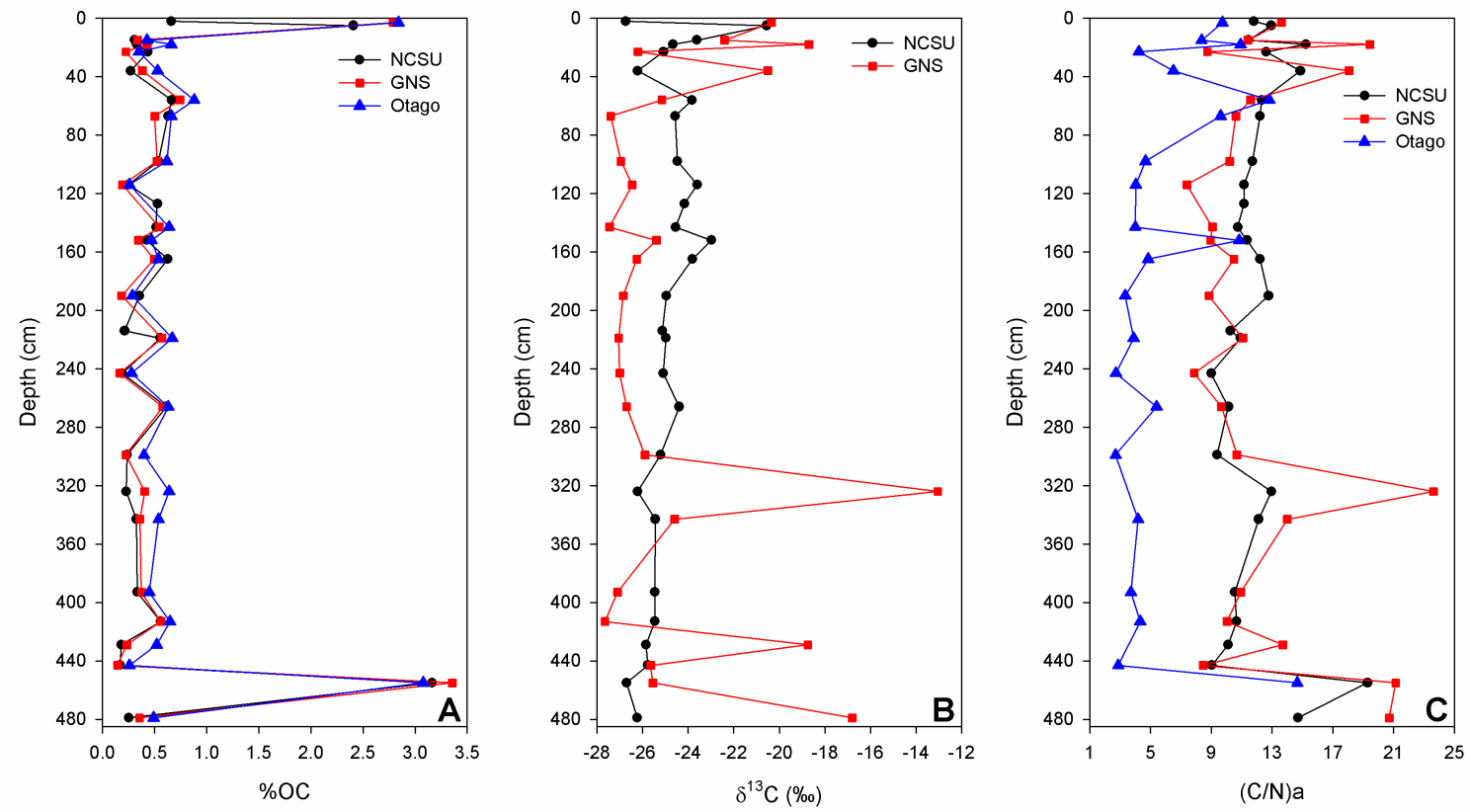

Figure 3.10: Inter-laboratory comparisons of $\% \mathrm{OC}, \delta^{13} \mathrm{C}$ and $(\mathrm{C} / \mathrm{N})$ a for the floodplain core.

Analyses for floodplain sediment OC concentrations show little variation between the laboratories at NCSU, GNS and Otago University. (Figure 3.10A). Contrastingly, there is considerable inter-laboratory variation in the $\delta^{13} \mathrm{C}$ values (Figure 3.10B). Those measured at GNS are a lot more variable than those determined at NCSU, with only limited similarity in down-core trends for the two. Some of these differences may be due to the analyses being carried out on bulk samples, which can be strongly influenced by inhomogeneity. Differences in the down-core $(\mathrm{C} / \mathrm{N})$ a trends suggest a strong influence by the detection of nitrogen $(\mathrm{N})$, as the $\% \mathrm{OC}$ values were quite comparable (Figure 3.10C). As the $\mathrm{N}$ content in 
the samples was very low, it proved difficult to detect in some cases, particularly at the GNS and Otago laboratories, which show marked differences in down-core $(\mathrm{C} / \mathrm{N})$ a values.
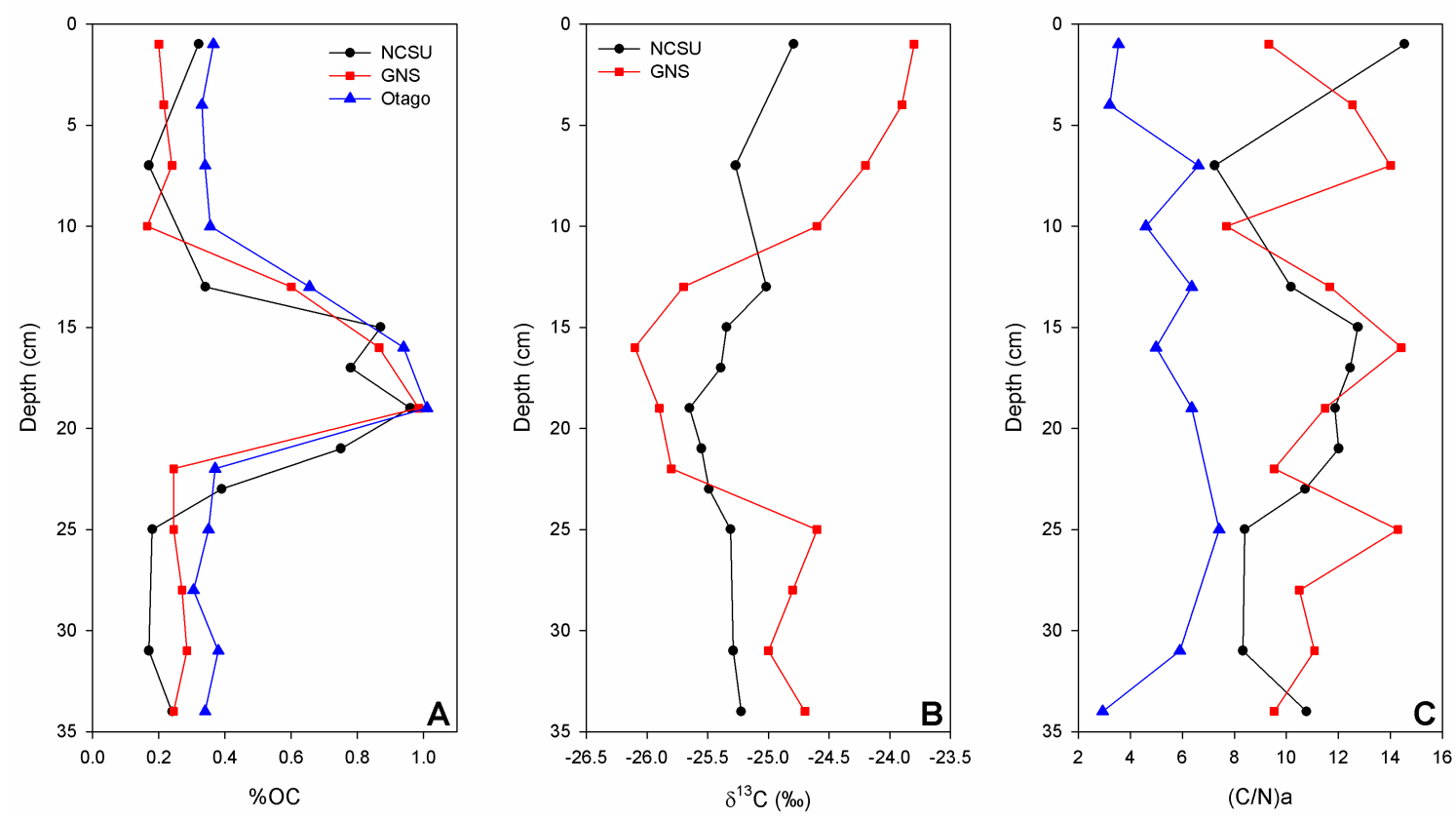

Figure 3.11: Inter-laboratory comparisons of $\% \mathrm{OC}, \delta^{13} \mathrm{C}$ and $(\mathrm{C} / \mathrm{N})$ a for core U2303. Note: the legend for Graph C is the same as that for Graph A.

The inter-laboratory comparisons for core U2303 (Figure 3.11) illustrate varying amounts of divergence. The down-core trends of \%OC (Figure 3.11A) are generally similar, while the $\delta^{13} \mathrm{C}$ values show reasonable variation (Figure 3.11B). Once more, the $(\mathrm{C} / \mathrm{N})$ a values show a great deal of variation, with basically no similar downcore trends (Figure 3.11C), again being strongly influenced by some $\mathrm{N}$ detection difficulties at the GNS and Otago laboratories. 

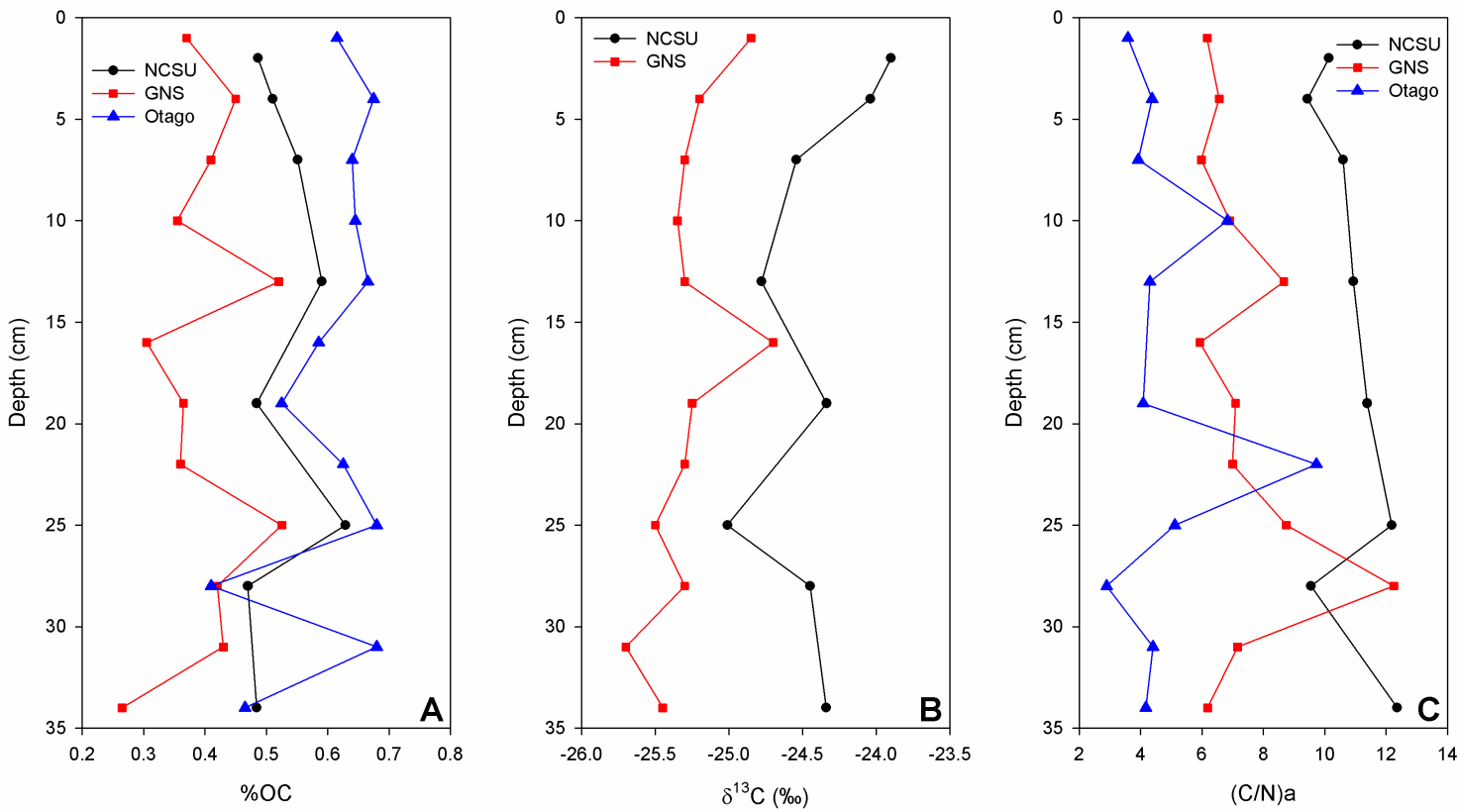

Figure 3.12: Inter-laboratory comparisons of $\% \mathrm{OC}, \boldsymbol{\delta}^{13} \mathrm{C}$ and $(\mathrm{C} / \mathrm{N})$ a for core $\mathrm{U} 2305$.

For core $\mathrm{U} 2305$, both $\% \mathrm{OC}$ and $\delta^{13} \mathrm{C}$ values show some inter-laboratory variation, though they generally exhibit similar down-core trends (Figures 3.12A and 3.12B). Once again the $(\mathrm{C} / \mathrm{N})$ a analyses carried out at Otago University and GNS show the greatest down-core variation (Figure 3.12C) while NCSU analyses are much more consistent.
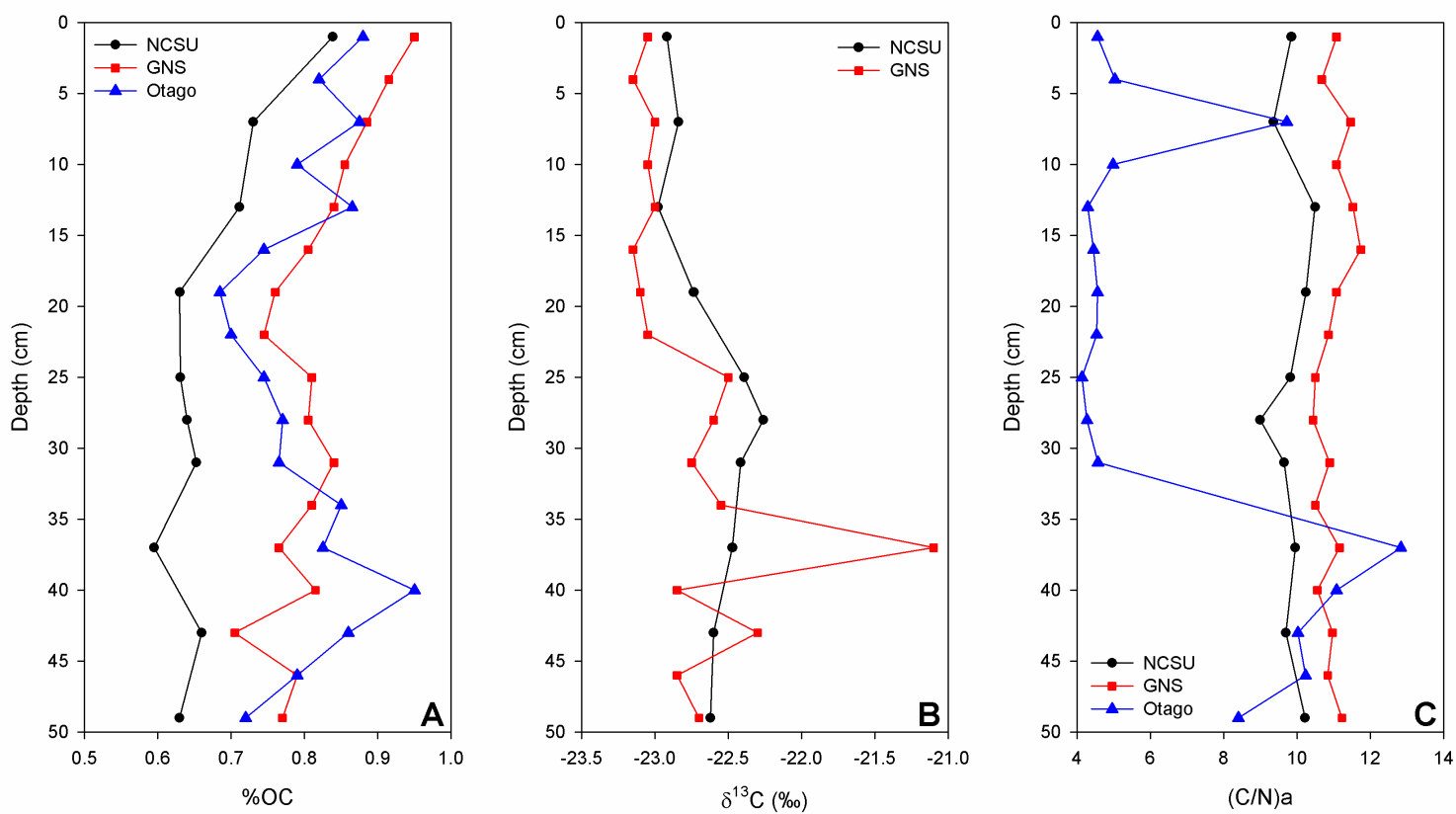

Figure 3.13: Inter-laboratory comparisons of $\% \mathrm{OC}, \delta^{13} \mathrm{C}$ and $(\mathrm{C} / \mathrm{N})$ a for core W697. 
While the down-core \%OC trends for core W697 (Figure 3.13A) are similar for the 3 laboratories, with \%OC generally decreasing with depth, the values show some variation. Once again the $\delta^{13} \mathrm{C}$ values differ between laboratories (Figure 3.13B), with the values from GNS showing more variation that those from NCSU. The down-core trends in $(\mathrm{C} / \mathrm{N})$ a values (Figure 3.13C) are quite similar for the NCSU and GNS laboratories, but the Otago results vary greatly. Once more this was most likely due to the low levels of $\mathrm{N}$ in the samples causing detection difficulties.

These comparisons illustrate various discrepancies between analyses performed by the different laboratories. However, measurements performed at the NCSU laboratory could be considered to be more rigorous and reliable due to several factors. Firstly, the issue of complete carbonate removal had been addressed (Section 3.6) thus any possible influence of carbonate had been eliminated, and secondly the majority of samples had been separated into size fractions and as a result were much more homogeneous in nature. Thirdly, the NCSU elemental analyser did not have difficulty detecting low levels of $\mathrm{N}$ in the samples, and fourthly, I carried out all of the analyses at NCSU myself thus providing a consistent level of rigour and avoiding any inter-operator error. These factors support the earlier statement that only data generated at NCSU was interpreted for this study.

\subsubsection{Effects of Sample Storage on Organic Carbon}

When the floodplain core was collected, it was refrigerated within a few hours of collection, but not frozen until about 2-3 months later. As a consequence, it was decided analyses should be carried out to determine whether the different storage conditions affected the organic contents and therefore could cause spurious results when analysed. To test the different storage conditions, short cores ( 700 mm) were collected from the floodplain and split, with one half frozen and the other half refrigerated as soon as possible after collection. After 2-3 months of storage, samples were analysed at the National Institute of Water and Atmospheric Research (NIWA) in Wellington. 
Table 3.3: Comparison of floodplain sample analyses following storage in refrigerator and freezer.

\begin{tabular}{lccccc}
\hline \multirow{2}{*}{ Sample Depth } & \multirow{2}{*}{ Sediment Type } & \multicolumn{2}{c}{ Refrigerated } & \multicolumn{2}{c}{ Frozen } \\
& & $\mathbf{\% O C}$ & $\boldsymbol{\delta}^{\mathbf{1 3}} \mathbf{C}$ & $\mathbf{0} \mathbf{0 C}$ & $\boldsymbol{\delta}^{\mathbf{1 3}} \mathbf{C}$ \\
\hline $200 \mathrm{~mm}$ & Silt & 0.53 & -24.62 & 0.38 & -25.21 \\
$300 \mathrm{~mm}$ & Coarse Sand & 0.22 & -25.99 & 0.30 & -26.11 \\
$380 \mathrm{~mm}$ (i) & Silt & 0.28 & -26.23 & 0.28 & -28.13 \\
$380 \mathrm{~mm}$ (ii) & Silt & 0.23 & -23.69 & 0.23 & -25.58 \\
$380 \mathrm{~mm}$ (iii) & Silt & 0.23 & -24.04 & 0.27 & -26.22 \\
$380 \mathrm{~mm}$ (iv) & Silt & 0.21 & -23.99 & 0.27 & -26.06 \\
$500 \mathrm{~mm}$ (i) & Coarse Sand & 0.29 & -18.27 & 0.23 & -26.79 \\
$500 \mathrm{~mm}$ (ii) & Coarse Sand & 0.24 & -26.58 & 0.22 & -26.12 \\
$500 \mathrm{~mm}$ (iii) & Coarse Sand & 0.23 & -26.21 & 0.21 & -26.23 \\
$500 \mathrm{~mm}$ (iv) & Coarse Sand & 0.22 & -26.08 & 0.19 & -26.61 \\
$600 \mathrm{~mm}$ & Silty Clay & 0.67 & -25.31 & 0.70 & -25.11 \\
\hline
\end{tabular}

These results (Table 3.3) indicate that the frozen samples tended to have slightly lighter $\delta^{13} \mathrm{C}$ values, though the differences were small and consistent. The greatest variation appeared to be due to sample heterogeneity, particularly in the coarser samples. Because of time constraints, and the inability to collect a replacement floodplain core, it was decided to continue with the original core, as there were no strong trends that could be explained by storage effects. 
"Rivers know this: there is no burry.

We shall get there some day."

Pooh's Little Instruction Book.

\section{CHAPTER 4: WAIPAOA RIVER FLOODPLAIN}

\subsection{INTRODUCTION}

To recognise terrestrially sourced sediment and organic carbon (OC) in the marine environment and identify biogeochemical changes that OC has undergone as a result of the transfer, it is necessary to establish its characteristics prior to discharge to the ocean. This chapter investigates characteristics of the Waipaoa River floodplain sediments, to establish a benchmark signature for erosion-related sediment and flood sequences and thereby support the recognition of flood layers within the marine environment. The influence of floodplain morphology and river dynamics on modulating OC transfers is also addressed in this chapter. A core of floodplain sediments was used as a proxy of suspended sediments, due to the lack of available samples over a range of river flows, and the limited timeframe of this study.

The amount and character of suspended sediment and particulate organic carbon (POC) discharged by a river to the ocean may be strongly influenced by exchanges between the river and its floodplain (Meade 1996), and such interactions will also determine whether a floodplain acts as an OC source or sink. A large amount of research into the role of terrestrial POC fluxes in the global carbon (C) cycle has been carried out on large, low-gradient rivers in continental settings (Milliman et al. 1984; Hedges et al. 1986, 1994; Richey et al. 1990; Depetris \& Kempe 1993). In such settings, large floodplains and deltas offer potential for processing of the OC as it is transported through the system, storing a large portion of sediment and POC and therefore influencing riverine inputs to the ocean.

More recently, studies have emphasised the importance of mountainous oceanic islands in global land to ocean sediment and POC fluxes (Milliman \& Syvitski 1992; Milliman 1995; Milliman et al. 1999; Lyons et al. 2002; Farnsworth \& Milliman 2003). Though small in landmass, the mountainous islands of the Pacific Rim may 
contribute up to $40 \%$ of the global land to ocean sediment flux (Farnsworth \& Milliman 2003) and up to 35\% of the global POC flux (Lyons et al. 2002). The tectonic instability of these mountainous islands (including New Zealand), combined with the very erodible sediments and high rainfall, means that short, steep rivers enable the rapid transport of water and sediment from land to ocean, hence the residence time of materials in these river systems is likely to be short in comparison to the large river systems.

Mountainous river floodplains are generally ephemeral in nature, with their morphology controlled by event-specific magnitude-frequency distributions of river discharge and sediment load. In the upper parts of steep river basins, floodplains are closely coupled to hillslopes, tend to be small in areal extent, and are formed by point bar deposition, channel dynamics and overbank sedimentation. Event-driven river channel and bank erosion causes constant changes of floodplain morphology, and where there is active river downcutting, more permanent floodplain terraces can be preserved. In the lower reaches of mountainous catchments, rivers have larger meander loops and correspondingly larger floodplain areas. In comparison, large continental rivers have much lower gradients and extensive floodplains, allowing more OC processing both during overbank deposition associated with flood events and during transport to the marine environment.

\section{McPhail's bend study site \& methodological approach}

Previous studies (Gomez et al. 1998, 1999) have established a detailed floodplain stratigraphy for the Waipaoa River at McPhail's bend over the last $\sim 150$ years (Figure 4.1). Sediment cores suggest that overbank sedimentation sequestered $5 \%$ of the total suspended sediment load over an 11-year period (1979-1990) but increased to $16 \%$ during events exceeding bankfull stage (Gomez et al. 1999). Expanding on that work, Gomez et al. (2003) estimated the flux of POC from the Waipaoa River to the Pacific Ocean to be $\sim 130 \mathrm{Mg} \mathrm{C} \mathrm{y}^{-1}$, with annual floodplain storage being $\sim 4 \%$ (3.6 $\left.\mathrm{MgC} \mathrm{y}^{-1}\right)$. This suggests that the Waipaoa River is very efficient at transporting terrestrial OC from land to ocean, with only a small percentage being stored on the floodplain during this period. However, as McPhail's bend is not representative of all the floodplain areas contained within the Waipaoa River basin, 
and research to date (Gomez et al. 2004b) is based on one core only, the influence of floodplains on OC fluxes requires further investigation.

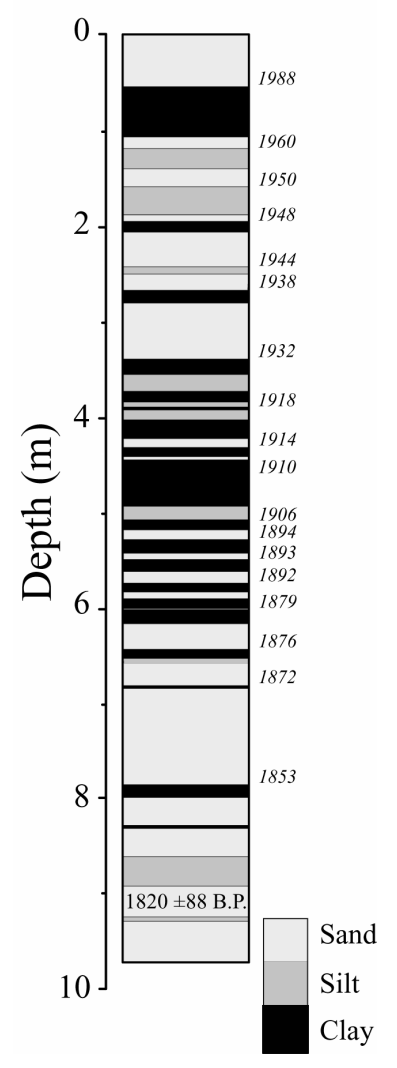

Figure 4.1: 1948-1988 flood layers at McPhail's bend (from Gomez et al. (1999)).

Sediments of the Waipaoa River floodplain provide a record of sediment transported during large flood events over the historical period. With the mean discharge being $34.7 \mathrm{~m}^{3} \mathrm{~s}^{-1}$ (Hicks et al. 2000) and overbank deposition only occurring on McPhail's bend when discharge exceeds $1800 \mathrm{~m}^{3} \mathrm{~s}^{-1}$ (i.e. 49 times the mean flow), the floodplain sediments only represent suspended sediments transported at high discharges (Gomez et al. 1998). The floodplain record contains a mixture of landslide-derived sediments (which make a greater contribution to the sediment supply at high river discharges), and sheet wash and gully-derived sediments, which are transported over a range of flows (Reid \& Page 2002).

It is widely recognised that deposition patterns across the floodplain can be spatially highly variable - generally flood deposits are thicker nearer the river channel, and this was illustrated by Gomez et al. (2004b) for McPhail's bend during the flood event of August 2002 (Figure 4.2). Individual flood layers will vary in thickness and 
character across the floodplain, thus using just one core of $40 \mathrm{~mm}$ diameter to represent a $0.5-\mathrm{km}^{2}$ area has limitations.

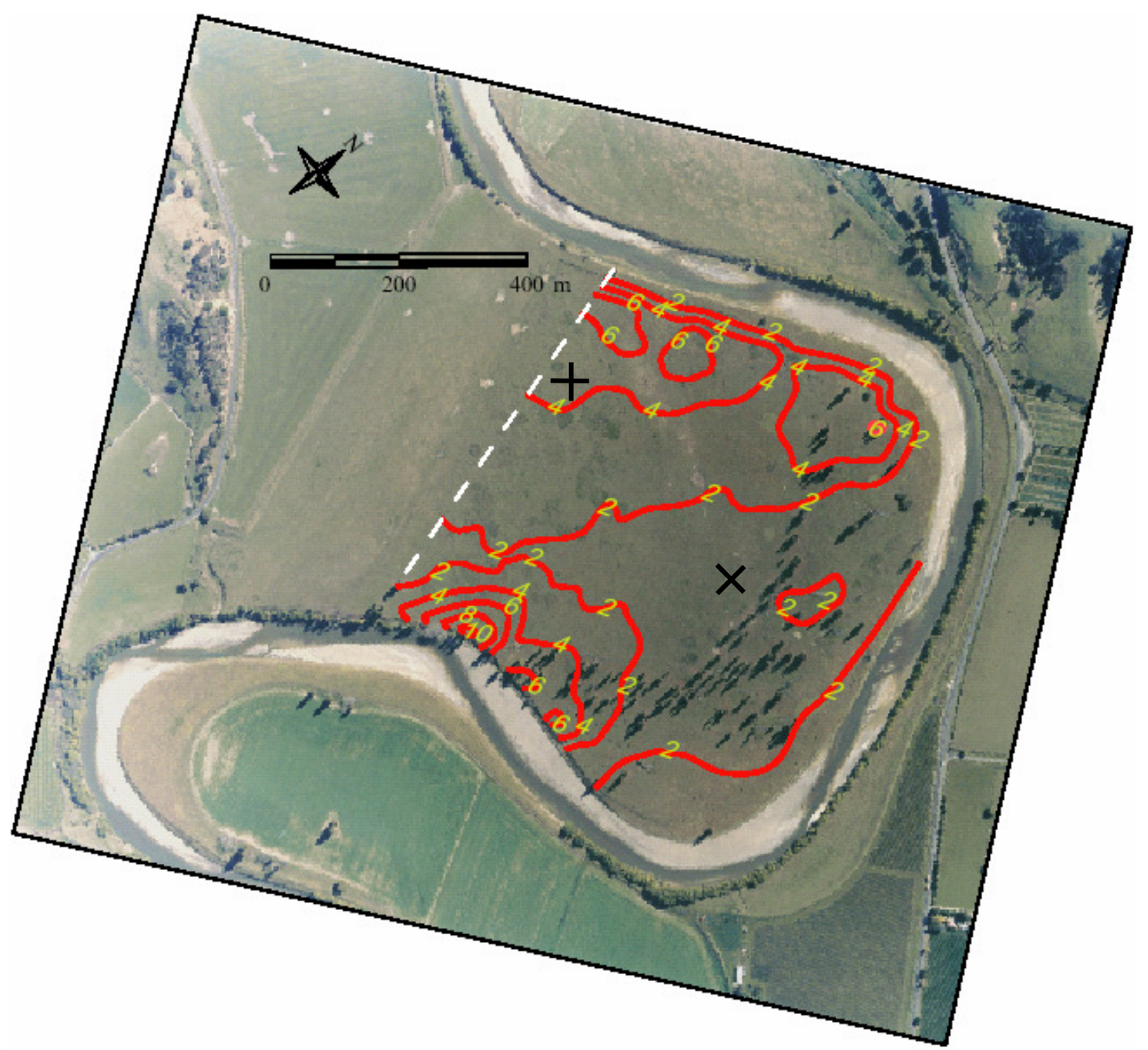

Figure 4.2: Aerial photograph of McPhail's bend, superimposed with isopachs of flood sediment thickness (in cm) deposited by the August 2002 storm event. The core site of Gomez et al. (1998; 1999; 2003; 2004b) is marked by the + and the core site for this study by the $\mathrm{X}$.

The McPhail's bend site, $32 \mathrm{~km}$ from the Waipaoa River mouth, was chosen for studying the floodplain record, as a detailed stratigraphy has previously been established and flood layers related to historic hydrologic records (Gomez et al. 1998, 1999). While the core for this study was collected within approximately $400 \mathrm{~m}$ of that studied by Gomez et al. (1998, 1999) (Figure 4.2), spatial variability of sediment layers across the floodplain resulted in different representations of flood events, such as the thickness and particle size of the deposits. Furthermore, several flood layers identified by Gomez et al. (1998) are not present in the core used for this study, and similarly new flood layers were identified. 
Down-core magnetic susceptibility measurements (Appendix B) were made to assist the stratigraphic comparison between the two cores, though good correlation between the cores proved problematic due to the spatial variation in floodplain deposition. However, by comparing descriptions and photographic records, it was possible to base the stratigraphy of the core collected for this study on that developed by Gomez et al. (1998, 1999).

The preparation and analytical methodologies used here differ to those used by Gomez et al. (1998; 1999; 2003; 2004b). A more stringent approach was taken (see Chapter 3 ) in order to reduce any loss of OC during sample processing and to allow correlations to be made with data from the international literature for other sedimentary systems such as the Eel River System, where the same procedures have been used. Unit thicknesses were corrected for core compaction, and each sample to be analysed was collected from the centre of its flood layer, to minimise any possible influence of post-depositional soil formation, oxidation etc.

This section of the study aims firstly to establish a benchmark signature of terrestrial OC within a stratigraphic floodplain sequence, to allow its characterisation following transportation to the marine environment by the Waipaoa River during storm events, and secondly to determine how the floodplain modulates OC transfers from land to ocean. It should be noted that this study does not investigate the role of bank erosion with respect to the recycling of floodplain sediment and OC back into the river. While it is likely to have been an important process in terms of how the floodplain modulated OC transfers prior to the construction of stop banks, the amount of bank erosion has since been reduced (M Hicks 2005, pers. comm.). 


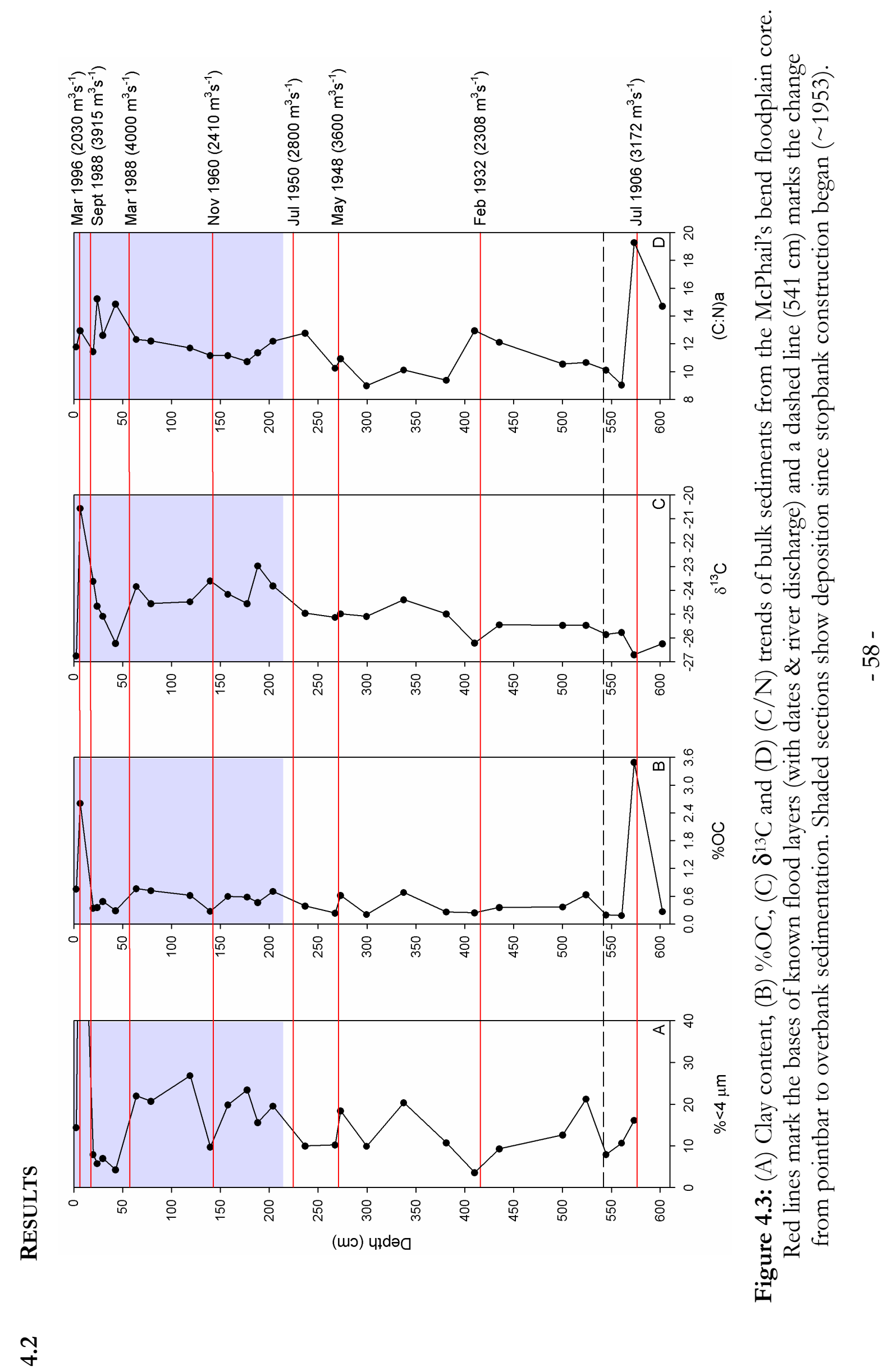


Flood layers were identified on the basis of their physical characteristics, the stratigraphic record developed by Gomez et al. $(1998,1999)$ and an extensive flood record. Particle size analyses of the 27 floodplain sediment layers show a reasonable amount of variation in clay content, illustrated as $\%$ of sediment finer than $4 \mu \mathrm{m}$ (Figure 4.3A). There is no clear relationship between clay content and flood discharge, with all but two of the samples containing <25\% clay. The March 1996 flood (discharge of $2030 \mathrm{~m}^{3} \mathrm{~s}^{-1}$ ) deposited sediment at the study site that is $100 \%$ clay, while the February 1932 flood had a similar discharge of $2308 \mathrm{~m}^{3} \mathrm{~s}^{-1}$ yet is represented by one of the coarsest sediments, containing only $3.6 \%$ clay.

The \%OC of floodplain sediments at McPhail's bend is generally low $(\sim 0.2-0.8 \%)$ except for the two samples at $7 \mathrm{~cm}$ and $573 \mathrm{~cm}$, with values of $2.6 \%$ and $3.5 \%$ respectively (Figure 4.3B). This is due to the sample at $7 \mathrm{~cm}$ containing plant material and the flood layer at $573 \mathrm{~cm}$ containing charcoal fragments. There is no apparent correlation between the $\% \mathrm{OC}$ of these sediments and the river discharge. The OC content of sediments is strongly controlled by the particle size, as illustrated by the graph of clay content and \%OC (Figure 4.4).

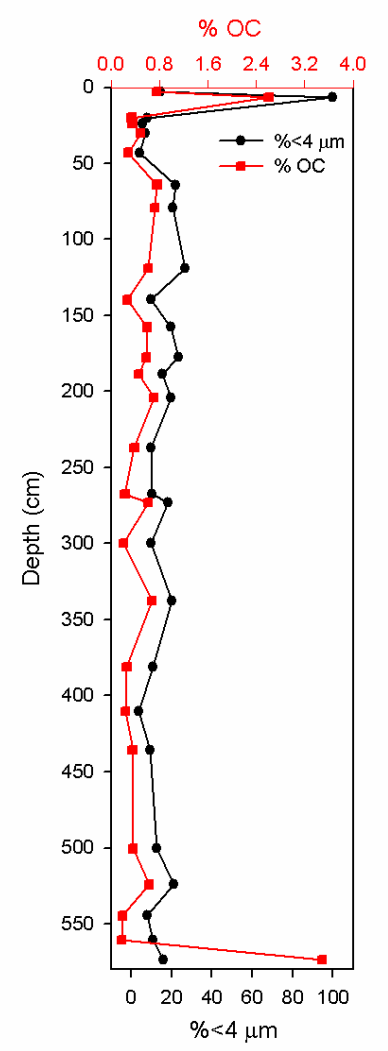

Figure 4.4: Relationship between clay content and \%OC for the bulk floodplain sediments from McPhail's bend. 
The above graph (Figure 4.4) illustrates the influence of particle size (and therefore surface area (SA)) on the OC content of floodplain sediments from McPhail's bend, with the finer sediments clearly having greater amounts of associated OC. Due to time constraints, the floodplain samples were not separated into the three size fractions, hence $\% \mathrm{OC}$ analyses were not carried out for the individual clay fractions.

Samples from the top $300 \mathrm{~cm}$ of the floodplain core show a slight trend of an increasingly heavy (less negative) $\delta^{13} \mathrm{C}$ signature with time (Figure $4.3 \mathrm{C}$ ) such that the more recent flood events have heavier $\delta^{13} \mathrm{C}$ values. While the 4 samples with the lightest (most negative) $\delta^{13} \mathrm{C}$ signatures were associated with the 1996, March 1988, 1932 and 1906 flood events, there is no apparent relationship between river discharge and $\delta^{13} \mathrm{C}$ signature.

Samples from the top $300 \mathrm{~cm}$ of the floodplain core also show a general trend of increasing $(\mathrm{C} / \mathrm{N})$ a with time (Figure 4.3D), with more recent flood events having higher $(\mathrm{C} / \mathrm{N})$ a values. The highest $(\mathrm{C} / \mathrm{N})$ a values were measured in sediments deposited during the 1906, 1932, March 1988 and 1996 flood events, but there does not appear to be a relationship between river discharge and $(\mathrm{C} / \mathrm{N})$ a values. There is no apparent relationship between $\% \mathrm{OC}$ or $\delta^{13} \mathrm{C}$ and $(\mathrm{C} / \mathrm{N})$ a within the floodplain sediments - for example, the March 1996 flood layer has a high \%OC, heavy $\boldsymbol{\delta}^{13} \mathrm{C}$ and moderate $(\mathrm{C} / \mathrm{N})$ a, while the July 1906 flood layer has a high \%OC, light $\delta^{13} \mathrm{C}$ and high $(\mathrm{C} / \mathrm{N})$ a.

A probable change from pointbar to overbank sedimentation between the July 1906 and February 1932 floods is in keeping with the previously documented river planform changes since 1868 (Figure 2.3). The location of this core on McPhail's bend is likely to have been approximately within the 1868 channel and then as the channel gradually shifted, deposition at the same site would have changed from pointbar to overbank.

Due to the amount of variation and lack of trends, it is hard to assign characteristic particle size, $\% \mathrm{OC}, \delta^{13} \mathrm{C}$ and $(\mathrm{C} / \mathrm{N})$ a values to flood events as a function of river 
discharge. While the 1996 and 1932 flood events had similar discharges of $2030 \mathrm{~m}^{3}$ $\mathrm{s}^{-1}$ and $2308 \mathrm{~m}^{3} \mathrm{~s}^{-1}$ respectively, their clay contents were $100 \%$ and $3.5 \%$ and $\mathrm{OC}$ contents $2.6 \%$ and $0.24 \%$ respectively. The $\delta^{13} \mathrm{C}$ signatures also varied greatly, being $-20.6 \%$ for the 1996 flood and $-26.2 \%$ for the 1932 event. The only property that was comparable was the $(\mathrm{C} / \mathrm{N})$ a value, which was 12.95 for both events.

\subsection{Discussion}

\subsubsection{Findings from this study}

Particle Size, \%OC, $\delta^{13} \mathrm{C}$ and $C: \mathrm{N}$ V ariations

The observed variation in floodplain sediment particle size may be due to the different flood events transporting sediment from the different rock types, associated with a range of erosion processes. In the Waipaoa catchment, gully erosion dominates on the finer bedrock, whereas landslides dominate on slightly coarser bedrock, but generally do not erode the bedrock, just the topsoil and regolith. On McPhail's Bend, the largest of the flood events, Cyclone Bola (March 1988) is represented by a coarse sediment layer (only $4.3 \%$ clay), reflecting the significance of landsliding as a sediment source, which is in keeping with the findings of Reid and Page (2002). However, there is no consistent relationship between particle size (\% clay) and river discharge, preventing the use of particle size as a reliable indicator of erosion process or sediment source. It may well be that particle size of overbank sediments is controlled by other river dynamics, such as the floodplain morphology and its influence on flow velocity.

The low OC content (generally $<0.8 \%$ ) of the floodplain alluvium is probably a reflection of its derivation from regolith and soils developed on weathered sedimentary rocks lacking in organic matter, most likely in response to the removal of native forest that began in the upper Waipaoa catchment in the late $19^{\text {th }}$ century. Gomez et al. (2003) determined the average OC content of weathered bedrock and gully-sourced material to be $\sim 0.3 \%$ and $0.4 \%$ respectively and being the dominant source of floodplain sediment, the generally low OC contents of floodplain sediments at McPhail's bend are in keeping with the source material. Although landsliding displaces both organic-rich soil and vegetation during the large flood 
events (e.g. Cyclone Bola, March 1988), the amount displaced is a small proportion of the total volume of sediment mobilised, so the contribution from the deeper soil profile outweighs that of the topsoil (Gomez \& Trustrum 2005). There is also very little time between floods to allow much soil development or accumulation of organic matter and topsoil - basically these floodplain deposits are raw sediment with incipient A horizons.

Another explanation for the low \%OC of McPhail's bend floodplain sediments is the stabilisation of POC content with high river flows, as suggested by Gomez et al. (2003). They found that when the Waipaoa River discharge exceeds about 5 times the mean flow $\left(\sim 174 \mathrm{~m}^{3} \mathrm{~s}^{-1}\right)$, the POC content stabilises at a low value of $\sim 0.6 \%$, markedly lower than during low to intermediate flows (as represented by OC concentrations of suspended sediments during low to intermediate flows).

While biogeochemical changes following deposition may result in some variation in $\delta^{13} \mathrm{C}$ values of flood layers (though this hasn't been thoroughly investigated), $\delta^{13} \mathrm{C}$ variations are likely to be largely driven by sediment and plant sources, with erosion processes largely determining what material is transported during flood events. For example, deep gully erosion dominantly transports bedrock material, containing ancient refractory $\mathrm{OC}$ with a lighter (more negative) $\delta^{13} \mathrm{C}$ signature. Contrastingly, shallower forms of erosion dominantly transport topsoil, containing younger and more labile OC, often in the form of plant material.

The trend of a slightly heavier $\delta^{13} \mathrm{C}$ signature with time in the top $300 \mathrm{~cm}$ of the floodplain core (Figure 4.3C) may be due to an increasing presence of C4 plants within the catchment, having an average $\delta^{13} \mathrm{C}$ value of about -14 to $-13 \%$, whereas the average $\delta^{13} \mathrm{C}$ value of C3 plants is generally in the range of -27 to $-26 \%$ o (Kendall et al. 2001). The 1996 flood sample has the heaviest value of $-20.6 \%$ and also contained many fine roots, which when extracted and analysed separately yielded a $\delta^{13} \mathrm{C}$ of $-14.5 \%$. This provides strong evidence for the presence of C4 plant matter, likely to be either Bermuda grass (Cynodon dactylon) rhizomes (see Chapter 2) or maize roots, transported in the flood sediments. Small areas of maize 
are grown on floodplains upstream of McPhail's bend and are a potential source of C4 plant matter during flood events that are large enough to inundate the crop. The exact source of Bermuda grass is unknown, but its presence in flood sediments has been noted by Pullar (1962). Thus the trend in the upper $300 \mathrm{~cm}$ may represent an increased presence of either Bermuda grass or maize crops within the Waipaoa River catchment. It is also possible that the large range of $\delta^{13} \mathrm{C}$ values of flood sediments at McPhail's bend represents a mixing of both C3 and C4 plant detritus with the eroded sediments.

The influence of C4 plants illustrates potential problems that may result when relating terrestrial $\delta^{13} \mathrm{C}$ values to marine sediments, which have integrated signals from a whole catchment. In this study, the terrestrial $\delta^{13} \mathrm{C}$ end member was estimated to be $-28.0 \%$ o (see Chapter 5) due to the relatively small contribution the C4 plants make to the terrestrial OC sources. Contrastingly, in a catchment with a significant C4 plant presence, a truer end member value would be less negative (heavier) and it would be necessary to analyse all dominant sediment and plant sources within the catchment to get a true indication of the combined terrestrial end member, as was done by Blair et al. (2003).

The range of $(\mathrm{C} / \mathrm{N})$ a values within the floodplain sediments is most likely associated with variations in the content of fresh organic matter. For example, raw organic matter has a higher $(\mathrm{C} / \mathrm{N})$ a ratio than decomposed organic matter or soil, due to the ratio lowering as organic matter decomposes. While there is no apparent relationship between $\% \mathrm{OC}$ or $\delta^{13} \mathrm{C}$ and $(\mathrm{C} / \mathrm{N})$ a within the floodplain sediments, some of the sediments with higher $\% \mathrm{OC}$ are associated with elevated $(\mathrm{C} / \mathrm{N}) \mathrm{a}$ values, probably due to the presence of relatively fresh plant material (e.g. July 1906). 


\subsubsection{Comparison with previous McPhail's bend studies}

It is important to compare the results from this study with other McPhail's bend studies (e.g. Gomez et al. 1998; 1999; 2003; 2004b) to illustrate how the floodplain behaves as a modulator of terrestrial sediment and OC prior to its discharge to the marine environment.
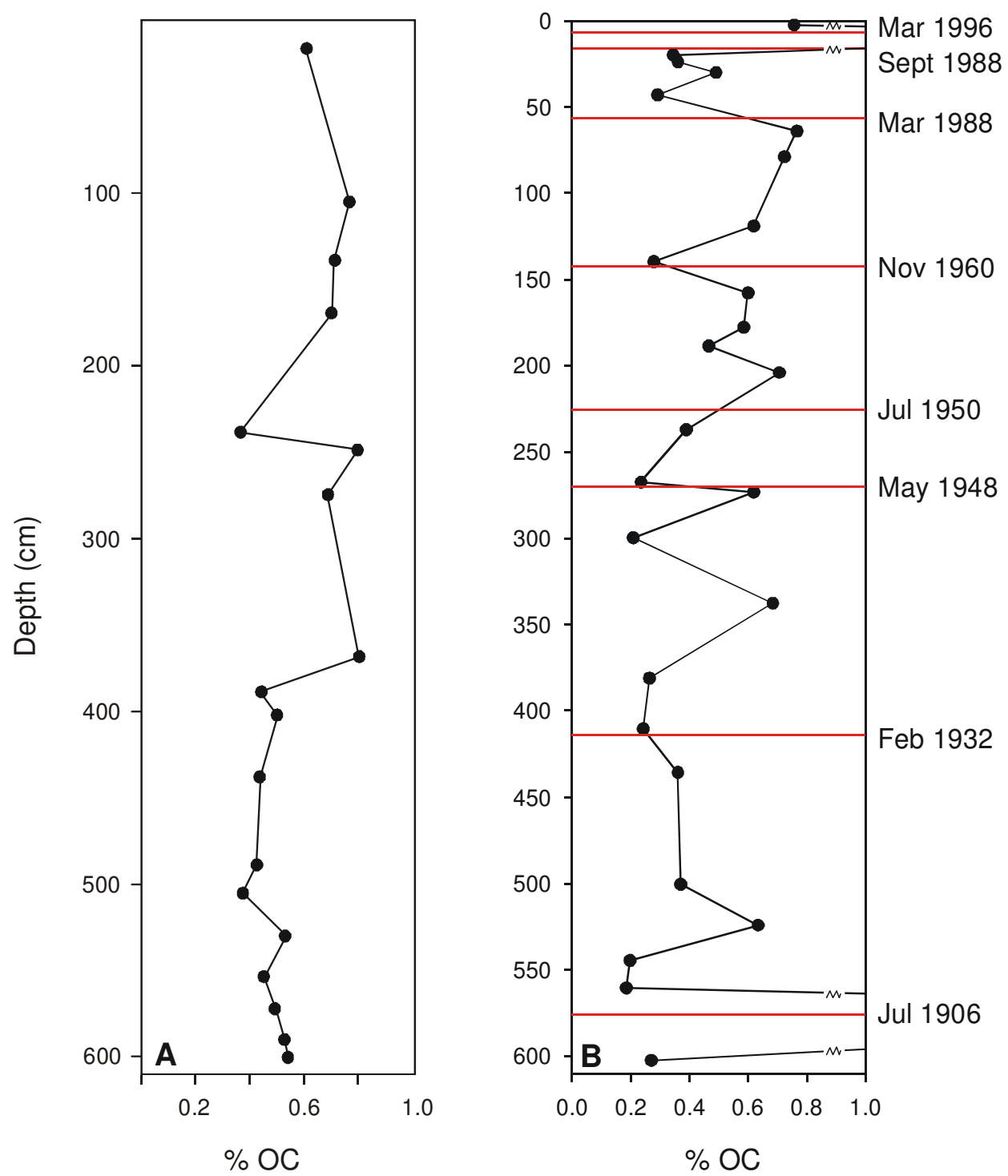

Figure 4.5: Comparison of OC contents for the two McPhail's bend cores analysed by (A) Gomez et al. (2004b) and (B) this study.

The down-core values and trends in this study differ from those of Gomez et al. (2003 and 2004b). As with the $\% \mathrm{OC}$ values (Figure 4.5) the $\delta^{13} \mathrm{C}$ values and $\mathrm{C} / \mathrm{N}$ ratios also vary, with all of these variations most likely due to the different stratigraphies recorded in the two cores. In this study, $\delta^{13} \mathrm{C}$ trends suggest an increasing influence of C4 plants (see 4.3.1) which was not identified in the core 
analysed by Gomez et al. (2003, 2004b). Downcore trends identified by Gomez et al. (2003, 2004b) and Gomez and Trustrum (2005) relating OC and $\delta^{13} \mathrm{C}$ to deforestation and changing erosion processes are also not identifiable in this study.

These differences may be due to one or more of four factors. Firstly, the sample selection used for this study differed from those used by Gomez et al. (2003 \& 2004b) by using complete bulk samples rather than the fine-medium silt fraction. By analysing bulk samples of varying particle size (i.e. this study), the amount of downcore $\% \mathrm{OC}$ variation would probably be greater than that revealed by using only the fine-medium silt fraction (i.e. Gomez et al. 2004b), as the particle size has a strong influence on the \%OC of bulk samples (Figure 4.4). This issue may have been overcome if each of the bulk floodplain samples had been separated into size fractions as was done for the marine samples, allowing characteristics for each of the size fractions to be established. Secondly, as previously mentioned, the preparation and analytical techniques for this study were very stringent, to reduce any possible loss of OC from the samples during their preparation. Thirdly, because different laboratories were used to analyse the sediments there are likely to be discrepancies between the results, as was found when conducting inter-laboratory comparisons (see 3.10.2). A fourth factor is spatial variability across the floodplain. The two cores were from sites only $\sim 400 \mathrm{~m}$ apart, but (as measured at McPhail's bend following the August 2002 storm) the thickness of flood sediments deposited on McPhail's bend varies greatly across the floodplain (Figure 4.2). This is in turn reflected in the different vertical stratigraphic records represented by the two cores.

\subsubsection{Role of the floodplain in modulating OC transfers}

The extent of differences between the two McPhail's bend cores, outlined above, demonstrates the extent to which erosion processes can influence the floodplain stratigraphy and in turn influence sediment and OC transfers from land to ocean. Changes in river morphology and flood dynamics account for the large spatial variability in flood layer thickness, particle size and associated geochemical characteristics. The extent to which the magnitudes and characteristics of different flood events can influence the distribution of sediment and associated OC is 
illustrated by comparing the sediment thicknesses for a moderate (2002) and a high magnitude (March 1988) flood event at the two sites on McPhail's bend.

In the large magnitude event of March 1988 (Cyclone Bola), sediment thicknesses were generally less at the site of Gomez et al. $(2003,2004 b)$ because either the flow velocity across that part of the floodplain was too high to permit deposition (Gomez et al. 1998), or sediments deposited during earlier stages of the flood were subsequently scoured by the high flows ( $N$ Trustrum 2005, pers. comm.). By comparison, the core used for this study exhibits a thicker flood layer for this same

flood event. Contrastingly, during the moderate magnitude event of August 2002, the reverse trend occurred, with greater thicknesses of sediment accumulating at the site of Gomez et al. (2003, 2004b) than at the site used for this study (Figure 4.2). Similarly, sediments at the different sites also show differing particle size characteristics and associated OC contents (Figure 4.5). These spatial and temporal variations in floodplain sediment and OC sequestration illustrate the role the floodplain can play in modulating OC transfers to the ocean.

\section{$4.4 \quad$ CONCLUSIONS}

Understanding the complex relationships between river behaviour and depositional processes is important for determining the extent to which the floodplain acts as a modulator of terrestrial sediment and OC before it is discharged to the marine environment. However, it is apparent that floodplain deposits within the Waipaoa River system show great variation and thus prevent the establishment of a clear benchmark signature for flood events that would be easily recognisable in the marine sedimentary record.

Whilst the influence of river reaches such as McPhail's bend appear to be relatively small in modulating OC transfers within the Waipaoa River system (i.e. total OC sequestration only $\sim 4 \%$ (Gomez et al. 2003)), there are significant floodplain areas within the Waipaoa River tributaries that overbank more frequently than the main stem at McPhail's bend, and therefore offer more opportunities for OC sequestration and modulation. Also, McPhail's bend does not represent the large 
areas of the lower Waipaoa floodplain system, where prior to stopbank construction (late 1940's), overbank deposition and associated OC sequestration and modulation may have been more extensive. Taking these factors into consideration, transmission losses of OC to the floodplain are $\sim 10 \%$ (Gomez \& Trustrum 2005). Therefore, when all of the floodplain areas in the entire Waipaoa catchment are taken into consideration and coupled with the large spatial and temporal distribution of floodplain OC, they could play a role in modulating OC transfers to the ocean. 
"Neither juggernaut man nor crawling thing Can bring a mountain weeping to its knees quicker than the rain

That demure leveller ocean-blessed cloud-sent maker of plains."

Hone Tuwhare.

\section{CHAPTER 5: USING TERRESTRIAL ORGANIC CARBON TO ASSIST IN FLOOD IDENTIFICATION ON THE CONTINENTAL SHELF \& SLOPE}

\section{$5.1 \quad$ INTRODUCTION}

Terrestrial organic carbon (OC) is an important constituent of riverine particulate matter, thus its distribution on continental margins is closely linked to the dispersal of riverine sediment (Leithold \& Hope 1999). Rivers draining small mountainous watersheds, such as the Waipaoa Sedimentary System (WSS), have recently come under increased scrutiny (Milliman \& Syvitski 1992; Milliman 1995; Milliman et al. 1999; Lyons et al. 2002; Farnsworth \& Milliman 2003) as they often transport large amounts of suspended sediment. Such point sources, together with the ocean circulation, influence sediment and associated OC dispersal and deposition in the marine environment.

During floods, it is common for high input rivers to generate positively buoyant (hypopycnal) sediment plumes at the mouth. Less commonly, and under particular conditions, rivers may form negatively buoyant (hyperpycnal) plumes that can result in the transport of riverine sediment beyond the continental shelf to depositional sites further offshore (Johnson et al. 2001; Parsons et al. 2001). The critical suspended sediment concentration required to produce a hyperpycnal plume in temperate latitudes is estimated to be $\sim 40000 \mathrm{mg} \mathrm{L}^{-1}$ in marine environments (Mulder \& Syvitski 1995). However, it has been suggested that under some conditions, hyperpycnal flows may form when river suspended sediment concentrations are much less, even as low as $\sim 5000 \mathrm{mg} \mathrm{L}^{-1}$ (Parsons et al. 2001). Hence many small mountainous rivers may in fact generate hyperpycnal flows on a more regular basis.

Hicks et al. (2004a) calculated that if the suspended sediment concentration threshold for hyperpycnal flows was $40000 \mathrm{mg} \mathrm{L}^{-1}$, the Waipaoa River would generate such a flow once every $\sim 40$ years. While being cautious of uncertainties, 
they also calculated that if the threshold was reduced to $20000 \mathrm{mg} \mathrm{L}^{-1}$, an average of 3-4 events would occur each year, and a threshold of $5000 \mathrm{mg} \mathrm{L}^{-1}$ would generally result in hyperpycnal flows forming monthly. Thus potentially, hyperpycnal flows from the Waipaoa River could be an important factor in transporting sediment across the shelf. Furthermore, their signature could be apparent in the depositional record (Hicks et al. 2004a) so long as they have not been disturbed by storm-wave or current action. However, it is currently thought that hypopycnal plumes are the normal dispersal mechanism for Waipaoa sediment on the continental shelf, and that mid-water plumes are unlikely to form because of the well-mixed structure of shelf waters (Carter \& Gomez In Review).

While recent studies have investigated the influence of hyperpycnal plumes on the dispersal and distribution of riverine sediment (Parsons et al. 2001; Warwick \& Milliman 2003; Dadson et al. 2003; Dadson et al. 2004; Hicks et al. 2004a) their influence on the transfer and fate of terrestrial OC across the continental shelf and beyond has not yet been well investigated. The consequential rapid transfer, deposition and burial of terrestrial OC in the marine environment could potentially result in those flood deposits and associated OC retaining a stronger terrestrial signature than non-flood sediments and allow the sequestration of large amounts of terrestrially sourced OC.

By looking at the down-core characteristics of three multi-cores from a range of water depths across the continental shelf and slope offshore from the WSS, perturbations in sediment supply within the WSS may be traceable given the caveat of post flood reworking (see Figure 2.1). If individual flood layers can be identified, it would allow comparisons of the OC characteristics in flood and non-flood sediments to be made, and so help address the questions of how flood events in the river catchment affect the transfer and fate of terrestrial OC through the marine environment, and how this environment influences the OC signature. 


\subsection{RESULTS}

\subsubsection{Sediment Accumulation Rates}

${ }^{210} \mathrm{~Pb}$ data from the 3 multi-cores were used with varying success to determine modern accumulation rates on the continental shelf and slope (see also 3.9.6 and Appendix D). The results for core U2303 are presented in Figure 5.1.

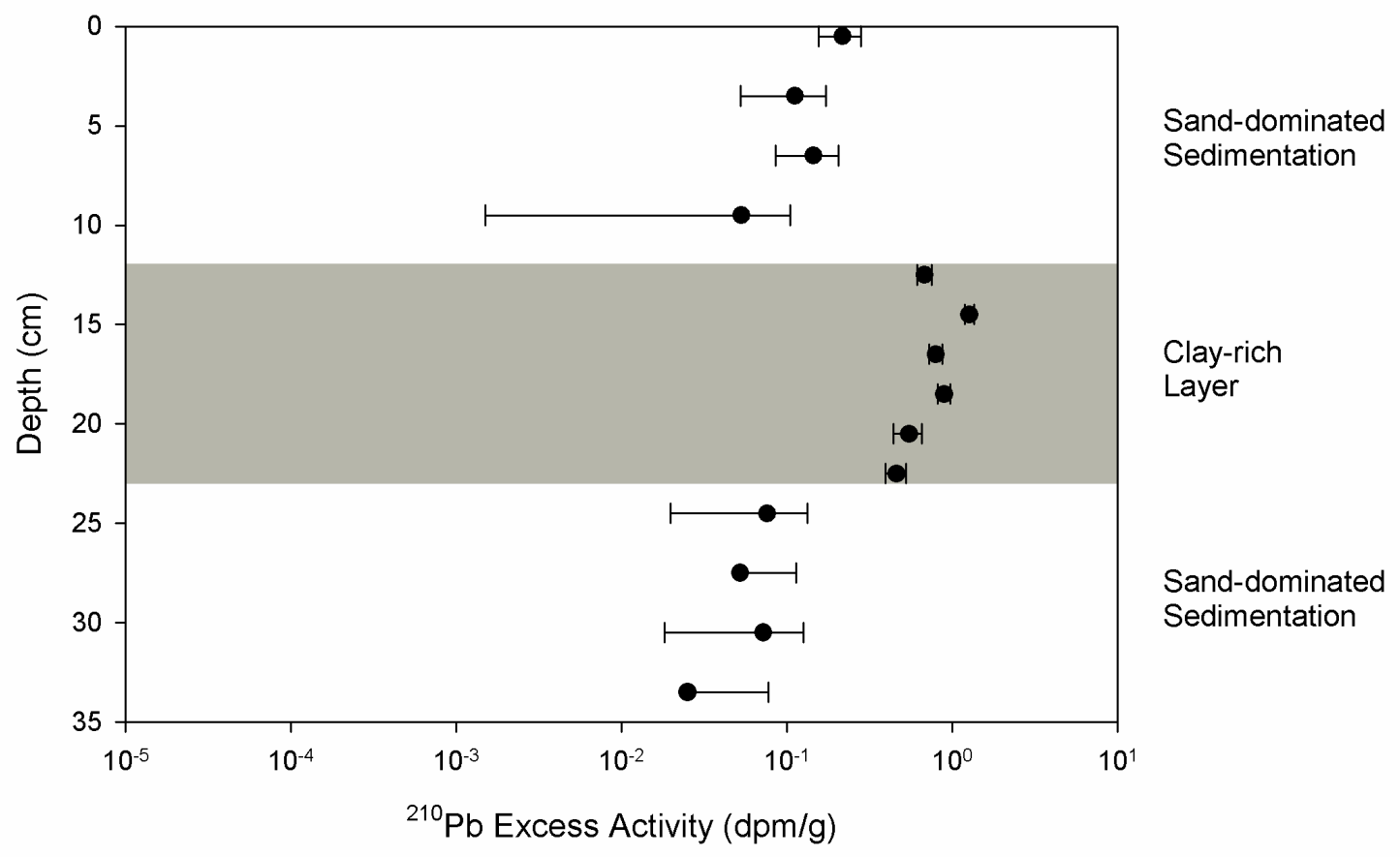

Figure 5.1: Excess ${ }^{210} \mathrm{~Pb}$ activity for the inner shelf core (U2303). (Uncertainty limits are standard errors).

In addition to the activities for most of the core being near the detection limit for ${ }^{210} \mathrm{~Pb}\left(0.1 \mathrm{dpmg}^{-1}\right)$, the measurement of inner shelf sedimentation rates was influenced by a clay-rich layer at 13-23 cm depth being sandwiched between coarser sediments. The ${ }^{210} \mathrm{~Pb}$ data were corrected for the difference in particle size by normalising the excess activity to the clay content of each sample (excess activity divided by $\%$ clay in sample), and plotting the result against core depth to reveal the comparative sedimentation rates (Figure 5.2). 


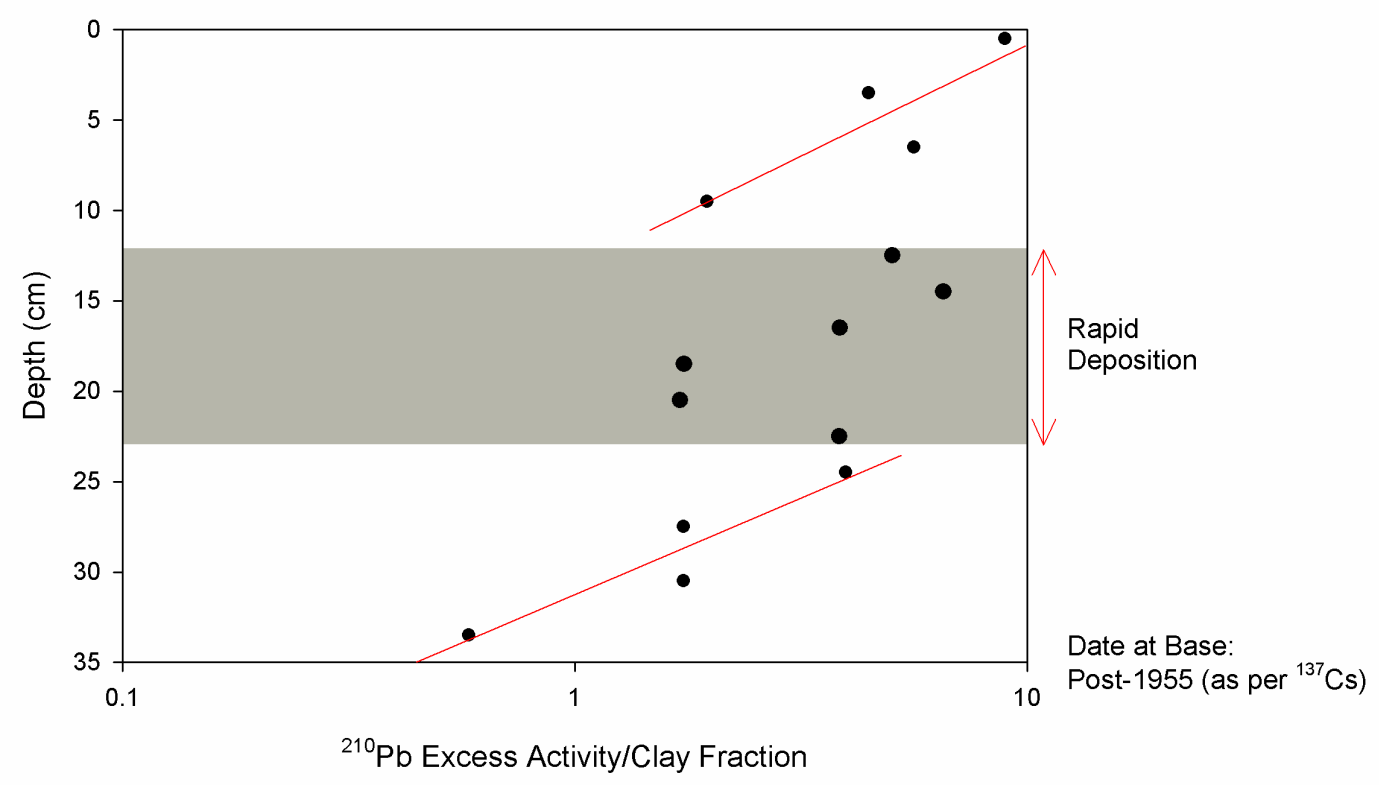

Figure 5.2: Core U2303 excess ${ }^{210} \mathrm{~Pb}$ activity corrected for clay content, indicating varying down-core sediment accumulation rates.

The normalised data suggest fairly consistent sediment accumulation prior to deposition of the flood layer and rapid deposition of the clay-rich layer at 13-23 cm depth, possibly the result of a river flood (Figure 5.2). It also indicates that following deposition of the layer, sedimentation returned to a steady accumulation rate. ${ }^{137} \mathrm{Cs}$ data and flood layer identification suggest that the sedimentation rate increased following deposition of the flood layer (see 5.3.1).

A complication is the presence of ${ }^{137} \mathrm{Cs}$ in the base sample at $34 \mathrm{~cm}$ depth, suggesting it was deposited since $\sim 1955$, which conflicts with the ${ }^{210} \mathrm{~Pb}$ data. If the ${ }^{210} \mathrm{~Pb}$ sedimentation rates are used, the sample at $13 \mathrm{~cm}$ depth yields an age of $\sim 50$ years (deposited in $\sim 1951$ ) and the sample at $34 \mathrm{~cm}$ depth yields an age of $\sim 82$ years (deposited in $\sim 1919$ ). However, using ${ }^{137} \mathrm{Cs}$ as an indicator of a 1955 age for the base of the core, it can be estimated that $24 \mathrm{~cm}$ of sediment (i.e. $34 \mathrm{~cm}$ less the rapidly deposited flood layer) accumulated over 46 years, giving an average sedimentation rate of at least $0.52 \mathrm{~cm} \mathrm{y}^{-1}$. Accordingly, ${ }^{137} \mathrm{Cs}$ was used for determining the sedimentation rate for core $\mathrm{U} 2303$ but the ${ }^{210} \mathrm{~Pb}$ data were useful supporting evidence for identifying the flood layer at $13-23 \mathrm{~cm}$ depth.

A most plausible reason for the discrepancy is that $210 \mathrm{~Pb}$ results document the periodic erosion of sediment from the sea floor by waves. Gorman et al. (2003) 
showed that the mean wave height for this part of the East coast is $1.57 \mathrm{~m}$, and the mean period $7.37 \mathrm{~s}$. Using linear wave theory to get orbital velocities, the oscillating flow generated by such a wave will disturb very fine sand in water depths of around $27 \mathrm{~m}$ and lead to periods of erosion interrupting the deposition (L Carter 2005, pers. comm.). This is also supported by the coarseness of the sediment above and below the flood layer, indicating that wave action has winnowed out fine silt and clay, leaving only coarse silt and sand lag. Given uncertainties of ${ }^{210} \mathrm{~Pb}$, the mean sedimentation rate from the ${ }^{137} \mathrm{Cs}$ time horizon is used.

Accumulation rates for the mid-shelf and upper slope cores were more easily determined through the use of ${ }^{210} \mathrm{~Pb}$ analyses, as there were no large down-core particle size changes and ${ }^{210} \mathrm{~Pb}$ activities were higher due to the sediments being finer. Sediment accumulation rates for the three multi-cores are summarised in Table 5.1.

Table 5.1: Modern accumulation rates for continental shelf and slope sediments. Note: U2305 rate calculated from presence of ${ }^{137} \mathrm{Cs}$, while those for U2305 and W697 are from ${ }^{210} \mathrm{~Pb}$ analyses. (Refer to Appendix D).

\begin{tabular}{lc}
\hline Core & $\begin{array}{c}\text { Average } \\
\text { Accumulation } \\
\text { Rates }\end{array}$ \\
\hline U2303: Inner Shelf, $27 \mathrm{~m}$ & $\geq 0.52 \mathrm{~cm} \mathrm{y}^{-1}$ \\
U2305: Mid-shelf, $56 \mathrm{~m}$ & $0.42 \mathrm{~cm} \mathrm{y}^{-1}$ \\
W697: Upper Slope, $1198 \mathrm{~m}$ & $0.13 \mathrm{~cm} \mathrm{y}^{-1}$ \\
\hline
\end{tabular}

Variations in sedimentation rates across the shelf and slope are likely to be due to a number of factors such as sediment supply, shelf bathymetry, water depth and ocean currents. The higher rate at the inner shelf site most likely reflects its proximity to the muddy Waipaoa River and its location at the mouth of Poverty Bay means it is not directly affected by the Wairarapa Coastal Current (WCC) or the East Cape Current (ECC). However, due to the relatively shallow water depth, sedimentation on the inner shelf may not be continuous, with the possible influence of wave base disturbance, as discussed above. The mid-shelf site of core U2305 is near a synclinal basin, where sediment preferentially accumulates. The deeper water 
also contributes to a higher sedimentation rate than on the inner shelf. The markedly lower sedimentation rate on the upper slope is most likely related to its distance from the river mouth. Here, there is a reduced sediment input, and the presence of the ECC transports sediments in a predominantly south west direction. Using these accumulation rates, the following rough ages have been assigned to possible flood layers within the shelf and slope cores (rough because the use of mean sedimentation rates masks variability relating to periods of either high or instantaneous deposition and/or phases of erosion).

Table 5.2: Approximate ages of flood layers within continental shelf sediments.

\begin{tabular}{lcc}
\hline Core & $\begin{array}{c}\text { Flood Layer } \\
\text { Depth }\end{array}$ & $\begin{array}{c}\text { Approximate } \\
\text { Age }\end{array}$ \\
\hline U2303: Inner Shelf, $27 \mathrm{~m}$ & $13-23 \mathrm{~cm}$ & $\sim 1951\left({ }^{210} \mathrm{~Pb}\right)$ \\
U2303: Inner Shelf, $27 \mathrm{~m}$ & $13-23 \mathrm{~cm}$ & $\sim 1980\left({ }^{137} \mathrm{Cs}\right)$ \\
U2305: Mid-shelf, $56 \mathrm{~m}$ & $7 \mathrm{~cm}$ & $\sim 1984(210 \mathrm{~Pb})$ \\
U2305: Mid-shelf, $56 \mathrm{~m}$ & $13 \mathrm{~cm}$ & $\sim 1970(210 \mathrm{~Pb})$ \\
U2305: Mid-shelf, $56 \mathrm{~m}$ & $25 \mathrm{~cm}$ & $\sim 1941(210 \mathrm{~Pb})$ \\
\hline
\end{tabular}

\subsubsection{Down-core Trends}

The following three figures present results for the down-core physical and chemical analyses carried out on the three multi-cores from the continental shelf and slope. The analyses included particle size, OC content (\%OC), stable carbon isotope signature $\left(\boldsymbol{\delta}^{13} \mathrm{C}\right)$ and atomic carbon to nitrogen ratios $((\mathrm{C} / \mathrm{N}) \mathrm{a})$. 


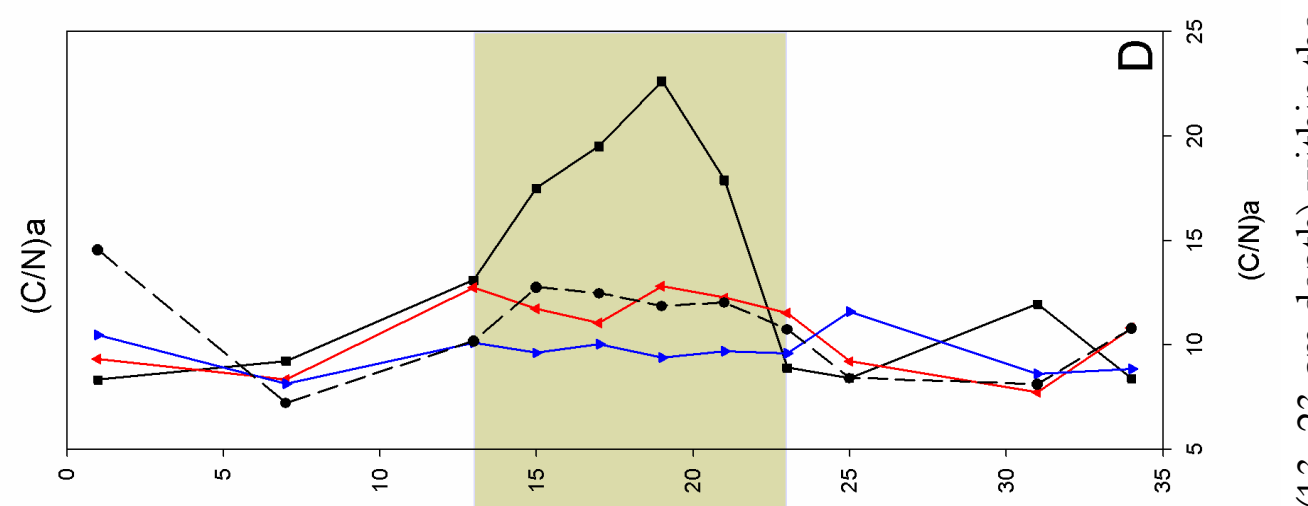

吉

$\sum_{0}^{\frac{\pi}{2}} \frac{\partial}{0}$

द्व

กิ

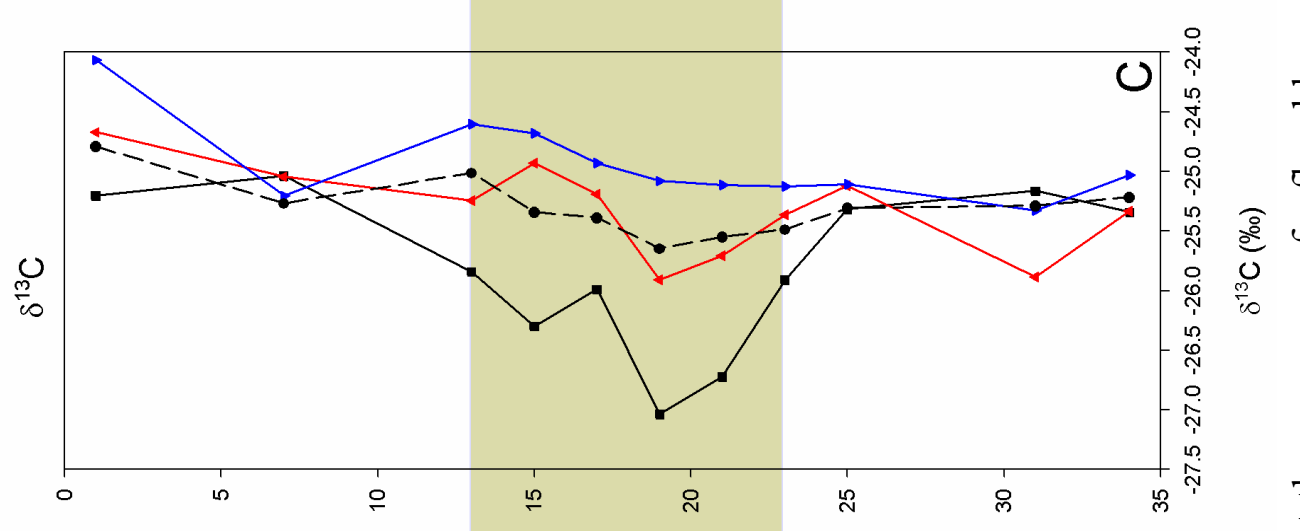

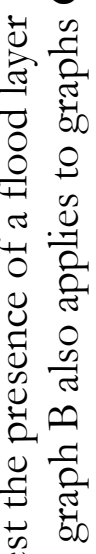

$\bigcup_{0}^{\infty}$

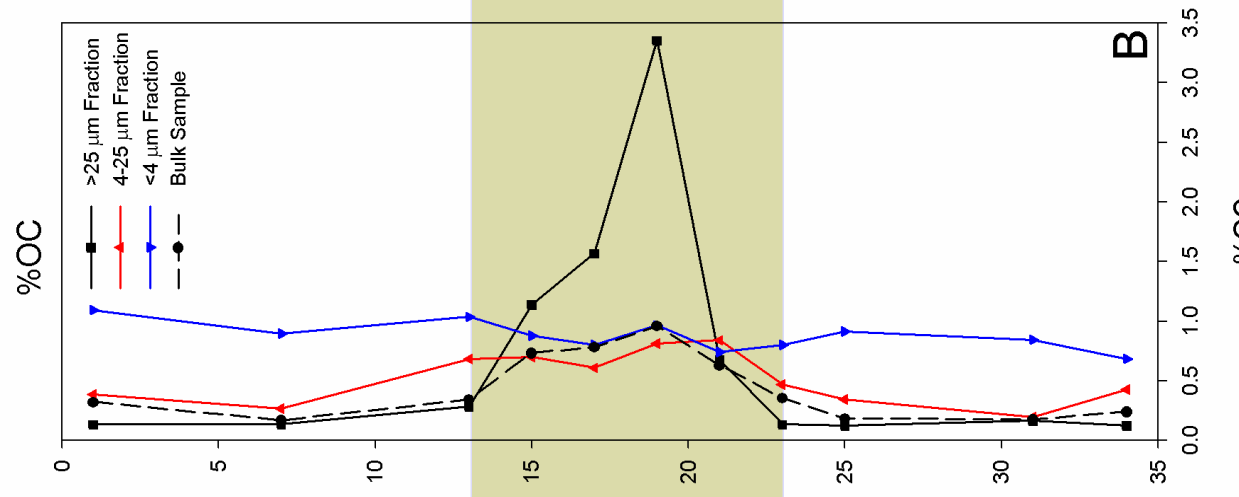

$=1$

as

过

- $\stackrel{\Xi}{0}$

乙而

บิ

चี กิ

ن

:

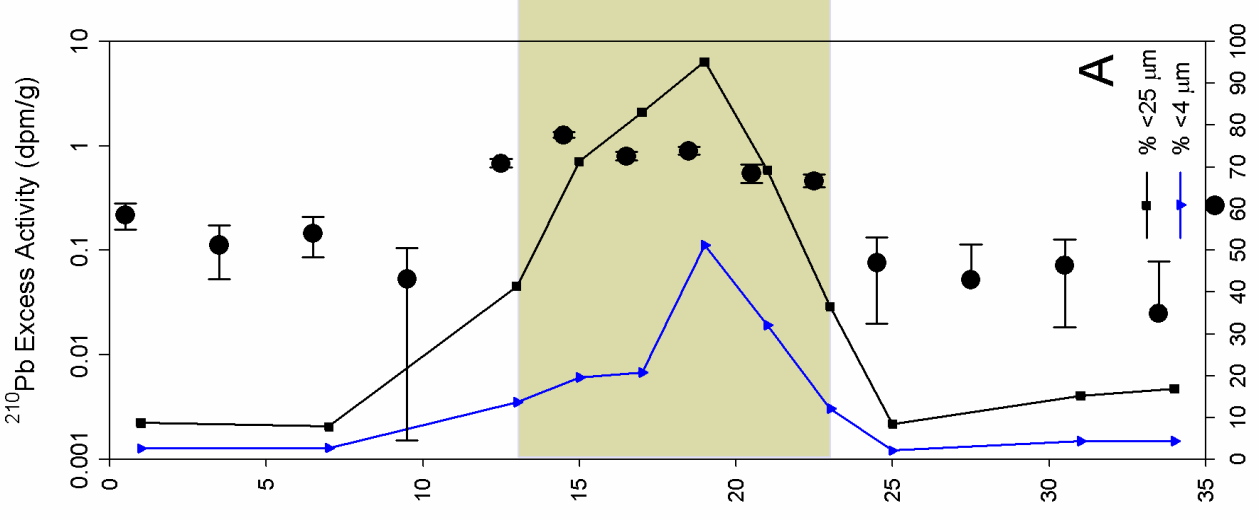

ن

○ी

คิ

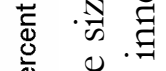


Inner shelf sediments (U2303) contain the $10 \mathrm{~cm}$ thick light grey clay-rich layer between dark grey silt and mud. Contacts between the layers are very sharp, with no evidence of bioturbation. As much as $95 \%$ of the sediment in the clay-rich layer is finer than $25 \mu \mathrm{m}$, compared to less than $16 \%$ in the sediments above and below. The clay-rich layer is finest in the middle, i.e. the the top half fines downwards and bottom half fines upwards (Figure 5.3A).

Bulk samples show increased \%OC in the clay-rich layer, but when individual size fractions were analysed, the highest OC contents in that layer were found in the coarse silt fraction $(>25 \mu \mathrm{m})$ and were greatest in the middle of the layer (Figure 5.3B). The clay fraction $(<4 \mu \mathrm{m})$ has little variation in $\% \mathrm{OC}$ with depth.

For all size fractions, $\delta^{13} \mathrm{C}$ values of the clay-rich layer are lighter (more negative) than those of most samples above and below, with values peaking in the centre of the layer. Again, the greatest variation is in the coarse silt fraction $(>25 \mu \mathrm{m})$, and the clay fraction does not show an obvious trend (Figure 5.3C).

The inner shelf clay-rich layer is strongly defined by $(\mathrm{C} / \mathrm{N})$ a of the coarse silt fraction $(>25 \mu \mathrm{m}$ ), with values being markedly higher (up to $\sim 23$ ) than in the sediments above and below ( 8) (Figure 5.3D). The bulk samples also show increased ratios in the $13-23 \mathrm{~cm}$ layer, though not as markedly as in the coarse silt fraction. The 4-25 $\mu \mathrm{m}$ fractions show a slight increase in $(\mathrm{C} / \mathrm{N})$ a values within the 13-23 cm layer, with values similar to the bulk samples, while the $<4 \mu \mathrm{m}$ fraction shows very little down-core variation. Lower $(\mathrm{C} / \mathrm{N})$ a values in the non-flood sediments may be the result of microbial processing during the transport and accumulation of sediments in the marine environment (Leithold \& Blair 2001) or due to different sediment sources of the flood and non-flood sediments.

Such down-core trends suggest that the clay-rich layer at $13-23 \mathrm{~cm}$ depth on the inner shelf represents the rapid deposition and preservation of a large flood event, possibly the result of a hyperpycnal flow emanating from the Waipaoa River. 


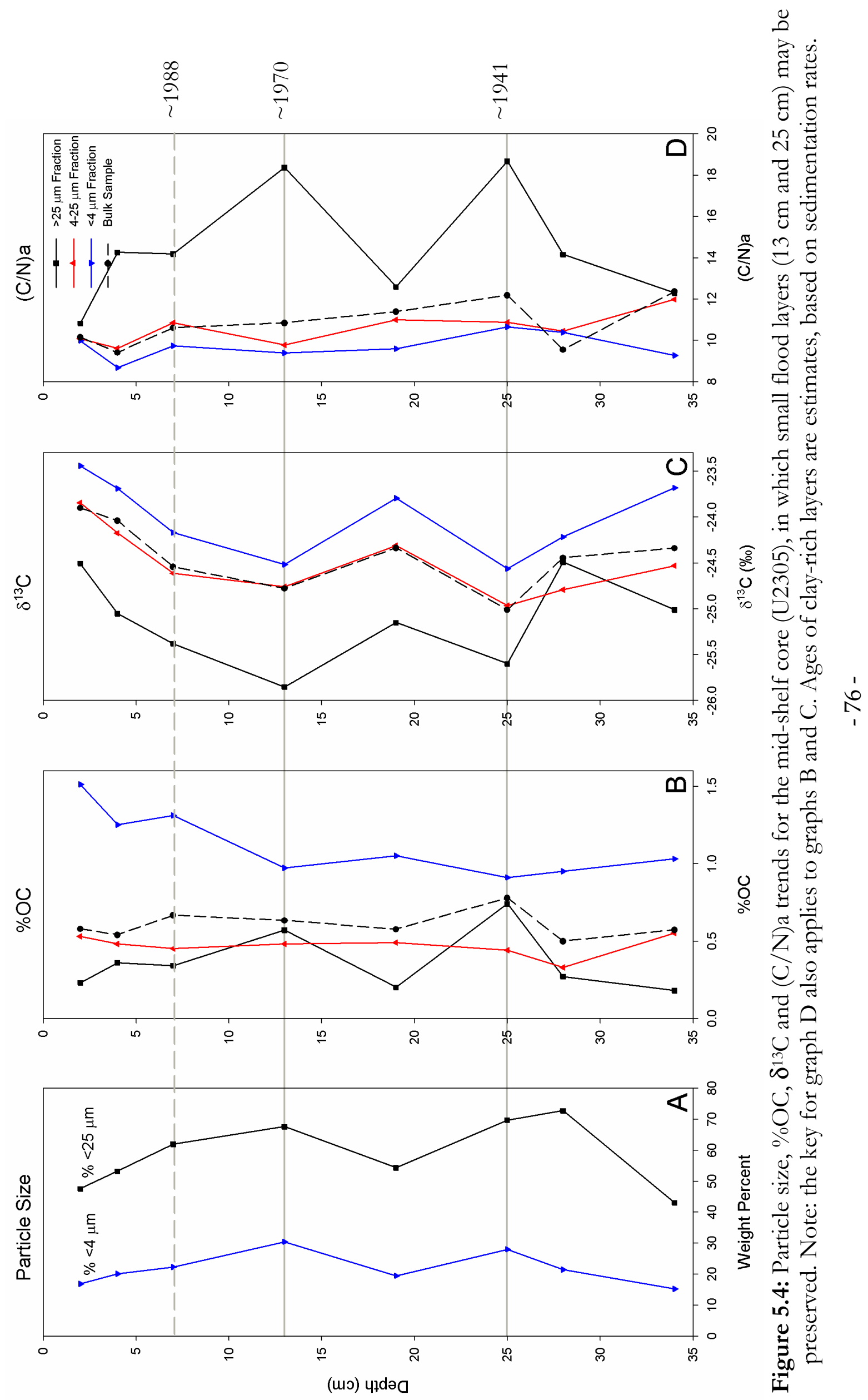


With increased water depth across the continental shelf, the sediments of the midshelf core (U2305) are finer than that of U2303, with at least $43 \%$ of particles in all of the bulk samples being finer than $25 \mu \mathrm{m}$ (Figure 5.4A). There are two thin layers at $13 \mathrm{~cm}$ and $25 \mathrm{~cm}$ depth that are a little more clay-rich, with $\sim 30 \%$ and $28 \%$ of each sample, respectively, being finer than $4 \mu \mathrm{m}$.

While the OC content of the coarse silt fraction $(>25 \mu \mathrm{m})$ of mid-shelf sediments is generally low $(<0.3 \%)$ it shows two peaks at 13 and $25 \mathrm{~cm}$ depths (Figure 5.4B). The bulk samples, $4-25 \mu \mathrm{m}$ and $<4 \mu \mathrm{m}$ fractions have little down-core variation, and the $<4 \mu \mathrm{m}$ fraction shows a slight trend of decreasing OC content with depth.

Again, the greatest down-core variation in $\delta^{13} \mathrm{C}$ values for core U2305 is in the $>25$ $\mu \mathrm{m}$ fraction, with the difference between the lightest and heaviest values being 1.4\%o (Figure 5.4C). Values for the bulk samples, 4-25 $\mu \mathrm{m}$ and $<4 \mu \mathrm{m}$ fractions are generally heavier (less negative) than the $>25 \mu \mathrm{m}$ fraction, and do not show as much down-core variation.

Mid-shelf $(\mathrm{C} / \mathrm{N})$ a ratios are highest in the $>25 \mu \mathrm{m}$ fraction (Figure 5.4D) at $13 \mathrm{~cm}$ and $25 \mathrm{~cm}$ depth, where values are 18.4 and 18.7 respectively. These values suggest an increased input of plant debris and soil carbon (Leithold \& Hope 1999). Bulk samples and finer fractions do not show much down-core variation and $(\mathrm{C} / \mathrm{N}) \mathrm{a}$ values do not exceed 12.4 .

The two clay-rich layers at 13 and $25 \mathrm{~cm}$ depth in core U2305 have similar textural and geochemical characteristics to the flood layer preserved in core U2303, but can not be readily identified in hand specimen or x-radiographs. At this mid-shelf site, evidence of any flood events within the WSS is likely to be a lot more subtle than on the inner shelf.

Additional particle size data were obtained for the top $9 \mathrm{~cm}$ of core U2305 (see section 3.5) for a more detailed examination of changes in particle size content and 
to facilitate the identification of the inner shelf flood layer (U2303, 13-23 cm) if it extended to and was preserved on the mid-shelf.

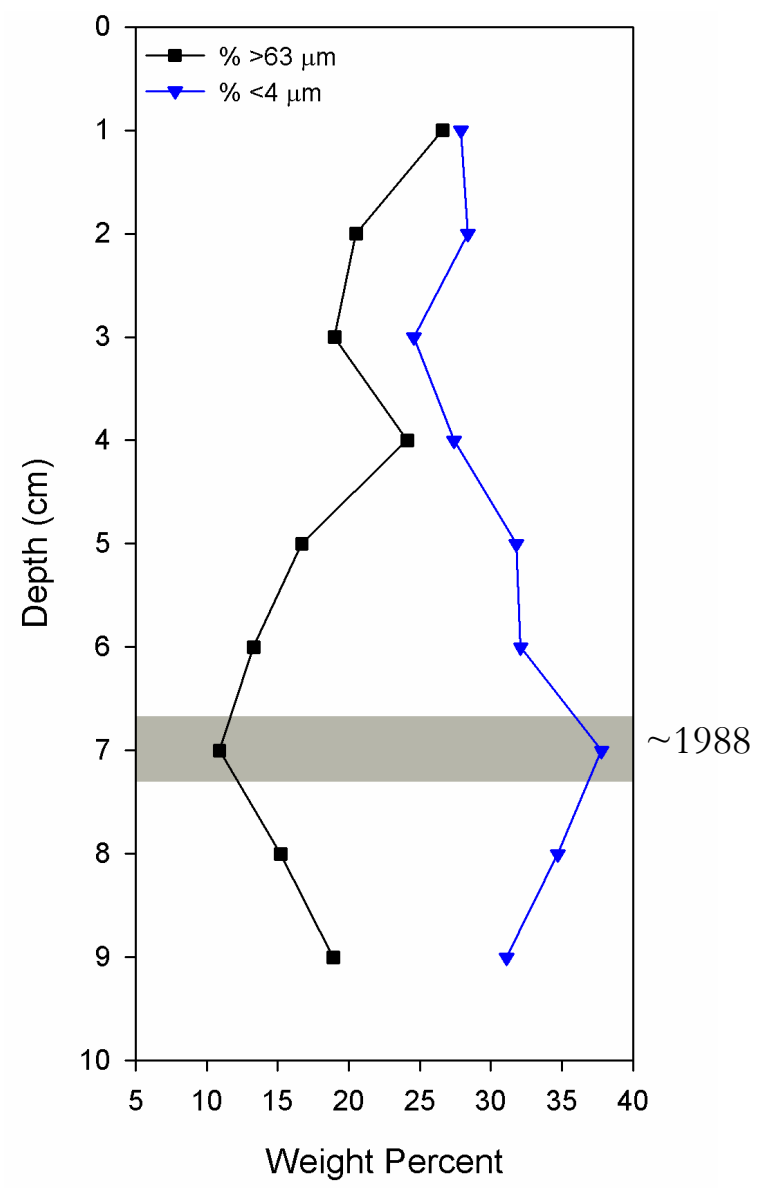

Figure 5.5: Particle size trend for the top $9 \mathrm{~cm}$ of the mid-shelf core (U2305). Age of the clay-rich layer is estimated from average sedimentation rates, using ${ }^{137} \mathrm{Cs}$.

It is evident that there is a clay-rich layer at $7 \mathrm{~cm}$ depth, where the sand content drops to $11 \%$ and the clay reaches $38 \%$ (Figure 5.5). This is comparable to the clay contents of samples at 13 and $25 \mathrm{~cm}$ depth, which were identified as likely flood events (Figure 5.4), thus the layer at $7 \mathrm{~cm}$ may also represent a flood deposit. ${ }^{210} \mathrm{~Pb}$ data, combined with historical records suggest it was most likely associated with Cyclone Bola in March 1988. 


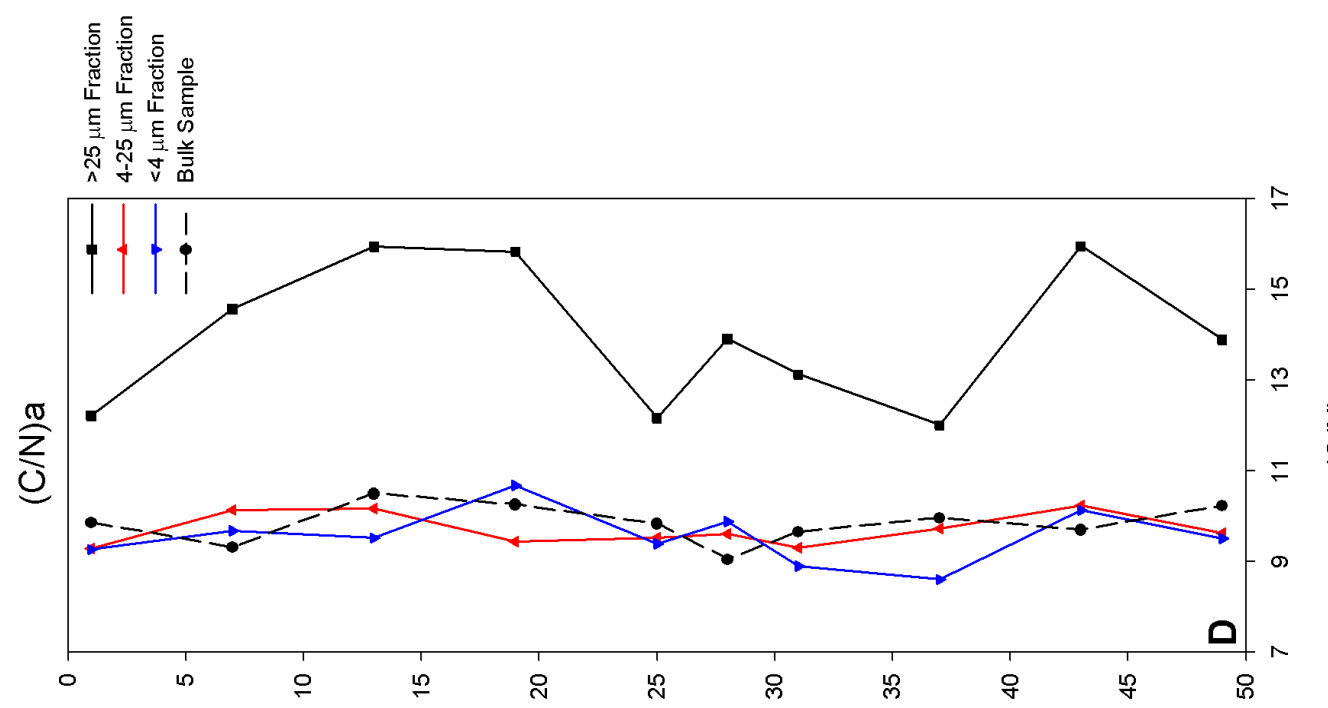

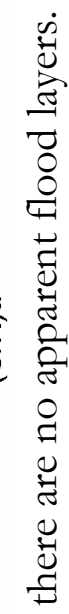

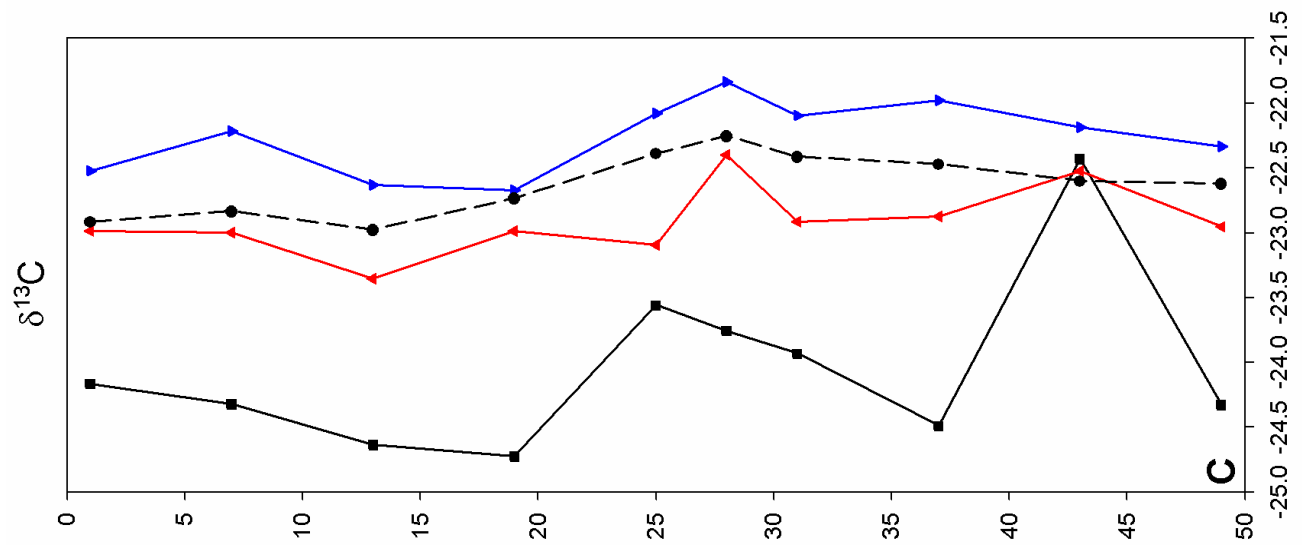

을

$\exists \bar{\Xi}$

ลิ

ôे

O

o 8

茴:

मे ते

হุ

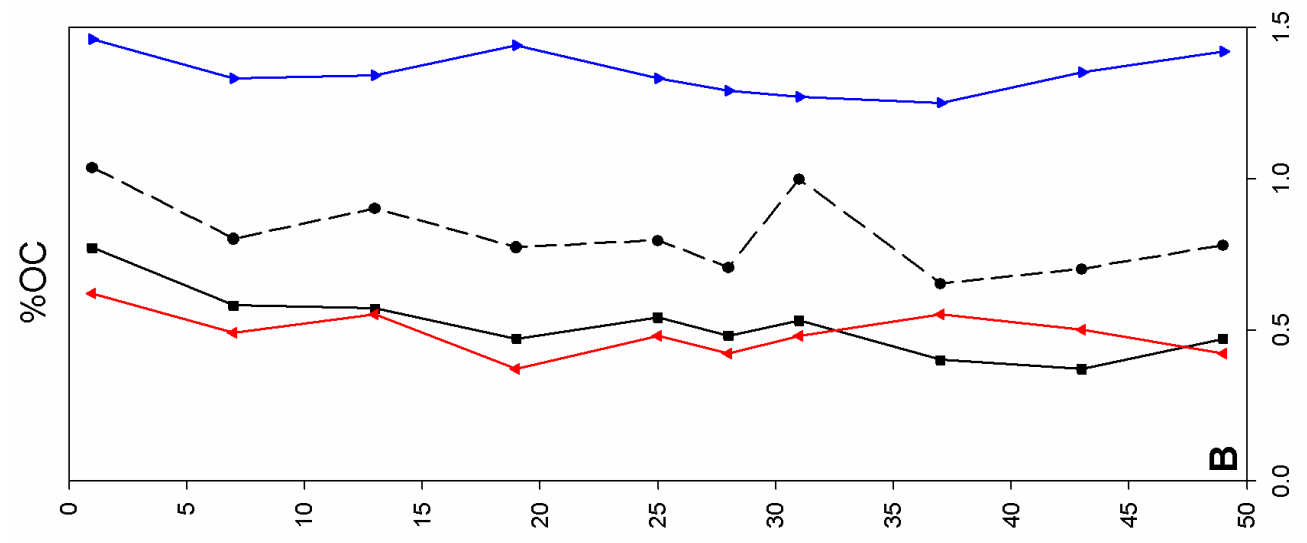

\&

टै त्ञ

क्ष

O

Z

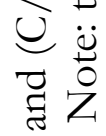

市

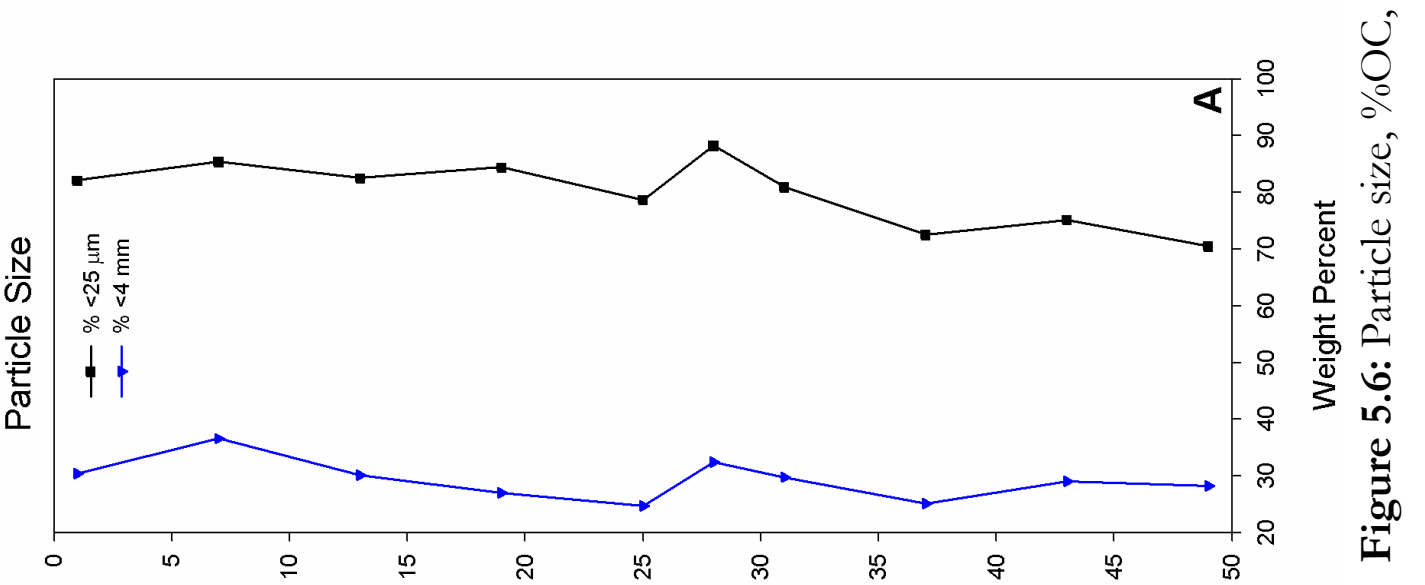

(u०) पұdəव 
Due to an increase in distance from terrestrial source, the sediment in the upper slope core (W697) is markedly finer than that of U2305, with at least $70 \%$ of the sediment in all samples being $<25 \mu \mathrm{m}$ and $\sim 25-30 \%$ being $<4 \mu \mathrm{m}$ (Figure 5.6A). One thin clay-rich layer is present at $27-28 \mathrm{~cm}$ depth, with $88 \%$ of the sample $<25$ $\mu \mathrm{m}$ and $32 \%<4 \mu \mathrm{m}$.

$\% \mathrm{OC}$ values of upper slope sediments are markedly higher in the $<4 \mu \mathrm{m}$ fraction than the 4-25 $\mu \mathrm{m}$ and $>25 \mu \mathrm{m}$ fractions, but there are no obvious peaks or trends (Figure 5.6B). There is very little down-core variation in $\delta^{13} \mathrm{C}$ values in the bulk samples, $<4 \mu \mathrm{m}$ and $4-25 \mu \mathrm{m}$ size fractions for the upper slope core, with values not varying more than $1.0 \%$ within each fraction. The $>25 \mu \mathrm{m}$ fraction has the lightest $\delta^{13} \mathrm{C}$ values and also shows the greatest down-core variation (Figure 5.6C).

Small amounts of particulate OC can have quite marked effects on $(\mathrm{C} / \mathrm{N})$ a values, and as in the shelf cores, the $>25 \mu \mathrm{m}$ fractions of the upper slope sediments have the highest $(\mathrm{C} / \mathrm{N})$ a values $(\sim 12-16)$ and show the greatest down-core variations (Figure 5.6D). The finer fractions and bulk samples show very little down-core variation, with all $(\mathrm{C} / \mathrm{N})$ a values being within the range of 9-11.

Possible flood deposits from the Waipaoa River were not observed on the upper slope. This may in fact be due to the sampling interval being too coarse to identify discrete flood layers at this site, where the sedimentation rate is as low $0.13 \mathrm{~cm} \mathrm{y}^{-1}$. 


\subsubsection{Clay Fraction Surface Areas and Carbon Loading}

To eliminate the influence of particle size variations, the specific surface area (SA) of clay particles was measured (see section 3.9.2) and the \%OC normalised to the $\mathrm{SA}$, to determine the carbon loading (OC:SA). Down-core trends in clay fraction SA and OC:SA for the three marine multi-cores are presented in Figure 5.7.
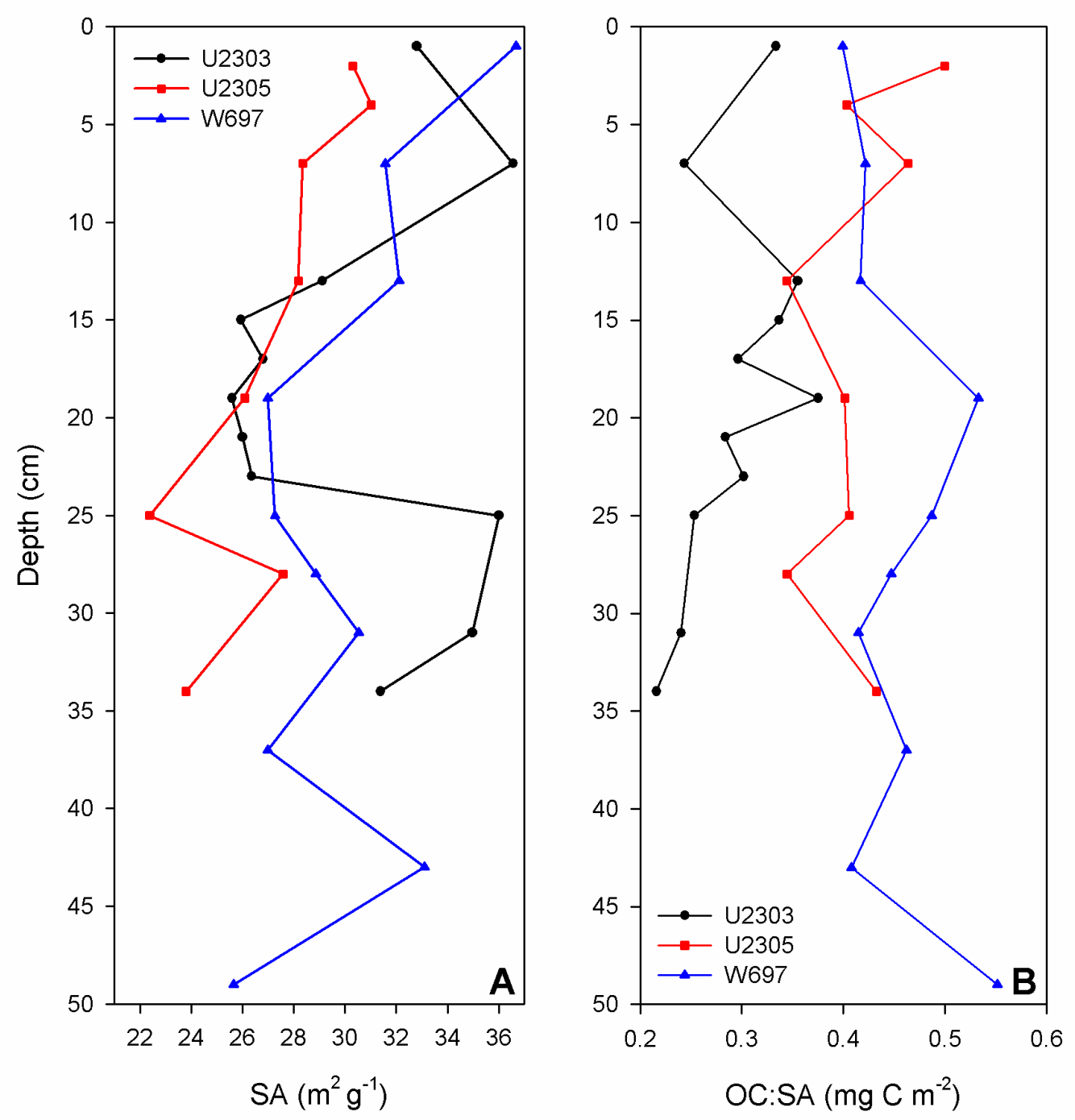

Figure 5.7: Down-core trends in (A) surface area and (B) carbon loading for the inner shelf (U2303), mid-shelf (U2305) and upper slope (W697) clay fractions.

The inner shelf core (U2303) clay fraction surface areas delineate the 13-23 cm clayrich (flood) layer well, with clay particle surface areas being lower than in the sediments above and below. This possibly reflects clay particles in the flood layer being coarser than those in the sediments above and below, or having different mineralogy. Reasons for this are unclear, but may be due to factors such as source, with more severe erosion during floods eroding different clay-bearing sediments, 
and hydraulic sorting of the clay particles during transport from the river to the shelf. Interestingly, this trend was not evident in the Eel Shelf sediments studied by Leithold et al. (2005), where there was found to be no difference between the surface areas of clays in flood and non-flood layers. When the OC content is normalised to the SA (OC:SA) for the $<4 \mu \mathrm{m}$ fraction, there is not such a marked trend, though the highest OC:SA value $(0.38)$ is in the middle of the flood layer, at $19 \mathrm{~cm}$ depth. This differs to findings of Leithold and Blair (2001) for the Eel Shelf, in which clay particles in flood sediments had lower OC:SA values than those in non-flood sediments, which was attributed to the loss of terrestrial OC from particles as they entered the marine environment, and the reloading of marine OC during gradual sedimentation (Leithold \& Blair 2001). The reason for the higher OC:SA of flood layer clays on the Poverty Bay shelf may be due to the markedly higher OC content and smaller surface areas of terrestrially-derived flood sediments compared to non-flood marine sediments, resulting in high OC:SA values for those flood layer clays.

Similar to the inner shelf flood layer, clay particles in the thin clay-rich layer at $25 \mathrm{~cm}$ depth on the mid-shelf (U2305) have the smallest SA of the clay fractions for that core, again reflecting the presence of larger clay particles. The other layer at $13 \mathrm{~cm}$ depth does not have a particularly small SA, but does have one of the lowest OC:SA values within the core. This more resembles data of Leithold and Blair (2001) and Leithold et al. (2005).

The clay fractions of samples in core U2305 generally show a decrease in SA with depth, ranging from $\sim 30-23 \mathrm{~m}^{2} \mathrm{~g}^{-1}$. Leithold et al. (2005) observed a similar trend in Eel shelf sediments, and found it could not be attributed to a change in particle size or clay mineralogy. Rather, it was considered likely to be due to iron diagenetic processes, in particular, a down-core production of pyrite and loss of ferrihydrite, which have a higher SA.

In accord with a general sediment fining across the shelf and slope, the clay fractions of upper slope sediments (core W697) have higher SA values (up to $~ 36.7$ $\left.\mathrm{m}^{2} \mathrm{~g}^{-1}\right)$ than the shelf cores, and similarly show a general decrease with core depth. 
OC:SA values show little down-core variation, but are higher than in other cores, with values between $\sim 0.40-0.55 \mathrm{mg} \mathrm{C} \mathrm{m}^{-2}$.

\subsubsection{Organic Carbon Sources}

Simple mass balance calculations can be used to estimate the relative proportions of terrestrial and marine $\mathrm{OC}$, but first, terrestrial and marine end-member values must be established. The mass balance method used in this study follows that used by Blair et al. (2003). The $\delta^{13} \mathrm{C}$ signature of the marine end-member was determined by plotting the $\% \mathrm{OC}$ values of surface marine samples against the $\% \mathrm{OC}$ multiplied by their corresponding $\boldsymbol{\delta}^{13} \mathrm{C}\left(\% \mathrm{OC} * \boldsymbol{\delta}^{13} \mathrm{C}\right)$, for bulk samples and clay fractions. The plots reveal a linear relationship with slope $\delta_{\mathrm{m}}$, providing the isotopic signature of modern marine OC being added to the particles (Figure 5.8). $\boldsymbol{\delta}_{\mathrm{m}}$ values are $-22.3 \%$ o and $-19.1 \%$ for the bulk samples and clay fractions respectively. Ideally these two end-member values would have been applied to their respective sediment fractions, but for this study it was decided to use the mean value of $-21.0 \%$ as the marine OC end-member in subsequent mass balance calculations.
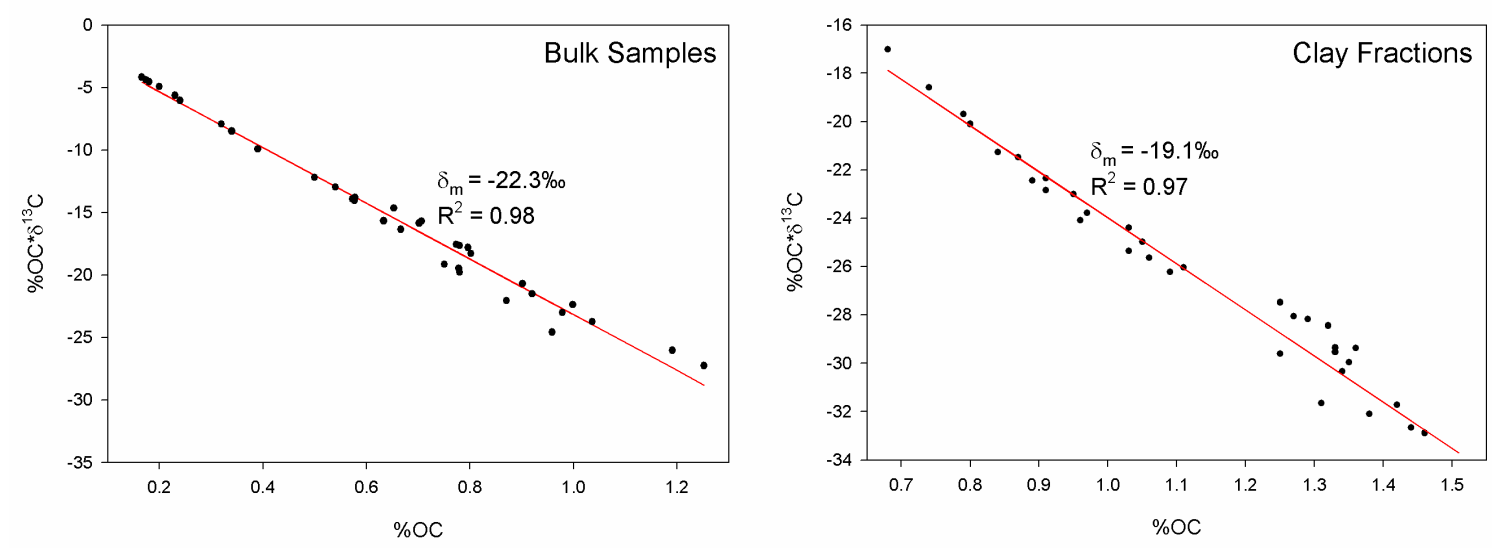

Figure 5.8: Determination of marine OC isotopic signature from bulk samples and clay fractions of shelf and slope sediments.

The $\delta^{13} \mathrm{C}$ signature of the terrestrial end-member was similarly determined, using data for a series of bulk suspended sediment samples collected from three sites within the Waipaoa River catchment (Kanakanaia, Te Arai and Omapere) during ambient conditions. The $\% \mathrm{OC}$ values were similarly plotted against $\% \mathrm{OC} * \delta^{13} \mathrm{C}$ for the samples from each site, with the slope $\left(\boldsymbol{\delta}_{t}\right)$ indicating the isotopic signature of 
modern terrestrial OC being added to the particles. $\delta_{\mathrm{t}}$ at Kanakanaia and Te Arai is $-27.7 \%$, and at Omapere is $-28.5 \%$ (Figure 5.9). From these results, a mean of $28.0 \%$ was subsequently used as the terrestrial OC end-member isotopic signature.
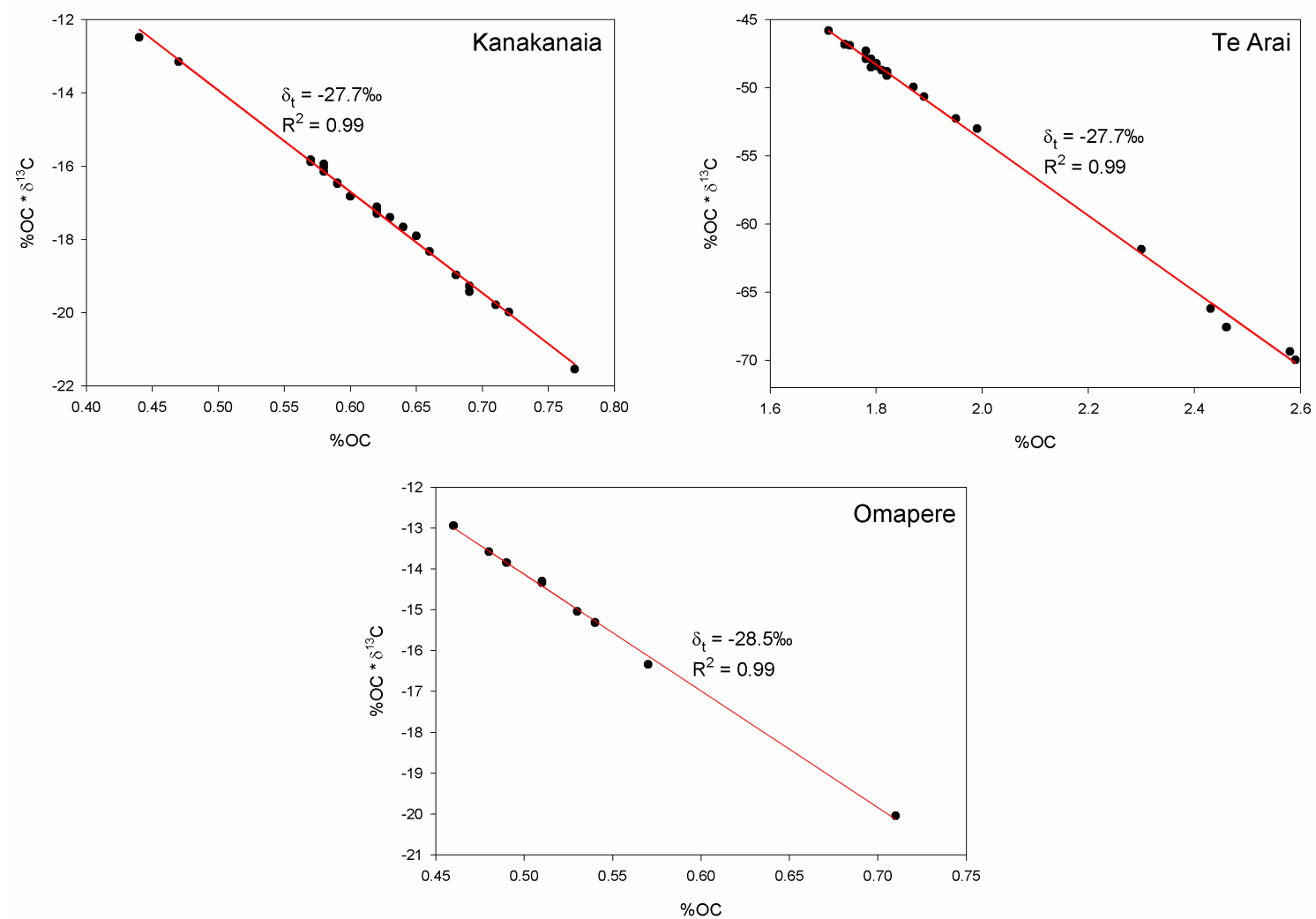

Figure 5.9: Determination of terrestrial OC isotopic signature, from suspended sediment samples collected at the Kanakanaia, Te Arai and Omapere sites.

Using derived terrestrial and marine end-member values, and assuming no temporal change, mass balances were estimated to define relative contributions of terrestrial and marine $\mathrm{OC}$ to the shelf and slope sediments. The terrestrial fraction of the total $\% \mathrm{OC}$ for each size fraction of the shelf and slope cores has been plotted (Figure 5.10) to illustrate the greater input of terrestrial OC associated with flood sediments. 


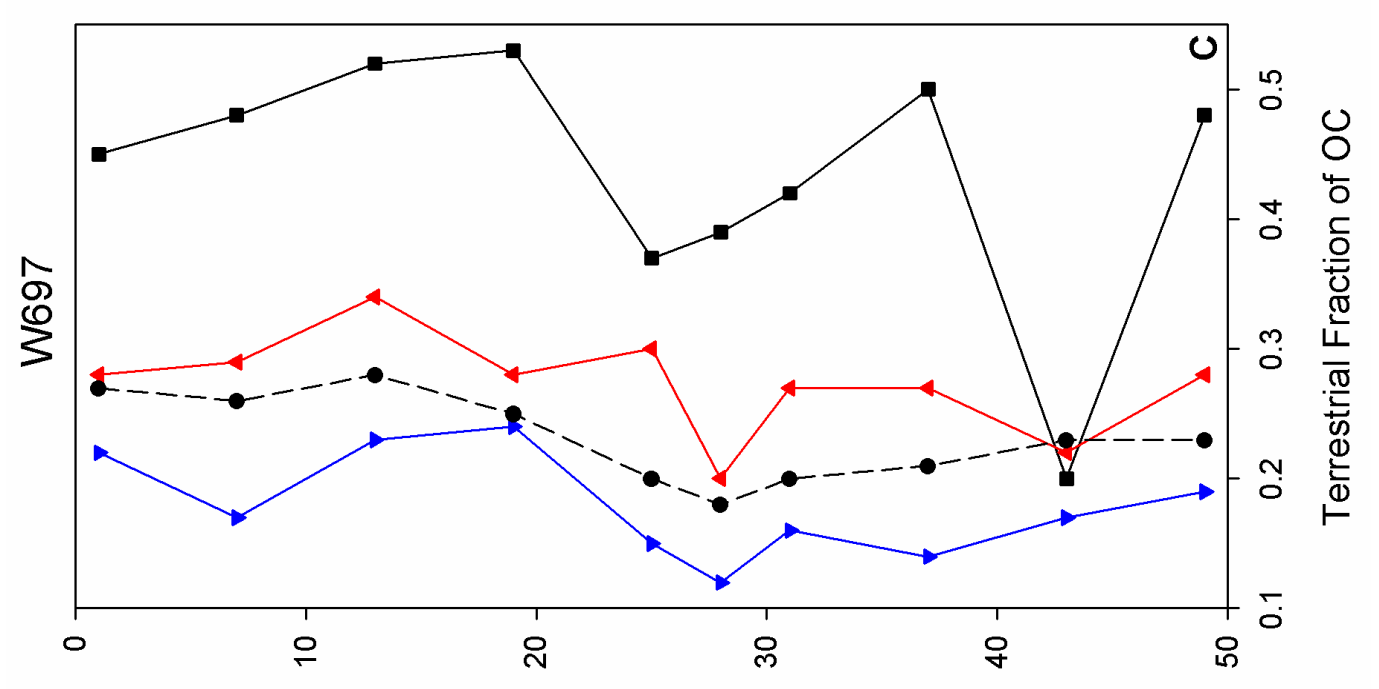

7
0
0
4

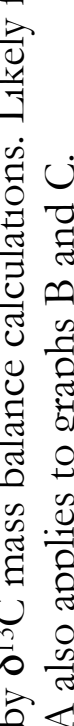

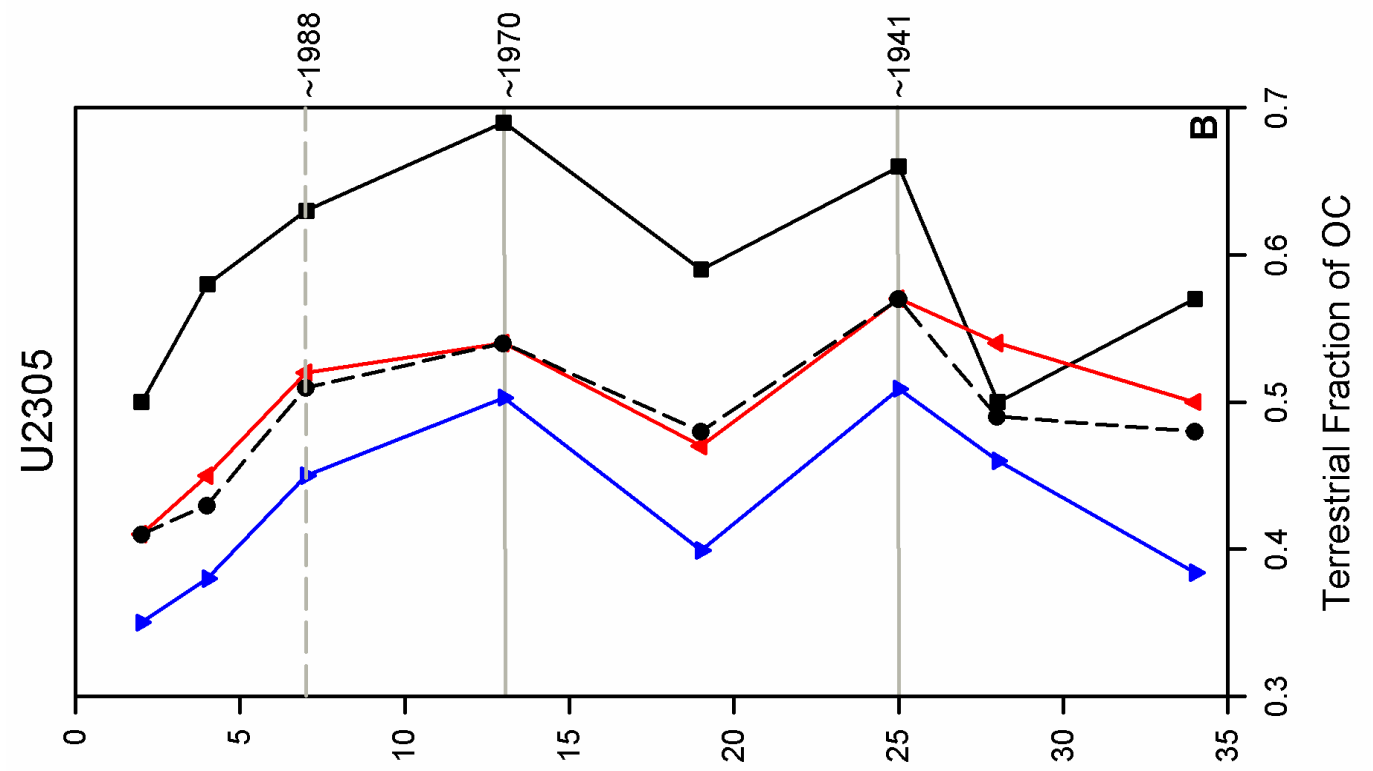

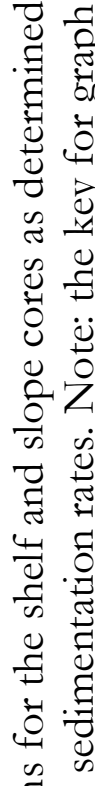

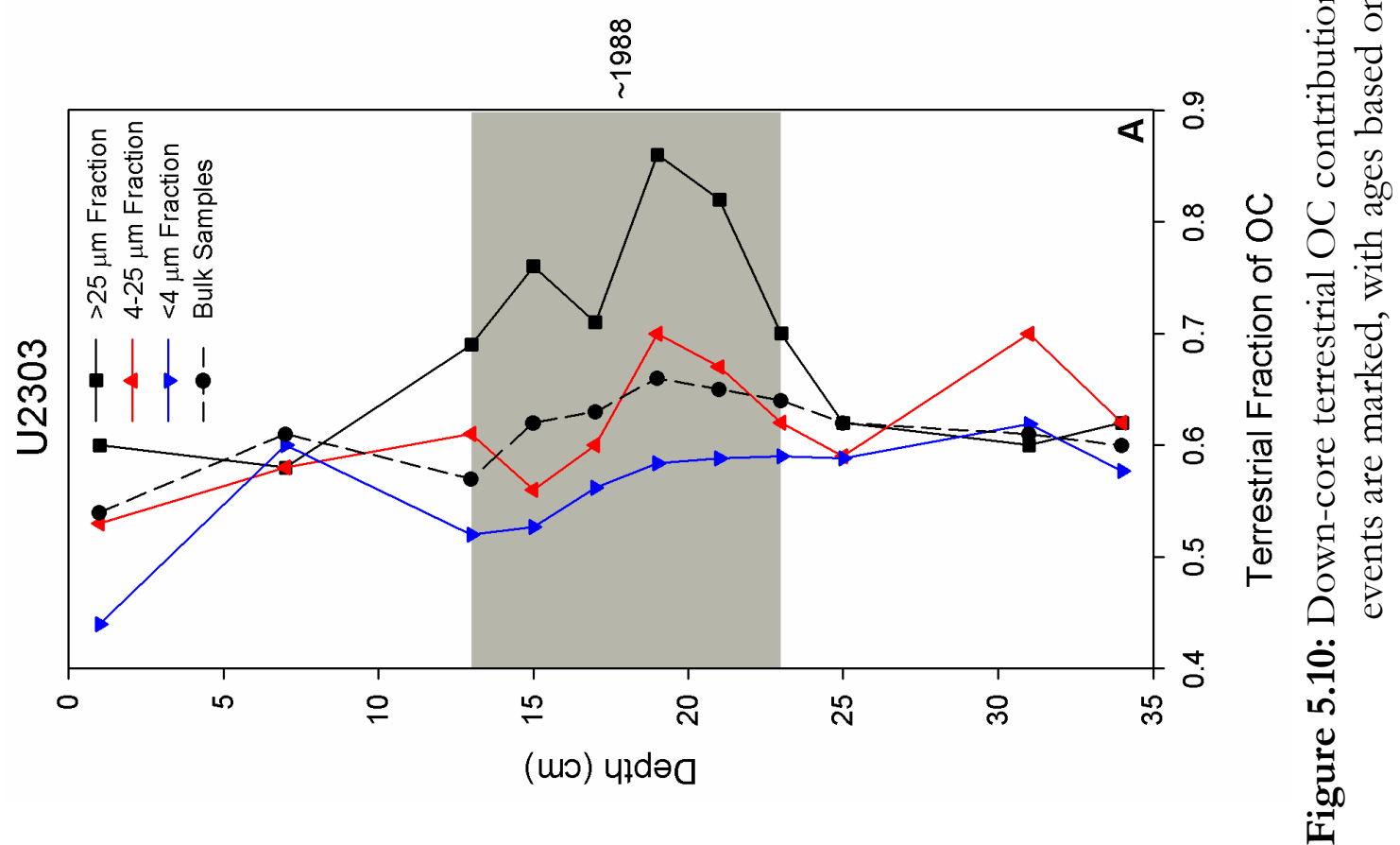


The pulse of terrestrial OC associated with the 13-23 cm clay-rich layer within the inner shelf sediments (core U2303) is well defined by the 4-25 $\mu \mathrm{m}$ and $>25 \mu \mathrm{m}$ fractions (Figure 5.10A). In both cases, the greatest proportion of terrestrial OC is in the $19 \mathrm{~cm}$ sample, i.e. in the middle of the clay-rich layer. The $<4 \mu \mathrm{m}$ fraction does not show much down-core variation in the contribution from terrestrial OC, ranging from $44 \%$ to $62 \%$ of the total OC content. These trends suggest that the source, and therefore biogeochemical characteristic of clay-sized particles on the inner shelf, does not vary greatly between flood and non flood conditions, and the greatest influx of terrestrial OC during flood events is through the transfer of coarse (i.e. $>25 \mu \mathrm{m}$ ) partially decomposed plant matter.

The character of the three flood deposits at $7 \mathrm{~cm}, 13 \mathrm{~cm}$ and $25 \mathrm{~cm}$ core depth on the mid-shelf (U2305) is confirmed by peaks in the terrestrial OC fraction for all size fractions at those depths (Figure 5.10B). The terrestrial contribution to the total OC is less on the mid-shelf than the inner shelf, for all size fractions. This probably reflects increased distance from point source resulting in enhanced replacement of some terrestrial OC by marine OC - a process that is facilitated by lower rates of burial $\left(0.42\right.$ vs $\left.0.52 \mathrm{~cm} \mathrm{y}^{-1}\right)$.

The upper slope core (W697) has yet smaller contributions from terrestrial OC sources, with it making up less than half of the total \%OC in most samples (Figure 5.10C). The coarse silt fraction $(>25 \mu \mathrm{m})$ again has the greatest contribution from terrestrial $\mathrm{OC}$, with peaks at $19 \mathrm{~cm}$ and $37 \mathrm{~cm}$, while the bulk samples and fine fractions show relatively little down-core variation. 


\section{$5.3 \quad$ DISCUSSION}

From the evidence presented (clay content, \%OC, $(\mathrm{C} / \mathrm{N}) \mathrm{a} \& \delta^{13} \mathrm{C}$ ), it is apparent that a flood event is preserved in the inner shelf stratigraphy. It occurred after 1955. Three thin flood layers are also present in the mid-shelf stratigraphy, estimated to have been deposited in about 1941 and 1970 and 1988, while no obvious flood layers have been identified on the upper continental slope. Evidence for hyperpycnal flows, the likely transport mechanism of large flood deposits, has not been identified beyond the mid-shelf within the transect of cores examined for this study. It is possible that either the hyperpycnal flows peter out about mid-shelf, or more likely, that they follow topographic lows, and the cores were taken outside of a favoured hyperpycnal pathway.

\subsubsection{Identification of flood layers}

Inner continental shelf

Several characteristics suggest that the $10 \mathrm{~cm}$ thick clay-rich layer preserved on the inner shelf (core U2303) is a flood deposit:

(i) The layer is sharply defined by its pale grey colour and markedly higher clay content (up to 95\%) than surrounding sediments (Figure 5.3A). Such a particle size characteristic has previously been attributed to the rapid accumulation of flocculated sediment following a flood (Drake 1999). However, unlike the Mediterranean hyperpycnal deposits identified by Mulder et al. (2001), which are composed of a coarsening-upward unit capped by a fining-upward unit, the flood layer in U2303 contains a slight fining-upward unit overlaid by a coarsening-upward unit, i.e. the flood layer is finest in the middle. This may be attributable to either current and/or wave-induced mixing of the flood layer following deposition (see section 5.2.1).

(ii) Coarse silt $(>25 \mu \mathrm{m}) \delta^{13} \mathrm{C}$ values are dominated by terrestrial sources $(\sim-27 \%$ ), whereas non-flood sediments have values of $\sim-25 \%$. Mass balance calculations indicate a greater contribution from terrestrial OC within the clay-rich layer, particularly in the coarsest size fraction, which contained a significant amount of terrestrial plant material.

(iii) The large amount of coarse $\mathrm{OC}(>25 \mu \mathrm{m})$ in a layer that is finer grained than surrounding sediments, and the preservation of immature plant material in the clayrich layer, indicates rapid emplacement and burial. 
(iv) ${ }^{210} \mathrm{~Pb}$ data confirm that deposition of the layer was rapid (i.e. a near-vertical $210 \mathrm{~Pb}$ profile).

Collectively, these trends indicate a rapid input of terrestrial sediment and coarse OC, as may be expected from a large flood event. The uppermost position of the layer and an estimated emplacement date of 1980 suggest it most likely resulted from Cyclone Bola in March 1988, a record storm in which the Waipaoa River delivered about three times its annual suspended sediment load in 6 days, inundating the continental shelf with mud (Foster \& Carter 1997). Anecdotal evidence suggests the mud was probably emplaced as a hyperpycnal flow, although the complex grain size distribution is not totally consistent with hyperpycnites, reflecting postdepositional reworking.

By using the age limit provided by ${ }^{137} \mathrm{Cs}$ at the base of core U2303, and assigning the flood layer to Cyclone Bola in 1988, it can be illustrated that the sedimentation rate was markedly higher following Cyclone Bola than it was previously. With the 23-34 $\mathrm{cm}$ section of the core being constrained by ages of 1988 and 1955, $11 \mathrm{~cm}$ of sediment was deposited in the 33 year period, giving a sedimentation rate of $\sim 0.3$ $\mathrm{cm} \mathrm{y}^{-1}$. Similarly, the upper $13 \mathrm{~cm}$ of the core was deposited between 1988 and 2001, yielding a higher sedimentation rate of $\sim 1 \mathrm{~cm} \mathrm{y}^{-1}$. Such an increase in sedimentation supports the finding of Trustrum et al. (1999) and Hicks et al. (2000) that the Waipaoa River suspended sediment load remained elevated for several years following Cyclone Bola. This was due to the remobilisation of sediment held in temporary storage sites (e.g. debris tails, colluvial footslopes and unstable river banks).

Further evidence for the identification of the flood layer is provided by its biogeochemical similarity to sediment also deposited on the floodplain during Cyclone Bola (Table 5.3). 
Table 5.3: Comparison of $\% \mathrm{OC}, \delta^{13} \mathrm{C}$ and $(\mathrm{C} / \mathrm{N})$ a for bulk samples and clay fractions of flood sediments (shaded boxes) and non-flood sediments (no shading) within the floodplain and shelf cores.

\begin{tabular}{lccccccc}
\hline & $\begin{array}{c}\text { Year of } \\
\text { deposition }\end{array}$ & $\begin{array}{c}\text { Bulk } \\
\text { \%OC }\end{array}$ & $\begin{array}{c}\text { Bulk } \\
\boldsymbol{\delta}^{13} \mathbf{C}\end{array}$ & $\begin{array}{c}\text { Bulk } \\
(\mathbf{C} / \mathbf{N}) \mathbf{a}\end{array}$ & $\begin{array}{c}<4 \mu \mathrm{mm} \\
\mathbf{\% O C}\end{array}$ & $\begin{array}{c}<4 \mu \mathrm{m} \\
\boldsymbol{\delta}^{\mathbf{1 3}} \mathbf{C}\end{array}$ & $\begin{array}{c}<4 \mu \mathrm{m} \\
(\mathbf{C} / \mathbf{N}) \mathbf{a}\end{array}$ \\
\hline Floodplain & 1988 (Bola) & 0.49 & -25.09 & 12.6 & 1.32 & -26.23 & 10.6 \\
$\mathbf{U} 2303 \mathbf{1 9} \mathbf{~ c m}$ & 1988 (Bola) & 0.96 & -25.65 & 11.9 & 0.96 & -25.09 & 9.4 \\
$\mathbf{U} 2305 \mathbf{1 3} \mathbf{~ c m}$ & $\sim 1970$ & 0.63 & -24.78 & 10.8 & 0.97 & -24.52 & 9.4 \\
$\mathbf{U} 2305 \mathbf{2 5} \mathbf{~ c m}$ & $\sim 1941$ & 0.78 & -25.01 & 12.2 & 0.91 & -24.56 & 10.6 \\
$\mathbf{U} 2303 \mathbf{3 1} \mathbf{~ c m}$ & Post-1954 & 0.17 & -25.29 & 8.1 & 0.84 & -25.33 & 8.6 \\
$\mathbf{U} 2305 \mathbf{2 8} \mathbf{~ c m}$ & $\sim 1934$ & 0.50 & -24.45 & 9.6 & 0.95 & -24.22 & 10.4 \\
\hline
\end{tabular}

When comparing bulk samples from the Cyclone Bola layers on the floodplain and in core U2303 $(19 \mathrm{~cm})$, it is apparent that the marine sample has higher \%OC and slightly lighter $\delta^{13} \mathrm{C}$, while in the clay fractions it is the floodplain sample that has the higher $\% \mathrm{OC}$ and lighter $\delta^{13} \mathrm{C}$. This probably reflects the greater input of coarse particulate OC to the bulk samples. If this is the case, it supports the value of using clay sized particles rather than bulk samples for determining the nature and history of the OC (this study; Blair et al. 2003). Though the coarse silt fractions can contain reasonable proportions of the particulate $\mathrm{OC}$ associated with both floodplain and marine samples, the characteristics of that size fraction have not been investigated in any detail for this study.

A SPOT image taken 18 days after Cyclone Bola (Figure 5.11) outlines the Waipaoa plume, which has moved anticlockwise around the coast and across the entrance of Poverty Bay due to a gyre within Poverty Bay (L Carter 2005, pers. comm.). It also depicts wisps of suspended sediment extending directly offshore, before being entrained and eventually merging within a northeastward turbid flow, the seaward boundary of which is $5 \mathrm{~km}$ offshore (Carter \& Gomez In Review). This image illustrates the influence of waves and offshore currents in the resuspension and redistribution of flood sediments, at least in shallow coastal waters. 


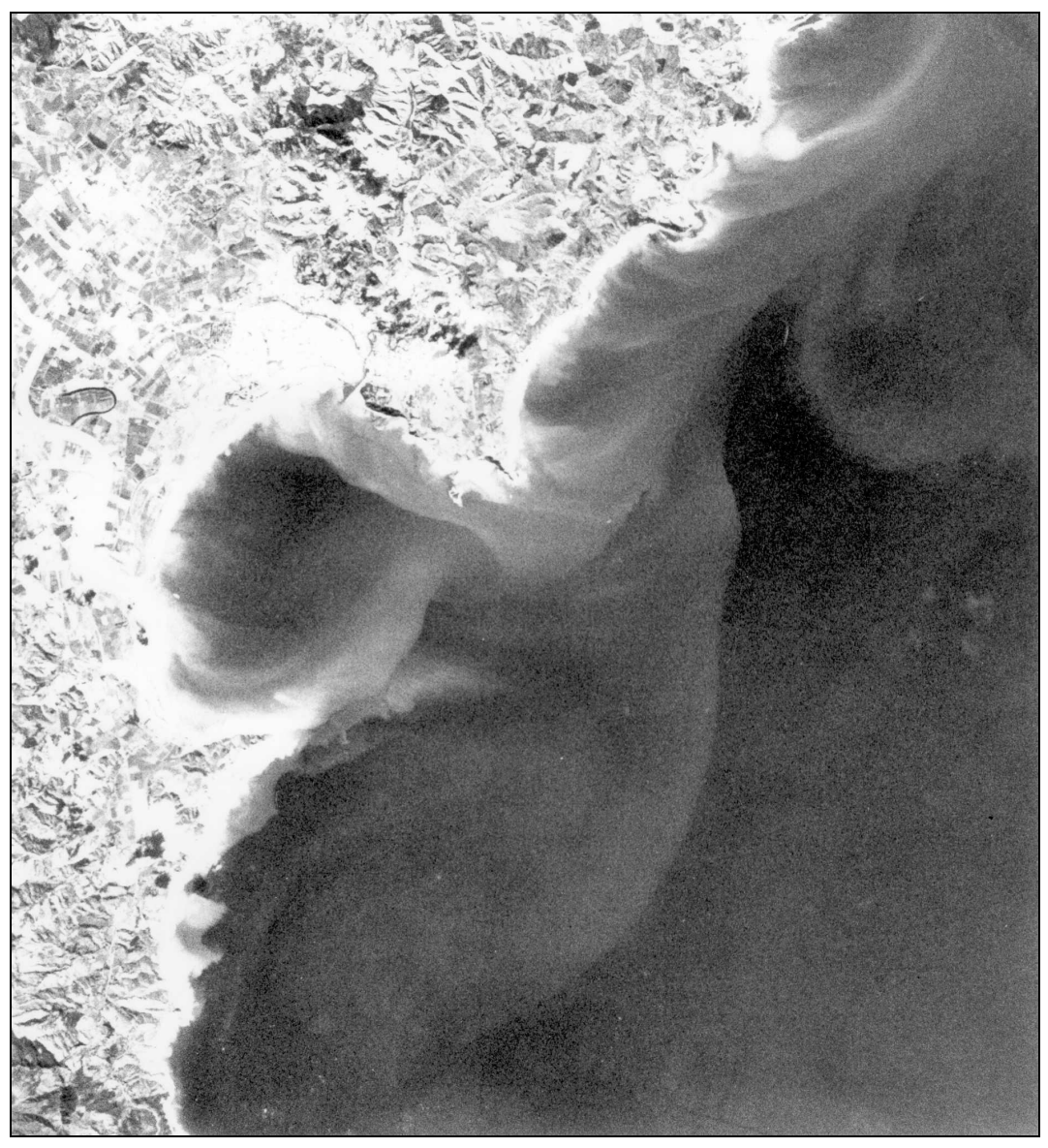

Figure 5.11: SPOT image of Poverty Bay, taken 18 days after Cyclone Bola (from Carter \& Gomez (In Review)).

Foster and Carter (1997) reported anecdotal observations that Cyclone Bola resulted in a fluid mud layer up to $\sim 2 \mathrm{~m}$ deep being deposited onto the continental shelf, yet in core $\mathrm{U} 2303$ only $10 \mathrm{~cm}$ of the flood layer remains. Although a certain amount of compaction cannot be ruled out, the fact that such a small proportion of the layer remains also potentially provides further evidence for the erosion and reworking of sediments through wave action, or remobilisation of the fluid mud off the shelf. The much finer layer $(\sim 1 \mathrm{~cm})$ preserved on the mid-shelf (U2305) also suggests that the probable Bola hyperpycnal flow may have petered out as it moved offshore from the river mouth, or most bypassed the shelf into Poverty Bay re-entrant. Wright et al. (1986) suggested that hyperpycnal plumes might be more confined than hypopycnal plumes, which can expel sediment great distances within extensive surface plumes (see data in Carter \& Gomez (In Review)). 


\section{Mid continental shelf}

The layers at $7 \mathrm{~cm}, 13 \mathrm{~cm}$ and $25 \mathrm{~cm}$ depth on the mid-shelf (core U2305) have some characteristics similar to that on the inner shelf. The layers are finer than the rest of the core and the $\% \mathrm{OC}$ of the bulk sample is greatest at these depths. Bulk samples also have stronger terrestrial (more negative) $\delta^{13} \mathrm{C}$ signatures than the nonflood sediments, e.g. for core U2303 the flood layer has a value of $-25.65 \%$, compared to $-25.29 \%$ for the non-flood sediment, and for U2305 the layers at 13 and $25 \mathrm{~cm}$ have $\delta^{13} \mathrm{C}$ values of $-24.78 \%$ and $-25.01 \%$ respectively, compared to the non-flood value of $-24.45 \%$ (Refer Table 5.3 and Figures 5.3 \& 5.4).

The $(\mathrm{C} / \mathrm{N})$ a values of bulk samples show good differentiation between the flood and non-flood sediments, with the Cyclone Bola floodplain deposit and flood layers in cores U2303 and U2305 having values between 10.8 and 12.6, while non-flood samples from cores U2303 and U2305 have lower (C/N)a values of 8.1 and 9.6 respectively. The higher values are probably associated with the increased input of plant material during the flood. These trends suggest the clay-rich layer in U2303 and the fine-grained layers in U2305 represent increased inputs of terrestrial sediment and plant matter. The higher $(\mathrm{C} / \mathrm{N})$ a values of the bulk samples, compared to those of the clay fractions, suggest that organic matter intimately associated with the clay particles may be protected from decomposition, compared to the particulate organic matter found to be most prevalent in the $>25 \mu \mathrm{m}$ fraction of flood deposits.

\section{Upper continental slope}

There is little evidence for flood deposits on the upper continental slope (W697). However, several comments are pertinent. The graphs of $\% \mathrm{OC}$ and $\delta^{13} \mathrm{C}$ (Figure 5.6) show fewer perturbations than those of the mid-shelf cores (i.e. the variations are moderated as the sediment is transported across the shelf to the upper slope and deposited more slowly). $\% \mathrm{OC}$ is higher in the $<4 \mu \mathrm{m}$ fraction (due to the greater SA available for OC adherence) than the 4-25 $\mu \mathrm{m}$ and $>25 \mu \mathrm{m}$ fractions, but there are no obvious peaks or trends in any of the 3 size fractions. The sediment at $17-18 \mathrm{~cm}$ depth has $\% \mathrm{OC}$ and $\delta^{13} \mathrm{C}$ values that are slightly more terrestrial in character than 
the remaining samples, though to a much lesser extent than for the clay-rich layers in cores U2303 and U2305.

Although a Cyclone Bola flood layer has been identified on the inner shelf (U2303, $13-23 \mathrm{~cm})$ and mid-shelf $(\mathrm{U} 2305,7 \mathrm{~cm})$ it has not proved possible to trace it onto the continental slope. This may be due to several factors: Firstly, any flood-derived fluid mud layers may be channelled off the continental shelf by gullies, thus bypassing the upper slope core site, as is the case with the Eel Canyon (Mullenbach et al. 2004). Secondly, being further from source, flood discharges are likely to run out of energy and the flood layer peter out before reaching the slope. Thirdly, the upper slope site is in the pathway of the East Cape Current, which may prevent some burial and preservation of flood deposits. And fourthly, sedimentation on the continental slope can be highly variable, due to the nature of canyon incision, mass movement and other slope processes.

\subsection{CONCLUSIONS}

Continental margins are important reservoirs in the global carbon cycle, especially those with large riverine inputs (Mackenzie et al. 1998) such as shelves of small mountainous river systems (Milliman \& Syvitski 1992; Ludwig et al. 1996; Leithold \& Hope 1999; Lyons et al. 2002).

Situated on the active collisional East Coast Continental Margin, the Waipaoa River delivers an average $\sim 15 \mathrm{Mt}^{-1}$ of suspended sediment. Most is dispersed by hypopycnal flows, but intermittently by hyperpycnal flows also. In March 1988, extreme flood river discharge associated with Cyclone Bola most likely produced a hyperpycnal plume, which is recorded as a $\sim 10 \mathrm{~cm}$ thick layer at $13-23 \mathrm{~cm}$ depth on the inner shelf and a $\sim 1 \mathrm{~cm}$ thick layer at $7 \mathrm{~cm}$ depth on the mid-shelf.

The flood layer deposited rapidly and was also quickly buried by marine sediments. Accordingly the associated OC has an isotopic signature characteristic of its terrestrial source. By comparison, OC associated with sediments above and below the flood layer have a less dominant terrestrial signature, due to more time spent in 
the seabed surface mixed layer and greater exposure to local organic productivity (Leithold \& Hope 1999).

While flood events such as Cyclone Bola have a large impact on sediment transport and deposition, the highly erodible rock types and active gullies of the WSS result in the river having a high suspended sediment load under all conditions. Therefore, the ambient conditions are also important as they contribute a far greater proportion of the sediments to the marine environment in the longer timeframes than the infrequent large events such as Cyclone Bola. However, the amount of terrestrial OC that is transported offshore in a single large event has been shown to be significant, and if future climate changes result in more frequent storm events, more terrestrial OC will be transferred and buried offshore. 


\section{CHAPTER 6: TRANSFORMATION OF ORGANIC CARBON SIGNATURE ACROSS THE CONTINENTAL SHELF \& SLOPE}

\subsection{INTRODUCTION}

It has been mooted that continental margins, particularly those dominated by large rivers, are the greatest storage sites of particulate organic carbon (POC), with an estimated $80-85 \%$ of global carbon (C) burial currently occurring in continental margins, mainly in river-dominated ocean margin environments (Berner 1982; Hedges \& Keil 1995). But as expressed in Chapter 5, the continental shelves offshore from small mountainous river systems are also important reservoirs of organic carbon (OC). They are dynamic regions that receive inputs of both terrestrially and marine sourced OC, with rivers providing the major conduits for the transfer of terrestrial OC to marine sediments (McKee 2003). However, the long-standing issue still remains as to why a large amount of terrestrial OC is exported at continental margins yet is not easily recognisable in the marine environment.

While the transport of terrestrial OC from land to ocean has been well studied (e.g. Milliman et al. 1984; Schubert \& Stein 1996; Hedges et al. 1997; Keil et al. 1997; Leithold \& Hope 1999; Schlünz \& Schneider 2000; Bauer et al. 2001; Leithold \& Blair 2001; McKee 2003; Blair et al. 2003; Leithold et al. 2005), its fate at riverdominated continental margins remains inadequately understood, due to OC sources at the land-ocean interface being poorly quantified and controls on depositional processes (remineralisation, export, burial) and relative fluxes being poorly understood and constrained (McKee 2003). It has been estimated that up to $430 \times 10^{12} \mathrm{~g} \mathrm{C} \mathrm{yr}^{-1}$ of terrestrial OC are transported to the world's oceans, though as little as $\sim 10 \%$ is subsequently buried in marine sediments (Schlünz \& Schneider 2000).

This chapter integrates results from Chapters 4 and 5, which indicate that some flood events emanating from the Waipaoa River can be identified within the continental shelf sediments (Chapter 5). The transport of large quantities of 
terrestrial sediment and associated OC to the shelf and slope make the Waipaoa Sedimentary System (WSS) an ideal location for studying the transformation of terrestrial OC once discharged to the marine environment. Using a transect of cores across the Poverty Bay continental shelf and slope to track the transfer of sediment and OC (see Chapter 3), this section of the study addresses two important research questions:

- Is terrestrial OC lost or preserved as sediment is transported from its source to its marine sink?

- What changes in biogeochemical signatures occur at various OC depositional sites along the source to sink system that identify contributions from marine sources?

\subsection{RESULTS}

\subsubsection{Offshore Trends}

To determine changing OC characteristics at various depositional sites, correlative sediments from the floodplain, shelf and slope were analysed for $\% \mathrm{OC}, \delta^{13} \mathrm{C}$, $(\mathrm{C} / \mathrm{N}) \mathrm{a}$ and OC:SA. The floodplain sample was collected straight after its deposition in August 2002, while the shelf and slope samples represent the $1 \mathrm{~cm}$ surface layer of the 6 cores collected from a range of water depths. Results are presented in Figure 6.1. 


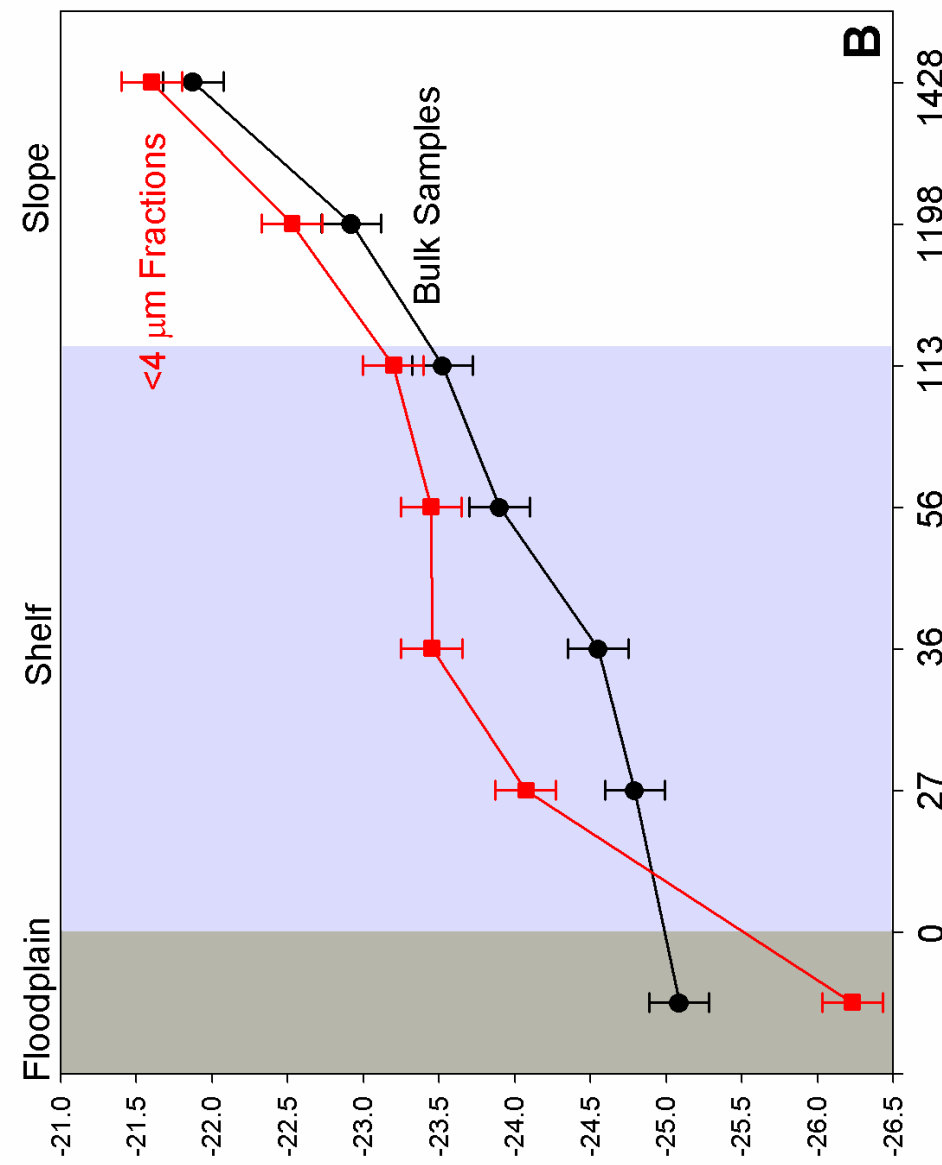

(o\%) $\supset_{\varepsilon l} \mathrm{Q}$

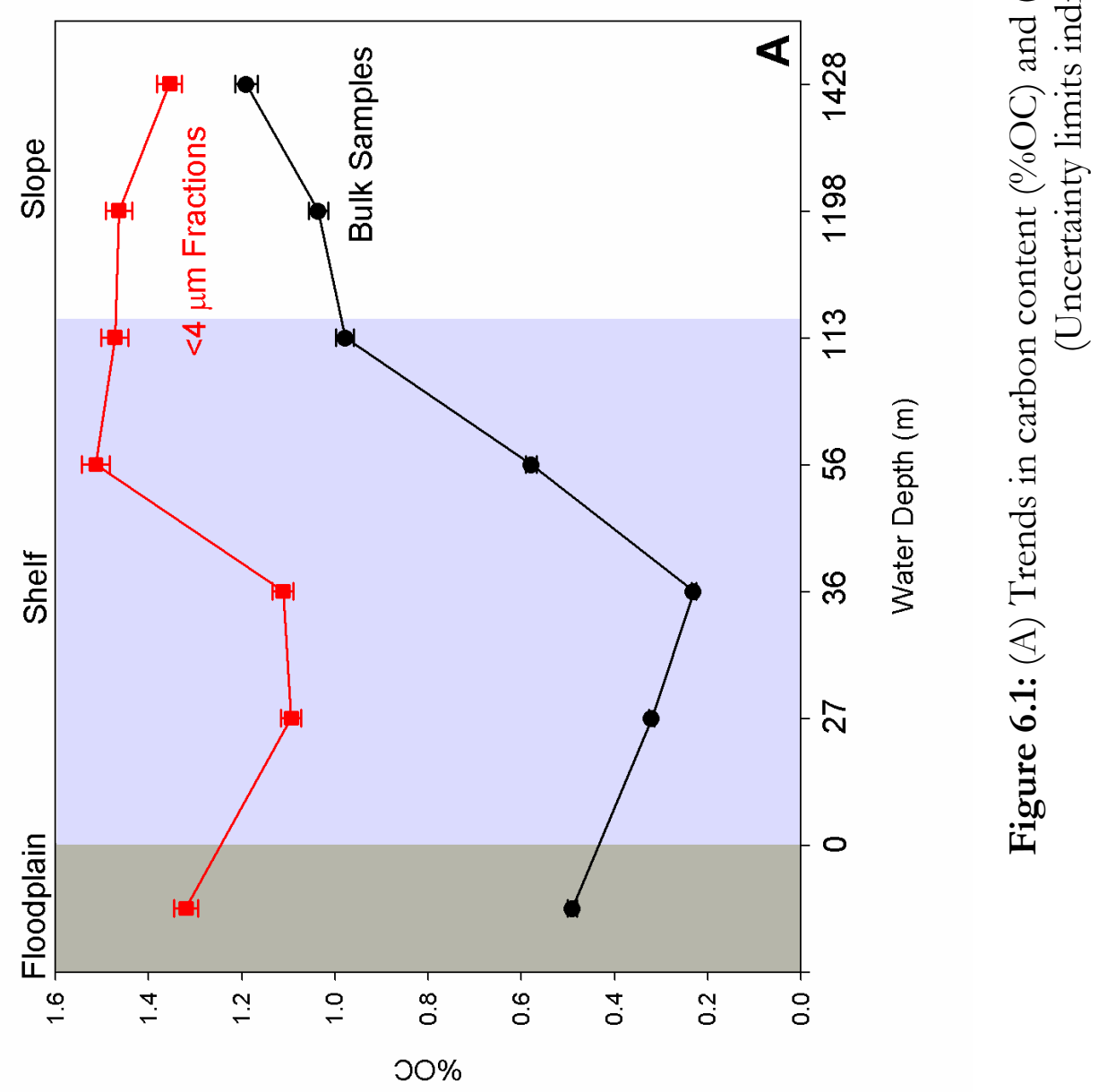


The surface transect generally shows an increasing OC content with increasing water depth (Figure 6.1A). Clay fractions have greater OC contents than the bulk samples, with highest values $(1.51 \%)$ on the mid-shelf (56 m water depth) and then decreasing slightly to $1.36 \%$ on the mid-slope $(1428 \mathrm{~m})$. The bulk samples show a steady increase in OC content, from $0.32 \%$ on the inner shelf $(27 \mathrm{~m})$ to $1.19 \%$ on the mid-slope $(1428 \mathrm{~m})$.

$\delta^{13} \mathrm{C}$ values display a consistent change with increasing water depth, becoming heavier (less negative) with distance across the continental shelf and slope (Figure 6.1B). Values for the bulk sediment samples and clay fractions are similar, ranging from $-25.1 \%$ on the floodplain to $-21.9 \%$ on the mid-slope $(1428 \mathrm{~m})$ for the bulk samples, and $-26.2 \%$ to $-21.6 \%$ for the clay fractions. The isotopic signatures for bulk samples and clay fractions become more similar with distance offshore, most likely reflecting a fining and homogenisation of sediment as it is transported further across the continental shelf and slope.

$(\mathrm{C} / \mathrm{N}) \mathrm{a}$ and OC:SA values were calculated for the transect samples (bulk samples and clay fractions) to further assist the identification of changing OC characteristics across the margin. Results are presented in Figure 6.2. 


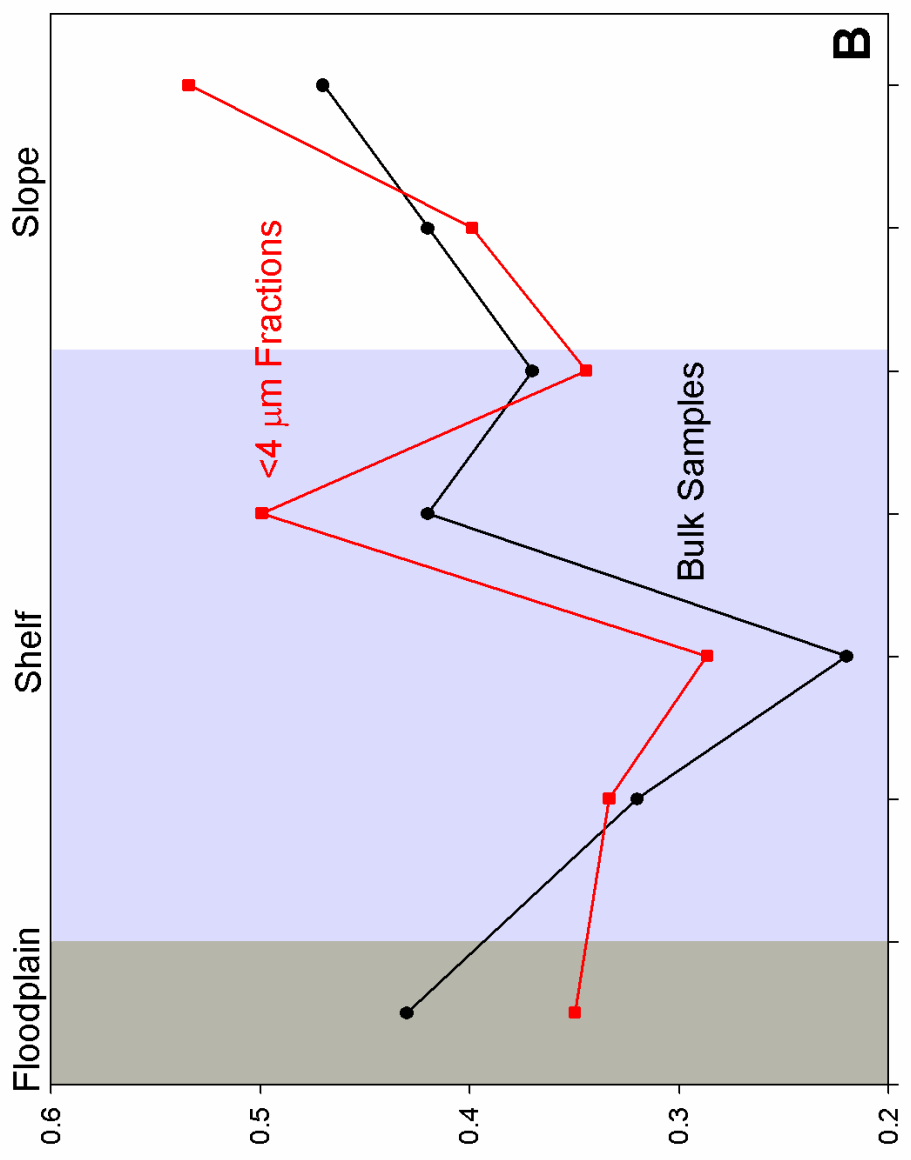

$(6 / 2 m) \forall S: 00$

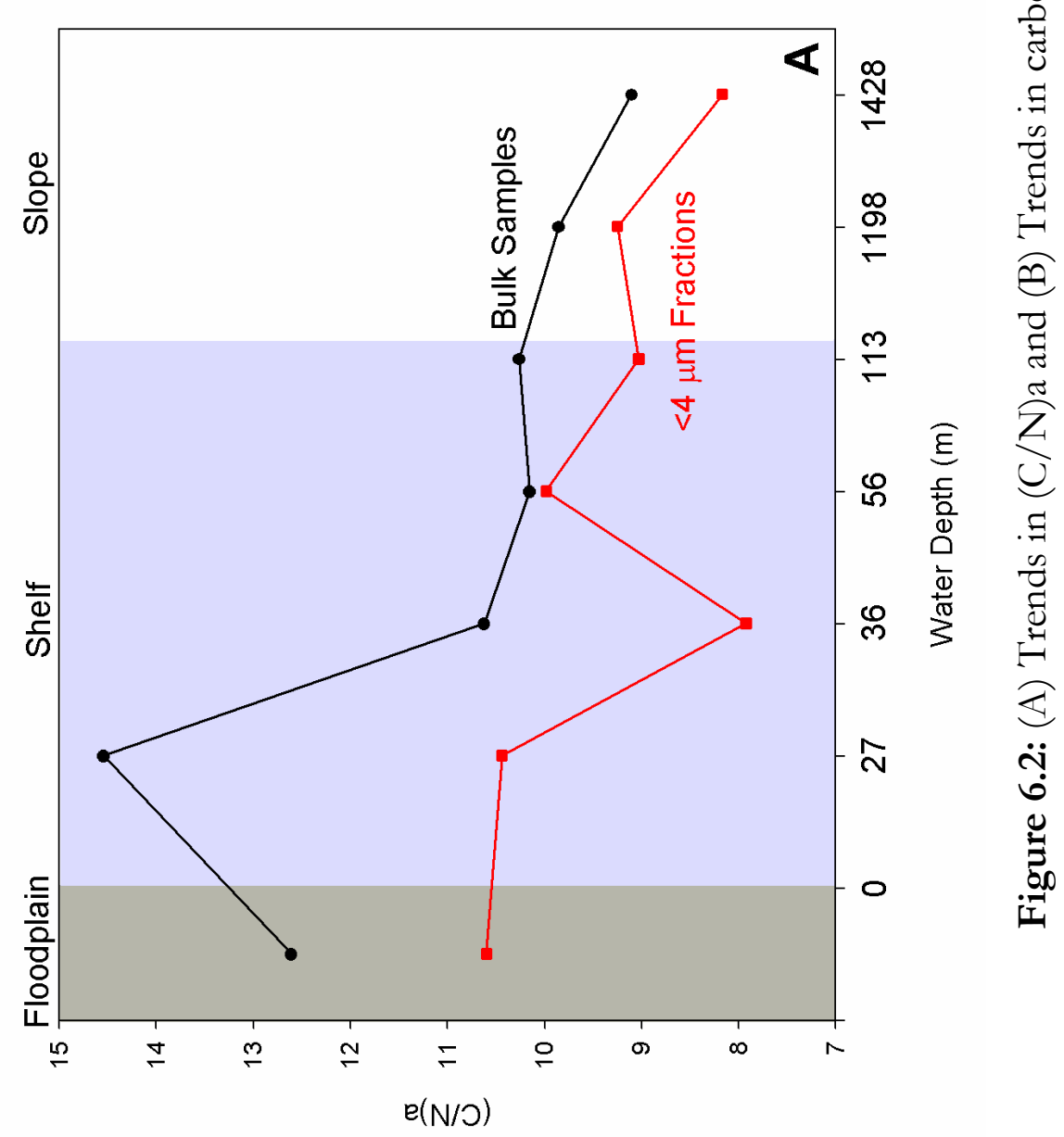


$(\mathrm{C} / \mathrm{N}) \mathrm{a}$ values for both bulk surface samples and their clay fractions show a decrease with distance across the continental shelf and slope (Figure 6.2A). The bulk samples have the greatest variation, ranging from 14.5 to 9.1, while clay fraction values vary between 10.6 and 8.2.

The trends in \%OC are largely influenced by particle size, i.e. much of the offshore trend of increasing $\% \mathrm{OC}$ is due to the fining of the sediments. This particle size effect was attenuated by using the OC:SA. Loadings were calculated for both the bulk samples and clay fractions of the transect surface samples; although not consistent, both show an increase with distance across the shelf and slope (Figure 6.2B). Values for the clay fractions $\left(0.29-0.53 \mathrm{~m}^{2} \mathrm{~g}^{-1}\right)$ are generally greater than those for the bulk samples $\left(0.22-0.42 \mathrm{~m}^{2} \mathrm{~g}^{-1}\right)$.

\subsubsection{Organic Carbon Source Determination}

As outlined in Chapter 5, simple mass balance calculations were used to estimate the relative proportions of terrestrial and marine OC in the shelf and slope sediments from the WSS, using $\delta^{13} \mathrm{C}$ values of $-28 \%$ and $-21 \%$ or for the terrestrial and marine end-members, respectively. Figure 6.3 illustrates the riverine and marine proportions of the total $\% \mathrm{OC}$ for both the bulk surface samples and their clay fractions. It indicates that as the \%OC increases with water depth and distance offshore, so does the proportion of marine OC, as determined by mass balance calculations. Relatively, the clay fractions show a more rapid increase in the proportion of marine OC than the bulk sediments. 


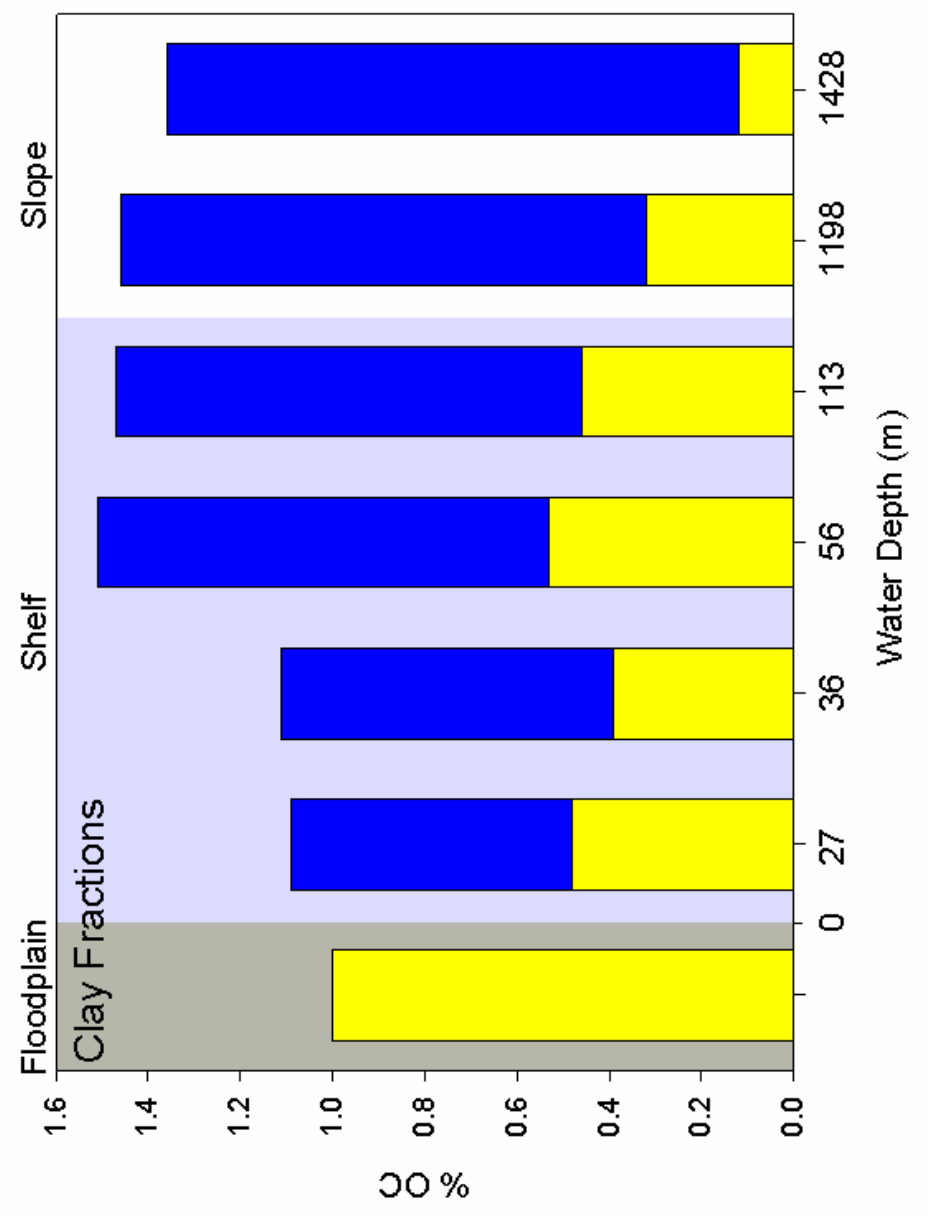

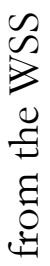

苛

ते

चु

足

हृ

范 穿

O

के है

종

$\bigcup_{0} \stackrel{0}{=}$

푸

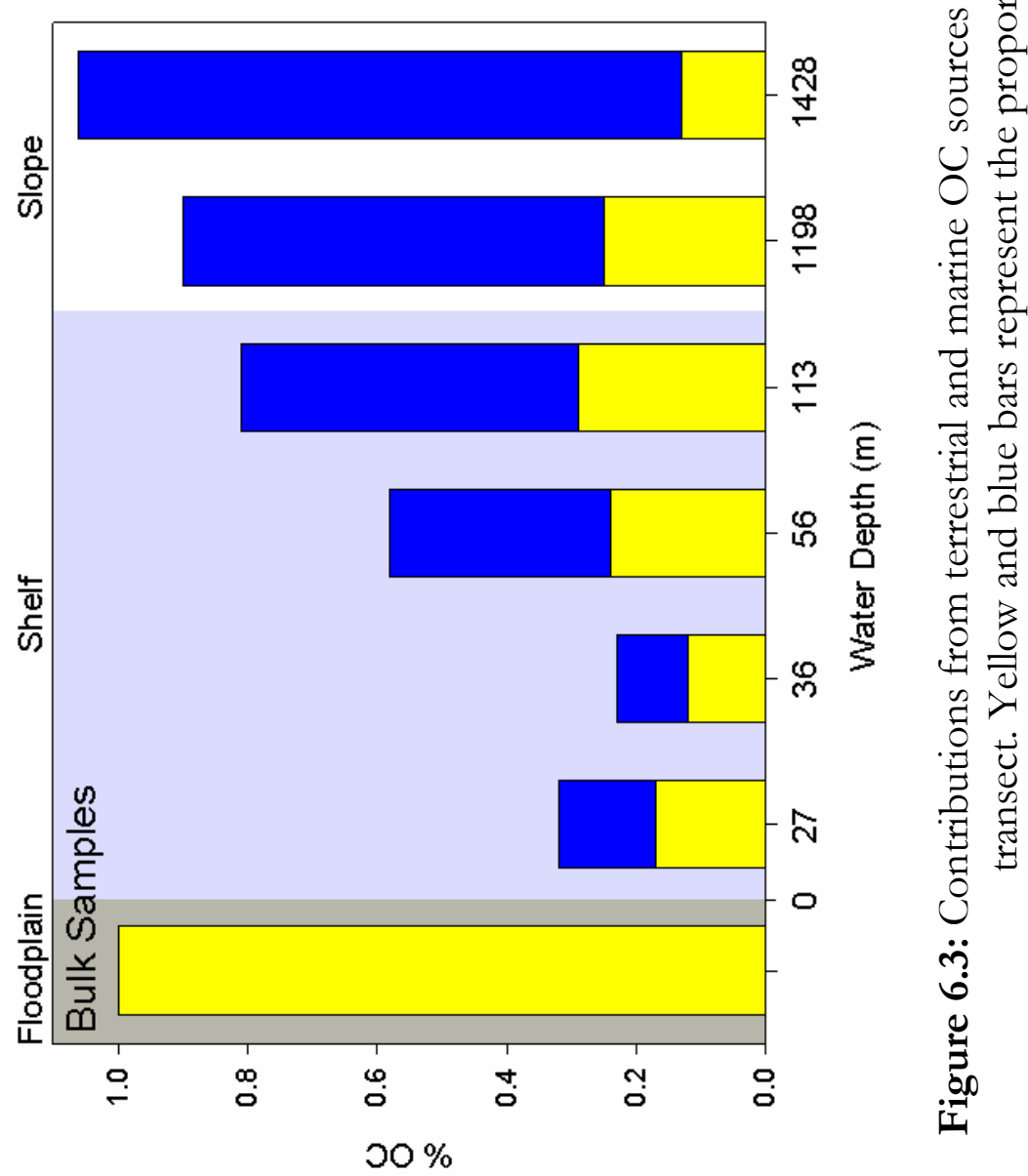



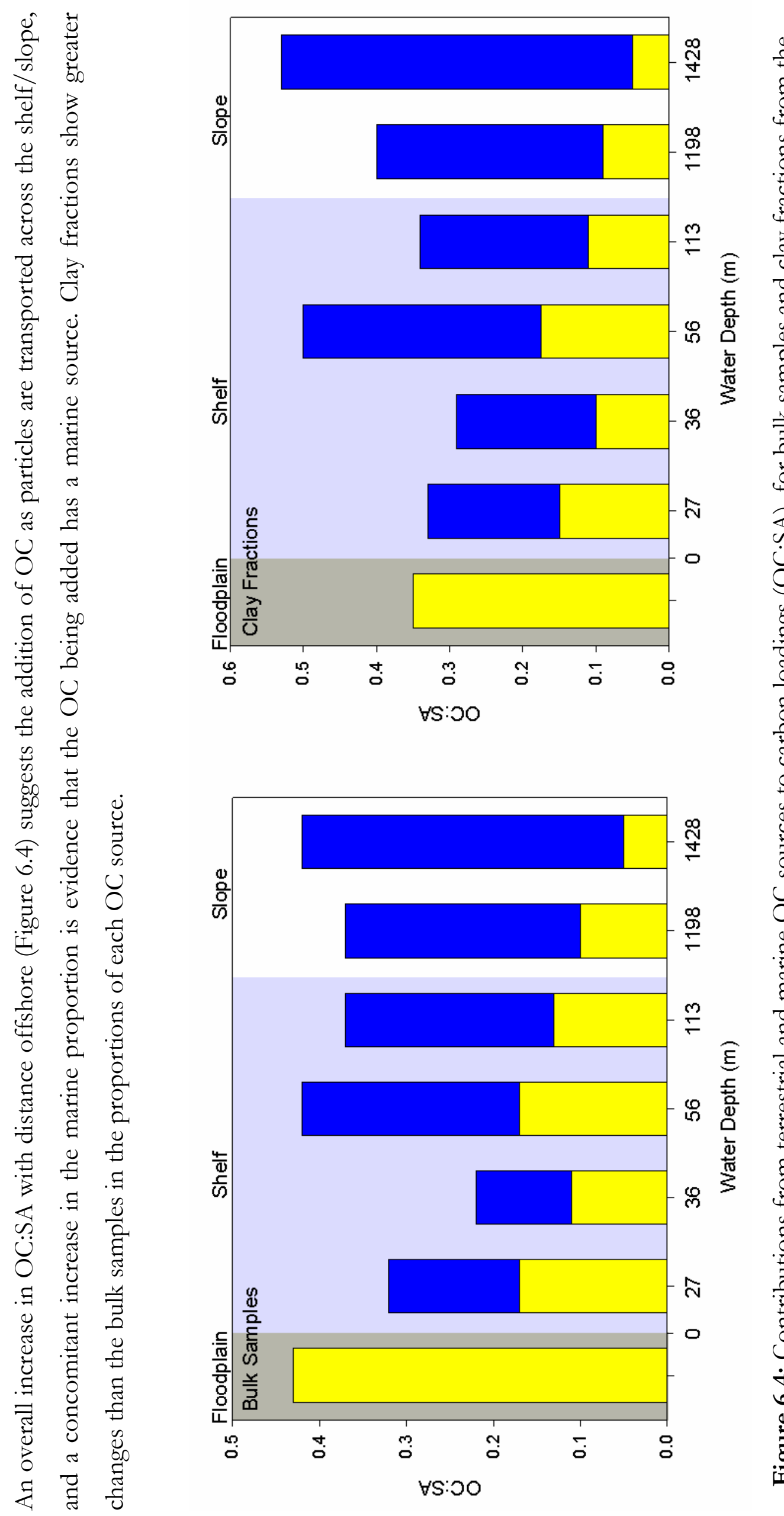

Eี

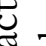

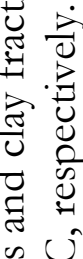

营 㤩 $\frac{\bar{d}}{3}$
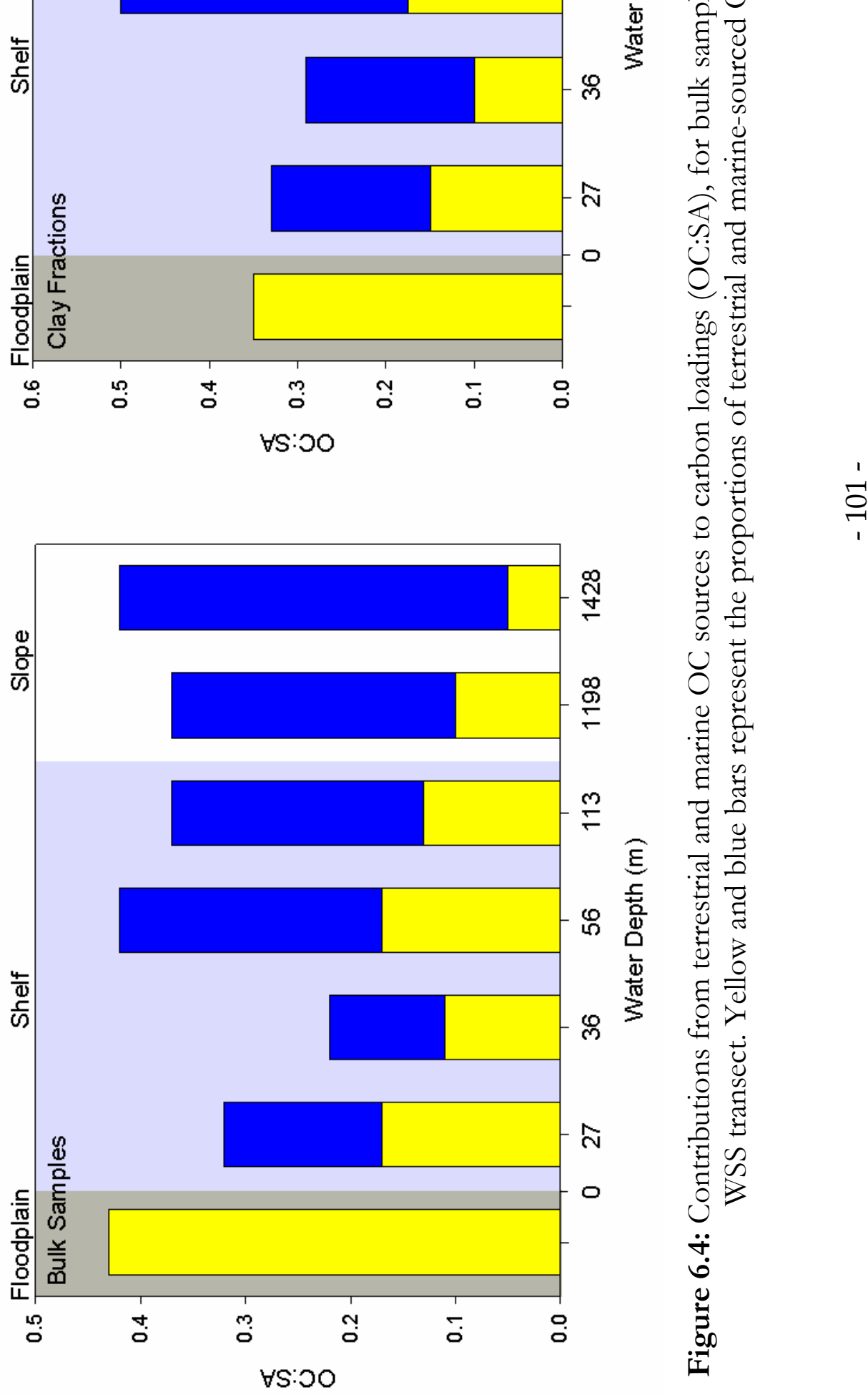

\&

음

৩ั

$\bigcirc$

:

हี

票

डิ त)

흠

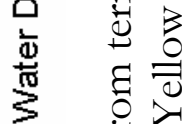

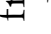

告

草苦

1 


\subsubsection{Carbon-14 Analyses}

The use of $\delta^{13} \mathrm{C}$ alone as an $\mathrm{OC}$ provenance indicator can be problematic due to overlapping signatures of potential OC sources, whereas using multiple carbon isotopes allows more specific tracing of the OC (Raymond \& Bauer 2001). Thus ${ }^{14} \mathrm{C}$ was used as a second tracer to help distinguish and determine the varying contributions from terrestrial and marine OC sources. ${ }^{14} \mathrm{C}$ has also proved a useful tracer in ocean margin sediments for determining the contributions made by both young and old sources of terrestrial OC (Bauer et al. 2001; Blair et al. 2003) thus making it possible to determine whether old terrestrial OC (e.g. kerogen from bedrock) is lost, or replaced by more modern OC from terrestrial or marine sources (or both) as the sediment passes through the WSS.

Because of its age (typically $>10^{5}$ years), kerogen contains no detectable ${ }^{14} \mathrm{C}$, thus the measurement of ${ }^{14} \mathrm{C}$ in samples can be used as an estimate of the amount of kerogen in a sample. Some end-member ${ }^{14} \mathrm{C}$ values have been determined for the WSS, though have not yet been well constrained. The bedrock has a $\Delta 14 \mathrm{C}$ value of 1000 (fraction modern $=0$ ), while plant $\mathrm{C}$ and modern marine $\mathrm{C}$ values are estimated to be about the same as the atmosphere, which is $\sim+40 \%$ (fraction modern $=\sim 1.04)(\mathrm{N}$ Blair 2005, pers. comm.).

The four WSS shelf and slope samples analysed for ${ }^{14} \mathrm{C}$ for this study were bulk surface samples from the shelf and upper slope core sites (Figure 3.1). In conjunction with the $\delta^{13} \mathrm{C}$ data, the $\Delta 14 \mathrm{C}$ values were used to determine the contributions of ancient terrestrial OC (dominantly kerogen), modern terrestrial OC and modern marine $\mathrm{OC}$ to the total carbon content of shelf and slope surface sediment samples (Figure 6.5). 

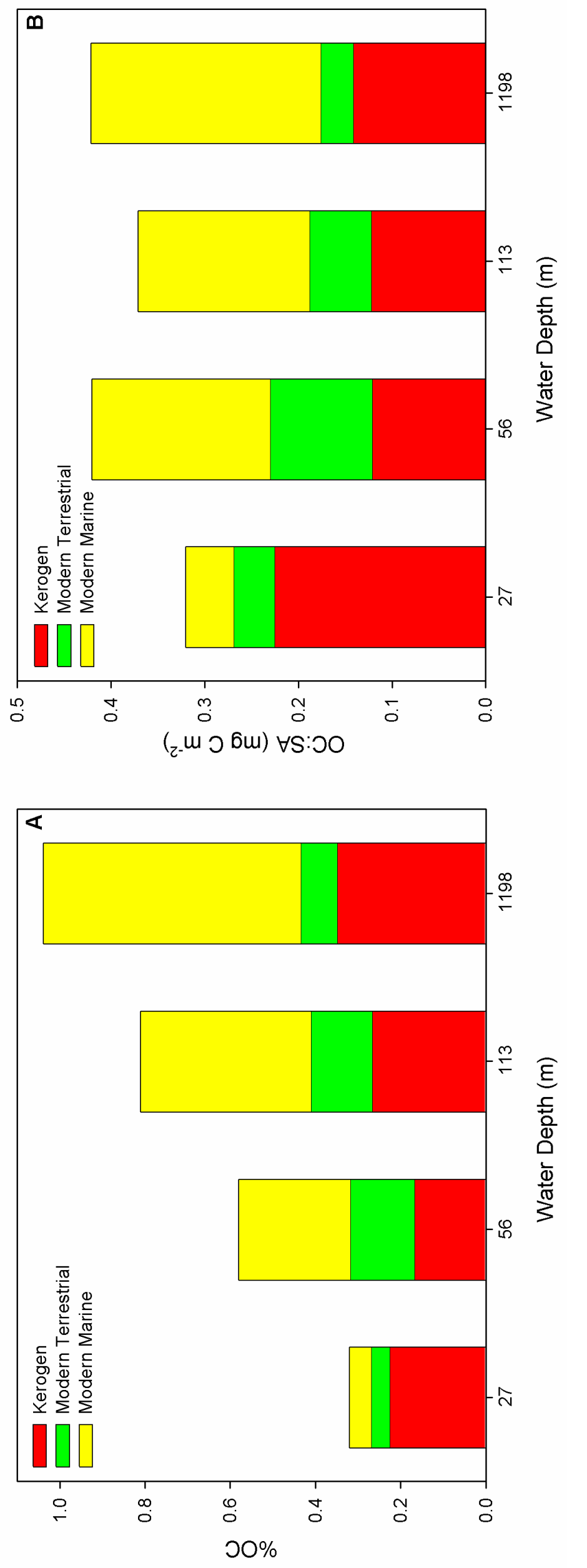

$\overbrace{1}^{1}$ 
Once again, the trend of increasing \%OC with water depth (Figure 6.5A) is largely influenced by the offshore fining of sediment. This particle size effect is attenuated by using OC:SA values rather than $\% \mathrm{OC}$, and a truer indication of the relative OC sources is obtained. Offshore trends are not so obvious in the OC:SA graph (Figure 6.5B), but it indicates that the marine fraction consistently increases, with loadings rising from 0.05 on the inner shelf to 0.25 on the upper slope. This is further evidence that marine $\mathrm{OC}$ is being added to the particles as they are deposited across the shelf and slope. From the mid-shelf to the upper slope, the modern terrestrial loadings decrease slightly, from $0.11(56 \mathrm{~m})$ to $0.07(113 \mathrm{~m})$ to $0.04(1198 \mathrm{~m})$. This would suggest that some modern terrestrial OC is being lost as particles deposit from the mid-shelf to the upper slope.

The small differences in OC:SA measurements between the mid-shelf (56 m), outer shelf $(113 \mathrm{~m})$ and upper slope $(1198 \mathrm{~m})$ (Figure 6.5B) suggest there is negligible loss of kerogen from the system, at least offshore from the mid-shelf.

The modern terrestrial components of sediment OC decrease offshore, while the modern marine component increases and there is no loss of kerogen beyond the mid-shelf (Figure 6.5B). The kerogen content is markedly higher on the inner shelf $(70.3 \%)$ than at the other three sites $(28.8 \%$ at the mid-shelf, $32.9 \%$ on outer shelf and $33.5 \%$ on upper slope). This may be because it is closest to the source of kerogen-rich bedrock within the WSS.

\subsubsection{Biomarkers}

Biomarkers are organic compounds with a chemical structure that has been formed by living organisms and is sufficiently stable to be recognised in materials such as suspended particles, sediments, and petroleum. Biomarkers include stable carbon and nitrogen isotopes, lignin oxidation products, and lipid biomarker compounds (Canuel \& Zimmerman 1999). For this study, three classes of lipid biomarker compounds were used (sterols, fatty acids and alcohols), alongside bulk parameters $\left(\% \mathrm{OC}, \delta^{13} \mathrm{C},(\mathrm{C} / \mathrm{N}) \mathrm{a}\right)$ to determine the relative inputs from terrestrial and marine OC sources (see Chapter 3). In order to reduce the effects of particle size differences while determining the importance of different sources relative to 
sediment OC, biomarker analyses were normalised to total OC content (E. Canuel 2004, pers. comm.).

For biomarker analyses of WSS sediments, the plant sterols used included 24methylcholest-5-en-3b-ol (campesterol), 24-ethylcholesta-5,22-dien-3b-ol (stigmasterol) and 24-ethylcholest-5-en-3b-ol (Figure 6.6). They are the dominant sterols in higher plants, however they are not exclusive to plants and can occur in some species of algae and phytoplankton.

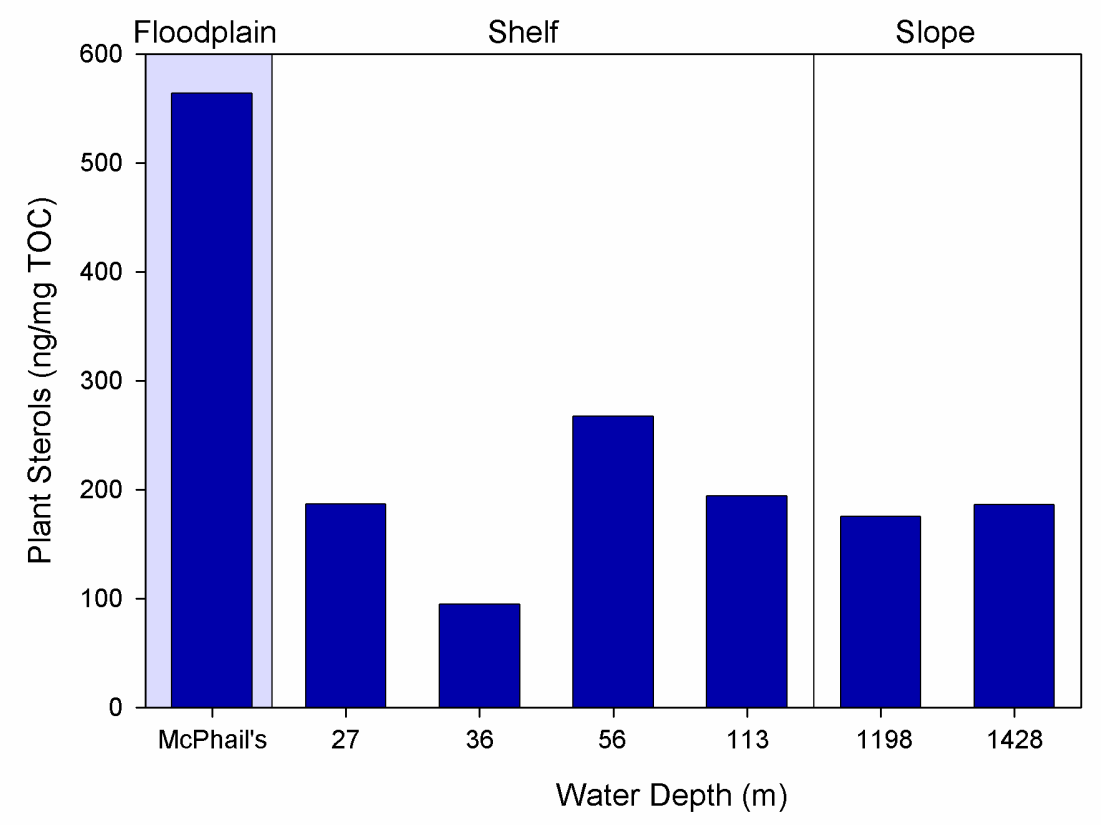

Figure 6.6: Concentrations of plant sterols normalised to sediment OC.

As illustrated in Figure 6.6, the concentration of plant sterols was highest in the floodplain sediment, having more than twice the concentration of any of the marine surface samples. This is not unexpected, given the abundance of vascular plants in the floodplain environment. The lower concentrations in marine sediments indicate a much smaller contribution of organic matter from vascular plants, and also possibly a small contribution from algae and/or phytoplankton. The highest concentration observed in the marine surface sediments, on the mid-shelf $(56 \mathrm{~m})$, may suggest preferential accumulation of terrestrially sourced sediment on the midshelf, as was indicated by the higher accumulation rate reported in Chapter 5. 
Long-chain alcohols are another good biomarker of vascular plants, occurring in plant waxes. Figure 6.7 illustrates the concentrations of long-chain $\left(\mathrm{C}_{22}-\mathrm{C}_{28}\right)$ alcohols normalised to sediment OC, for the transect of WSS sediments.

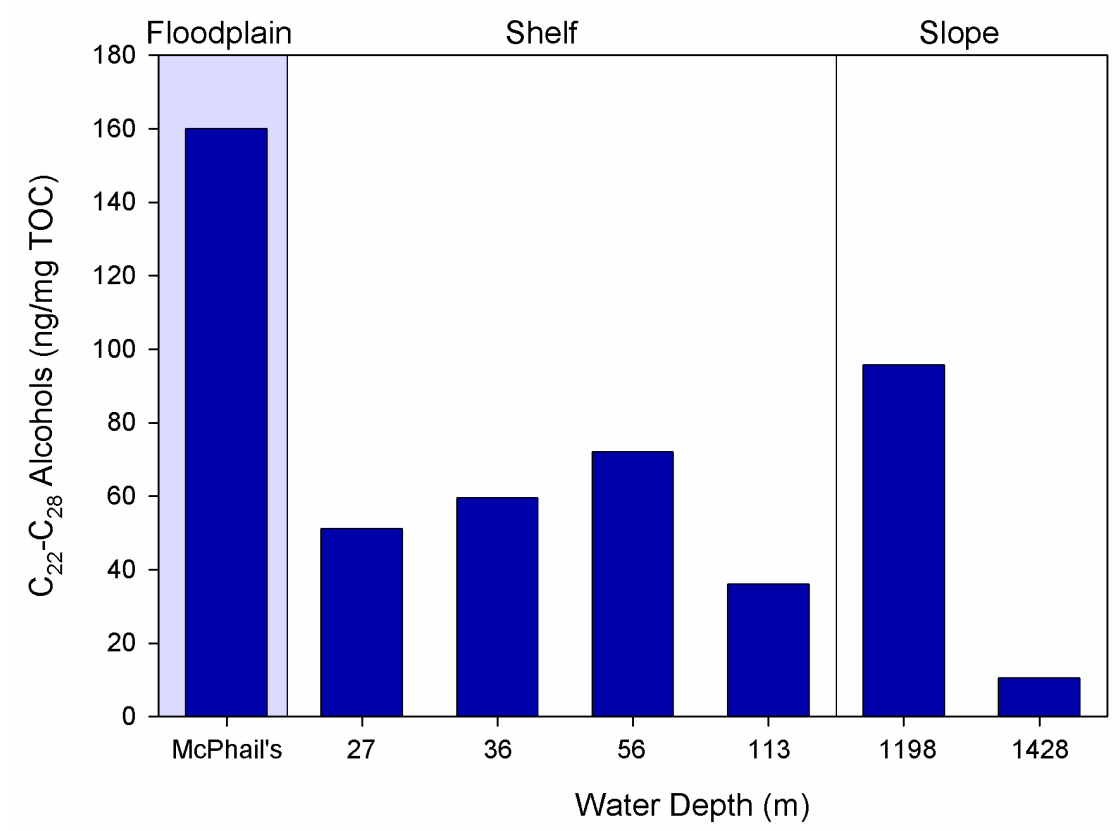

Figure 6.7: Concentrations of long-chain $\left(\mathrm{C}_{22}-\mathrm{C}_{28}\right)$ alcohols normalised to sediment OC.

Similar to the plant sterol trends, Figure 6.7 illustrates an abundance of vascular plant organic matter within the floodplain sediment, and lower levels within the continental shelf and slope surface sediments. Of the marine surface samples, the upper slope site $(1198 \mathrm{~m}$ ) has the greatest concentration of terrestrially derived OC, though once again the mid-shelf site $(56 \mathrm{~m})$ also shows elevated concentrations. The high concentration on the upper slope may in fact indicate that some externally sourced sediment is being transported from outside the WSS by the East Cape Current (ECC), and is not actually representing the offshore transport of sediment within the WSS.

The presence of dinoflagellate sterols within sediments indicates OC contributions from marine phytoplankton. Results are presented in Figure 6.8. 


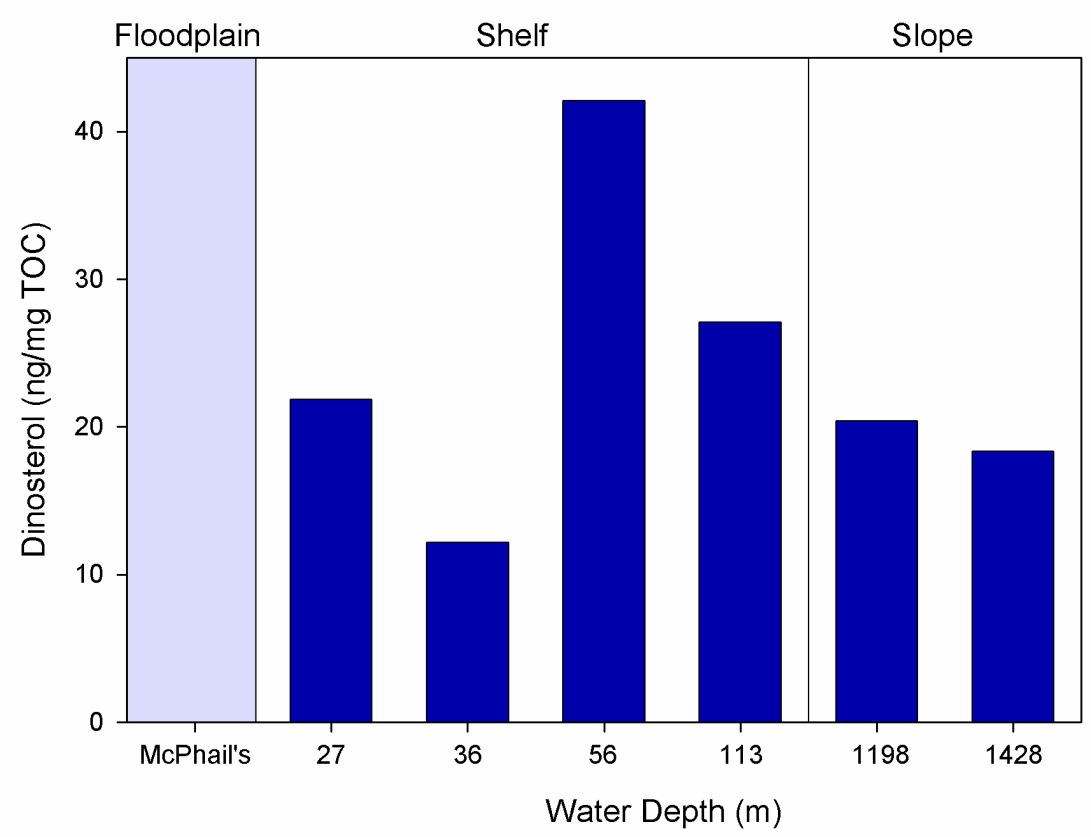

Figure 6.8: Concentrations of dinoflagellate sterols normalised to sediment OC.

As expected, only the marine WSS sediments contain OC that is sourced from phytoplankton. The greatest concentration is on the mid-shelf $(56 \mathrm{~m})$, again where the accumulation rate is highest, and offshore from there concentrations decrease with distance. Once again, this trend might result from the increased influence of ocean currents on the outer shelf and slope.

Derived from marine algae, diatom sterols were used as an indicator of the marinesourced OC within the WSS sediments. Results are presented in Figure 6.9.

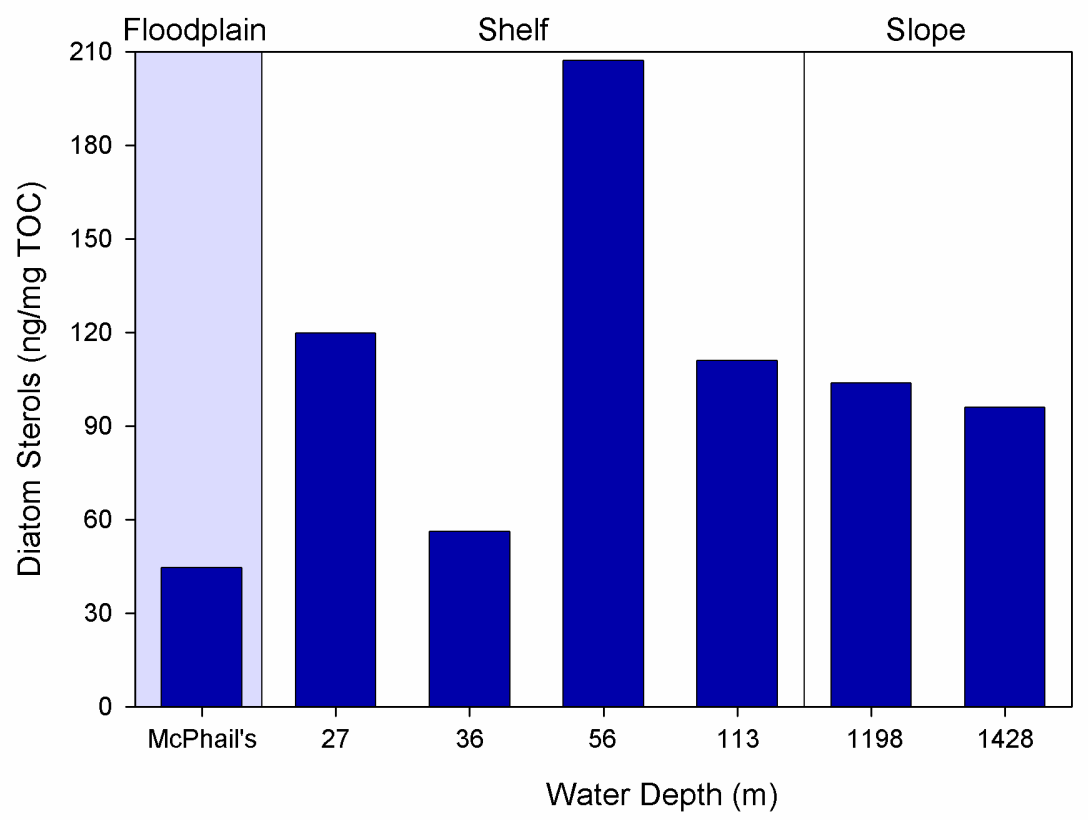

Figure 6.9: Concentrations of diatom sterols normalised to sediment OC. 
Concentrations of the diatom sterols show a fair amount of variation within the WSS transect of floodplain and surface marine sediments, with no obvious trend (Figure 6.9). The concentration is greatest on the mid-shelf $(56 \mathrm{~m})$, most likely associated with the higher accumulation rate, while the floodplain and inner-mid shelf (36 m) sediments exhibit the lowest concentrations.

To assess the relative importance of terrestrial plant and marine algal contributions to sediment OC, the ratio of plant-to-diatom sterols was calculated (Figure 6.10).

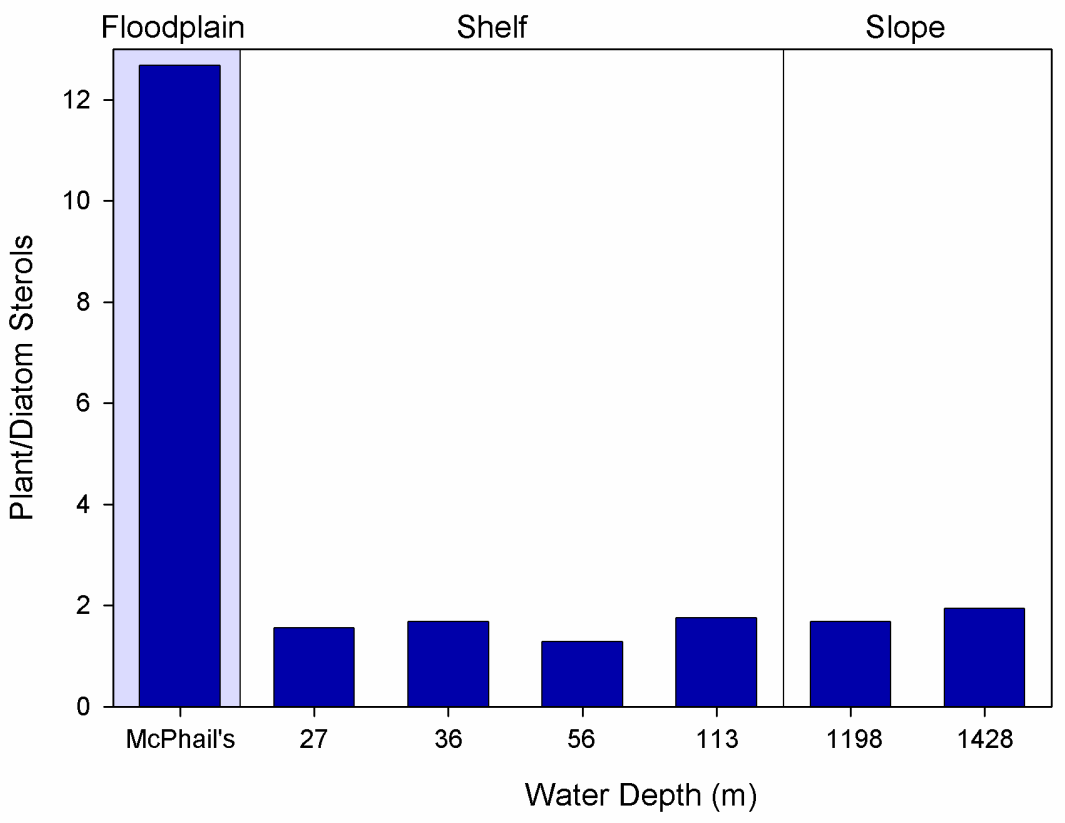

Figure 6.10: Ratio of plant-to-diatom sterols.

The highest ratio (12.7) was measured in the floodplain sample (Figure 6.10), while offshore samples all had ratios of between 1.3 and 1.9, though there is not a simple offshore change in the ratio. These ratios indicate that terrestrially sourced OC is present within sediments right across the continental shelf and slope.

Occurring in the waxes of vascular plants, long-chain $\left(\mathrm{C}_{22}-\mathrm{C}_{32}\right)$ fatty acids are a good terrestrial biomarker, and were determined for the WSS transect (Figure 6.11). 


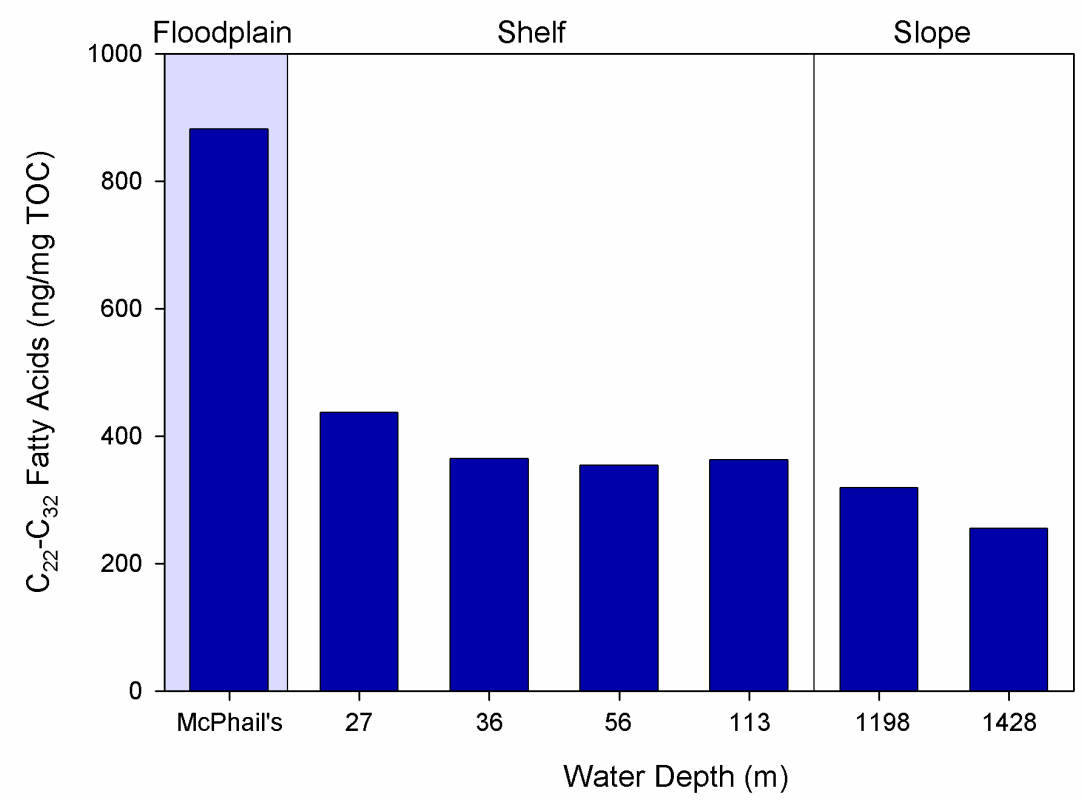

Figure 6.11: Concentrations of long-chain $\left(\mathrm{C}_{22}-\mathrm{C}_{32}\right)$ fatty acids normalised to sediment OC.

The long-chain fatty acids decrease in concentration across the continental margin. That they persist to the mid-slope $(1428 \mathrm{~m})$ indicates that terrestrially sourced OC is carried and deposited at these distal sites (Figure 6.11).

While long-chain fatty acids are almost exclusively terrestrial in origin, short-chain saturated fatty acids are commonly related to a marine source. However, short-chain fatty acids are also found in lacustrine/freshwater environments, so they cannot be used alone to distinguish between aquatic and marine inputs. 


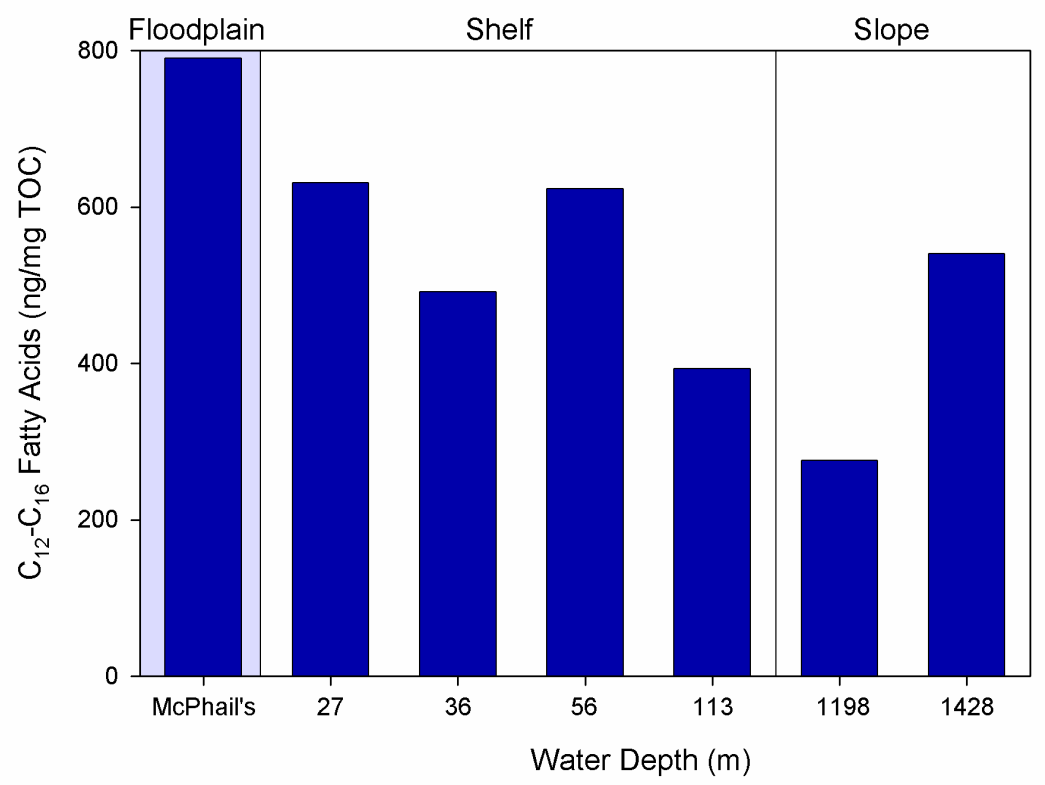

Figure 6.12: Concentrations of short-chain $\left(\mathrm{C}_{12}-\mathrm{C}_{16}\right)$ saturated fatty acids normalised to sediment OC.

Results suggest an irregular decrease in short-chain fatty acids across the WSS transect (Figure 6.12) except for slightly elevated concentrations on the mid-shelf (56 m) and mid-slope (1428 m).

The ratio of terrestrial to aquatic fatty acids, normalised to sediment OC, was calculated as the ratio of long-chain (plant) fatty acids to short-chain (algal/bacterial) fatty acids. A ratio of less than one signifies the dominance of aquatic organic matter; a ratio of one signifies equal contributions of fatty acids from both terrigenous and aquatic sources; and a ratio greater than one indicates a dominance of terrigenous organic matter. Trends for sediments analysed from the WSS are illustrated in Figure 6.13. 


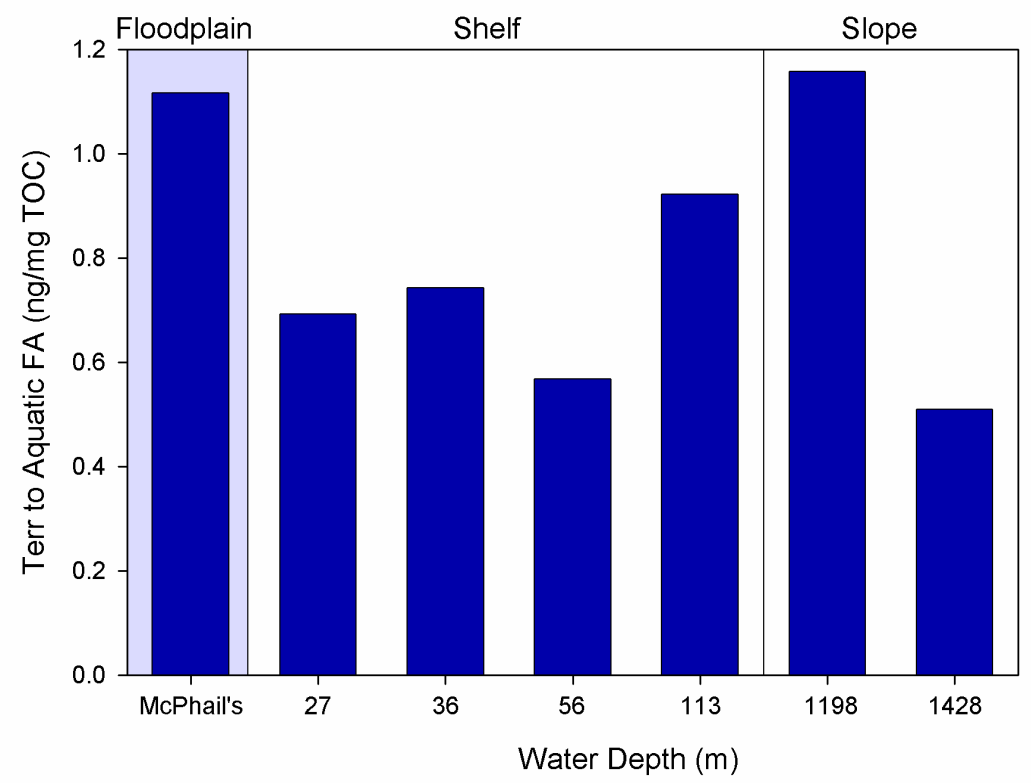

Figure 6.13: Ratio of terrestrial-to-aquatic fatty acids normalised to sediment OC.

The resultant graph (Figure 6.13) illustrates a dominance of terrestrially sourced OC in the floodplain and upper continental slope $(1198 \mathrm{~m})$ sediments, while aquatic organic matter dominates in all other offshore surface samples.

While likely spatial variation and possible effects from differences in the susceptibility of these biomarkers to degradation need to be considered, the combination of trends illustrated by the range of biomarkers can be used to make some inferences about the changes in OC composition within the WSS. Several of the biomarkers indicate a general increase in marine-sourced OC and a concomitant decrease in terrestrially sourced OC with distance from the Waipaoa River across the continental shelf and slope. Although it does decrease offshore, the biomarker analyses also indicate that the terrestrial OC persists out to the mid-slope, with several of the biomarkers suggesting preferential accumulation on the outer shelf and upper slope. 


\subsection{Discussion}

The results of this study indicate that with increasing distance offshore from the Waipaoa River, sediments generally exhibit increased $\% \mathrm{OC}$, heavier $\delta^{13} \mathrm{C}$ values, a decrease in $(\mathrm{C} / \mathrm{N})$ a values and an increase in OC:SA. The $\delta^{13} \mathrm{C}$ mass balances suggest that the proportion of marine-sourced OC increases at the expense of terrestrially sourced $\mathrm{OC}$, and the ${ }^{14} \mathrm{C}$ mass balances highlight the persistence of kerogen across the shelf and slope and confirm at least some replacement of modern terrestrial OC by modern marine OC.

It has been hypothesised that continental shelves are the sites of active exchange between terrestrial and marine OC sorbed to mineral grains (Leithold \& Hope 1999). This study has found that the concentration o 
as soils, lowland storage sites, the river, water column and surface marine sediments. This also results in the POC having a bimodal age distribution (modern and ancient) which has been suggested by Blair et al. (2004) to be typical for short, steep, high sediment yield systems.

This study has established that the kerogen content on the inner shelf is more than double that on the mid-shelf, outer shelf and upper slope. This suggests the proximity of the inner shelf to the kerogen-dominated sediment source, with the dominance of kerogen also resulting in a relatively small fraction of modern terrestrial OC on the inner shelf. Kerogen prevalence, in conjunction with lower $\% \mathrm{OC}$ and OC:SA values indicate that inner shelf sediment is derived more from gully-eroded bedrock than surface-wash material and soils, which contain greater quantities of modern terrestrial OC.

It may also reflect the differences in hydraulic conditions influencing the transport and deposition of OC on the shelf. As kerogen is denser than modern plant material, it is likely to remain in the shallower and more turbulent zones, whereas the light plant material will be easily winnowed out. As the shelf sediments become finer with distance offshore, the proportion of kerogen changes very little, reflecting its persistence as sediments are transported across the shelf to the upper slope.

A further explanation for the high kerogen content is that the inner shelf retains flood deposits better than other shelf and slope sites where the flood signal becomes progressively weaker (see Chapter 5).

The ${ }^{14} \mathrm{C}$ mass balances and some biomarkers show increased kerogen contents on the outer shelf and upper slope. The reason for this is unclear, but may be due to the preferential accumulation of kerogen-rich sediments at these locations due to the influence of ocean currents. It appears that the ECC may be transporting terrestrially dominated sediment to the upper slope site (W697) from outside the WSS, also illustrated by some of the biomarker trends (L Carter 2005, pers. comm.). Carter \& Gomez (In Review) illustrate that suspended sediment discharged by the Waipaoa River generally moves anticlockwise around Poverty Bay before emerging 
onto the continental shelf, from where it is moved along the inner-mid shelf to the northeast by the Wairarapa Coastal Current (reinforced by the flood tide and occasional direct wind stress). The seaward edge of the northeast plume is entrained by the ECC, which facilitates transport towards the shelf edge. Furthermore, Stephens et al. (2001) indicates an across-shelf benthic flow which may shift sediment to the shelf and slope. Finally, hyperpycnal flows are a further mechanism for transporting the kerogen-rich sediments as far as the outer shelf and upper slope.

\section{Biomarkers as indicators}

For this study, three classes of lipid biomarker compounds were used (sterols, fatty acids and alcohols) alongside bulk parameters $\left(\% \mathrm{OC}, \delta^{13} \mathrm{C},(\mathrm{C} / \mathrm{N}) \mathrm{a}\right)$ to determine the relative inputs from terrestrial and marine OC sources. For the most part, sterols and long-chain alcohols are relatively stable, and within the fatty acids (FA) group, stability increases with increasing chain length (i.e. long-chain FA are more stable than short-chain FA) (E Canuel 2005, pers. comm.). It has also been established that on a molecular basis, fatty acids exhibit the widest range in degradation, and that rates for individual compounds can generally be related to their biological source (Canuel \& Martens 1996). Fatty acids derived from phytoplankton had higher degradation rates than the long chain fatty acids derived from vascular plants, while bacterial fatty acids showed the most variability, possibly due to their production within the sediments. Such source-related trends were found to be less apparent for the sterols (Canuel \& Martens 1996). This study confirms the resistance of the terrestrially-sourced biomarkers (plant sterols, long chain alcohols and long-chain fatty acids) with their preservation at depositional sites across the continental shelf and slope. The use of biomarkers in combination with other techniques has also greatly strengthened their value for this study.

The biomarker analyses of surface samples from the WSS transect illustrate three main points. Firstly, they support $\delta^{13} \mathrm{C}$ and $\Delta^{14} \mathrm{C}$ findings that terrestrial $\mathrm{OC}$ is being transferred across the continental margin. This is well illustrated by the findings that plant sterols, long chain alcohols and long chain fatty acids (biomarkers indicative of vascular plants), were present at each of the shelf and slope sites, persisting as far as 
the mid-slope. In support of these findings, the ratio of plant-to-diatom sterols also indicate that terrestrial OC is present in sediments right across the continental shelf and slope.

Secondly, biomarkers suggest some preferential accumulation on the mid-shelf. This was illustrated by the concentrations of plant sterols, long chain alcohols, dinosterols, diatom sterols and short chain fatty acids being markedly higher in the mid-shelf surface sediment than other transect sites. The increased concentrations of plant sterols and long chain alcohols is most likely due to the higher sedimentation rate at this site, resulting in a greater input of terrestrially derived sediment which would also favour better preservation of terrestrial OC due to rapid burial. Plant sterols can also occur in some species of phytoplankton, and with the dinosterols, diatom sterols and short chain fatty acids all indicative of marine sourced OC, the increased concentrations of all of these biomarkers on the midshelf suggest that input from phytoplankton is greatest at this site, which again may be due to the influence of ocean currents.

Thirdly, biomarkers suggest the introduction of sediment and associated OC from the north via the ECC. This was illustrated by both the increased concentration of long chain alcohols and a high ratio of terrestrial to aquatic fatty acids on the upper continental slope, which lies under the path of the ECC.

While likely spatial variation and possible differences in the susceptibility of the biomarkers to degradation need to be considered, the combination of trends illustrated by the biomarkers support the interpretations from $\% \mathrm{OC},(\mathrm{C} / \mathrm{N}) \mathrm{a}$, $\mathrm{OC}: \mathrm{SA}, \delta^{13} \mathrm{C}$ and $\Delta^{14} \mathrm{C}$ measurements across the continental margin.

\section{OC Transformations}

The exchange of OC within the marine environment is prompted by a combination of physical, biological and chemical processes. The introduction of marine OC may proceed via the incorporation of water borne debris into the sediment matrix, followed by its partial reprocessing by infauna and microbes. The newly exposed terrestrial OC associated with the sediment is vulnerable to enzymatic attack, 
photolytic oxidation, and desorption, in a way similar to the loss of POC from soils as a result of agricultural tillage (Blair et al. 2004), thus resulting in the loss of modern terrestrial OC.

If the sediment particles remain in the water column and/or seabed surface mixed layer for a sufficient (yet undetermined) length of time, they can potentially lose more of their terrestrial OC than if they are buried quickly. The rapidly deposited and buried flood layer on the inner shelf illustrates this well, with its strong terrestrial signature having been preserved between sediments which are characteristically marine. As discussed, the surface sediments at the inner shelf site indicate that generally the deposition of modern terrestrial OC is low. Average accumulation rates presented in Chapter 5 (Table 5.1) decrease with distance across the shelf and slope, and in conjunction with biogeochemical process occurring in the water column and seabed surface mixed layer, are likely to influence the preservation or loss of terrestrial OC in the marine environment. It has already been demonstrated that the rapid accumulation and burial of sediment on the inner shelf resulted in the preservation of terrestrially-sourced OC, while slower sediment accumulation on the upper slope $\left(0.13 \mathrm{~cm} \mathrm{y}^{-1}\right)$ gives greater opportunity for the processing of OC whilst sediment is in the water column and seabed surface mixed layer, and has resulted in the replacement of some terrestrial OC with marine OC (Blair et al. 2004; McKee et al. 2004; Leithold et al. 2005).

The addition of marine-sourced OC will also be influenced by its supply and availability, such as through plankton productivity. Carter et al. (2002) suggested that both the ECC and Wairarapa Eddy improve local nutrient levels and production, with the ECC transporting upwelled water from the East Cape and the Wairarapa Eddy possibly being a zone of elevated plankton productivity. This is also indicated by the increased concentration of dinoflagellate sterols and diatom sterols beyond the mid shelf. The greater influences these currents have on the continental slope are likely to be another reason for the greater input of marine OC with distance across the continental shelf and slope. 


\subsection{CONCLUSIONS}

By investigating the biogeochemical characteristics of individual size fractions in addition to bulk sediments, it has been possible to track the changes in OC sources as sediment is transported to depositional sites offshore from the Waipaoa River. This study has determined that:

(i) Very little kerogen is lost from the WSS sediments following their discharge to the marine environment, and it remains essentially unaltered, being preserved as far offshore as the mid-slope.

(ii) Sediments lose some of their terrestrially sourced OC as they are processed at various depositional sites across the continental shelf and slope.

(iii) There is a concurrent addition of marine sourced OC to the particles, such that the sediments gain a stronger marine biogeochemical signature with distance.

Thus it is suggested that New Zealand's East Cape Continental Margin (ECCM) is typical of those dominated by large river systems, receiving considerable inputs of both terrestrially and marine sourced OC, and resulting in the storage of reasonable amounts of OC in continental shelf and slope sediments. However, the issue of terrestrial OC not being recognisable in the marine environment has not been experienced in the WSS, with evidence that while some terrestrially sourced OC is lost, a reasonable proportion is preserved as far offshore as the mid-slope. 
Konrad Loren:.

\section{CHAPTER 7: ORGANIC CARBON TRANSFORMATIONS AND CONCEPTUAL MODELLING}

\subsection{INTRODUCTION}

It has recently been estimated that mountainous Pacific Rim islands may contribute up to $40 \%$ of the global land to ocean sediment flux (Farnsworth \& Milliman 2003) and $35 \%$ of the POC flux (Lyons et al. 2002). New Zealand's Waipaoa River is representative of those draining small mountainous catchments, with a high annual POC yield $(\sim 86.7 \mathrm{Kt}$ ), of which $\sim 4-9 \%$ is sequestered on the floodplain (Gomez et al. 2003; Gomez \& Trustrum 2005). This illustrates that the Waipaoa River is very efficient at transporting terrestrial POC to the ocean.

In this chapter, evidence presented in the earlier chapters for the transfer and preservation of terrestrial OC from terrestrial source to marine sink, and the biogeochemical changes it undergoes in depositional environments from the floodplain to the continental slope, is used to provide a conceptual framework linking some of the key processes.

\subsection{KEY FINDINGS}

While one of the aims of this study was to establish a benchmark biogeochemical signature for river flood events, the variable signatures of overbank deposits on the Waipaoa River floodplain has prevented such a signature being determined (see Chapter 4). However, both terrestrial and marine end-member $\delta^{13} \mathrm{C}$ signatures have been estimated ( $-28 \%$ and $-21 \%$ respectively), and used in mass balance equations to define the relative contributions of terrestrial and marine OC in shelf and slope sediments (see Chapter 5).

Previous studies (Gomez et al. 2003) established that the McPhail's bend section of the Waipaoa River floodplain plays a minor role in the modulation of OC transfers 
within the Waipaoa Sedimentary System (WSS), with total OC sequestration only $\sim 4 \%$ of the estimated riverine POC flux. However, if all of the floodplain areas in the entire Waipaoa catchment were considered, they would have a greater modulating effect on OC transfers to the ocean.

Investigations of WSS marine sediments indicate that during Cyclone Bola the extreme river discharge is likely to have produced a hyperpycnal plume, part of which is preserved as a $\sim 10 \mathrm{~cm}$ thick layer on the inner shelf and a $\sim 1 \mathrm{~cm}$ thick layer on the mid-shelf (Figures 5.3 and 5.4). The flood layer contains a significant amount of terrestrial OC (up to $86 \%$ of $\mathrm{OC}$ in $>25 \mu \mathrm{m}$ fraction) which was subsequently buried by normal marine deposits (in which $\sim 60 \%$ of OC in $>25 \mu \mathrm{m}$ fraction is terrestrial), thereby preserving its strong terrestrial flood signature. However, the importance of ambient conditions (high frequency/low magnitude events, i.e. river discharge $<1800 \mathrm{~m}^{3} \mathrm{~s}^{-1}$ at McPhail's bend) to sediment and OC accumulation in the marine environment over long timeframes (months to years) is also apparent. Over such timeframes, flood events could potentially dominate sediment and OC sequestration on the inner shelf, while ambient conditions dominate seaward of the mid-shelf.

Carbon loading (OC:SA) and ${ }^{14} \mathrm{C}$ data have revealed the contributions of kerogen, modern terrestrial OC and modern marine OC to the total OC of shelf and slope surface sediments. It has been established that there is very little kerogen lost from the WSS sediments following their discharge to the ocean, and it is preserved across the margin to the mid-slope. It is also apparent that as the sediments are physically and biologically processed at various depositional sites across the continental shelf and slope, they lose some of their modern terrestrial OC and the concurrent addition of marine-sourced OC results in the sediments gaining a stronger marine biogeochemical signature. Thus, on the mid-slope only $8 \%$ of the bulk sediment OC consists of modern terrestrial OC, $58 \%$ is modern marine OC and 34\% is kerogen (see Chapter 6 and Figure 7.2).

Results from this study verify and add considerably to understanding the OC transfers and transformations from source to sink as originally postulated in Chapter 
1 (Figure 1.1). The processes that control OC input and its subsequent transformation through the WSS are complex, as they reflect the different biophysical processes affecting the floodplain, continental shelf and slope as summarised in Figure 7.1. 


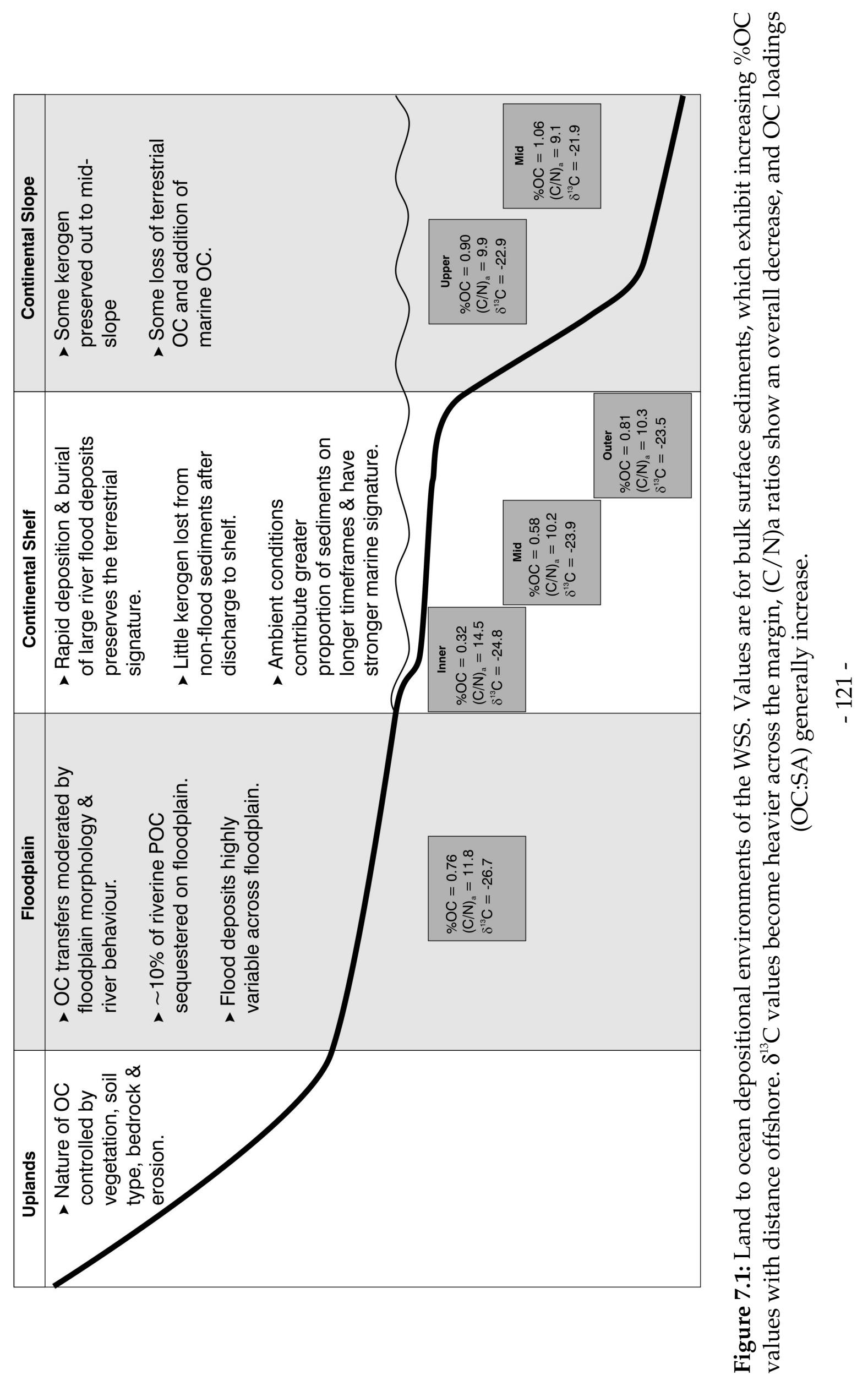




\section{Floodplain processes}

Flood events within the Waipaoa River system vary due to the variety of sediment and OC sources and plant matter contents, thus exacerbating the establishment of a benchmark signature for flood deposits that is easily recognisable in the marine sedimentary record. Complex relationships between river behaviour and depositional processes determine the extent to which the floodplain acts as a modulator of terrestrial sediment and OC before it is discharged to the marine environment. While previous studies (Gomez et al. 2003, 2004b; Gomez \& Trustrum 2005) of selected floodplain reaches show that the Waipaoa River is an effective conduit of terrestrial OC to the marine environment, consideration of all the floodplain areas in the entire Waipaoa catchment, and the high variability in sediment OC content $(\sim 0.2-3.5 \%)$ indicate that they may have an appreciable modulating effect on OC transfers to the ocean (see Chapter 4). This is especially so during large magnitude flood events, when greater amounts of terrestrial sediment $(\sim 16 \%)$ and associated OC $(\sim 10 \%)$ are sequestered on the floodplain (Gomez \& Trustrum 2005).

\section{Continental shelf and slope processing of terrestrial OC}

Following discharge to the marine environment, the physical and biological reworking of terrestrial sediment has a large impact on diagenetic reactions that occur in surface sediments, and therefore on the composition of materials buried in the continental shelf and slope environments (McKee et al. 2004). The processes responsible for the transfer of sediment and OC across the continental shelf and slope are driven by a combination of both large river flood events and ambient river discharge conditions, as well as the margin circulation. The amount of terrestrial OC preserved offshore in a single large flood event (such as Cyclone Bola) can be significant (as discussed above), and if such a layer is rapidly deposited and buried by ambient marine sediments, its terrestrial geochemical signature can be well preserved (e.g. a bulk sample $\delta^{13} \mathrm{C}$ of $\sim-25.7 \%$ compared to non-flood $\delta^{13} \mathrm{C}$ values of $\sim-24.8 \%$ ). During ambient conditions (river discharge $<1800 \mathrm{~m}^{3} \mathrm{~s}^{-1}$ at McPhail's bend), the slower transfer of sediments across the margin results in particles losing some of their terrestrially sourced OC while gaining some marine sourced OC (see Chapter 6). Thus the sediments have a stronger marine biogeochemical signature 
with distance as they are processed at various depositional sites across the continental shelf and slope (Figure 7.2).

The influence of currents offshore from the WSS, particularly the East Cape Current (ECC), is manifested in the occurrence of sediments with a stronger terrestrial signature being present on the upper slope site, inferred as having been transported southwards from northern fluvial sources by the ECC (Figure 7.2). There does not appear to be such a strong influence on sediment and OC transport by the Wairarapa Coastal Current (WCC).

\subsection{CONCEPTUAL MODELS}

\section{Biogeochemical Processes affecting OC transformations}

As rivers are the foremost link between the terrestrial and marine $\mathrm{C}$ pools, it is the movement of $\mathrm{C}$, rather than the amount being stored in reservoirs, which is of key importance to the global C cycle (Schlesinger 1997). This thesis has investigated the biogeochemical signature of sediment-associated OC to determine how it changes as particles move through the WSS from their terrestrial source to their marine sink. Changes occur primarily in bioactive reservoirs, where older material is degraded and new organic matter added as a result of contact with surficial terrestrial and marine productivity (Blair et al. 2004). It is the relative fluxes of material through and around these reservoirs, and the residence times within them that control and influence OC character. Thus the bypassing or rapid transfer through reservoirs results in minimal biogeochemical alteration of the OC, while lengthy processing within a reservoir results in greater alteration of the biogeochemical signature.

Blair et al. (2004) predicted that material buried on the continental shelf off active margins is characteristically a simple mixture of OC derived from kerogen, modern terrestrial and modern marine sources. This study has confirmed that this is the case for the WSS (Figure 7.2), with a particularly high kerogen component being present on the inner shelf. Very little kerogen is lost from the sediments following their discharge to the marine environment, and it remains essentially unaltered out to the 
mid-slope as highlighted by the ${ }^{14} \mathrm{C}$ mass balances which also confirm there is some replacement of modern terrestrial OC by modern marine OC.

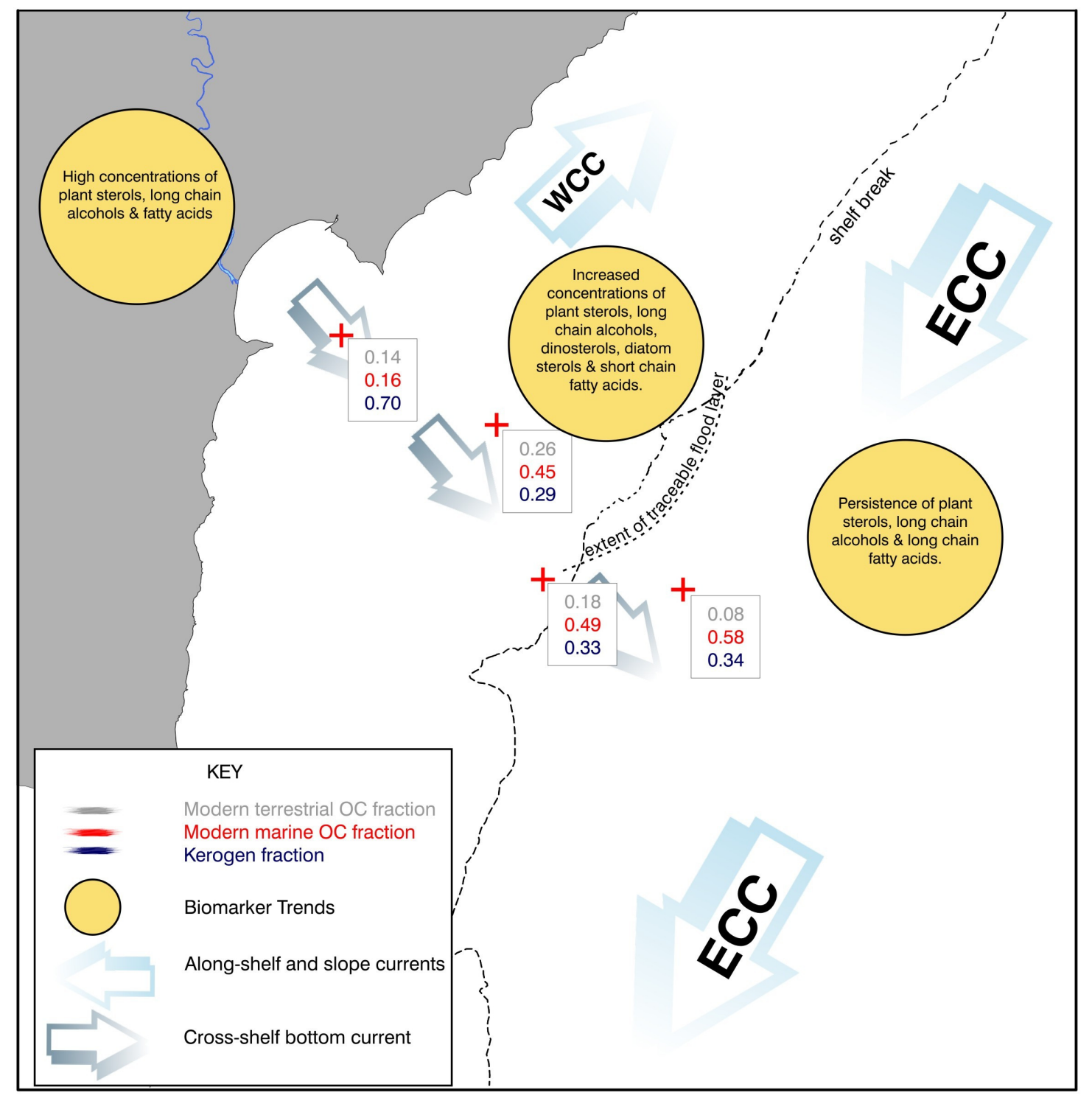

Figure 7.2: Diagrammatic model of OC transfers and transformations across the depositional environments of the WSS. Proportions of modern terrestrial OC, modern marine $\mathrm{OC}$ and kerogen are indicated, as determined by ${ }^{14} \mathrm{C}$ mass balances. Together with biomarker trends, these illustrate that kerogen is preserved across the depositional environments, and that there is also some replacement of modern terrestrial OC by modern marine OC.

Findings from this study indicate two prominent similarities between the WSS and north California's Eel River system as described by Leithold and Blair (2001) and Blair et al. (2003). Firstly, deep erosion of bedrock means that $\geq 50 \%$ of OC delivered to both shelves consists of kerogen. The rapid transfer of sediment and 
associated $\mathrm{OC}$ to the marine environment results in little time for diagenetic alteration in various depositional reservoirs, therefore the kerogen is transported through the system and $\sim 50 \%$ of it is reburied on the continental slope. Secondly, as particles are transported across the continental shelf and slope, some modern terrestrial OC is lost and marine OC is added, such that in both the WSS and Eel River System, slope sediment OC is dominated by modern marine OC and kerogen (Figure 7.2).

The addition of marine OC to sediment particles is likely the result of both direct addition of particulate detritus derived from modern primary production, and the microbial colonisation of particles (Blair et al. 2004). Such biological processes occurring in the marine environment are modelled in Figure 7.3.

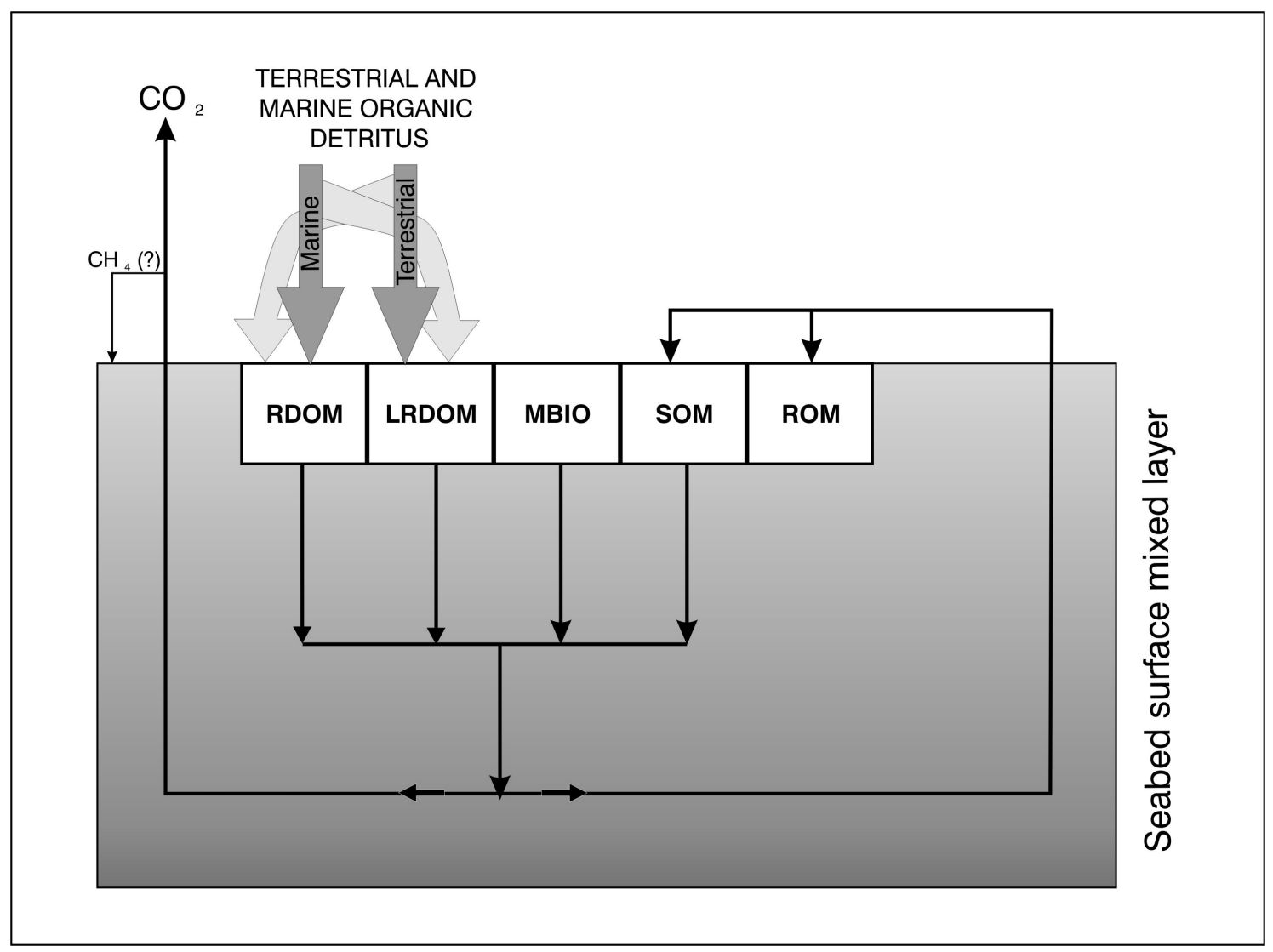

Figure 7.3: Diagrammatic model of OC processing in the surface mixed layer of the seabed, as particles are transported across the shelf and slope. The surface mixed layer compartments are: RDOM, readily decomposed organic matter; LRDOM, least readily decomposable organic matter; MBIO, marine biomass; SOM, stabilised organic matter; ROM, recalcitrant organic matter (including kerogen).

Figure based on the Roth C model and adapted from Parshotam et al. (1995). 
Variation in the contribution of terrestrial and marine inputs to the sediment, and the relative contribution from each to the readily decomposed organic matter (RDOM) and resistant organic matter (ROM) depends on factors including (a) the frequency and magnitude of storm events and (b) the location across the depositional environment.

Upon discharge to the marine environment, the processing of particles and associated OC (of both terrestrial and marine origin) occurs in the seabed surface mixed layer, during transport across the shelf and slope. Based on an existing terrestrial model for the processing of soil OC (Parshotam et al. 1995), Figure 7.3 provides a schematic representation of the stages of processing that may occur in the seabed surface mixed layer. It illustrates possible steps of OC processing, and the likely $\mathrm{CO}_{2}$ emissions associated with each step, as it proceeds through the cycle. It also raises the possibility of methane being produced as a result of the OC being buried rather than oxidised. If particles spend insufficient time in the surface mixed layer, there is less opportunity for the processing of OC, and the terrestrial signature is likely to be retained (e.g. the inner-shelf flood layer).

\subsection{GLObal SignificANCE AND FUTURE DiRECTIONS}

This study has extended the state of knowledge of New Zealand's land to ocean OC fluxes. Previous studies have broadly estimated the amounts of OC lost from New Zealand's landscape (Tate et al. 2000; Hicks et al. 2004b; Scott et al. In Press) but this work has extended investigations to the marine environment, thus providing new knowledge on the amounts of terrestrial OC preserved in the marine environment, the modes of emplacement and new knowledge about the biogeochemical transformations from terrestrial source to marine sink.

This study addresses the significance of small mountainous river systems in the processing of OC, as compared to larger river systems in continental settings, with the transfer and fate of terrestrial OC being largely controlled by erosional, transport and depositional processes characterising the respective river systems. In large, lowgradient rivers with vast floodplains (e.g. Amazon, Yangtze, Fly and Paraná), there 
are extensive opportunities for the storage and processing of large portions of terrestrial OC in the floodplain and delta (Blair et al. 2004), therefore they have a strong modulating influence on riverine inputs to the ocean. In such systems, sediments have been found to rapidly lose a large portion $(\sim 70 \%)$ of their terrestrial OC on discharge to the ocean, which is gradually replaced with marine OC (see Blair et al. (2004) and references therein). Contrastingly, short and steep mountainous systems deliver eroded sediment and OC straight to the river channel and then it is rapidly transferred to the marine environment. There are few opportunities for extensive storage and processing of the OC prior to delivery to the ocean, thus the original terrestrial OC signal is preserved to a large extent in the marine environment. This is well illustrated by continental slope sediments offshore from the WSS retaining about $50 \%$ of their terrestrial OC, of which $\sim 80 \%$ consists of kerogen (Figure 7.2).

Associated with the greater processing (and oxidation) of terrestrial OC in large continental rivers is the considerable opportunity for related $\mathrm{CO}_{2}$ production. In contrast, short steep mountainous catchments such as the WSS offer little opportunity for oxidation of bedrock OC during transport from source to sink, potentially burying greater proportions of terrestrial OC offshore. Associated with this OC burial is the potential for greater methane production, and the trapping of methane in sediments. Such occurrence of methane-rich deposits was demonstrated by Lewis and Marshall (1996), who identified methane seeps on the continental slope off East Cape, and suggested they were likely to be indicators of sedimentological and tectonic processes at convergent margins.

Given that previous estimates of annual global discharges of POC from rivers to the oceans varies by a factor of three (see Table 1.1) and that mountainous oceanic islands such as New Zealand could contribute up to $40 \%$ of this global figure (see Chapter 1), results from this study could be combined with volumetric measurements of well constrained and dated sedimentary deposits to determine the amount of this terrestrial POC that is sequestered in such margin environments over the last $\sim 100$ years. 
This study provides the first quantitative assessment of land to ocean OC transfers from New Zealand, and in conjunction with sediment budgets, is a vital step toward global OC budgets for small mountainous island environments. It has also identified the preservation of large river flood events on New Zealand's continental shelf as a mechanism for the preservation of significant amounts of terrestrially sourced OC following its discharge to the marine environment.

\section{Future directions}

While this study has advanced New Zealand's knowledge of OC cycling from terrestrial source to marine sink, it has revealed several areas where targeted research is required to place land to ocean OC budgets for small mountainous islands in the global context:

- A more comprehensive investigation and definition of floodplain sedimentation and therefore OC characteristics, to constrain the high variability in that environment and link to sediment and source variability, and floodplain processes. An alternative approach of using suspended sediments sampled form the water column rather than floodplain sediments could be used to overcome the issue of floodplain variability.

- Further evaluation of flood event deposits preserved within the marine sediments, in particular ${ }^{14} \mathrm{C}$ data and calculation of mass balance equations for the down-core samples from the inner shelf cores. This would help to better quantify the rates and pathways of $\mathrm{OC}$ in the marine environment, and contributions from the terrestrial biosphere. Such an evaluation would require more detailed sampling of the slower accumulating slope sediments and deeper sampling on the shelf, to account for the different sedimentation rates.

- Determine the processes that occur in bioactive reservoirs, and their influence on the OC signature across the source to sink continuum.

- Combine the findings of this study with sediment budgets to develop OC budgets for the East Cape Continental Margin (ECCM) - New Zealand's highest input margin, in order to better define national and global OC budgets. 
- Determine the contribution of terrestrial and marine organic detritus to the production of $\mathrm{CO}_{2}$ and $\mathrm{CH}_{4}$ in the marine environment, to establish the origin of vast $\mathrm{CH}_{4}$ reserves in deep abyssal regions of New Zealand's east coast. 


\section{REFERENCES}

Aller, RC, Blair, NE, Xia, Q \& Rude, PD 1996, 'Remineralization rates, recycling and storage of $C_{\text {org }}$ in Amazon Shelf sediments', Continental Shelf Research, vol. 16, no. 5-6, pp. 753-786.

Amo, M \& Minagawa, M 2003, 'Sedimentary record of marine and terrigenous organic matter delivery to the Shatsky Rise, western North Pacific, over the last 130 kyr', Organic Geochemistry, vol. 34, no. 9, pp. 1299-1312.

Appleby, PG \& Oldfield, F 1992, 'Application of 210Pb to sedimentation studies', in M Ivanovich \& RS Harmon (eds), Uranium-series disequilibrium; applications to earth, marine and environmental sciences, Clarendon Press, Oxford, pp. 731-778.

Barnes, PM, Nicol, A \& Harrison, T 2002, 'Late Cenozoic evolution and earthquake potential of an active listric thrust complex above the Hikurangi subduction zone, New Zealand', Geological Society of America Bulletin, vol. 114, no. 11, pp. 1379-1405.

Bauer, JE, Druffel, ERM, Wolgast, DM \& Griffin, S 2001, 'Sources and cycling of dissolved and particulate organic carbon in the northwest Atlantic continental margin', Global Biogeochemical Cycles, vol. 15, no. 3, pp. 615-636.

Berner, RA 1982, 'Burial of organic-carbon and pyrite sulfur in the modern ocean Its geochemical and environmental significance', American Journal of Science, vol. 282, no. 4 , pp. 451-473.

Berryman, K, Marden, M, Eden, DN, Mazengarb, C, Ota, Y \& Moriya, I 2000, 'Tectonic and paleoclimate significance of Quaternary river terraces of the Waipaoa River, East Coast, New Zealand', New Zealand Journal of Geology and Geophysics, vol. 43 , no. 2 , pp. $229-245$. 
Betts, HD, Trustrum, NA \& DeRose, RC 2003, 'Geomorphic changes in a complex gully system measured from sequential Digital Elevation Models, and implications for management', Earth Surface Processes and Landforms, vol. 28, no. 10, pp. 1043-1058.

Bianchi, TS, Lambert, CD, Santschi, PH \& Guo, L 1997, 'Sources and transport of land-derived particulate and dissolved organic matter in the Gulf of Mexico (Texas shelf/slope): The use of lignin-phenols and loliolides as biomarkers', Organic Geochemistry, vol. 27, no. 1-2, pp. 65-78.

Bianchi, TS, Mitra, S \& McKee, BA 2002, 'Sources of terrestrially-derived organic carbon in lower Mississippi River and Louisiana shelf sediments: implications for differential sedimentation and transport at the coastal margin', Marine Chemistry, vol. 77, no. 2-3, pp. 211-223.

Black, HJ, Dainat, M, Koster, M \& Meyer-Reil, L-A 2002, 'A multiple corer for taking virtually undisturbed samples from shallow water sediments', Estuarine, Coastal and Shelf Science, vol. 54, no. 1, pp. 45-50.

Blair, NE \& Carter, WD 1992, 'The carbon isotope biogeochemistry of acetate from a methanogenic marine sediment', Geochimica Cosmochimica Acta, vol. 56, no. 3, pp. 1247-1258.

Blair, NE, Leithold, EL, Ford, ST, Peeler, KA, Holmes, JC \& Perkey, DW 2003, 'The persistence of memory: The fate of ancient organic carbon in a modern sedimentary system', Geochemica et Cosmochemica Acta, vol. 67, no. 1, pp. 63-73.

Blair, NE, Leithold, EL \& Aller, RC 2004, 'From bedrock to burial: The evolution of particulate organic carbon across coupled watershed-continental margin systems', Marine Chemistry, vol. 92, no. 1-4, pp. 141-156.

Branauer, S, Emmett, PH \& Teller, E 1938, 'Adsorption of gases in multimolecular layers', Journal of the American Chemical Society, vol. 30, pp. 309-319. 
Canuel, EA 2001, 'Relations between river flow, primary production and fatty acid composition of particulate organic matter in San Francisco and Chesapeake Bays: a multivariate approach', Organic Geochemistry, vol. 32, no. 4, pp. 563-583.

Canuel, EA \& Martens, CS 1996, 'Reactivity of recently deposited organic matter: Degradation of lipid compounds near the sediment-water interface, Geochimica Cosmochimica Acta, vol. 60, no. 10, pp. 1793-1806.

Canuel, EA \& Zimmerman, AR 1999, 'Composition of particulate organic matter in the southern Chesapeake Bay: Sources and reactivity', Estauries, vol. 22, no. 4, pp. 980-994.

Carter, L \& Gomez, B In Review, 'Suspended sediment dispersal on the continental margin off the high discharge Waipaoa River, New Zealand - observations from anchor stations and satellites'.

Carter, L, Manighetti, B, Elliot, M, Trustrum, N \& Gomez, B. 2002, 'Source, sea level and circulation effects on the sediment flux to the deep ocean over the past 15 ka off eastern New Zealand', Global and Planetary Change, vol. 33, no. 3-4, pp. 339355.

Chen, C-TA, Liu, K-K \& MacDonald, R 2001, 'Continental margins and seas as carbon sinks', Stockholm, Global Change Newsletter, vol. 46, pp. 11-13.

Chiswell, SM \& Roemmich, D 1998, 'The East Cape Current and two eddies: a mechanism for larval retention?', New Zealand Journal of Marine and Freshwater Research, vol. 32, no. 3, pp. 385-397.

Craig, H 1953, 'The geochemistry of stable carbon isotopes', Geochemica et Cosmochemica Acta, vol. 3, pp. 53-92. 
Crockett, JS \& Nittrouer, CA 2004, 'The sandy inner shelf as a repository for muddy sediment: an example from Northern California', Continental Shelf Research, vol. 24, no. 1 , pp. $55-73$.

Dadson, SJ, Hovius, N, Chen, H, Dade, WB, Hsieh, M-L, Willett, SD, Hu, J-C, Horng, M-J, Chen, M-C, Stark, CP, Lague, D \& Lin, J-C 2003, 'Links between erosion, runoff variability and seismicity in the Taiwan orogen', Nature, vol. 426, pp. 648-651.

Dadson, SJ, Hovius, N, Chen, H, Dade, WB, Lin, J-C, Hsu, M-L, Lin, C-W, Horng, M-J, Chen, TC, Milliman, JD \& Stark, CP 2004, 'Earthquake-triggered increase in sediment delivery from an active mountain belt', Geology, vol. 32, no. 8, pp. 733-736.

Depetris, PJ \& Kempe, S 1993, 'Carbon dynamics and sources in the Paraná River', Limnology and Oceanography, vol. 38, no. 2, pp. 382-395.

DeRose, RC, Gomez, B, Marden, M \& Trustrum, NA 1998, 'Gully erosion in Mangatu Forest, New Zealand, estimated from Digital Elevation Models', Earth Surface Processes and Landforms, vol. 23, no. 11, pp. 1045-1053.

Drake, DE 1999, 'Temporal and spatial variability of the sediment grain-size distribution on the Eel shelf: the flood layer of 1995', Marine Geology, vol. 154, no. 14, pp. 169-182.

Eden, DN \& Trustrum, NA (eds) 1994, 'Waipaoa Catchment study: literature review', Landcare Research unpublished working report', Palmerston North, New Zealand.

Eden, DN, Palmer, AS, Cronin, SJ, Marden, M \& Berryman, K 2001, 'Dating the culmination of river aggradation at the end of the last glaciation using distal tephra compositions, eastern North Island, New Zealand', Geomorphology, vol. 38, no. 1-2, pp. 133-151. 
Fahl, K \& Stein, R 1997, 'Modern organic carbon deposition in the Laptev Sea and the adjacent continental slope: surface water productivity vs terrigenous input', Organic Geochemistry, vol. 26, no. 5-6, pp. 379-390.

Farnsworth, KL \& Milliman, JD 2003, 'Effects of climatic and anthropogenic change on small mountainous rivers: the Salinas River example', Global and Planetary Change, vol. 39, no. 1-2, pp. 53-64.

Field, CB, Behrenfeld, MJ, Randerson, JT \& Falkowski, P 1998, 'Primary production of the biosphere: Integrating terrestrial and oceanic components', Science, vol. 281, no. 5374 , pp. $237-240$.

Foster, G \& Carter, L 1997, 'Mud sedimentation on the continental shelf at an accretionary margin - Poverty Bay, New Zealand', New Zealand Journal of Geology and Geophysics, vol. 40, no. 2, pp. 157-173.

Gomez, B \& Trustrum, NA 2005, 'Landscape disturbance and organic carbon in alluvium bordering steepland rivers, East Coast Continental Margin, New Zealand', in C Garcia \& RJ Batalla (eds), Catchment dynamics and river processes: Mediterranean and other climate regions, Elsevier, Amsterdam.

Gomez, B, Eden, DN, Peacock, DH \& Pinkney, EJ 1998, 'Floodplain construction by recent, rapid vertical accretion: Waipaoa River, New Zealand', Earth Surface Processes and Landforms, vol. 23, no. 5, pp. 405-413.

Gomez, B, Eden, DN, Hicks, DM, Trustrum, NA, Peacock, DH \& Wilmshurst, J 1999, 'Contribution of floodplain sequestration to the sediment budget of the Waipaoa River, New Zealand, in SB Marriott \& J Alexander (eds), 'Floodplains: Interdisciplinary Approaches', Geological Society, London, Special Publications, vol. 163, pp. 69-88. 
Gomez, B, Fulthorpe, C, Carter, L, Berryman, K, Browne, G, Green, M, Hicks, DM, Trustrum, NA 2001, 'MARGINS Source to Sink: New Zealand Focus Area', EOS, Transactions, American Geophysical Union, vol. 82, no. 14.

Gomez, B, Trustrum, NA, Hicks, DM, Rogers, KM, Page, MJ \& Tate, KR 2003, 'Production, storage and output of particulate organic carbon: Waipaoa River basin, New Zealand', Water Resources Research, vol. 39, no. 6, pp. 1161-1169.

Gomez, B, Carter, L, Trustrum, NA, Palmer, AS \& Roberts, AP 2004a, 'El NiñoSouthern Oscillation signal associated with middle Holocene climate change in intercorrelated terrestrial and marine sediment cores, North Island, New Zealand', Geology, vol. 32, no. 8, pp. 653-656.

Gomez, B, Brackley, HL, Hicks, DM, Neff, H \& Rogers, KM 2004b, 'Organic carbon in floodplain alluvium: Signature of historic variations in erosion processes associated with deforestation, Waipaoa River basin, New Zealand', Journal of Geophysical Research, vol. 109. F04011, doi:10.1029/2004JF000154.

Goni, MA, Ruttenberg, KC, Eglinton, TI 1998, 'A reassessment of the sources and importance of land-derived organic matter in surface sediments from the Gulf of Mexico', Geochemica et Cosmochemica Acta, vol. 62, no. 18, pp. 3055-3075.

Gorman, RM, Bryan, KR \& Laing, AK 2003, Wave hindcast for the New Zealand region: nearshore validation and coastal wave climate', New Zealand Journal of Marine and Freshwater Research, vol. 37, no. 3, pp. 567-588.

Hedges, JI 1992, 'Global biogeochemical cycles - progress and problems', Marine Chemistry, vol. 39, no. 1-3, pp. 67-93.

Hedges, JI \& Keil, RG 1995, 'Sedimentary organic matter preservation: an assessment and speculative synthesis', Marine Chemistry, vol. 49, no. 2-3, pp. 81-115. 
Hedges, JI \& Oades, JM 1997, 'Comparative organic geochemistries of soils and marine sediments', Organic Geochemistry, vol. 27, no. 7/8, pp. 319-361.

Hedges, JI, Clark, WA, Quay, PD, Richey, JE, Devol, AH \& Santos, U 1986, 'Composition and fluxes of particulate organic material in the Amazon River', Limnology and Oceanography, vol. 31, no. 4, pp. 717-738.

Hedges, JI, Cowie, GL, Richey, JE, Quay, PD, Benner, R, Strom, M \& Forsberg, BR 1994, 'Origins and processing of organic matter in the Amazon River as indicated by carbohydrates and amino acids', Limnology and Oceanography, vol. 39, no. 4, pp.743761.

Hedges, JI, Keil, RG \& Benner, R 1997, 'What happens to terrestrial organic matter in the ocean?', Organic Geochemistry, vol. 27, no. 5-6, pp. 195-212.

Hicks, DM \& Shankar, U 2003, Sediment from New Zealand rivers, NIWA Chart, Miscellaneous Series No. 79. NIWA, Wellington.

Hicks, DM, Gomez, B \& Trustrum, NA 2000, 'Erosion thresholds and suspended sediment yields, Waipaoa River Basin, New Zealand', Water Resources Research, vol. 36, no. 4, pp. 1129-1142.

Hicks, M, Shankar, U, McKerchar, A, Hume, T, Basher, L, Lynn, I, Jessen, M, Page, MJ \& Webb, T 2002, 'River suspended sediment yields to the New Zealand coasts and estuaries', poster paper presented to New Zealand Marine Sciences Symposium, Nelson, New Zealand, September.

Hicks, DM, Gomez, B \& Trustrum, NA 2004a, 'Event suspended sediment characteristics and the generation of hyperpycnal plumes at river mouths: East Coast Continental Margin, North Island, New Zealand', The Journal of Geology, vol. 112, no. 4 , pp. $471-485$. 
Hicks, DM, Quinn, J \& Trustrum, NA 2004b, 'Stream sediment load and organic matter', in J Harding, P Mosley, C Pearson \& B Sorrell (eds), Freshwaters of New Zealand, NZ Hydrological \& Limnological Societies, Christchurch.

IPCC 1995, 'Climate Change 1995: The science of climate change', JT Houghton, LG Meira Filho, BA Callander, N Harris, A Kattenberg, K Maskell, (eds), Cambridge University Press, Cambridge, UK.

Ittekot, V 1998, 'Global trends in the nature of organic matter in river suspensions', Nature, vol. 332, pp. 436-438.

Jobbagy, EG \& Jackson, RB 2000, 'The vertical distribution of soil organic carbon and its relation to climate and vegetation', Belowground Processes and Global Change, vol. 10, no. 2, pp. 423-436.

Johnson, KS, Paull, CK, Barry, JP \& Chavez, FP 2001, 'A decadal record of underflows from a coastal river into the deep sea', Geology, vol. 29, no. 11, pp. 10191022.

Keil, RG, Mayer, LM, Quay, PD, Richey, JE \& Hedges, JI 1997, 'Loss of organic matter from riverine particles in deltas', Geochemica et Cosmochemica Acta, vol. 61, no. 7, pp. $1507-1511$.

Kuehl, S, Carter, L, Gomez, B \& Trustrum, N 2003, 'Final report from the NSF MARGINS Source-to-Sink Workshop on the Waipaoa Focus Area, 4-9 May 2003. Gisborne and Wellington, New Zealand', viewed 12 July 2004, $<$ http://www.vims.edu/margins/finalreport.html $>$.

Lal, R 1995, 'Global soil erosion by water and carbon dynamics', in R Lal, J Kimble, E Levine \& BA Stewart (eds) Soils and global change, CRC Press, Boca Raton, Florida, pp. 131-142. 
Lal, R 2003, 'Soil erosion and the global carbon budget', Environment International, vol. 29 , no. 4, pp. 437-450.

Leithold, EL \& Blair, NE 2001, 'Watershed control on the carbon loading of marine sedimentary particles', Geochemica et Cosmochemica Acta, vol. 65, no. 14, pp. 2231-2240.

Leithold, EL \& Hope, RS 1999, 'Deposition and modification of a flood layer on the northern California shelf: Lessons from and about the fate of terrestrial particulate organic carbon', Marine Geology, vol. 154, no. 1-4, pp. 183-195.

Leithold, EL, Perkey, DW, Blair, NE \& Creamer, TN 2005, 'Sedimentation and carbon burial on the northern California continental shelf: the signatures of land-use change', Continental Shelf Research, vol. 25, no. 3, pp. 349-371.

Lewis, KB \& Marshall, BA 1996, 'Seep faunas and other indicators of methane-rich dewatering on New Zealand convergent margins, New Zealand Journal of Geology and Geophysics, vol. 39, no. 2, pp. 181-200.

Lewis, KB, Collot, J-Y \& Lallemand, SE 1998, 'The dammed Hikurangi Trough: a channel fed trench blocked by subducting seamounts and their wake avalanches (New Zealand-France GeodyNZ Project)', Basin Research, vol. 10, no. 4, pp. 441-468.

Lewis, KB, Barnes, PM, Collot, J-Y, Mercier de Lapinay, B, Delteil, J \& Geodynz Team 1999, Central Hikurangi Geodynz swath maps, NIWA Chart, Miscellaneous Series 77, National Institute of Water and Atmosphere (NIWA), Wellington.

Lewis, KB, Lallemand, SE \& Carter, L 2004, 'Collapse in a Quaternary shelf basin off East Cape, New Zealand: evidence for passage of a subducted seamount inboard of the Ruatoria giant avalanche', New Zealand Journal of Geology and Geophysics, vol. 47, no. 3, pp. 415-429.

Ludwig, W, Probst, J-L \& Kempe, S 1996, 'Predicting the oceanic input of organic carbon by continental erosion', Global Biogeochemical Cycles, vol. 10, no. 1, pp. 23-42. 
Lyons, WB, Nezat, CA, Carey, AE \& Hicks, DM 2002, 'Organic carbon fluxes to the ocean from high-standing islands', Geology, vol. 30, no. 5, pp. 443-446.

Mackenzie, FT, Lerman, A \& Ver, LM 1998, 'Role of the continental margin in the global carbon balance during the past three centuries', Geology, vol. 26, no. 5, pp. 423-426.

Mazengarb, C \& Speden, IG 2000, Geology of the Raukumara area, 1:250 000 geological map 6, Institute of Geological \& Nuclear Sciences, Lower Hutt, New Zealand.

McKee, BA 2003, 'RiOMar: The transport, transformation and fate of carbon in river-dominated ocean margins', Report of the RiOMar Workshop, 1-3 Novemebr 2002. Tulane University, New Orleans, LA. 48 p.

McKee, BA, Aller, RC, Allison, MA, Bianchi, TS \& Kineke, GC 2004, 'Transport and transformation of dissolved and particulate materials on continental margins influenced by major rivers: benthic boundary layer and seabed processes', Continental Shelf Research, vol. 24, no. 7-8, pp. 899-926.

Meade, RH 1996, 'River-sediment inputs to major deltas', in JD Milliman \&. BU Haq (eds), Sea-level rise and coastal subsidence: causes, consequences and strategies, Amsterdam, Kluwer Academic Publishers.

Meybeck, M 1993, 'Riverine transport of atmospheric carbon: sources, global typology and budget' Water, Air and Soil Pollution, vol. 70, no. 1-4, pp. 443-463.

Meybeck, M \& Vörösmarty, C 1999, 'Global transfer of carbon by rivers', Global Change Newsletter, vol. 37, pp. 18-19.

Milliman, JD 1995, 'Sediment discharge to the ocean from small mountainous rivers: the New Guinea example', Geo-Marine Letters, vol. 15, pp. 127-133. 
Milliman, JD \& Syvitski, JPM 1992, 'Geomorphic/tectonic control of sediment discharge to the ocean: the importance of small mountainous rivers', Journal of Geology, vol. 100, pp. 525-544.

Milliman, JD, Qinchun, X \& Zuosheng, Y 1984, 'Transfer of particulate organic carbon and nitrogen from the Yangtze River to the ocean', American Journal of Science, vol. 284, pp. 824-834.

Milliman, JD, Farnsworth, KL \& Albertin, CS 1999, 'Flux and fate of fluvial sediments leaving large islands in the East Indies', Journal of Sea Research, vol. 41, no. 1-2, pp. 97-107.

Molloy, L 1993, The living mantle: soils in the New Zealand landscape, $2^{\text {nd }}$ edn, New Zealand Society of Soil Science, Canterbury.

Moore, PR \& Mazengarb, C 1992, 'Geology and landforms of Raukumara Peninsula', in JM Soons \& MJ Selby (eds), Landforms of New Zealand, Longman Paul, Auckland, pp. 334-343.

Mulder, T \& Syvitski, JPM 1995, 'Turbidity currents generated at river mouths during exceptional discharges to the world oceans', Journal of Geology, vol. 103, pp. 285-298.

Mulder, T, Migeon, S, Savoye, B \& Jouanneau, J-M 2001, 'Twentieth century floods recorded in the deep Mediterranean sediments', Geological Society of America, vol. 29, no. 11, pp. 1011-1014.

Mullenbach, BL, Nittrouer, CA, Puig, P \& Orange, DL 2004, 'Sediment deposition in a modern submarine canyon: Eel Canyon, northern California', Marine Geology, vol. 211, pp. 101-119. 
National Ocean Sciences AMS Facility (NOSAMS) 1999, General statement of ${ }^{14} \mathrm{C}$ procedures at the National Ocean Sciences AMS Facility. Woods Hole Oceanic Institute, Massachusetts, USA.

Olsson, IU 1970, 'The use of oxalic acid as a standard', in IU Olsson (ed.), Radiocarbon variations and absolute chronology, Nobel Symposium, 12th Proceedings, John Wiley \& Sons, New York.

Orpin, AR 2004, 'Holocene sediment deposition on the Poverty-slope margin by the muddy Waipaoa River, East Coast New Zealand', Marine Geology, vol. 209, no. 1 4, pp. 69-90.

Orpin, AR, Carter, L, Lewis, KB, Alexander, CR \& Kuehl, SA 2003, 'Quantifying deposition from the very muddy Waipaoa River on the Poverty shelf and margin indentation, East Coast, New Zealand', paper presented to MARGINS Source-toSink NSF-NZ Waipaoa Focus Site Workshop, Gisborne, Palmerston North \& Wellington, 4-9 May.

Ota, Y, Hull, AG, Iso, N, Ikeda, Y, Moriya, I \& Yoshikawa, T 1992, 'Holocene marine terraces on the northeast coast of North Island, New Zealand, and their tectonic significance', New Zealand Journal of Geology and Geophysics, vol. 35, pp. 273288.

Page, MJ, Trustrum, NA \& DeRose, RC 1994a, 'A high resolution record of storminduced erosion from lake sediments, New Zealand', Journal of Paleolimnology, vol. 11, no. 3, pp. 333-348.

Page, MJ, Trustrum, NA \& Dymond, JR 1994b, 'Sediment budget to assess the geomorphic effect of a cyclonic storm, New Zealand', Geomorphology, vol. 9, no. 3, pp. 169-188. 
Page, MJ \& Trustrum, NA 1997, 'A late Holocene lake sediment record of the erosion response to land use change in a steepland catchment, New Zealand', Zeitschrift fur geomorphologie Neue Folge, vol. 41, no. 3, pp. 369-392.

Page, MJ, Reid, LM \& Lynn, IH 1999, 'Sediment production from Cyclone Bola landslides, Waipaoa catchment', Journal of Hydrology (NZ), vol. 38, no. 2, pp. 289-308.

Page, MJ, Trustrum, NA \& Gomez, B 2000, 'Implications of a century of anthropogenic erosion for future land use in the Gisborne-East Coast region of New Zealand', New Zealand Geographer, vol. 56, no. 2, pp. 13-24.

Page, M, Trustrum, N, Brackley, H, Gomez, B, Kasai, M \& Marutani, T 2001, 'Waipaoa River', in T Marutani, GJ Brierley, NA Trustrum \& MJ Page (eds), Sourceto-sink sedimentary cascades in Pacific Rim geo-systems, Matsumoto Sabo Work Office, Ministry of Land, Infrastructure and Transport, Japan, pp. 86-100.

Page, MJ, Trustrum, NA, Brackley, HL \& Baisden, WT 2004, 'Erosion-related soil carbon fluxes in a pastoral steepland catchment, New Zealand', Agriculture, Ecosystems and Environment, vol. 103, no. 3, pp. 561-579.

Parshotam, A, Tate, KR \& Giltrap, DJ 1995, 'Potential effects of climate and landuse change on soil carbon and $\mathrm{CO}_{2}$ emissions from New Zealand's indigenous forests and unimproved grasslands', Weather and Climate, vol. 15, no. 2, pp. 47-56.

Parsons, JD, Bush, JWM \& Syvitski, JPM 2001, 'Hyperpycnal plume formation from riverine outflows with small sediment concentrations', Sedimentology, vol. 48, no. 2, pp. $465-478$.

Peacock, DH 1998, 'Integrated management of an aggrading floodplain, Poverty Bay, East Coast, North Island, New Zealand: a case study', in Cathay Pacific Risk Management Co. Ltd (eds), Proceedings; Seminar on project risk management, August 1988, Beijing, China. 
Petsch, ST, Berner, RA \& Eglinton, TI 2000, 'A field study of the chemical weathering of ancient sedimentary organic matter', Organic Geochemistry, vol. 31, no. 5, pp. $475-487$.

Probst, JL 2002, 'The role of continental erosion and river transport in the global carbon cycle: perspectives', paper presented to Land use, erosion and carbon sequestration international colloquium, Montpellier, France, 23-28 September.

Pullar, WA 1962, Soils and agriculture of the Gisborne Plains, New Zealand Soil Bureau Bulletin 20, New Zealand Department of Scientific and Industrial Research, Wellington, New Zealand.

Raymond, PA \& Bauer, JE 2001, 'Use of ${ }^{14} \mathrm{C}$ and ${ }^{13} \mathrm{C}$ natural abundances for evaluating riverine, estuarine, and coastal DOC and POC sources and cycling: a review and synthesis', Organic Geochemistry, vol. 32, no. 4, pp. 469-485.

Reid, LM \& Page, MJ 2002, 'Magnitude and frequency of landsliding in a large New Zealand catchment', Geomorphology, vol. 49, no. 1-2, pp. 71-88.

Richey, JE, Hedges, JI, Devol, AH \& Quay, PD 1990, 'Biogeochemistry of carbon in the Amazon River', Limnology and Oceanography, vol. 35, no. 2, pp. 352-371.

Rosser, BJ 1997, 'Downstream fining in the Waipaoa River; an aggrading, gravel-bed river, East Coast, New Zealand', MSc thesis, Massey University, Palmerston North, New Zealand.

Sarmiento, JL \& Sundquist, ET 1992, 'Revised budget for the oceanic uptake of anthropogenic carbon dioxide', Nature, vol. 356, no. 6370, pp. 589-593.

Schlesinger, WH 1997, Biogeochemistry: an analysis of global change, 2nd ed, Academic Press, San Diego, 588p. 
Schlünz, B \& Schneider, RR 2000, 'Transport of terrestrial organic carbon to the oceans by rivers: re-estimating flux- and burial rates', International Journal of Earth Sciences, vol. 88, no. 4, pp. 599-606.

Schubert, CJ \& Stein, R 1996, 'Deposition of organic carbon in Arctic Ocean sediments: terrigenous supply vs marine productivity', Organic Geochemistry, vol. 24, no. 4, pp. 421-436.

Scott, DT, Baisden, WT, Davies-Colley, RJ, Gomez, B, Hicks, DM, Page, MJ, Preston, NJ, Trustrum, NA, Tate, KR \& Woods, RA In Press, 'Localised erosion affects New Zealand's national carbon budget', Geophysical Research Letters, Submitted June 2005.

Stanton, BR, Sutton, PJH \& Chiswell, SM 1997, 'The East Auckland Current, 199495', New Zealand Journal of Marine and Freshwater Research, vol. 31, no. 4, pp. 537-549.

Stephens, SA, Bell, RG \& Black, KP 2001, 'Complex circulation in a coastal embayment: shelf-current, wind and density-driven circulation in Poverty Bay, New Zealand', Journal of Coastal Research, Special Issue, ICS 2000 Proceedings, vol. 34, pp. 45-59.

TA Instruments 2002, Thermogravimetric Analyser instrument manual, TA Instruments, New Castle, DE, USA.

Tate, KR, Parshotam, A \& Ross, DJ 1995, 'Soil carbon storage and turnover in temperate forests and grasslands - a New Zealand perspective', Journal of Biogeography, vol. 22, pp. 695-700.

Tate, KR, Scott, NA, Parshotam, A, Brown, L, Wilde, RH, Giltrap, DJ, Trustrum, NA, Gomez, B \& Ross, DJ 2000, 'A multi-scale analysis of a terrestrial carbon budget. Is New Zealand a source or sink of carbon?' Agriculture, Ecosystems and Environment, vol. 82, no. 1-3, pp. 229-246. 
Tate, KR, Scott, NA, Saggar, S, Giltrap, DJ, Baisden, WT, Newsome, PF, Trotter, CM \& Wilde, RH 2003, 'Land-use change alters New Zealand's terrestrial carbon budget: uncertainties associated with estimates of soil carbon change between 19902000', Tellus, vol. 55B, pp. 364-377.

Tate, KR, Wilde, RH, Giltrap, DJ, Baisden, WT, Saggar, S, Trustrum, NA, Scott, NA \& Barton, JP 2005, 'Soil organic carbon stocks and flows in New Zealand: system development, measurement and modelling', Canadian Journal of Soil Science, vol. 85 , no. 4 , pp. $481-489$.

Trotter, CM, Tate, KR, Saggar, S, Scott, NA \& Sutherland, MA 2004, 'A multi-scale analysis of a national terrestrial carbon budget and the effects of land-use change' in $\mathrm{M}$ Shiyomi, H Kawahata, H Koizumi, A Tsuda \& Y Awaya (eds), Global environmental change in the ocean and on land, TERRAPUB, Tokyo, pp. 311-341.

Trustrum, NA, Reid, LM, Page, MJ, Gomez, B, Marden, M, Peacock, DW \& Hicks, DM 1998, 'The Waipaoa project: sediment budgets for catchment management', paper presented to NZSSS and NZARM Conference, Gisborne, November.

Trustrum, NA, Gomez, B, Page, MJ, Reid, LM \& Hicks, DM 1999, 'Sediment production, storage and output: the relative role of large magnitude events in steepland catchments', Zeitschrift fur geomorphologie (Supplementband), vol. 115, pp. 7186.

Trustrum, NA, Tate, KR, Page, MJ, Sidorchuk, A\& Baisden, WT 2002, 'Towards a national assessment of erosion-related soil carbon losses in New Zealand', paper presented to $12^{\text {th }}$ International Soil Conservation Organisation Conference, 26-31 May, Beijing, China.

Warwick, JA \& Milliman, JD 2003, 'Hyperpycnal sediment discharge from semiarid southern California rivers: Implications for coastal sediment budgets', Geology, vol. 31, no. 9, pp. 781-784. 
Wilmshurst, JM, Eden, DN \& Froggatt, PC 1999, 'Late Holocene forest disturbance in Gisborne, New Zealand: a comparison of terrestrial and marine pollen records', New Zealand Journal of Botany, vol. 37, no. 3, pp. 523-540.

Wright, LD, Yang, ZS, Bornhold, BD, Keller, GH, Prior, DB \& Wiseman, WJ 1986, 'Hyperpycnal plumes and plume fronts over the Huanghe (Yellow River) delta front', Geo-Marine Letters, vol. 6, pp. 97-105. 


\section{APPENDIX A: CORE DESCRIPTIONS \\ (I) WAIPAOA RIVER FLOODPLAIN (MCPHAIL'S BEND)}

Collected: $\quad 12^{\text {th }}$ February 2002

GPS: $\quad 2937625,6284666$

NZMS: $\quad$ Y17/376846

\section{Section $1 \quad 0-280 \mathrm{~mm}$}

$0-67 \mathrm{~mm}$

10YR 4/2 (dark greyish brown) topsoil. Many fine roots. Friable consistence. Indistinct lower boundary.

67-147 mm

Overall 10YR 6/2 (light brownish grey) mixture of silt through to sand. Generally coarsening upward. Loose consistence. Sharp lower boundary.

$147-153 \mathrm{~mm}$

Sloping and indistinct layer of 2.5Y 6/4 (light yellowish brown) silty clay.

$153-160 \mathrm{~mm}$

Sloping and indistinct layer of fine sand.

$160-166 \mathrm{~mm}$

Sloping and indistinct layer of $2.5 \mathrm{Y} 6 / 4$ (light yellowish brown) silty clay.

$166-172 \mathrm{~mm}$

Sloping and indistinct layer of fine sand.

172-199 mm

Sloping layer of 2.5Y 6/4 (light yellowish brown) silty clay.

$199-205 \mathrm{~mm}$

Layer of 10YR 5/1 (grey) sand (up to $2 \mathrm{~mm}$ ). Loose consistence. Sharp lower boundary.

$205-211 \mathrm{~mm}$

Layer of 2.5Y 6/4 (light yellowish brown) silty clay - indistinct amongst coarser sediments. Possibly is just the finest upper part of the unit below. Friable consistence. Indistinct lower boundary.

$211-258 \mathrm{~mm}$

Overall 10YR 6/2 (light brownish grey) mixture of silt through to sand. Appears to coarsen upward. Loose consistence. Distinct lower boundary.

$258-280 \mathrm{~mm}$

Layer of 2.5Y 6/4 (light yellowish brown) silty clay. No apparent layering. Firm consistence. (Cyclone Bola fines)

\section{Section $2 \quad 280-600 \mathrm{~mm}$}

$280-300 \mathrm{~mm}$

Continued from above - 2.5Y 6/4 (light yellowish brown) silt. No apparent layering. Firm consistence. Sharp lower boundary. (Cyclone Bola fines)

300-570 mm

Overall 10YR 5/1 (grey) coarse sand $(<\sim 3 \mathrm{~mm})$. Very loose consistence. No apparent layering. Mixture of lithologies. Sharp lower boundary. (Cyclone Bola sand deposit)

570-600 mm

2.5Y 5/2 (greyish brown) clay-rich sediment. Firm consistence. Some iron staining. (Buried soil?). 


\section{Section 3}

$600-668 \mathrm{~mm}$

$2.5 \mathrm{Y} 5 / 2$ (greyish brown) clay with some streaky/patchy iron staining - 5YR 4/6 (yellowish red). Firm consistence. Indistinct lower boundary.

$668-832 \mathrm{~mm}$

$2.5 \mathrm{Y} 5 / 2$ (greyish brown) silty clay with some streaky/patchy iron staining - 5YR $4 / 6$ (yellowish red). Firm consistence. Indistinct lower boundary.

$832-1010 \mathrm{~mm}$

2.5Y 5/2 (greyish brown) clay with some streaky/patchy iron staining - 5YR 4/6 (yellowish red). Possibly some very faint layering? Firm consistence.

\section{Section 4}

\section{$1010-1300 \mathrm{~mm}$}

$1010-1088 \mathrm{~mm}$

Continued from above $-2.5 \mathrm{Y} 5 / 2$ (greyish brown) clay with some streaky/patchy iron staining - 5YR 4/6 (yellowish red). Few small patches of grit and/or pumice. Few fine roots at top of section. Possibly some very faint layering? Firm consistence. Faint/indistinct lower boundary.

$1088-1215 \mathrm{~mm}$

Overall 2.5Y $5 / 2$ (greyish brown) silty clay with some streaky iron staining - 5YR 4/6 (yellowish red). Firm consistence. Indistinct lower boundary.

$1215-1300 \mathrm{~mm}$

2.5Y 5/2 (greyish brown) clay with some iron staining - 5YR 4/6 (yellowish red). Firm consistence. (Buried soil?).

\section{Section $5 \quad 1300-1620 \mathrm{~mm}$}

$1300-1355 \mathrm{~mm}$

2.5Y 5/4 (light olive brown) silt with some faint iron staining. Firm consistence. Gradational indistinct lower boundary.

$1355-1432 \mathrm{~mm}$

$2.5 \mathrm{Y} 5 / 4$ (light olive brown) fine sand with some iron staining and faint layering. Loose consistence. Indistinct lower boundary. (Possibly $\sim 1960$ floods)

$1432-1620 \mathrm{~mm}$

2.5Y 5/4 (light olive brown) silty clay with some faint iron staining. Firm consistence.

\section{Section $6 \quad 1620-1920 \mathrm{~mm}$}

$1620-1764 \mathrm{~mm}$

2.5Y 5/4 (light olive brown) silty clay with some faint iron staining. Firm consistence. Faint lower boundary.

$1764-1800 \mathrm{~mm}$

2.5Y 5/4 (light olive brown) clay with some 5YR 4/6 (yellowish red) iron staining. Firm consistence. Faint lower boundary. (Possibly top of a flood deposit?)

$1800-1920 \mathrm{~mm}$

2.5Y 5/4 (light olive brown) silty sand with some 5YR 4/6 (yellowish red) iron staining, mostly in the finer sediments. Very faint layering. Firm consistence. 


\section{Section 7}

$1920-1962 \mathrm{~mm}$

2.5Y 5/4 (light olive brown) silt/fine sand with some 5YR 4/6 (yellowish red) iron staining, mostly in the finer sediments. Very faint layering. Firm consistence. Indistinct lower boundary.

$1962-2124 \mathrm{~mm}$

Overall 2.5Y 4/4 (olive brown) silty clay. Some faint iron staining. No apparent layering. Firm consistence. Faint lower boundary. (Possibly top of a flood deposit?) $2124-2220 \mathrm{~mm}$

2.5Y 4/4 (olive brown) silty sand with some very faint iron staining. Very faint layering. Firm consistence.

\section{Section 8}

$2220-2520 \mathrm{~mm}$

$2220-2520 \mathrm{~mm}$

2.5Y 4/4 (olive brown) silty sand. No apparent layering. Firm consistence.

\section{Section 9}

\section{$2520-2820 \mathrm{~mm}$}

$2520-2720 \mathrm{~mm}$

$2.5 \mathrm{Y} 4 / 4$ (olive brown) silty sand. No apparent layering. Firm consistence. Faint lower boundary.

$2720-2748 \mathrm{~mm}$

$2.5 \mathrm{Y} 4 / 4$ (olive brown) clay layer with patches of 5YR 4/6 (yellowish red) iron staining. Firm consistence. Indistinct lower boundary. (Buried soil?).

$2748-2820 \mathrm{~mm}$

2.5Y 4/4 (olive brown) silty sand with some 5YR 4/6 (yellowish red) iron staining.

Firm consistence.

\section{Section $10 \quad 2820-3130 \mathrm{~mm}$}

$2820-2864 \mathrm{~mm}$

2.5Y 4/4 (olive brown) silty sand with some 5YR 4/6 (yellowish red) iron staining. Appears to contain some dark flecks of organic matter or charcoal in lower $20 \mathrm{~mm}$. Firm consistence. Indistinct lower boundary.

$2864-2947 \mathrm{~mm}$

$2.5 \mathrm{Y} 4 / 4$ (olive brown) silty sand. Very faint layering. Firm consistence. Indistinct lower boundary.

$2947-2958 \mathrm{~mm}$

2.5Y 4/4 (olive brown) silty sand. Appears to contain some dark flecks of organic matter or charcoal. Firm consistence. Indistinct lower boundary.

$2958-3096 \mathrm{~mm}$

2.5Y 4/4 (olive brown) silty sand. Very faint layering. Firm consistence. Indistinct lower boundary.

$3096-3130 \mathrm{~mm}$

$2.5 \mathrm{Y} 4 / 4$ (olive brown) silty clay with patches of 5YR 4/6 (yellowish red) iron staining. Firm consistence. (Buried soil?).

\section{Section $11 \quad 3130-3600 \mathrm{~mm}$}

$3130-3264 \mathrm{~mm}$

$2.5 \mathrm{Y} 4 / 4$ (olive brown) silt. No apparent layering. Firm consistence. Indistinct lower boundary. 
$3264-3600 \mathrm{~mm}$

2.5Y 4/4 (olive brown) silty clay with some 5YR 4/6 (yellowish red) iron staining.

Firm consistence.

\section{Section $12 \quad 3600-3890 \mathrm{~mm}$}

$3600-3610 \mathrm{~mm}$

2.5Y 4/4 (olive brown) silty clay with some 5YR 4/6 (yellowish red) iron staining.

Firm consistence. Indistinct lower boundary.

$3610-3890 \mathrm{~mm}$

2.5Y 4/4 (olive brown) silt. No apparent layering. Firm consistence.

\section{Section $13 \quad 3890-4190 \mathrm{~mm}$}

$3890-4065 \mathrm{~mm}$

Continuation of interval above $-2.5 \mathrm{Y} 4 / 4$ (olive brown) silt. Some faint iron staining in lower $70 \mathrm{~mm}$. No apparent layering. Firm consistence. Sharp lower boundary.

$4065-4190 \mathrm{~mm}$

Overall colour of $5 \mathrm{Y} 4 / 2$ (olive grey) sand $(<\sim 3 \mathrm{~mm}$ ) of mixed lithologies. Very loose consistence. No apparent layering. Very similar to 20-290 $\mathrm{mm}$ layer in section 2. (NB: Some sample lost from bottom because of very loose consistence). (Possibly 1932 flood?)

\section{Section $14 \quad 4190-4520 \mathrm{~mm}$}

$4190-4520 \mathrm{~mm}$

Overall colour of $2.5 \mathrm{Y} 4 / 4$ (olive brown) silty sand, with some layering and faint layers of pale coloured pumice grains, up to $\sim 2 \mathrm{~mm}$ in size. One piece of wood/charcoal $(10 \times 2 \mathrm{~mm}) 10 \mathrm{~mm}$ from top of section. Firm to loose consistence (pumice layers are looser than silt).

\section{Section $15 \quad 4520-4820 \mathrm{~mm}$}

$4520-4820 \mathrm{~mm}$

2.5Y 4/4 (olive brown) sandy silt, with few fine pumice grains throughout (mostly near top). Firm consistence. (NB: Finer than section 14).

\section{Section $16 \quad 4820-5190 \mathrm{~mm}$}

$4820-5098 \mathrm{~mm}$

$2.5 \mathrm{Y} 4 / 4$ (olive brown) silt with very few pumice grains. Sediment appears to get finer with depth. Some iron staining. Firm consistence. Gradual and indistinct lower boundary.

$5098-5190 \mathrm{~mm}$

$2.5 \mathrm{Y} 4 / 4$ (olive brown) silty clay with some iron staining. Firm consistence.

Section 17

$$
5190-5510 \mathrm{~mm}
$$

$5190-5228 \mathrm{~mm}$

2.5Y 4/4 (olive brown) silty clay with some 5YR 4/6 (yellowish red) streaks of iron staining. Firm consistence. Sharp lower boundary, accentuated by iron staining.

$5228-5260 \mathrm{~mm}$

$2.5 \mathrm{Y} 6 / 4$ (light yellowish brown) clay, with a patch $(7 \times 18 \mathrm{~mm})$ of iron staining.

Firm consistence. Sharp lower boundary, marked by iron staining. 
$5260-5330 \mathrm{~mm}$

2.5Y 4/4 (olive brown) silty clay with some 5YR 4/6 (yellowish red) streaks of iron staining. Firm consistence. Faint lower boundary.

$5330-5362 \mathrm{~mm}$

2.5Y 6/4 (light yellowish brown) clay, with some iron staining. Firm consistence. Gradational lower boundary.

5362-5407 mm

2.5Y 4/4 (olive brown) silty clay with some 5YR 4/6 (yellowish red) streaks of iron staining. Firm consistence. Distinct lower boundary.

5407-5510 mm

Predominantly $2.5 \mathrm{Y} 4 / 4$ (olive brown) medium sand. Some fine pumice grains. Loose consistence. (Possibly represents change from point-bar to overbank deposition)

\section{Section 18}

\section{$5510-5830 \mathrm{~mm}$}

$5510-5521 \mathrm{~mm}$

Predominantly $2.5 \mathrm{Y} 4 / 4$ (olive brown) medium sand. Some fine pumice grains. Loose consistence. Distinct lower boundary.

$5521-5675 \mathrm{~mm}$

Predominantly 2.5Y 5/4 (light olive brown) silty sediment. Some faint layering, with some containing fine pumice grains. Firm consistence. Sharp wavy lower boundary. $5675-5691 \mathrm{~mm}$

Wavy layer of medium sand, predominantly $2.5 \mathrm{Y} 4 / 2$ (dark greyish brown) in colour. Loose consistence. Distinct wavy lower boundary.

$5691-5755 \mathrm{~mm}$

Predominantly 2.5Y 4/0 (dark grey) clay-rich sediment (buried soil?) with black flecks of charcoal/organic matter throughout. Layer of 7.5YR 4/4 (brown) iron staining near base. Firm consistence. Distinct lower boundary. (Probably 1906 flood)

$5755-5830 \mathrm{~mm}$

Predominantly $2.5 \mathrm{Y} 4 / 2$ (dark greyish brown) medium sand. Some fine pumice grains. Loose consistence.

\section{Section $19 \quad 5830-6230 \mathrm{~mm}$}

$5830-6230 \mathrm{~mm}$

Predominantly $2.5 \mathrm{Y} 4 / 2$ (dark greyish brown) medium sand. Some fine pumice grains. Loose consistence. Slight coarsening of sand with depth.

\section{Section 20}

$6230-6560 \mathrm{~mm}$

6230-6354 mm

Predominantly $2.5 \mathrm{Y} 4 / 2$ (dark greyish brown) medium sand. Some fine pumice grains. Loose consistence. Slight coarsening of sand with depth. Distinct sloping lower boundary.

6354-6560 mm

Predominantly $2.5 \mathrm{Y} \mathrm{5/2}$ (greyish brown) fine sand. No apparent layering. Firm consistence. 


\section{Section 21}

$6560-6870 \mathrm{~mm}$

6560-6630 mm

Predominantly 2.5Y 5/2 (greyish brown) fine sand. No apparent layering. Loose consistence. Gradational lower boundary.

$6630-6690 \mathrm{~mm}$

Predominantly $2.5 \mathrm{Y} \mathrm{5/2}$ (greyish brown) medium pumiceous sand. No apparent layering. Loose consistence. Sloping indistinct lower boundary.

$6690-6870 \mathrm{~mm}$

Predominantly $2.5 Y 3 / 2$ (very dark greyish brown) coarse sand, grit and pebbles (up to $\sim 15$ x $15 \mathrm{~mm})$. Mixed lithologies. Very loose consistence. 
(II) MARINE MULTI-CORES

U2303 (Inner shelf)

Collected: $\quad 25^{\text {th }}$ March 2001

Location: $\quad 38^{\circ} 45.015 \mathrm{~S}, 178^{\circ} 01.996 \mathrm{E}$

Water depth: $27.2 \mathrm{~m}$

0-13 cm: Brown sandy mud.

13-22 cm: Grey mud, darkening downwards.

22-34 cm: Grey-brown sandy-mud.

\section{U2304 (Inner-mid shelf)}

Collected: $\quad 25^{\text {th }}$ March 2001

Location: $\quad 38^{\circ} 46.163 \mathrm{~S}, 178^{\circ} 05.889 \mathrm{E}$

Water depth: $\quad 36.4 \mathrm{~m}$

0-6 cm: Brown muddy sand.

6-16 cm: Light grey sandy mud.

16-19 cm: Dark grey sandy mud.

19-26 cm: Brown muddy sand.

26-33 cm: Light grey sandy mud.

U2305 (Mid-shelf mud belt)

Collected: $\quad$ 25 $\quad$ th March 2001

Location: $\quad 38^{\circ} 48.690 \mathrm{~S}, 178^{\circ} 10.185 \mathrm{E}$

Water depth: $\quad 56.4 \mathrm{~m}$

0-3 cm: Brown sandy mud.

3-34 cm: Dark grey mud.

U2306 (Outer shelf)

Collected: $\quad$ 25 $\quad$ th March 2001

Location: $\quad 38^{\circ} 55.076 \mathrm{~S}, 178^{\circ} 12.615 \mathrm{E}$

Water depth: $113.2 \mathrm{~m}$

0-4 cm: Disturbed sediment.

4-47 cm: Olive grey sandy mud.

W697 (Upper slope feeder canyon)

Collected: $\quad 12^{\text {th }}$ May 2001

Location: $\quad 38^{\circ} 55.48 \mathrm{~S}, 178^{\circ} 20.02 \mathrm{E}$

Water depth: $1198 \mathrm{~m}$

0-50 cm: Mud.

W699 (Mid-slope platform)

Collected: $\quad$ 13 $3^{\text {th }}$ May 2001

Location: $\quad 39^{\circ} 3.62 \mathrm{~S}, 178^{\circ} 33.90 \mathrm{E}$

Water depth: $1428 \mathrm{~m}$

0-51 cm: Massive unconsolidated mud, some sandy units. 
APPENDIX B: MAGNETIC SUSCEPTIBILITY MEASUREMENTS FOR WAIPAOA RIVER FLOODPLAIN (MCPHAIL'S BEND) CORE

Sensor Type: Bartington MS2E1

Range: 0.1

Units: CGS

Alignment: Core axis

Interval: $2 \mathrm{~cm}$

\begin{tabular}{|c|c|c|}
\hline $\begin{array}{l}\text { Original Depth } \\
\qquad(\mathrm{cm})\end{array}$ & $\begin{array}{c}\text { Corrected } \\
\text { Depth }(\mathrm{cm})\end{array}$ & $\begin{array}{c}\text { Magnetic } \\
\text { Susceptibility } \\
\text { (cgs) }\end{array}$ \\
\hline 1 & 13 & 19.9 \\
\hline 3 & 40 & 15.7 \\
\hline 5 & 67 & 26.4 \\
\hline 7 & 93 & 30.1 \\
\hline 9 & 120 & 45.0 \\
\hline 11 & 147 & 31.7 \\
\hline 13 & 173 & 16.1 \\
\hline 15 & 200 & 12.3 \\
\hline 17 & 226 & 51.8 \\
\hline 19 & 253 & 26.6 \\
\hline 21 & 280 & 8.3 \\
\hline 23 & 300 & 13.0 \\
\hline 25 & 320 & 7.3 \\
\hline 27 & 340 & 7.6 \\
\hline 29 & 360 & 9.0 \\
\hline 31 & 380 & 7.8 \\
\hline 33 & 400 & 9.5 \\
\hline 35 & 420 & 13.1 \\
\hline 37 & 440 & 11.9 \\
\hline 39 & 460 & 8.7 \\
\hline 41 & 480 & 5.0 \\
\hline 43 & 500 & 10.8 \\
\hline 45 & 520 & 8.5 \\
\hline 47 & 540 & 14.5 \\
\hline 49 & 560 & 50.3 \\
\hline 51 & 580 & 65.5 \\
\hline 53 & 600 & 5.0 \\
\hline 55 & 627 & 12.5 \\
\hline 57 & 654 & 14.9 \\
\hline 59 & 682 & 13.1 \\
\hline 61 & 709 & 11.4 \\
\hline
\end{tabular}

Appendix B 


\begin{tabular}{|c|c|c|}
\hline 63 & 736 & 11.2 \\
\hline 65 & 764 & 13.0 \\
\hline 67 & 791 & 12.6 \\
\hline 69 & 818 & 11.9 \\
\hline 71 & 846 & 11.9 \\
\hline 73 & 873 & 14.2 \\
\hline 75 & 901 & 9.0 \\
\hline 77 & 928 & 9.8 \\
\hline 79 & 955 & 8.8 \\
\hline 81 & 983 & 8.9 \\
\hline 83 & 1010 & 6.9 \\
\hline 85 & 1034 & 10.7 \\
\hline 87 & 1058 & 11.0 \\
\hline 89 & 1082 & 11.3 \\
\hline 91 & 1106 & 10.4 \\
\hline 93 & 1130 & 9.1 \\
\hline 95 & 1155 & 10.1 \\
\hline 97 & 1179 & 9.7 \\
\hline 99 & 1203 & 10.4 \\
\hline 101 & 1227 & 8.1 \\
\hline 103 & 1252 & 6.4 \\
\hline 105 & 1276 & 7.4 \\
\hline 107 & 1300 & 1.9 \\
\hline 109 & 1328 & 13.1 \\
\hline 111 & 1356 & 16.0 \\
\hline 113 & 1383 & 17.9 \\
\hline 115 & 1411 & 15.4 \\
\hline 117 & 1439 & 15.3 \\
\hline 119 & 1467 & 14.4 \\
\hline 121 & 1495 & 16.8 \\
\hline 123 & 1523 & 16.0 \\
\hline 125 & 1550 & 16.2 \\
\hline 127 & 1578 & 16.7 \\
\hline 129 & 1606 & 15.7 \\
\hline 131 & 1632 & 7.6 \\
\hline 133 & 1656 & 12.8 \\
\hline 135 & 1680 & 12.8 \\
\hline 137 & 1704 & 14.5 \\
\hline 139 & 1728 & 15.2 \\
\hline 141 & 1752 & 15.7 \\
\hline 143 & 1776 & 14.3 \\
\hline 145 & 1800 & 30.4 \\
\hline
\end{tabular}




\begin{tabular}{|c|c|c|}
\hline 147 & 1824 & 37.2 \\
\hline 149 & 1848 & 52.9 \\
\hline 151 & 1872 & 55.7 \\
\hline 153 & 1896 & 44.4 \\
\hline 155 & 1920 & 29.7 \\
\hline 157 & 1944 & 44.8 \\
\hline 159 & 1968 & 18.6 \\
\hline 161 & 1992 & 18.7 \\
\hline 163 & 2016 & 21.0 \\
\hline 165 & 2040 & 18.8 \\
\hline 167 & 2064 & 16.0 \\
\hline 169 & 2088 & 17.7 \\
\hline 171 & 2112 & 19.2 \\
\hline 173 & 2136 & 22.1 \\
\hline 175 & 2160 & 21.0 \\
\hline 177 & 2184 & 20.0 \\
\hline 179 & 2208 & 22.3 \\
\hline 181 & 2235 & 21.0 \\
\hline 183 & 2265 & 22.1 \\
\hline 185 & 2295 & 26.8 \\
\hline 187 & 2325 & 19.8 \\
\hline 189 & 2355 & 16.2 \\
\hline 191 & 2385 & 22.9 \\
\hline 193 & 2415 & 20.4 \\
\hline 195 & 2445 & 24.5 \\
\hline 197 & 2475 & 35.0 \\
\hline 199 & 2505 & 21.6 \\
\hline 201 & 2531 & 15.4 \\
\hline 203 & 2553 & 22.2 \\
\hline 205 & 2575 & 26.5 \\
\hline 207 & 2597 & 24.6 \\
\hline 209 & 2620 & 20.9 \\
\hline 211 & 2642 & 19.7 \\
\hline 213 & 2664 & 20.6 \\
\hline 215 & 2686 & 27.2 \\
\hline 217 & 2709 & 24.1 \\
\hline 219 & 2731 & 16.9 \\
\hline 221 & 2753 & 18.7 \\
\hline 223 & 2775 & 20.6 \\
\hline 225 & 2798 & 22.9 \\
\hline 227 & 2820 & 13.6 \\
\hline 229 & 2842 & 18.4 \\
\hline
\end{tabular}

Appendix B 


\begin{tabular}{|c|c|c|}
\hline 231 & 2864 & 16.6 \\
\hline 233 & 2886 & 18.3 \\
\hline 235 & 2909 & 17.6 \\
\hline 237 & 2931 & 17.6 \\
\hline 239 & 2953 & 18.7 \\
\hline 241 & 2975 & 30.2 \\
\hline 243 & 2997 & 20.1 \\
\hline 245 & 3019 & 21.8 \\
\hline 247 & 3041 & 19.7 \\
\hline 249 & 3064 & 21.0 \\
\hline 251 & 3086 & 19.9 \\
\hline 253 & 3108 & 19.7 \\
\hline 255 & 3130 & 13.9 \\
\hline 257 & 3175 & 22.2 \\
\hline 259 & 3220 & 23.1 \\
\hline 261 & 3264 & 22.2 \\
\hline 263 & 3309 & 24.2 \\
\hline 265 & 3354 & 25.0 \\
\hline 267 & 3399 & 23.1 \\
\hline 269 & 3443 & 24.0 \\
\hline 271 & 3488 & 24.6 \\
\hline 273 & 3533 & 26.8 \\
\hline 275 & 3577 & 24.0 \\
\hline 277 & 3596 & 24.5 \\
\hline 279 & 3616 & 27.9 \\
\hline 281 & 3636 & 26.5 \\
\hline 283 & 3655 & 33.8 \\
\hline 285 & 3675 & 31.3 \\
\hline 287 & 3694 & 35.0 \\
\hline 289 & 3714 & 43.4 \\
\hline 291 & 3733 & 36.8 \\
\hline 293 & 3753 & 38.2 \\
\hline 295 & 3773 & 40.8 \\
\hline 297 & 3792 & 38.3 \\
\hline 299 & 3812 & 37.9 \\
\hline 301 & 3831 & 39.1 \\
\hline 303 & 3851 & 30.1 \\
\hline 305 & 3871 & 34.1 \\
\hline 307 & 3890 & 32.2 \\
\hline 309 & 3915 & 24.4 \\
\hline 311 & 3940 & 29.0 \\
\hline 313 & 3965 & 19.6 \\
\hline
\end{tabular}

Appendix B 


\begin{tabular}{|c|c|c|}
\hline 315 & 3990 & 21.2 \\
\hline 317 & 4015 & 66.1 \\
\hline 319 & 4040 & 130.9 \\
\hline 321 & 4065 & 310.4 \\
\hline 323 & 4090 & 281.1 \\
\hline 325 & 4115 & 36.3 \\
\hline 327 & 4140 & 63.7 \\
\hline 329 & 4165 & 14.4 \\
\hline 331 & 4190 & 15.3 \\
\hline 333 & 4218 & 35.3 \\
\hline 335 & 4245 & 31.6 \\
\hline 337 & 4273 & 31.2 \\
\hline 339 & 4300 & 43.5 \\
\hline 341 & 4328 & 30.2 \\
\hline 343 & 4355 & 29.5 \\
\hline 345 & 4383 & 36.6 \\
\hline 347 & 4410 & 39.1 \\
\hline 349 & 4438 & 46.1 \\
\hline 351 & 4465 & 67.3 \\
\hline 353 & 4493 & 37.9 \\
\hline 355 & 4520 & 34.8 \\
\hline 357 & 4547 & 40.5 \\
\hline 359 & 4575 & 56.6 \\
\hline 361 & 4602 & 55.6 \\
\hline 363 & 4629 & 48.9 \\
\hline 365 & 4656 & 47.7 \\
\hline 367 & 4684 & 24.2 \\
\hline 369 & 4711 & 47.7 \\
\hline 371 & 4738 & 41.8 \\
\hline 373 & 4765 & 28.5 \\
\hline 375 & 4793 & 37.1 \\
\hline 377 & 4820 & 35.1 \\
\hline 379 & 4843 & 29.0 \\
\hline 381 & 4866 & 28.2 \\
\hline 383 & 4889 & 28.3 \\
\hline 385 & 4913 & 30.8 \\
\hline 387 & 4936 & 24.8 \\
\hline 389 & 4959 & 23.7 \\
\hline 391 & 4982 & 23.3 \\
\hline 393 & 5005 & 21.3 \\
\hline 395 & 5028 & 19.7 \\
\hline 397 & 5051 & 17.2 \\
\hline
\end{tabular}

Appendix B 


\begin{tabular}{|c|c|c|}
\hline 399 & 5074 & 15.2 \\
\hline 401 & 5098 & 16.0 \\
\hline 403 & 5121 & 16.3 \\
\hline 405 & 5144 & 17.9 \\
\hline 407 & 5167 & 18.4 \\
\hline 409 & 5190 & 12.4 \\
\hline 411 & 5216 & 17.5 \\
\hline 413 & 5241 & 18.3 \\
\hline 415 & 5267 & 19.4 \\
\hline 417 & 5292 & 18.1 \\
\hline 419 & 5318 & 18.4 \\
\hline 421 & 5344 & 20.2 \\
\hline 423 & 5369 & 23.4 \\
\hline 425 & 5395 & 22.5 \\
\hline 427 & 5420 & 96.1 \\
\hline 429 & 5446 & 99.2 \\
\hline 431 & 5472 & 71.8 \\
\hline 433 & 5497 & 73.1 \\
\hline 435 & 5521 & 43.3 \\
\hline 437 & 5542 & 27.4 \\
\hline 439 & 5564 & 31.1 \\
\hline 441 & 5585 & 33.0 \\
\hline 443 & 5606 & 22.5 \\
\hline 445 & 5628 & 19.0 \\
\hline 447 & 5649 & 24.9 \\
\hline 449 & 5670 & 126.3 \\
\hline 451 & 5691 & 113.5 \\
\hline 453 & 5713 & 16.0 \\
\hline 455 & 5734 & 18.6 \\
\hline 457 & 5756 & 67.8 \\
\hline 459 & 5777 & 81.6 \\
\hline 461 & 5798 & 805.8 \\
\hline 463 & 5820 & 322.4 \\
\hline 465 & 5843 & 704.2 \\
\hline 467 & 5869 & 33.2 \\
\hline 469 & 5895 & 51.7 \\
\hline 471 & 5920 & 41.6 \\
\hline 473 & 5946 & 89.7 \\
\hline 475 & 5972 & 15.4 \\
\hline 477 & 5998 & 15.7 \\
\hline 479 & 6023 & 13.4 \\
\hline 481 & 6049 & 13.2 \\
\hline
\end{tabular}




\begin{tabular}{|c|c|c|}
\hline 483 & 6075 & 27.6 \\
\hline 485 & 6101 & 16.2 \\
\hline 487 & 6127 & 21.3 \\
\hline 489 & 6153 & 21.9 \\
\hline 491 & 6178 & 19.3 \\
\hline 493 & 6204 & 23.6 \\
\hline 495 & 6230 & 6.9 \\
\hline 497 & 6257 & 19.7 \\
\hline 499 & 6285 & 37.5 \\
\hline 501 & 6312 & 23.0 \\
\hline 503 & 6340 & 42.5 \\
\hline 505 & 6367 & 150.9 \\
\hline 507 & 6395 & 25.2 \\
\hline 509 & 6422 & 25.4 \\
\hline 511 & 6450 & 52.6 \\
\hline 513 & 6477 & 34.2 \\
\hline 515 & 6505 & 180.6 \\
\hline 517 & 6532 & 36.3 \\
\hline 519 & 6560 & 71.8 \\
\hline 521 & 6580 & 44.6 \\
\hline 523 & 6600 & 39.7 \\
\hline 525 & 6620 & 12.7 \\
\hline 527 & 6640 & 12.1 \\
\hline 529 & 6660 & 9.4 \\
\hline 531 & 6680 & 9.7 \\
\hline 533 & 6700 & 67.6 \\
\hline 535 & 6720 & 6.8 \\
\hline 537 & 6740 & 7.3 \\
\hline 539 & 6760 & 10.5 \\
\hline 541 & 6780 & 7.3 \\
\hline 543 & 6800 & 13.0 \\
\hline 545 & 6820 & 14.5 \\
\hline 547 & 6840 & 17.9 \\
\hline 549 & 6860 & 7.9 \\
\hline
\end{tabular}



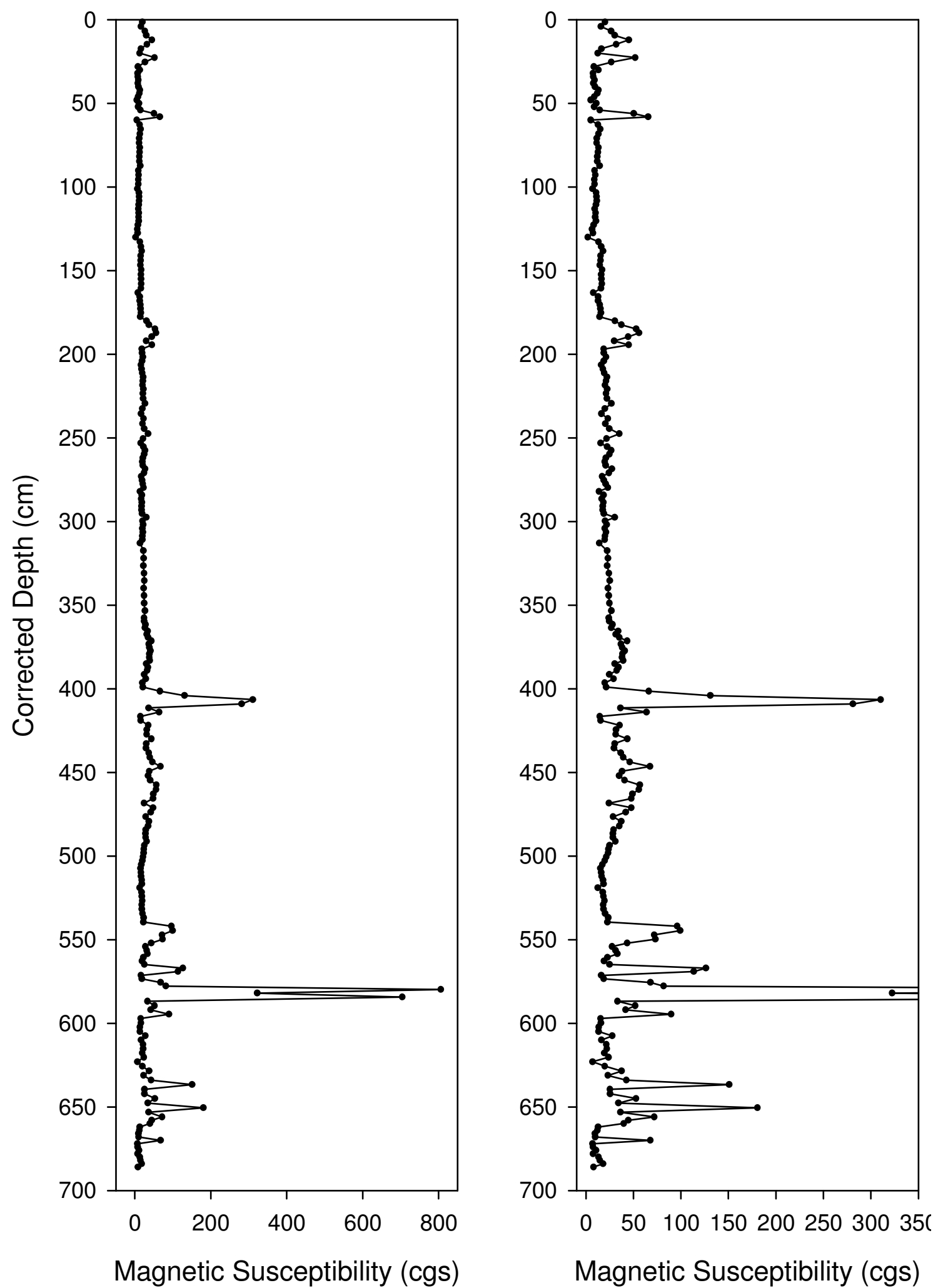

Graphs of magnetic susceptibility for McPhail's bend floodplain core. (Same data, on different $\mathrm{x}$-axis scales). 


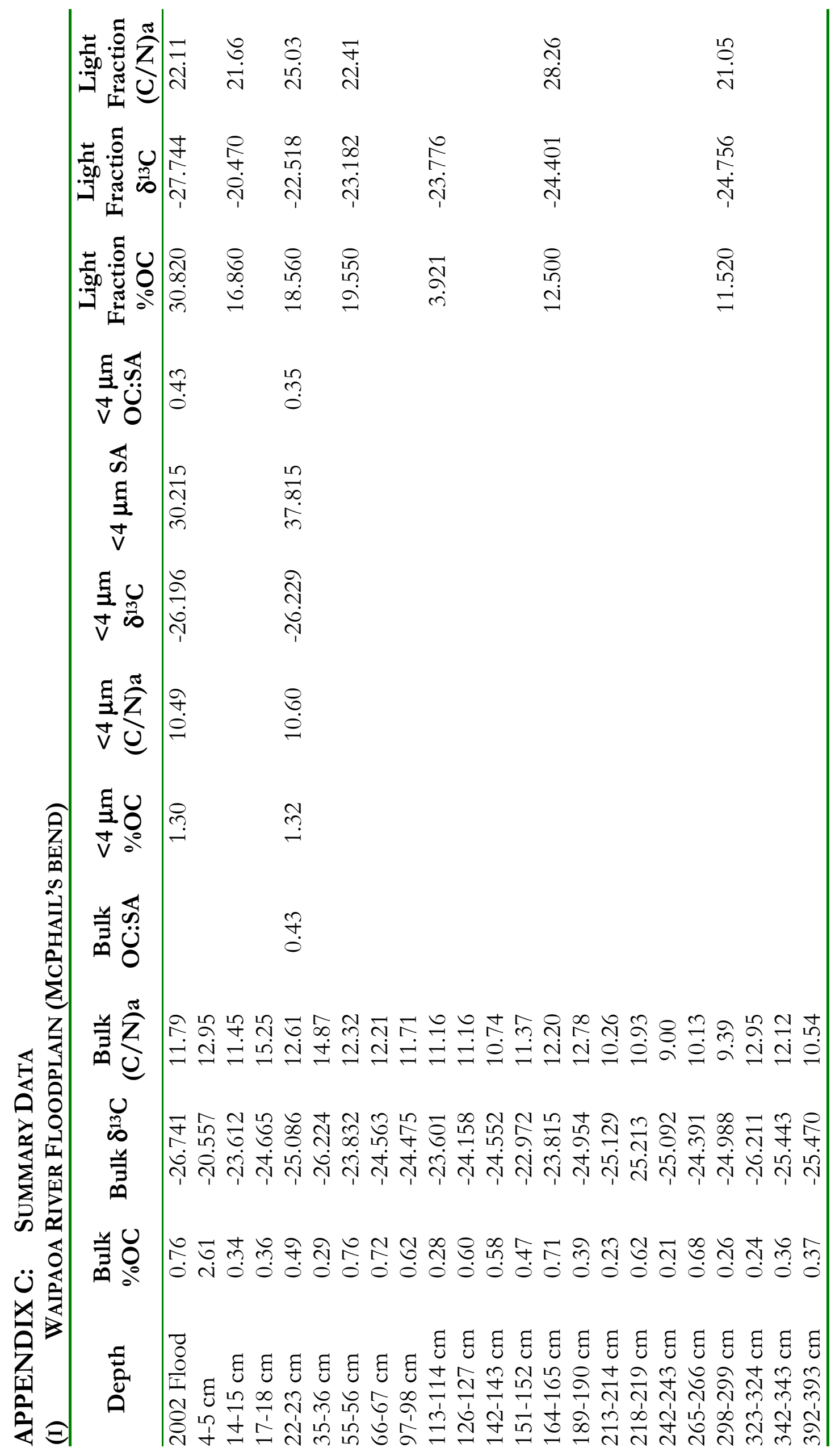

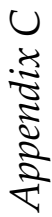




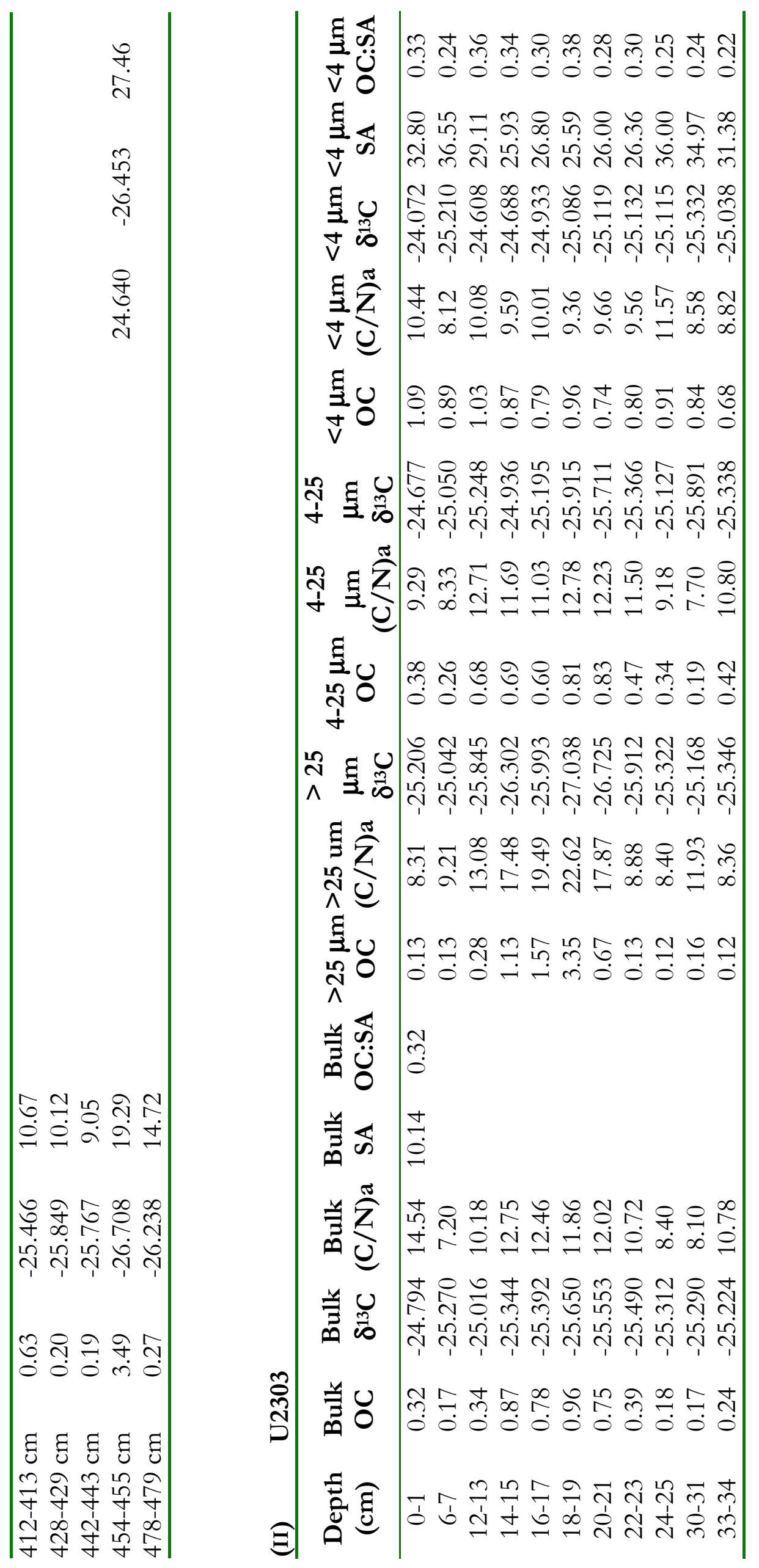




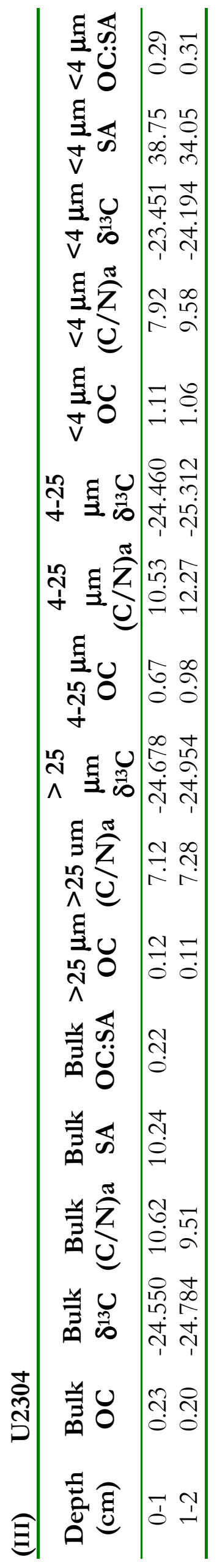

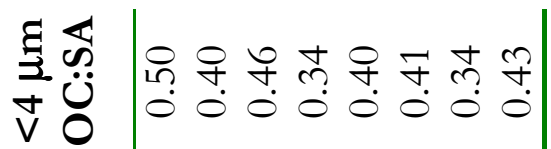

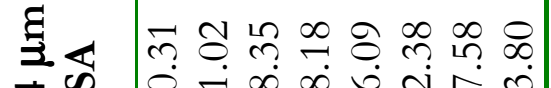

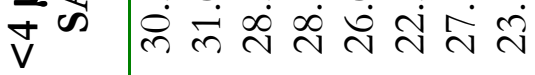

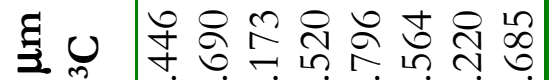

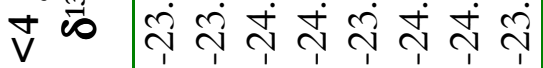

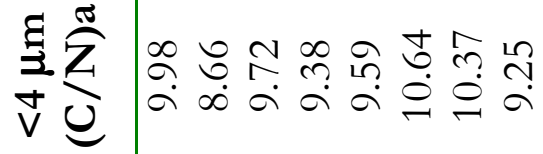

v

ก g uำ

+

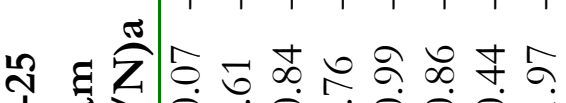

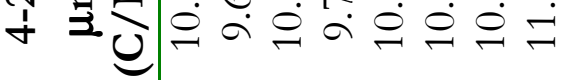

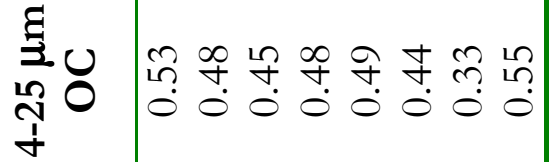

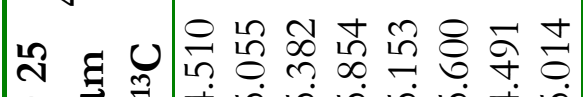

$\wedge$ 三

छ

约

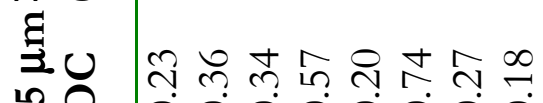

ผ

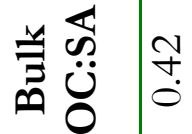

节出 唡

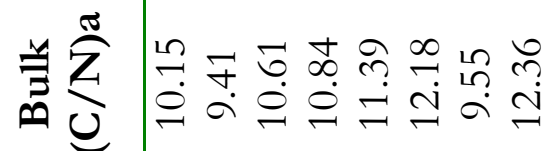

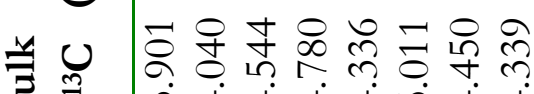

ต

沶 兰

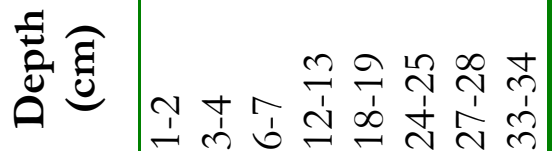




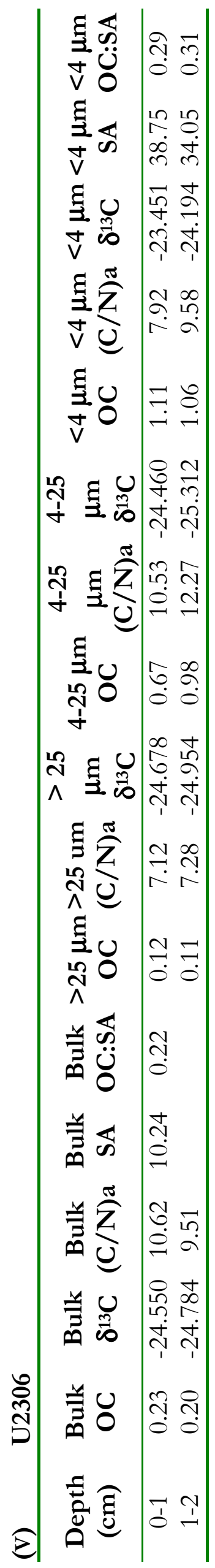

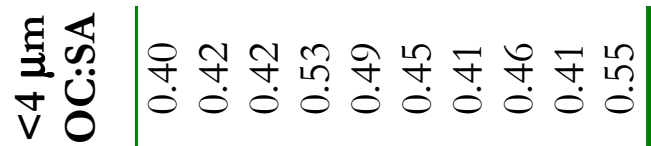

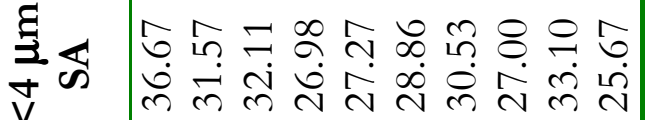

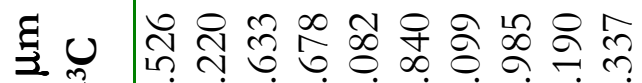

ปั

莳

ป

ง ง U

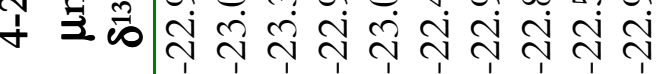

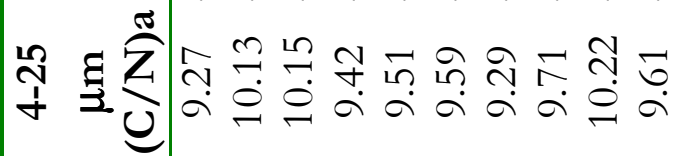

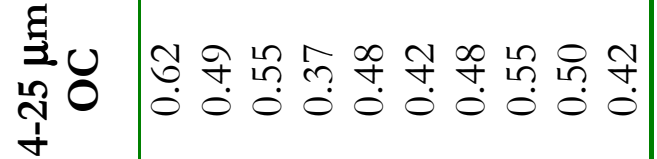

๙

$\wedge$ E

छ

슨 ํㅝㄴ

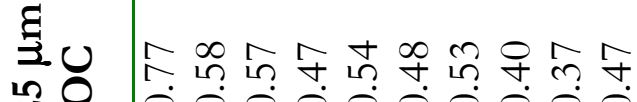

î

幽 范

ต

兰吕 离

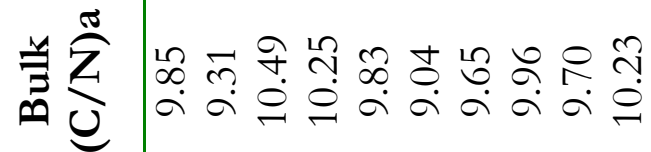

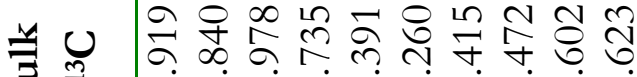

๑

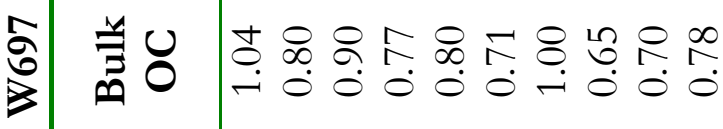

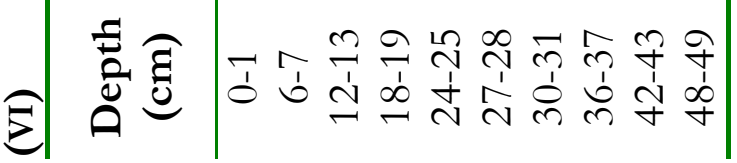




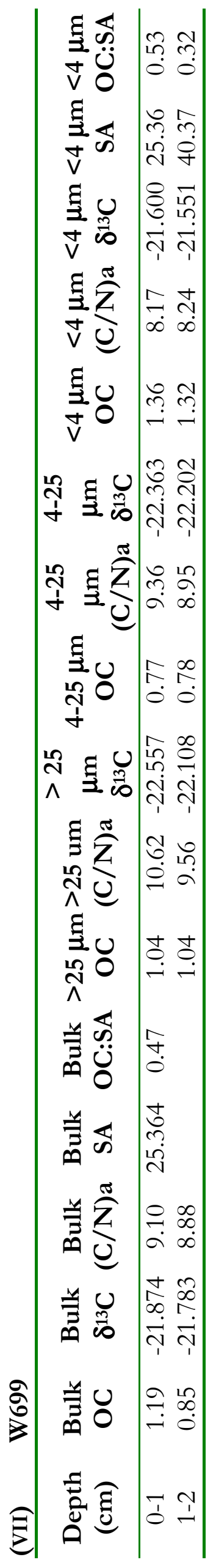




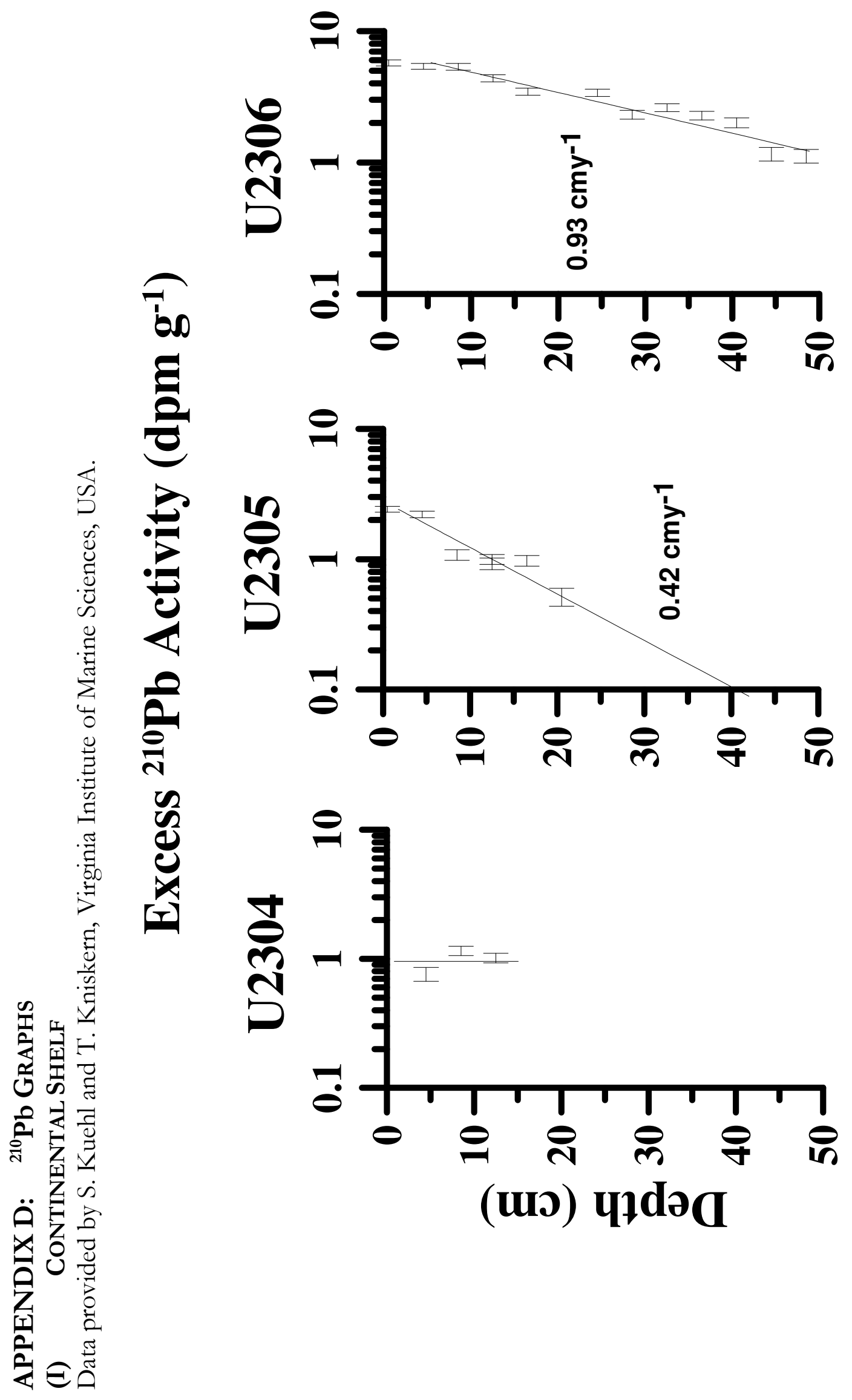




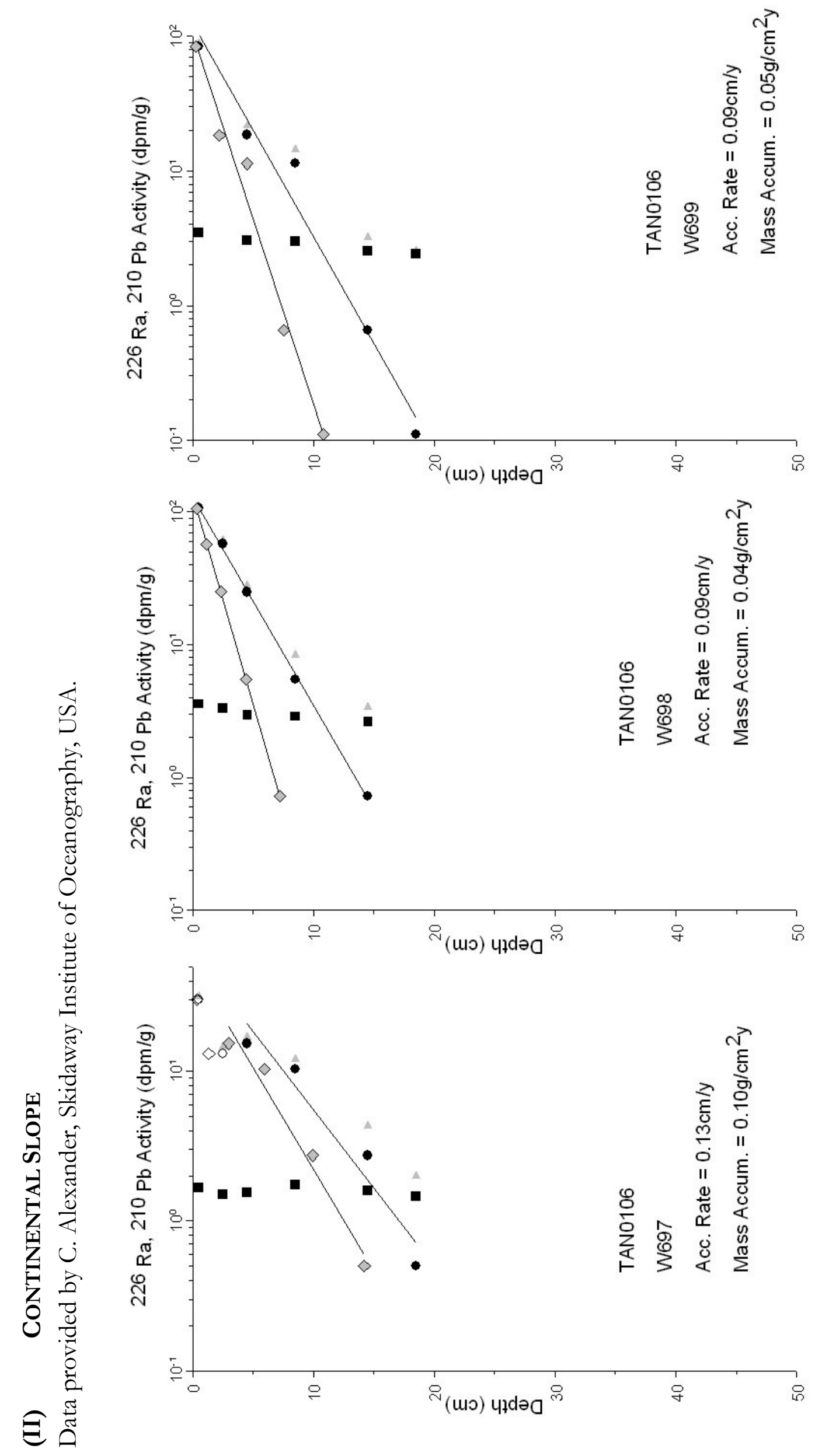

